\title{
Influence of food safety culture on food handler behaviour and food safety performance of food processing organisations
}
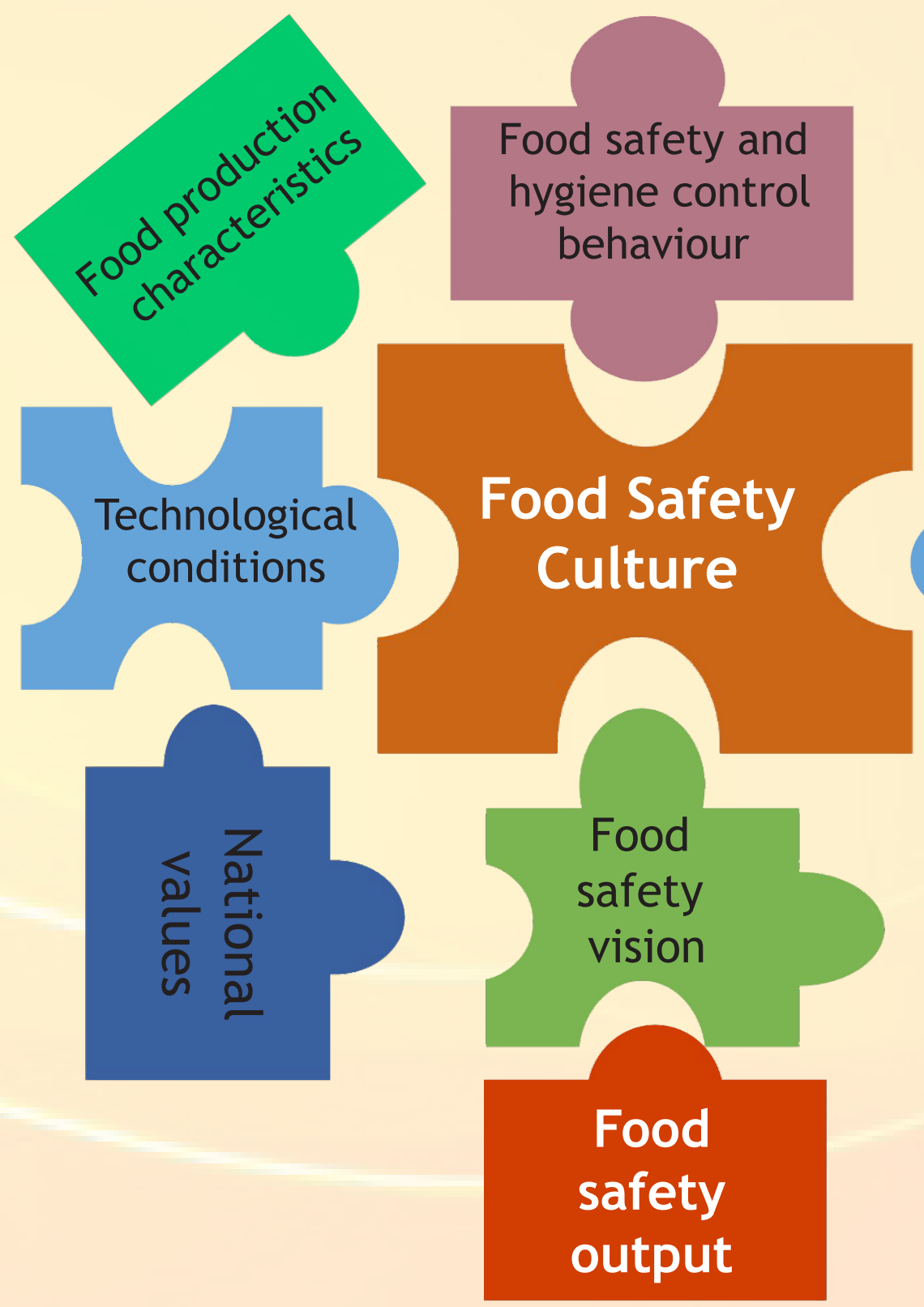

Food safety governance

Formal food safety program 



\section{Propositions}

1. Interventions to improve an organisation's food safety culture are only effective when tailored to the context in which the company operates.

(this thesis)

2. Whether a company allows a researcher to conduct food safety culture assessments reflects their food safety culture.

(this thesis)

3. Globalisation does not lead to convergence of cultures.

4. Hustling is a new successful coping strategy in Africa.

5. Introversion hinders progression in research.

6. Development aid perpetuates poverty rather than alleviating it.

7. Social science research requires a person who is patient and open-minded.

Propositions belonging to the thesis, entitled:

"Influence of food safety culture on food handler behaviour and food safety performance of food processing organisations"

Shingai Patricia Nyarugwe

Wageningen, 11 February 2020 

Influence of food safety culture on food handler behaviour and food safety performance of food processing organisations

Shingai Patricia Nyarugwe 


\section{Thesis committee}

\section{Promotors}

Prof. Dr Vincenzo Fogliano

Professor of Food Quality and Design

Wageningen University \& Research

Dr Pieternel A. Luning

Associate professor, Food Quality and Design Group

Wageningen University \& Research

\section{Co-promotor}

Dr Anita Linnemann

Assistant professor, Food Quality and Design Group

Wageningen University \& Research

\section{Other members}

Prof. Dr R. Ruben, Wageningen University \& Research

Prof. Dr L. Jacxsens, Ghent University, Belgium

Prof. Dr C.A. Wallace, University of Central Lancashire, Preston, UK

Dr K. Kirezieva, Cargill B.V, Utrecht

This research was conducted under the auspices of the Graduate School VLAG (Advanced Studies in Food Technology, Agrobiotechnology, Nutrition and Health Sciences) 


\title{
Influence of food safety culture on food handler behaviour and food safety performance of food processing organisations
}

\author{
Shingai Patricia Nyarugwe
}

\section{Thesis}

submitted in fulfilment of the requirements for the degree of doctor at Wageningen University

by the authority of the Rector Magnificus

Prof. Dr A.P.J. Mol, in the presence of the

Thesis Committee appointed by the Academic Board to be defended in public

on Tuesday 11 February 2020

at 4 p.m. in the Aula. 
Shingai P. Nyarugwe

Influence of food safety culture on food handler behaviour and food safety performance of food processing organisations, 181 pages

PhD Thesis, Wageningen University, Wageningen, the Netherlands (2020)

With references, with summary in English

ISBN: 978-94-6395-184-5

DOI: https://doi.org/10.18174/504736 


\section{Table of Contents}

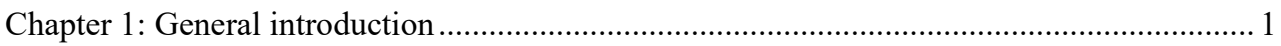

Chapter 2: Determinants for conducting food safety culture research ................................. 19

Chapter 3: Food safety culture assessment using a comprehensive mixed-methods approach:

A comparative study in dairy processing organisations in an emerging economy

Chapter 4: Prevailing food safety culture in companies operating in a transition economydoes product riskiness matter?

Chapter 5: An intercontinental analysis of food safety culture in view of food safety governance and national values

Chapter 6: General discussion.

References

Summary 165

Acknowledgements 169

About the author 171

Overview of completed training activities 172 



\section{Chapter 1}

\section{General introduction}




\subsection{Food safety concerns}

Food safety is a global concern and of importance to many food processing companies and regulators owing to the continued foodborne outbreaks and inconsistent microbiological safety of the food products. Globally, at least 600 million (i.e. approximately 1 in 10 people) foodborne illnesses occur yearly (WHO, 2015). In 2016, the Centers for Disease Control and Prevention (CDC) reported 839 foodborne outbreaks, which resulted in 14,259 illnesses (Centers for Disease Control and Prevention (CDC), 2018). In the same year, the EU reported 4786 outbreaks (European Food Safety Authority European Centre for Disease Prevention Control, 2017). However, the highest burden, namely a third of the global burden (WHO, 2016), of foodborne illnesses was reported in Africa followed by Asia (Figure 1.1; WHO, 2015). WHO (2016) also reported that approximately 91 million people fall ill each year due to foodborne diseases. For example in 2018, 978 cases of Listeriosis alone were reported in South Africa (World Health Organization, 2018). In Ghana, at least 420,000 cases of foodborne illnesses are annually reported (Ababio \& Lovatt, 2015). However, foodborne illnesses remain underreported in transition countries and are more informally documented due to a lack of surveillance systems (Grace, 2015; Kussaga et al., 2014a; Mensah et al., 2012).

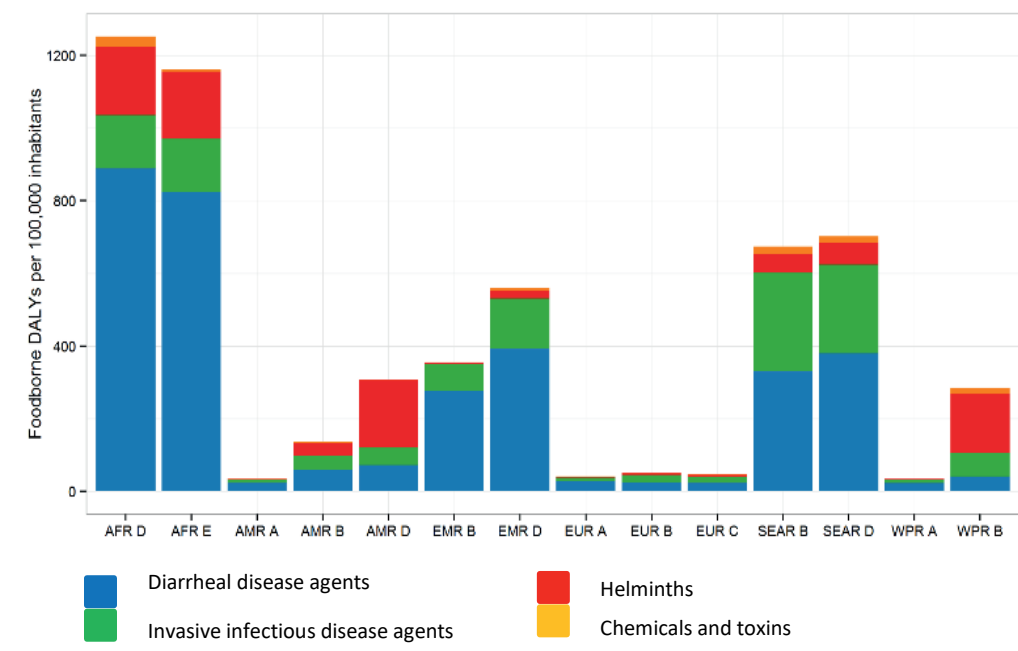

Figure 1.1 The global burden of foodborne disease (DALYS per 100,000 population) by hazard groups and by region for 2010 (Havelaar et al., 2015).

AFR D, AFR E, AMR A, refers to country groupings for global assessment according to WHO sub regions. Subregions ${ }^{1}$ : AFR=Africa; AMR=Americas; EMR=Eastern Mediterranean; EUR=Europe; SEA=South-East Asia; WPR=Western Pacific 
The continued occurrence of outbreaks can be attributed to the complexity of food safety as the food chain has become globalised (Lineback et al., 2009; Nguz, 2007). Raw materials sourcing, product processing, and distribution are dependent on a fragmented system that demands more reliance on harmonised regulations and standards, and food safety practices (GFSI, 2018). Moreover, with globalisation, food companies are confronted with multiple national cultures in their daily operations from actors in the supply chain as well as the workforce, which is often multinational (Nyarugwe et al., 2016; Seymen \& Bolat, 2010; Van Oudenhoven, 2001). As such, national values, food safety governance, and the dynamic political, economic, socio-cultural and technological aspects of the companies' environment foster the complexity (Lineback et al., 2009). An enquiry into most foodborne illnesses relating to the food industry uncovered issues such as food safety practices of food handlers, structural deficiencies (e.g., staff, equipment, cleaning, systems) and commitment of management (Pennington, 2009; Powell et al., 2011), amongst many others.

The situation is worsened in transition countries, which are confronted with e.g. use of unsafe water in the processing of food, out-dated/poorly designed equipment, inadequate raw material control, too much product handling, poor food production practices, inadequate tools and infrastructure, insufficient legislation and inadequate enforcement of food safety standards thus resulting in a high-risk food production environment (Kussaga et al., 2013; Kussaga et al., 2014a; Macheka et al., 2013; Nanyunja et al., 2015; WHO, 2015). Moreover, economic instability, wherein food is in short supply, worsens the situation, because companies get away with producing substandard products as consumers are more concerned about survival than food safety (Mensah et al., 2012).

To reduce the global burden, regulators, especially in developed countries, established legislation, e.g. the Safe Food for Canadians Act (CFIA, 2012), the Food Safety Modernisation Act (FDA, 2011) and the General Food Law (EC, 2004). The food industry is also collaborating to reduce food safety risks (Emond \& Taylor, 2018; GFSI, 2018). However, continued and recent food safety failures, even in companies in developed countries with well-established legislation, have resulted in the public mistrust of the food industry and also regulators (Powell et al., 2011; Wadamori et al., 2017). This is because regulations do not always result in proper food hygiene as food handlers and organizations have an influence through correct implementation, commitment to and showing concern for food safety (Amjadi $\&$ Hussain, 2005). The situation is even direr in some African countries, were inadequate 
legislation, which is often fragmented, and incapacitation of the enforcers challenges food safety (Grace, 2015; Kussaga et al., 2014a).

\subsection{Food Safety Management Systems and food safety performance}

Incessant food safety challenges necessitated the development and implementation of food safety management systems (FSMS) as companies view this as a gateway to improved food safety performance. As such, public and private standards to design the FSMS, such as ISO, $\mathrm{BRC}$ and FSSC, have been put in place to mitigate these food safety challenges and to assure food safety. These FSMS comprise of food safety policies, procedures and guidance to develop standard operating procedures and training programs, thus ensuring compliance to regulations (Manning, 2018b).

However, these FSMS have shortcomings to guarantee improved food safety performance as there are still issues with food safety performance in the developed as well as the developing/transition economies (Marder et al., 2018; Rapid Alert System for Food \& Feed, 2014; World Health Organization, 2018). This is because the performance of these FSMS is dependent on their application and usefulness, and on the context in which the organisations operate (e.g. Luning et al., 2011b; Wallace, 2014). Moreover, limited knowledge and understanding of individuals implementing the system, inadequate food safety and hygiene training, lack of accountability, and inadequate resources also contribute to the ineffectiveness of the FSMS (e.g. Clayton et al., 2002; Manning, 2018b; Powell et al., 2011). More often, FSMS are regarded as the formal documented system, necessary for e.g. exporting, which does not really reflect the way that they are implemented in actual practice (Griffith et al., 2017). In addition, companies with FSMS in place can be complacent (Consumer Goods Forum (CGF), 2011; Powell et al., 2013) as they believe that having an FSMS guarantees food safety.

The infectiveness of FSMS can be traced back to behavioural practices (e.g. inadequate food handler practices, negligence and non-compliance to food safety and hygiene requirements) of personnel in food industries and poor management practices (e.g. Griffith et al., 2010a; Powell et al., 2011; Pennington, 2009; Watson et al., 2018). Moreover, FSMS effectiveness is also anchored on inspections and third-party audits (Powell et al., 2013). Organisations that passed audits have still reported foodborne outbreaks, questioning the utility of both audits and inspections (Powell et al., 2013). For example, in the widely cited case of the Peanut 
Corporation of America, where there was a foodborne outbreak, third-party audits had been conducted and the company scored high in the ratings (Pennington, 2009; Powell et al., 2011). Although some researchers commend the use of audits and inspections in food safety assurance, they only represent a snapshot in time, are dependent on auditor competence and motivation for auditing, and often companies know when the auditors are coming and "prepare" for the audit (De Boeck et al., 2018; Kleboth et al., 2016 Powell et al., 2013). Organisations are therefore often not proactive and consistent in auditing their own systems and seeking to improve their FSMS, which also is dependent on and brings out their culture of food safety. The ineffectiveness of FSMS in assuring food safety has therefore triggered researchers to look beyond these traditional, formal and technical-oriented FSMS (De Boeck et al., 2019) towards a more integrated approach as discussed in section 1.3.

\subsection{Recognising the role of food safety culture in food production systems and food safety performance}

Failure of FSMS to guarantee food safety has led the food industry, regulators and the academia to seek ways to improve food safety performance. Studies on food safety are now shifting their orientation towards a multidisciplinary approach and are incorporating psychological, social and behaviour change concepts (De Boeck et al., 2017; Taylor, 2011; Yiannas, 2015) to the existing FSMS to improve food safety performance in organisations. Human factors are increasingly being acknowledged to be substantially influential to food safety performance (De Boeck et al., 2019; Greig et al., 2007; Powell et al., 2011). As such, this has led to the increasing recognition of food safety culture (FS-culture) to be influential in an organisation's food safety performance and as a plausible direction to assure food safety. Moreover, the evidence presented from a number of industries suggests that an organisation's FS-culture is an "emerging risk factor" (CGF, 2011; Griffith et al., 2010b; Powell et al., 2011) when inadequate or poorly embedded in the organisation. Furthermore, food safety scares in the industry suggesting a link to inadequate FS-culture have been previously reported (Fatimah et al., 2014b; Pennington, 2009; Powell et al., 2011). Therefore, organisations such as the Global Food Safety Initiative (GFSI) and Campden-BRI have been active in creating awareness of FS-culture in the food industry (Emond \& Taylor, 2018; GFSI, 2018).

Griffith et al. (2010b) defined FS-culture as the "aggregation of the prevailing constant learned, shared attitudes, values and beliefs contributing to the hygiene behaviours used within a particular food handling environment". It comprises both the tangible (i.e. what an 
organisation has) and the intangible (i.e. what an organisation is) aspects of an organisation's culture related to increasing or decreasing food safety risks. What an organisation "has" includes an organisation's context, controls for safety improvement and safety practices. What it "is" includes attitudes, values, beliefs and norms (Reason, 1998; Thompson et al., 1996). Both what it has and is influence the willingness of individuals towards food safety behaviour (Reason, 1998) and reflect the prevailing FS-culture.

FS-culture studies have defined determinants for conducting FS-culture research (Nyarugwe et al., 2016). These include evaluating factors such as individual characteristics of the organisational members, technological and organisational characteristics, FSMS, and an organisation's internal and external environment (e.g. De Boeck et al., 2015; Fatimah et al., 2014b; Griffith et al., 2010a; Taylor, 2011). These crucial elements that are essential in realising good food performance, are illustrated in Figure 1.2.

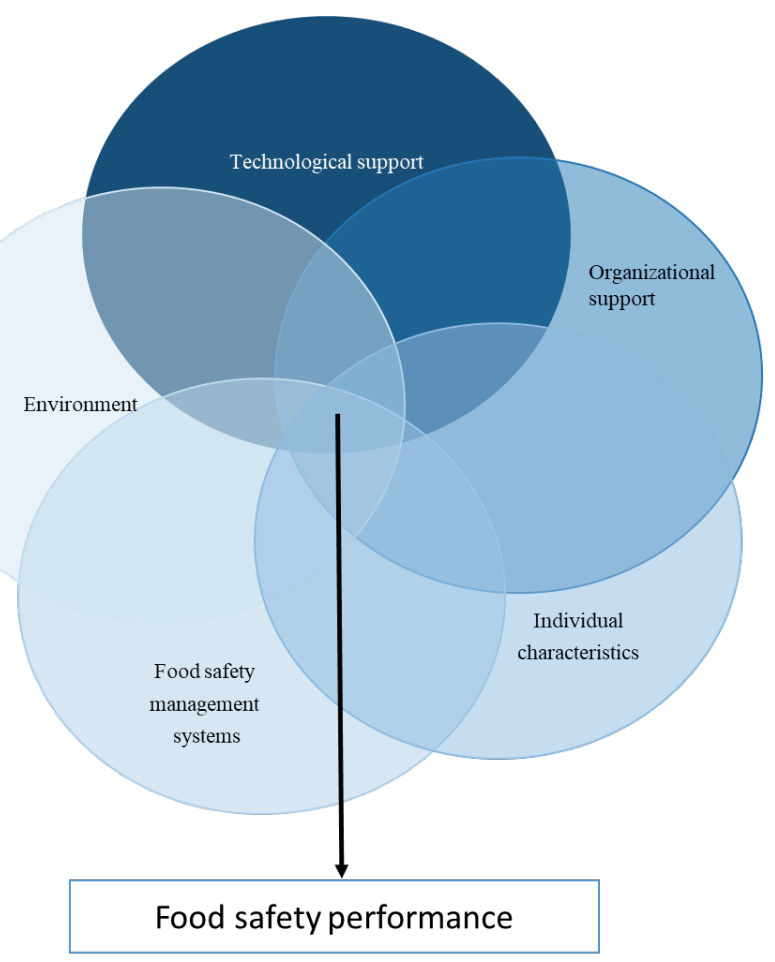

Figure 1.2 Food safety performance is dependent on organisational, technological, environmental, FSMS and people characteristics 
FS-culture goes beyond the functional aspects of FSMS (Manning, 2018b) and the more traditional methods such as sampling, testing, inspections and auditing, and requires companies to change the way things are done in the workplace. Moreover, it requires teamwork, commitment, engagement, communication, accountability, perseverance, and time. It may also require a shift in human behaviour as behaviour could be associated with the prevailing FS-culture (Griffith et al., 2010a). Moreover, a shift may be needed in personal characteristics (e.g. attitudes, values) and of the organisational culture (group values, attitudes etc.) in addition to the FSMS and the technological system environment, if improvements in food safety performance and reduction in the global burden of foodborne illnesses is to be achieved.

\subsection{Scope of the research: Emerging economies}

Our research was conducted in emerging economies as food safety is more concerning in these countries owing to the inconsistent food safety performance. Kussaga et al. (2014a) found that most products in African countries do not adhere to set microbiological criteria due to inadequacies in the context that they operate in.

Emerging economies are "low-income, rapid-growth countries using economic liberalization as their primary engine" (Hoskisson et al., 2000; Marquis \& Raynard, 2015). These are categorized into developing countries in e.g. Asia, Africa, Latin America and transition economies e.g. China (Hoskisson et al., 2013; Hoskisson et al., 2000). Emerging economies are characterised by the level of economic development, the pace of economic development, and the extent and stability of the free market system (Arnold \& Quelch, 1998). Emerging economies are also characterised by inadequate regulatory systems and they operate in a dynamic environment with volatile economies, social changes and sometimes political instability, which could lead to social unrest (Arellano, 2008; Arnold \& Quelch, 1998).

Regarding food safety, food safety systems in most emerging economies are fragmented, legislation and policies are inadequate, and not harmonized, legislation enforcement is poor and there is limited surveillance on foodborne illnesses (Grace, 2015). Moreover, the environmental instability owing to the political, economic, social and technological environmental aspects also increases the risk of food safety challenges. Some of these include, but are not limited to, increasing population, volatile incomes, changing demographics, urbanisation, globalisation, fluctuating prices of commodities, limited government support, 
and dynamics in agricultural investments (Grace, 2015; Ortega \& Tschirley, 2017; Unnevehr, 2003).

\subsection{Problem statement}

In spite of a growing awareness of the risk that foodborne illnesses pose to the health situation and socio-economic development of countries, food safety still remains marginalised in the developing/transition countries (WHO, 2015). Moreover, the implemented FSMS are inadequate as evidenced by the fact that food processing companies continue to face food safety challenges. Organisations are also typically depicted by a context where they operate with limited/inappropriate resources, lack of employee motivation to follow safe food handling practices and lack of management commitment towards food safety (Powell et al., 2011; Fatimah et al., 2014a), to mention a few. Moreover, cost-saving, profit-making cultures commonly predominate over FS-culture (CGF, 2011; Powell et al., 2011). Furthermore, a negative FS-culture, in which food handlers' self-reported practices, norms, attitudes and behavioural practices are inadequate, often exists (Powell et al., 2011). These continued challenges have raised the need to evaluate the prevailing FS-culture of organisations to understand the contributors and influencers to an organisation's prevailing FS-culture.

Despite a growing body of literature on FS-culture, FS-culture research is still in its infancy when compared with other culture research domains such as organisational and safety culture. Current FS-culture research focuses on different dimensions of the FS-culture and food safety climate concepts adapted from different organisational and safety culture studies (e.g. De Boeck et al., 2017; Taylor, 2011). The concept is therefore, still developing (De Boeck et al., 2015; Fatimah et al., 2014a) and its role and implication in food safety performance needs further research. Moreover, the FS-culture concept is still not well understood by all levels in the food industry, including middle and top management (Griffith et al., 2010a), especially in transition countries, e.g. Zimbabwe (Nyarugwe et al., 2018), as there are still knowledge gaps on what FS-culture entails, its measurement, how it could be improved and the possible causal relationships between the FS-culture components and food safety performance. In addition, the relationship between FS-culture and food handler behaviour is still under-explored. Most research focuses on the assessment of FS-culture and food safety climate within the food processing environment and not on the context in which the organisations operate. Therefore, an approach is needed that not only considers the organisation's prevailing FS-culture, but also the environment in which the companies operate. Moreover, comprehensive 
methodologies are required to understand and evaluate an organisation's FS-culture (De Boeck et al., 2019; Jespersen \& Wallace, 2017).

This thesis, therefore, sought to identify research gaps, to develop a FS-culture research framework, and methodologies to evaluate the FS-culture of food processing companies, within the organisational context and the broad national context. Such an analysis could provide insight into tangible, FS-culture specific interventions and support the development of a roadmap that would clearly define how FS-culture can be improved.

\subsection{Concepts, theories, and approaches}

This section briefly describes concepts (i.e. national values and food safety governance), theories and approaches (i.e. the contingency theory, systems approach, techno-managerial approach, principles of diagnostic tool and method triangulation) used in the $\mathrm{PhD}$ research.

\subsubsection{Concepts}

\section{National values}

In the increasingly globalised world, food establishments are becoming multinational and are thus embedded in different national/societal cultures. Moreover, with globalisation, the complexity of an organisation's FS-culture increases as organisations have to consider the national values of their workers and of the country that the organisation is operating in (Van Oudenhoven, 2001). Hofstede's cultural dimensions (Figure 1.3) have therefore been widely used to study national culture, as they are comprehensive, acceptable and have proven to give an understanding of organisational culture and/or performance (Burke et al., 2008; Mearns \& Yule, 2009; Casey et al., 2015). Hofstede defined national culture as the "collective programming of the mind that distinguishes the members of one group or category of people from others" (Hofstede et al., 2010). Six cultural dimensions, which consist of power distance, uncertainty avoidance, individualism vs collectivism, masculinity vs femininity, long vs short-term orientation and indulgence vs restraint, are used to assess national differences (Hofstede et al., 2010). In this thesis the prevailing FS-culture of an organisation is further analysed, taking into consideration national culture. Such an analysis could help understand the way food entities operate, and why employees behave the way they do. Moreover, it could enable appropriate FS-culture interventions that are specific and tailored to 
the organisations to be applied rather than generic practices, which might not be a fit with the organisations and country.

\begin{tabular}{|c|c|c|}
\hline Low & Cultural dimension & High \\
\hline $\begin{array}{c}\text { Equality } \\
\text { (decentralised) }\end{array}$ & Power Distance & $\begin{array}{c}\text { Hierarchical } \\
\text { (centralised) }\end{array}$ \\
\hline $\begin{array}{c}\text { Collectivist } \\
\text { (group interests) }\end{array}$ & Individualism vs collectivism & $\begin{array}{c}\text { Individualistic } \\
\text { (self interests) }\end{array}$ \\
\hline $\begin{array}{c}\text { Feminine } \\
\text { (modest) } \\
\text { Risk tolerant } \\
\text { (Comfortable with } \\
\text { ambiguity) }\end{array}$ & Masculinity vs femininity & $\begin{array}{c}\text { Masculine } \\
\text { (assertive) }\end{array}$ \\
\hline $\begin{array}{c}\text { Short-term } \\
\text { (past and present) }\end{array}$ & Uncertainty avoidance & $\begin{array}{c}\text { Risk intolerant } \\
\text { Uncomfortable with } \\
\text { ambiguity }\end{array}$ \\
\hline $\begin{array}{c}\text { Restraint } \\
\text { (suppressed gratification) }\end{array}$ & Long vs short-term orientation & $\begin{array}{c}\text { Long-term } \\
\text { (future- oriented) }\end{array}$ \\
\hline & Indulgence vs restraint & $\begin{array}{c}\text { Indulgent } \\
\text { (free gratification) }\end{array}$ \\
\hline 0 & & \\
\hline
\end{tabular}

Figure 1.3 Hofstede's six cultural dimensions (adapted from Hofstede et al., 2010)

\section{Food safety governance}

To understand the complexities of FS-culture, the external environment and in particular food safety governance is crucial as it plays an important role in food safety assurance and could shape an organisation's prevailing FS-culture. Food safety governance is that sub-system of the broad national context that describes the legislation, standards, entities (both public and private) and enforcement practices/strategies aimed at assuring that food processing organisations comply with food safety standards and regulations (Kirezieva \& Luning, 2017; Kirezieva et al., 2015a).

Food safety governance is differently structured in different countries and countries have set different public requirements, which are elaborated, implemented and enforced differently (e.g. CFIA, 2012; EC, 2004; FDA, 2011). Countries also respond differently to food safety concerns regulatory-wise (Martinez et al., 2007). For example, in some countries e.g. in the US (FDA, 2011) and within the EU (EC, 2004), there are clear authorities for food safety control, while in some transition countries the legislation is obsolete, the system fragmented and poorly coordinated, and regulators lack requisite resources to assure food safety (Macheka et al., 2013; Pswarayi et al., 2014). Moreover, in most transition countries food safety is not a legal requirement. Most companies only implement voluntary standards to 
remain competitive and also for export purposes as they cite high costs for implementing and adhering to the system (Macheka et al., 2013).

Food safety is also differently enforced in different countries with enforcement strategies ranging from direct command and control, market self-regulation and co-regulation (Kirezieva et al., 2015a). The level of public intervention to food safety problems also differs, ranging from doing nothing (no intervention), self-regulation (voluntary codes of practice i.e. private standards), co-regulation (statutory or Government-backed codes of practice), information and education, incentive-based structures to direct command and control (Martinez et al., 2007). This thesis examines the role of food safety governance on an organisation's prevailing FS-culture, food safety vision, and food safety programs. This is justified because food safety governance could influence the motivation, implementation and adherence to food safety by food processing organisations. The assumption is that how private and especially public authorities, i.e. Governments, intervene in food safety issues determines the pace with which organisations will prioritise food safety within their organisations.

\subsubsection{Theories and approaches}

\section{A systems approach to food safety culture assessment}

The systems approach is considered to understand the complexity of FS-culture, as it involves numerous interlinking factors. The systems approach is a holistic and structured approach that offers a conceptual framework for solving problems and addresses root causes of food safety challenges by considering problems in their entirety (Banson et al., 2015). As such the approach is not based on linearity, where parts are taken into account, but considers the whole picture and explores the interdependences and synergies of different elements and subsystems (Arnold \& Wade, 2015). Adjusting one part of the system can significantly affect the functioning of the whole system due to the relations between the subsystems (Banson et al., 2015). The approach also offers an understanding of the relationships between elements through its ability to depict complex and dynamic processes (Rubenstein-Montano et al., 2001). Moreover, it elucidates the complex interactions between subsystems of an organisation and between individuals, groups, other organisations, and the external environment of an organisation (Martins \& Terblanche, 2003). 
The systems approach also links various disciplines (Arnold \& Wade, 2015). As synonymous with any system, the approach additionally defines boundaries that distinguish aspects of the environment that are contained in the system (Rubenstein-Montano et al., 2001) and interact with the organisation's FS-culture and the relationships among the subsystems in the system. Evidently, understanding how various aspects of the system interact with the environment is crucial in managing a system and how the system operates in its environment (RubensteinMontano et al., 2001).

Hence this research on FS-culture is grounded on the systems theory approach because FSculture is multidimensional and a result of several interlinked factors; a single factor cannot reflect an organisation's prevailing FS-culture. Consequently, the systems approach is a viable way to assess the prevailing FS-culture of an organisation.

\section{The food business context (Contingency Theory)}

The interaction between a system and its environment must be assessed to fully understand how a system functions (Donaldson, 2001). Companies never operate in isolation, and therefore the environment (context) in which they operate plays a critical role in their performance (Chenhall, 2006). This recognition is based on the contingency theory, which specifies that the effectiveness of a system depends on the optimal fit between the internal system operations and its environment. Organisations should have this fit to have a good performance (Figure 1.4; Donaldson, 2001). However, the complexity and dynamic nature of the environment make it difficult to achieve high performance and companies must understand the environment to improve and sustain the company's performance (Husted, 2000). As such, FS-culture should be assessed in view of the context in which the company operates to improve performance and to tailor interventions to the specific context wherein the company operates (Sousa \& Voss, 2008).

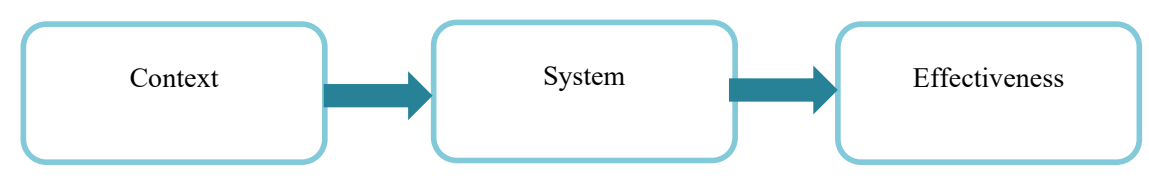

Figure 1.4 Contingency theory based on Donaldson (2001) and Sousa and Voss (2008). 
The influence of context has been elaborated in food safety management studies (Kirezieva et al., 2015a; Luning et al., 2015) and is well documented in the occupational safety and health fields (Kaplan et al., 2010; Mearns \& Yule, 2009). However, the scientific literature on these factors is limited in the field of FS-culture. Moreover, existing studies have assessed FSculture at company level, but the impact of the organisation's context is yet to be scientifically well studied. Context factors that influence food safety performance include external characteristics such as the political, economic, social and technological environment, food safety governance, national culture, sector values and internal characteristics that include size, location, organisational structure, and product and process characteristics (Chenhall, 2006; De Boeck et al., 2017; Fatimah et al., 2014b; Luning et al., 2011b; Taylor, 2011; Thompson et al., 1996; Van der Spiegel et al., 2003). It is important to identify the crucial contingency variables that distinguish between contexts and provide more effective internal organisation designs (Sousa \& Voss, 2008). This thesis is therefore founded on the contingency theory as an organisation's prevailing FS-culture must be analysed in view of the internal and external company environment.

\section{The techno-managerial approach}

FS-culture is dynamic, complex, with numerous interlinking factors at play and it requires the integrative use of theories to understand it. Luning and Marcelis (2006) proposed a technomanagerial approach to study complex dynamic systems involved in realising food quality. The approach uses both technological and managerial theories to analyse the influence of human behaviour on food systems and vice versa (Luning \& Marcelis, 2006). The integrative use of both theories is expected to be more beneficial in analysing FS-culture, than merely using one approach (Luning \& Marcelis, 2009a). Luning and Marcelis (2006) proposed that this approach could provide better insights into food quality issues and allow better prediction of the behaviour of systems thus allowing the development of specific solutions rather than generic best practices. De Boeck et al. (2017) also emphasised the importance of human and techno-managerial approaches to FS-culture and food safety performance. Moreover, Van der Spiegel et al. (2003) reiterated that for food quality assurance, the performance of production systems is controlled by integrating and assessing both technological and managerial aspects of the system. 
The techno-managerial approach is also anchored on the assumption that food safety is dependent on food dynamics related to the technological and environmental conditions, and people dynamics related to administrative conditions, and that both systems are interdependent. To analyse food quality, Luning and Marcelis (2007) therefore developed a model to assess an organisation's environment, and both technological and managerial functions using the techno-managerial approach (Figure 1.5). The techno-managerial approach forms the backbone of this thesis as it supports the identification of both technological and managerial functions (technological and organisational enabling conditions) and environmental functions (internal and external company environment) that contribute to the realisation of desirable product output.

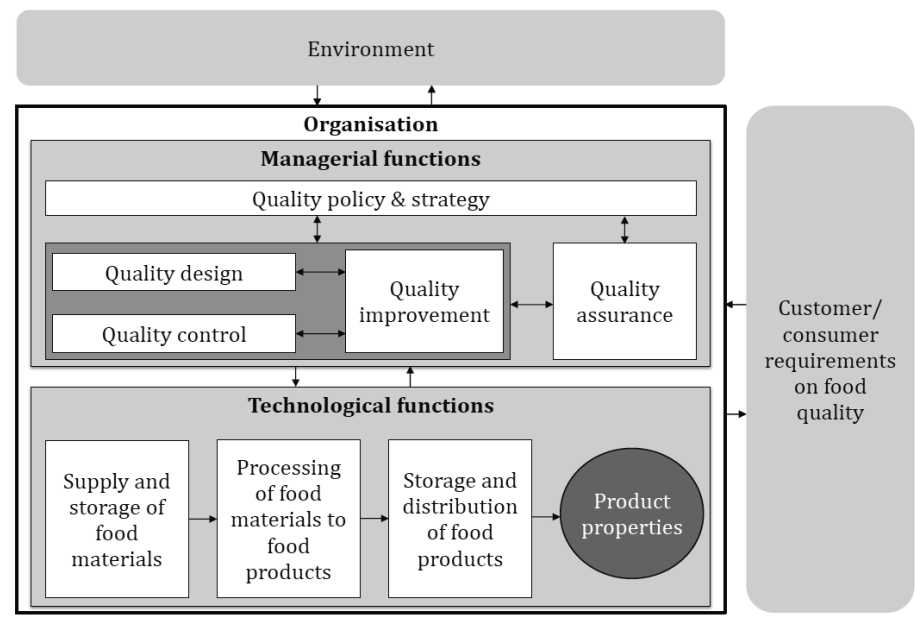

Figure 1.5 Food quality management functions model (Luning \& Marcelis, 2007)

\section{Principles of diagnostic tool}

Research in food quality management involves analyses of food production systems and people systems that are both crucial in realising food quality (Luning \& Marcelis, 2006). Likewise FS-culture research considers both human systems and food production systems (De Boeck et al., 2017; Nyarugwe et al., 2018). A diagnostic tool as such, offers guidance on the assessment of food safety systems, allows differentiated assessment of the system owing to the systematic assessment of key factors, and provides insights into improvement opportunities (Luning et al., 2008). In addition, a diagnostic tool can be used to analyse the influence of the company environment on the food safety performance of a system (Kirezieva et al., 2015a; Luning et al., 2015; Luning et al., 2011b). Principles behind differentiated 
assessment involve assessment of core activities that influence a system's output. A diagnostic tool, therefore, incorporates detailed grids describing different levels, in this case of FS-culture, which describe different stereotype situations to enable a differentiated assessment of an organisation's “food safety control system situation” (Luning et al., 2008). Several studies have used the differentiated assessment approach in food safety performance (Kirezieva et al., 2013b; Luning et al., 2011b; Luning et al., 2008), FS-culture (e.g. Wright et al., 2012) and safety culture (Foster \& Hoult, 2013). This thesis applies the principles of differentiated assessment in developing FS-culture assessment tools to analyse the prevailing FS-culture in food processing organisations and to provide a basis for tailored interventions that could be useful to improve FS-culture. The assessment tool focuses on evaluating FSculture at the operational level since that level has a more direct influence on the production process and the final product safety. The operational level is assumed to reflect the FS-culture at the strategic and tactical levels as both levels directly and indirectly (Flin \& Yule, 2004) influence how the operational level executes food safety/hygiene control activities. Concepts, theories and approaches in this thesis are used as the foundation of the conceptual framework (Figure 1.6).

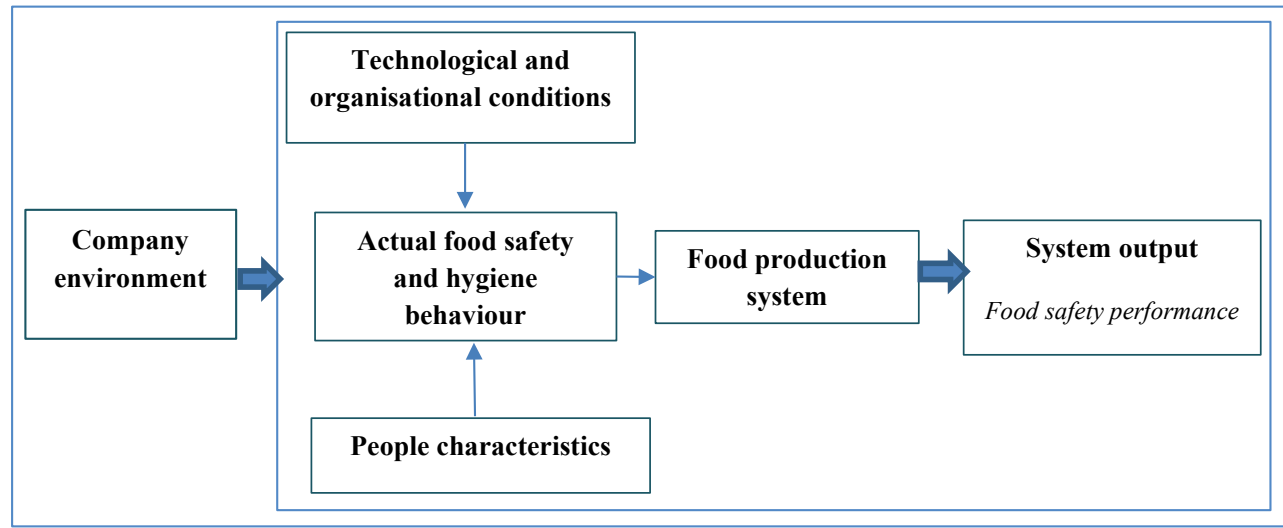

Figure 1.6 Conceptual framework for analysing an organisation's prevailing food safety culture

\section{Method triangulation}

The complexity and the multidimensionality of FS-culture necessitate method triangulation to systematically assess an organisation's prevailing FS-culture. Kopinak (1999) defines method triangulation as "a means to gather information pertaining to the same phenomenon through more than one method, primarily to determine if there is a convergence and hence, increased 
validity in the findings". The assumption is that findings are more robust if different methods lead to similar conclusions (Carugi, 2016). The methodology is particularly suitable for complex, multi-layered and multidimensional situations as it uncovers detailed multidimensional perspectives of the situation being studied (Carugi, 2016; Kopinak, 1999). Moreover, combining different methods allows the weaknesses of one method to be mitigated by the counterbalancing strength of other methods (Bauwens, 2010; Carugi, 2016; Yeasmin \& Rahman, 2012).

FS-culture research is therefore increasingly recognizing the importance of method triangulation (De Boeck et al., 2019; Jespersen \& Wallace, 2017; Manning, 2018a; Nyarugwe et al., 2018). Method triangulation permits assessment of different aspects of FS-culture using different methods, allowing for comprehensive evaluation. Moreover, applying method triangulation in FS-culture assessments could elaborate findings and uncover underlying issues, thus improving robustness, internal consistency and generalizability, and allowing for tailored interventions to be applied to improve an organisation's FS-culture.

\subsection{Objective and outline of the thesis}

The main objective of this thesis was to investigate how an organisation's FS-culture influences food handlers' food safety and hygiene behaviour, and the food safety performance of an organisation. Furthermore, we aimed to study the influence of the internal and external company environment on an organisation's FS-culture and food safety performance, with emerging economies as case studies. The objectives were realised through the following research questions:

i. What is the current knowledge on FS-culture and what are the determinants for conducting FS-culture research?

ii. Which factors at the organisational level influence the prevailing FS-culture of food processing companies?

iii. Which assessment methods are necessary to measure the prevailing FS-culture of an organisation?

iv. Which factors in the internal and external company environment influence an organisation's prevailing FS-culture?

v. Which factors in the external company environment could influence the prevailing FS-culture of companies operating in different countries? 
To achieve our research objectives and to address the research questions, the research considered both theoretical concepts and practical analysis of the prevailing FS-culture in food processing organisations (Figure 1.7). Chapter 1 presents the general introduction, which provides the background to the study regarding food safety challenges, the need for FSculture research, concepts and theories, and outlines the research objectives. Chapter 2 outlines determinants for conducting FS-culture research as identified through a critical literature review. The objective was to find commonalities in the national, organisational and safety culture literature and get an understanding of the state-of-the-art on FS-culture to identify aspects that could be used in elaborating FS-culture research. Next, Chapter 3 assesses the prevailing FS-culture of an organisation using elements identified in the critical literature review. In addition, a mixed-methods approach was developed to assess an organisation's FS-culture to capture the different facets (multidimensionality) of an organisation's prevailing FS-culture. Subsequently a research framework was developed in Chapter 4 building on previous research. Moreover, the influence of the external company environment was assessed within the national context. Chapter 5 further explores the influence of the external company environment, specifically national values and food safety governance, on an organisation's prevailing FS-culture from an intercontinental perspective. Finally, Chapter 6 presents the general discussion of the core findings from an integrated perspective, concluding remarks and recommendations for further research. 


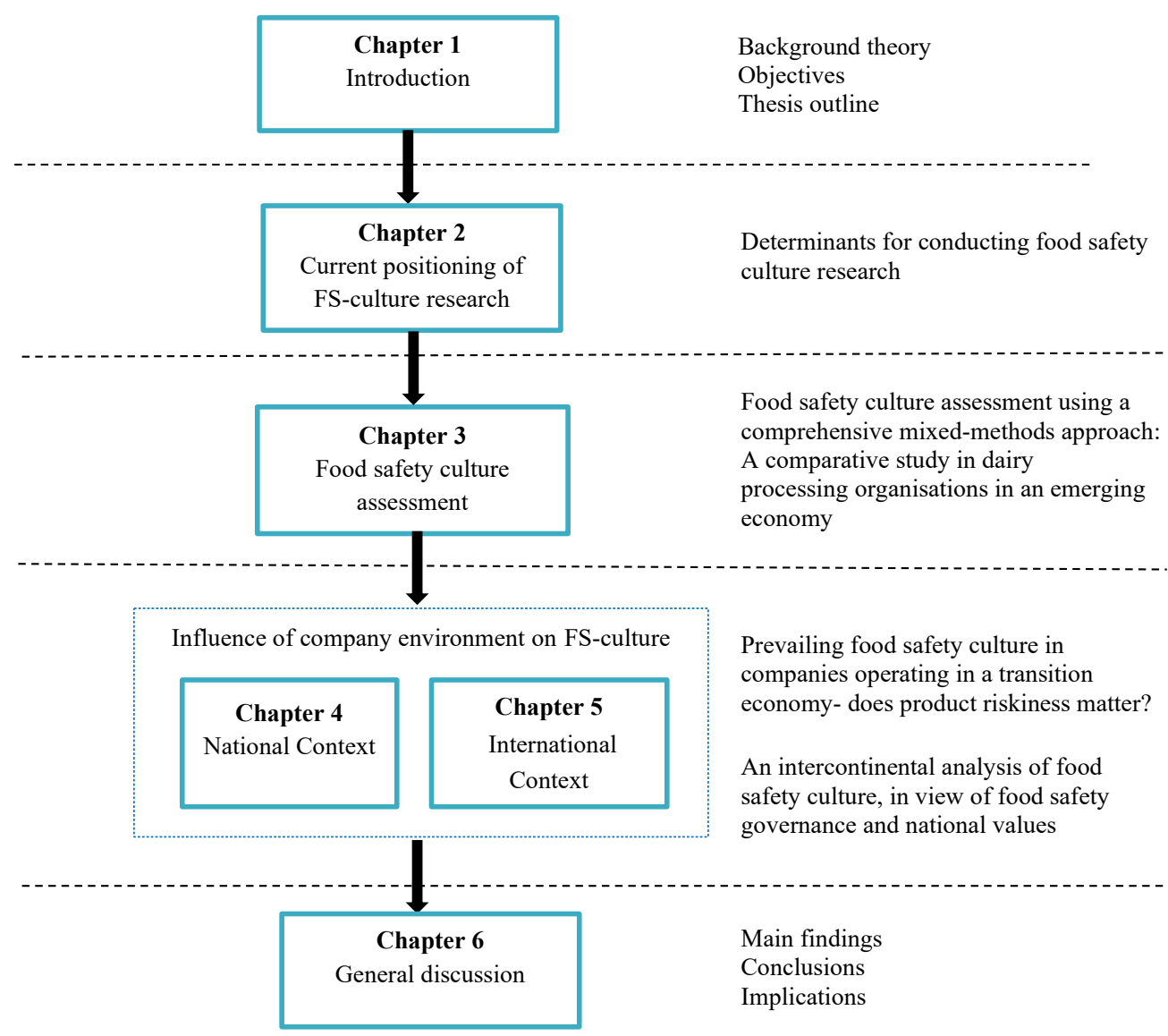

Figure 1.7 Thesis outline 



\section{Chapter 2}

\section{Determinants for conducting food safety culture research}

Published as: Nyarugwe, S. P., Linnemann, A., Hofstede, G. J., Fogliano, V., \& Luning, P. A. (2016). Determinants for conducting food safety culture research. Trends in Food Science \& Technology, 56, 77-87. 


\begin{abstract}
Foodborne outbreaks continue to occur regardless of existing food safety measures indicating the shortcomings of these measures to assure food safety. This has led to the recognition of food safety culture as a key contributory factor to the food safety performance of food establishments. The aim of this paper is to identify determinants for conducting food safety culture research, using the systems approach as the underlying philosophy to guide the structured reconsideration of national, organisational and safety culture literature, in view of food safety. Food safety culture is complex and many interlinking factors are at play. The analysis of 'culture' literature showed that food safety culture research should acknowledge the impact of national culture, specify hierarchical level(s) (strategic, tactical, and operational), establish underlying mechanisms, and consider the company's food risks and context characteristics. Major elements to be considered in food safety culture research include organisational and administrative characteristics (i.e. food safety vision, communication, commitment, leadership, training), technical facilities/resources (i.e. food hygiene/safety tools, equipment, \& facilities), employee characteristics (i.e. attitudes, knowledge, perceptions and risk awareness), group characteristics, crucial FSMS characteristics, and actual food safety performance. Methodological requirements for food safety culture research include use of the systems approach, measurable indicators, classification systems for differentiated assessment, and use of multiple methods to enhance research validity. The identified food safety culture research determinants provide an underpinned and transparent starting point to the common understanding and research of food safety culture.
\end{abstract}




\subsection{Introduction}

Existing measures to secure flawless production of safe food products have proven to be insufficient by recurring foodborne outbreaks. This has resulted in a unanimous global objective and initiative within the food industry (Consumer Goods Forum (CGF), 2011) to adopt Food Safety Management Systems (FSMS), which have been extensively and markedly acknowledged as measures to assure food safety. Although the food industry, third party auditors and regulators have placed substantial effort on implementing (EC, 2004; FDA, 2011; CFIA, 2012; Powell et al., 2013; Luning et al., 2015; Global Food Safety Initiative (GFSI), 2016) and improving FSMS, incidences of foodborne illnesses still continue to be reported (Rapid Alert System for Food \& Feed, 2014; Crim et al., 2015).

The continued occurrence of foodborne illnesses coupled with inconsistencies in food safety indicates the shortcomings of current FSMS, raising questions on the adequacy of these systems to fully guarantee food safety as evidenced by recent papers (e.g. Kirezieva et al., 2013a; Onjong et al., 2014). The shortcomings could be because FSMS are elaborated differently in practice (FAO, 2007; Kirezieva et al., 2015b) and are not always well adapted to cope with the risks inherent to the companies' context characteristics (Luning et al., 2011b; Kirezieva et al., 2013b). The shortcomings could also be attributed to neglecting the impact of different food safety enforcement philosophies and practices, which differently influence the implementation of and adherence to public and private standards and guidelines by the organisations (Pederson \& Hernández, 2014; Kirezieva et al., 2015a). Moreover, due to globalisation, multiple national cultures often exist in organisations, which increases the complexity of the organisation's culture and could have a significant bearing on the effectiveness of FSMS (Pederson \& Hernández, 2014).

Above observations led to the supposition that food safety culture (FS-culture) might be contributing to food safety performance (Yiannas, 2009; Griffith et al., 2010b; Ungku Fatimah et al., 2014a). Evidence presented from a number of industries (e.g. Pennington, 2009; Powell et al., 2011) suggested that an organisation's FS-culture is an "emerging risk factor" (Griffith et al., 2010b; CGF, 2011) when inadequate, and that there is a link between food safety and the prevailing FS-culture (Powell et al., 2011; Ijabadeniyi, 2013; Ungku Fatimah et al., 2014b). The most cited cases of John Tudor \& Sons, Maple Leaf Foods Inc. and the Peanut Corporation of America, in which foodborne illness outbreaks were attributed to the existence of a poor FS-culture stress the importance of FS-culture (e.g. Powell et al., 
2011; Ijabadeniyi, 2013). To achieve a good food safety performance organisations therefore need to have a well-elaborated FSMS and a positive FS-culture in place (Powell et al., 2011; De Boeck et al., 2015). Food industries have thus taken a profound interest in the concept of FS-culture to reduce the potential for food safety failures (Yiannas, 2009; Griffith et al., 2010a; CGF, 2011). However, the FS-culture concept is still built on limited conceptual foundations and has been far less investigated compared to organisational and safety culture (Griffith et al., 2010a; Ungku Fatimah et al., 2014a).

Recent studies developed tools to measure FS-culture (e.g. Wright et al., 2012; Ungku Fatimah et al., 2014a; De Boeck et al., 2015), maturity models (Jespersen et al., 2016) and FSculture concepts (Taylor, 2011). However, the studies used differing approaches and concepts from various disciplines (e.g. Griffith et al., 2010b; Taylor, 2011; Jespersen et al., 2016). The aim of this study is therefore to identify the determinants for conducting food safety culture research, using the systems approach as the underlying philosophy to guide the structured reconsideration of national, organisational and safety culture literature as presented in Figure 2.1 and sections 2.3-7. National culture literature is discussed first to set the context and elaborate its role in organisational, safety and FS-culture. Organisational culture literature is discussed to provide a deeper understanding of culture concepts. Safety culture literature is examined to provide insight in typical safety related issues in high risk fields. FSMS principles are described since they are crucial to the existence of a positive FS-culture (Powell et al., 2011). An evaluation of current FS-culture concepts provides an overview of the current understanding of FS-culture and its role in food safety performance. The paper concludes with research recommendations.

\subsection{Approach and literature search strategy}

\subsubsection{Approach}

The systems approach was used to position food safety culture (Figure 2.1) and to guide the literature reconsideration in the different 'culture' research fields with the intention to identify the "determinants" (Table 2.4) for conducting FS-culture research. 


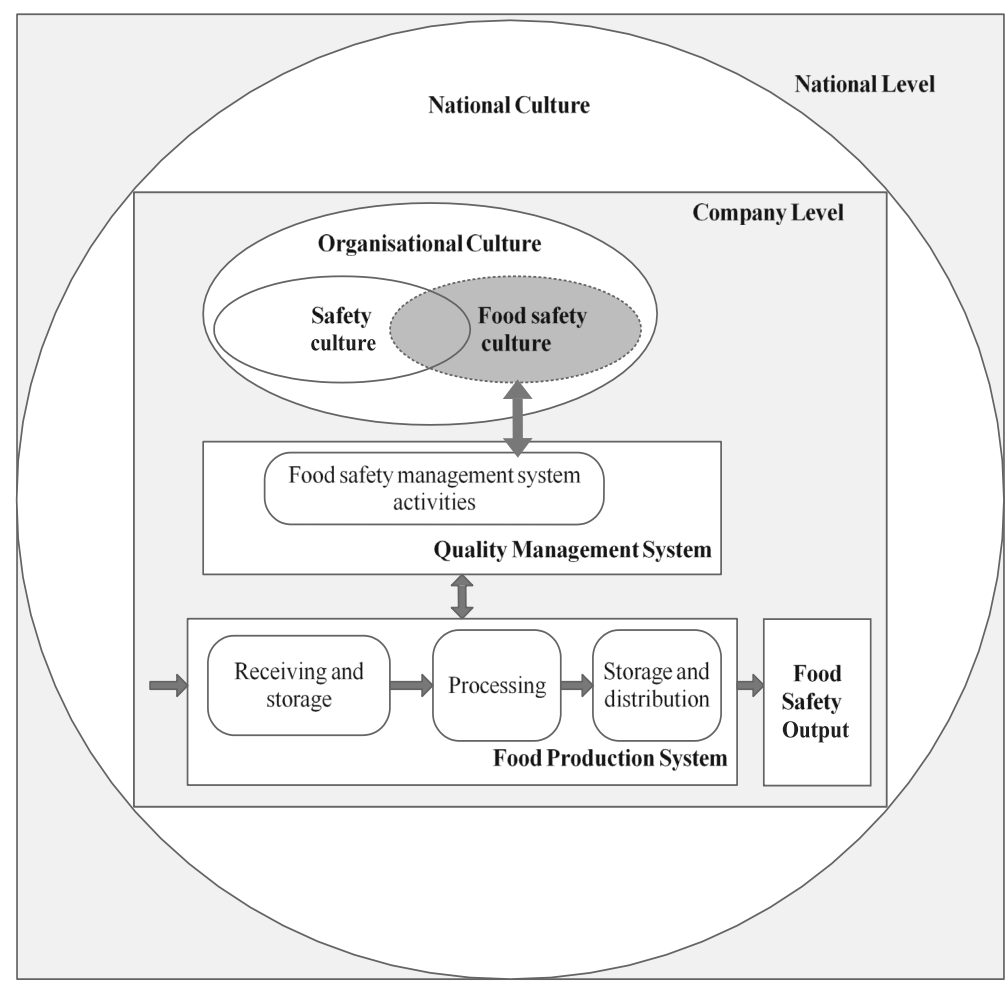

Figure 2.1 Proposed positioning of food safety culture from a systems perspective (adapted from Luning \& Marcelis, 2007).

The arrows in the figure show the direction of influence. The figure shows that national culture is the overarching culture and that FS-culture can be analysed at both the company and national level.

The systems approach is a structured way to study the interdependence and relationships of system components (Arnold \& Wade, 2015), and recognises the synergy of elements in systems and the hierarchy of systems where subsystems participate in a bigger hierarchy of systems (Skyttner, 2005). The approach transcends and links numerous disciplines (Arnold \& Wade, 2015). Figure 2.1 presents the proposed positioning of FS-culture and the possible interplay between the broad national level (national culture), and the company level (organisational culture, FSMS, food production system and food safety output), in view of food safety. This positioning is derived from the food quality functions model, which identifies functions that contribute to the realisation of a desirable product output (Luning \& Marcelis, 2007) and gives insight into components we propose to be interlinked when researching FS-culture and its relationship with food safety performance. 
It is important to note that the figure is a simplified presentation to enable conceptualisation of the proposed positioning of FS-culture. The reality is more complex as many organisations are multinational, are located in multiple geographical locations, and are confronted with different internal and external influences (e.g. operational characteristics, sector or market requirements).

\subsubsection{Literature search strategy and results}

A literature search was conducted in EBSCOhost and Thomson Reuters Web of Science platforms, Google Scholar and the Elsevier-Scopus database using the following keywords: national culture, organisational culture, organisation performance, safety culture, safety performance, food safety culture, culture of food safety and food safety management system(s). The search strategy (Figure 2.2) comprised the following inclusion criteria: (i) articles published in English, with preference for peer-reviewed articles, (ii) scope of the study, (iii) national, organisational and safety culture articles from 1990 onwards to obtain fairly recent articles and FS-culture articles spanning all years since there are limited studies.

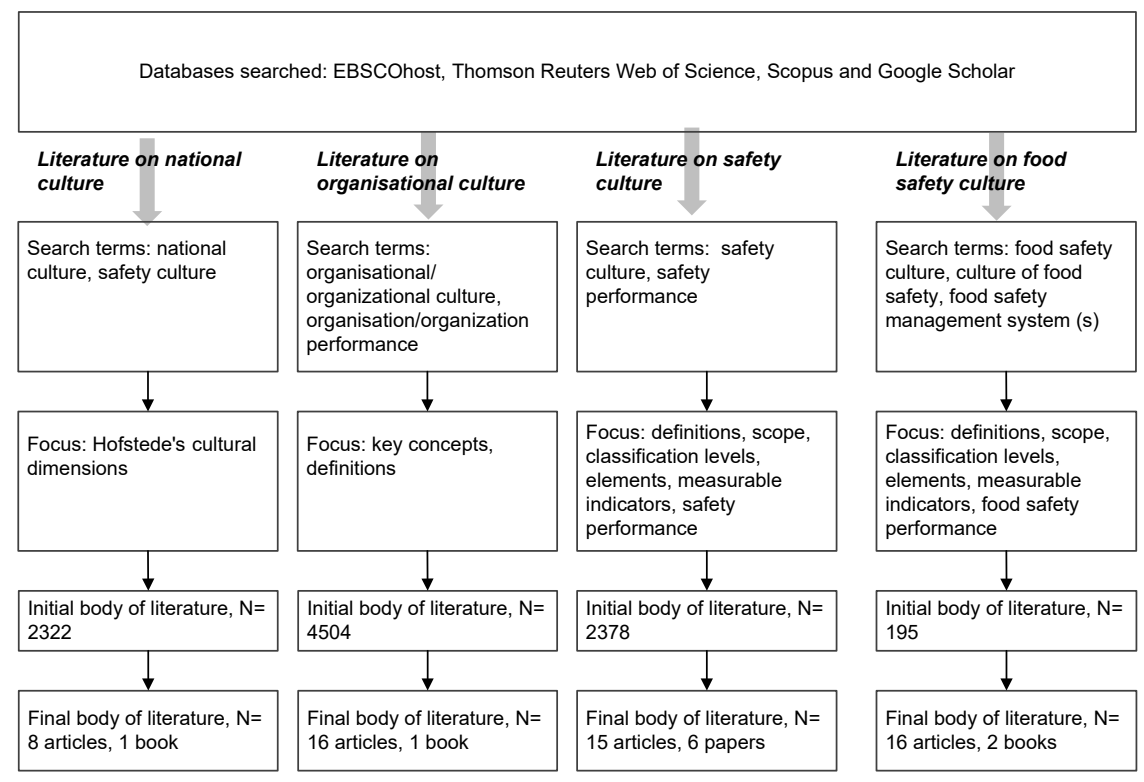

Figure 2.2 Data collection process based on searches in EBSCOhost, Thomson Reuters Web of Science, Elsevier-Scopus and Google Scholar 
Titles and abstracts of retrieved articles were reviewed and screened for relevance based on whether articles covered the research objective and the inclusion criteria. If the abstracts provided insufficient information, the whole article was scanned and in some instances, crossreferenced articles were manually searched for. In other instances, selected keywords yielded broader, irrelevant publications, for example, for FS-culture, articles only focusing on microbiology were obtained. Upon careful consideration of the keywords and implications thereof, quotation marks were used to search for phrases and Boolean operators AND, OR used to obtain pertinent information. Full versions of the selected articles were screened to obtain useful articles based on the following criteria: national culture articles had to focus on Hofstede's cultural dimensions in organisations, organisational, safety and food safety culture on definitions, scope, classification levels, elements, and measurable indicators. The search results are shown in Figure 2.2 and the findings are presented in sections 2.3-7.

\subsection{National culture and its relationship with organisational culture}

In general, culture is defined for a group of people and it is what differentiates one group from another (Ogbonna, 1992). At national level, culture is that "which distinguishes members of one group (nation/society) from those of another" (Hofstede et al., 2010). Table 2.1 shows key national culture definitions and key aspects derived from national culture studies that could be essential in FS-culture research. Existing studies acknowledge national culture as part of an organisation's context that influences how organisations operate and perform (Figure 2.1) (Lok \& Crawford, 2004; Havold, 2007; Burke et al., 2008; Mearns \& Yule, 2009). This is because individuals bring values adopted from their national cultures to the workplace, which through socialisation (Mearns \& Yule, 2009) influence the workplace culture (Newman \& Nollen, 1996; Havold, 2007; Burke et al., 2008; Mearns \& Yule, 2009; Seymen \& Bolat, 2010). The extent to which individual values are influenced by the national culture and how well these values fit with the workplace culture could pose differences on the performance of organisations in different countries (Newman \& Nollen, 1996; Lok \& Crawford, 2004).

To assess national differences in values, Hofstede defined six cultural dimensions (Table 2.1) (Hofstede et al., 2010). The first dimension, power distance distinguishes between high power distance cultures where decision-making is centralised and employees are barely involved in decision making (are expected to do "what the boss says should be done") (Nakata \& Sivakumar, 1996) and low power distance cultures where decision-making is decentralised 
and employees expect to be consulted (Hofstede et al., 2010). The second dimension focuses on individualism vs collectivism and distinguishes individualistic cultures where people are expected to look after their self-interests and achievement is based on personal merit rather than on group effort, and collectivistic cultures where group interests prevail over individuals' (Hofstede et al., 2010).

Table 2.1: Key aspects derived from national culture literature essential to establish food safety culture research determinants

\begin{tabular}{|c|c|c|}
\hline \multicolumn{2}{|r|}{ Definitions/Key aspects } & References \\
\hline \multirow[t]{4}{*}{$\begin{array}{l}\text { Definition } \\
\text { (s) }\end{array}$} & $\begin{array}{l}\text { - "Central organising principle of employees' understanding of work, their } \\
\text { approach to it, and the way in which they expect to be treated" }\end{array}$ & - Newman \& Nollen, 1996 \\
\hline & $\begin{array}{l}\text { "Profound beliefs, values and practices shared by the vast majority of } \\
\text { people belonging to a certain nation and are reflected in the ways people } \\
\text { behave at school, in the family, on the job, etc., and they are reinforced by } \\
\text { national laws and governmental policies with respect to family life, } \\
\text { business, etc." }\end{array}$ & - Van Oudenhoven, 2001 \\
\hline & $\begin{array}{l}\text { - "Collective programming of the mind that distinguishes the members of } \\
\text { one group or category of people from others" }\end{array}$ & - Hofstede et al., 2010 \\
\hline & $\begin{array}{l}\text { - "Collective mental programming specific to inhabitants of a particular } \\
\text { geographic region" }\end{array}$ & - Casey et al., 2015 \\
\hline \multirow[t]{4}{*}{$\begin{array}{l}\text { Key } \\
\text { aspects }\end{array}$} & - National culture shapes an organisation's culture. & $\begin{array}{l}\text { - Newman \& Nollen, 1996; } \\
\text { Mearns \& Yule, 2009; Seymen } \\
\text { \& Bolat, 2010; Starren et al., } \\
\text { 2013; Casey et al., } 2015\end{array}$ \\
\hline & $\begin{array}{l}\text { - Hofstede defined six cultural dimensions that differentiate national } \\
\text { cultures: }\end{array}$ & - Hofstede et al., 2010 \\
\hline & $\begin{array}{ll}\text { - } & \text { power distance } \\
\text { - } & \text { individualism vs collectivism } \\
\text { - } & \text { masculinity vs femininity } \\
\text { - } & \text { uncertainty avoidance } \\
\text { - } & \text { long vs short term orientation } \\
\text { - } \quad \text { indulgence vs restraint }\end{array}$ & \\
\hline & $\begin{array}{l}\text { - Cultural dimensions influence: } \\
\begin{aligned} \text { - } & \text { risk and safety perceptions } \\
\text { - } & \text { values and attitudes of personnel in organisations } \\
\text { - } & \text { management commitment and employees' participation } \\
\text { - } & \text { risk taking behaviour } \\
\text { - } & \text { safety management systems } \\
\text { - } & \text { organisational safety performance }\end{aligned}\end{array}$ & $\begin{array}{l}\text { Newman \& Nollen, 1996; Van } \\
\text { Oudenhoven, 2001; Havold, } \\
\text { 2007; Mearns \& Yule, 2009; } \\
\text { Seymen \& Bolat, 2010; Lu et } \\
\text { al., 2012; Starren et al., 2013; } \\
\text { Casey et al., } 2015\end{array}$ \\
\hline
\end{tabular}

The third dimension is masculinity vs femininity where masculine cultures have people that are assertive and are unlikely to assist others unless they get credit, whereas in feminine cultures people assist others and value relationships and other people over material success (Hofstede et al., 2010). For uncertainty avoidance, individuals in a culture high in uncertainty avoidance are expressive and avoid ambiguous situations, whereas individuals in low 
uncertainty avoidance cultures are less expressive and feel secure (Hofstede et al., 2010). The fifth dimension is long vs short-term orientation where long-term oriented cultures are typified by patience, long-term goals and future rewards, and short-term oriented cultures focus on prevailing issues (Hofstede et al., 2010). The sixth dimension is indulgence versus restraint where indulgent cultures are typified by free gratification, whereas restraint cultures are typified by supressed gratification (self-control) regulated by social norms (Hofstede et al., 2010). These dimensions have been extensively used as they are comprehensive, relevant, acceptable and convenient when assessing the role of national culture in organisational/safety culture and safety performance (e.g. Newman \& Nollen, 1996; Van Oudenhoven, 2001; Mearns \& Yule, 2009; Seymen \& Bolat, 2010).

From a food safety perspective, Wallace (2009) and Taylor (2011) proposed that the dimensions could potentially influence the effectiveness of FSMS and the organisation's FSculture. For example, both studies suggested that in individualistic cultures, personnel prefer individual recognition for their effort and in collectivistic cultures, personnel strive to achieve food safety goals by working together as a team. Wallace (2009) hypothesised that personnel in feminine cultures are likely to assist each other to achieve food safety requirements and in masculine cultures, personnel focus on getting the job done. Furthermore, in low uncertainty avoidance cultures, personnel are "more receptive of new ideas and will likely take on new responsibilities" and organisations in long-term oriented cultures focus on having well established and comprehensive food safety policies/systems (Wallace, 2009). In short-term oriented cultures organisations may provide temporary measures to address food safety concerns (Taylor, 2011).

In addition to the cultural dimensions, national cultural differences are observed in a country's food safety governance philosophy, strategies and practices (e.g. legislation, public and private standards, and enforcement practices) (Kirezieva et al., 2015a). Food safety governance is aimed at assuring organisation's compliance to food regulations and standards and influences the organisation's FSMS (Rouvière \& Caswell, 2012; Kirezieva et al., 2015a) and FS-culture depending on the positioning of the country on the cultural dimensions scores. For example, some countries have enforcement practices that are reactive (punitive) and others have proactive approaches (preventive). Some countries have legislation in place (e.g. EC, 2004; FDA, 2011; CFIA, 2012) whilst others do not have/have outdated legislation (FAO, 2007; Kussaga et al., 2014a). Countries can have different enforcement strategies, 
which can vary from self-regulation to direct command and regulation from the government and enforcement philosophies that are either systematic or facilitative (Kirezieva et al., 2015a). This observation could be a result of and explain differences in national cultures towards food safety.

Moreover, with globalisation, companies are increasingly becoming multinational thus increasing the complexity of an organisation's culture (Van Oudenhoven, 2001; Seymen \& Bolat, 2010). These companies are confronted with multiple national cultures in their daily operations. An understanding of the culture where the company operates and the differences in culture of the members in the organisation is required in order to apply the appropriate research approach to the individuals in the firm and to the cultural context the organisation operates in (Ghemawat \& Reiche, 2011). In this paper, we point out the need to take into account national cultural differences (cultural dimensions and food safety governance) when conducting organisational culture/ FS-culture research. Understanding these cultural differences enable the right research approach to be taken because an approach which is effective in one culture might not be effective in another culture due to differences in risk and safety perceptions, management/leadership style, values and attitudes, to mention a few (Ghemawat \& Reiche, 2011).

\subsection{Key aspects of organisational culture useful in FS-culture research}

In organisations, culture is that which distinguishes organisations and shapes them into what they are (Ashkanasy et al., 2000). Schein, (2010), one of the principal experts in organisational culture (e.g. Denison, 1997) defines organisational culture as "a pattern of shared basic assumptions that the group learned as it solved its problems of external adaptation and internal integration, that has worked well enough to be considered valid and, therefore, to be taught to new members as the correct way you perceive, think, and feel in relation to those problems". Schein's work has been commonly used as a theoretical foundation to characterise organisational culture in various researches (e.g. Bloor, 1999; Balmer \& Wilson, 2001; Martins \& Terblanche, 2003).

As expressed in Figure 2.1, organisational culture is shaped by national culture (Seymen \& Bolat, 2010), thus it differs within an organisation (multinationals), within a country and from country to country (Van Oudenhoven, 2001). Table 2 shows key organisational culture definitions and aspects, which permeate organisational culture literature that would be useful 
in FS-culture research. When describing organisational culture, two distinct approaches (functionalist and interpretive) are predominantly used. The functionalist approach assumes organisational culture as the ideal an organisation must achieve and describes what an organisation "has" (tangible) (e.g. policies, procedures and structures). The interpretive approach assumes organisational culture as an emergent social entity and describes what an organisation "is" (intangible) (e.g. shared beliefs, assumptions, values, and attitudes) (Davies et al., 2000; Glendon \& Stanton, 2000). Most studies (Table 2) implicitly imply what an organisation is. To understand organisational culture both approaches should be synthesised as what an organisation "is" assists in understanding the organisation and helps to provide appropriate and specific interventions in positively changing what an organisation "has" (De Witte \& van Muijen, 1999; Davies et al., 2000; Maull et al., 2001). Moreover, both approaches help in understanding organisational culture and its subcomponents.

When describing an organisation's culture, key elements found in literature are values, assumptions, beliefs, artefacts, and symbols. Theoretically, values, assumptions, and beliefs, assist in understanding an organisation's culture but because they are intangible, they are difficult to assess empirically and are of little value when evaluating an organisation's prevailing culture. However, these values, assumptions and beliefs can be indirectly deciphered through tangible and observable manifestations (artefacts and symbols) such as layout of an organisation and protective clothing (Bloor, 1999; Martins \& Terblanche, 2003; Schein, 2010). An example is that of values, which are presumed to be reflected in work practices (Hofstede, 2001; Van den Berg \& Wilderom, 2004). To measure them and derive meaning, the values should be operationalised and work practices (perceived and actual) should be evaluated as they are more demonstrable (Van den Berg \& Wilderom, 2004) and provide insight into the underlying values to execution of work activities in a certain manner.

Organisational culture studies acknowledge the existence of different subcultures between and within organisations (e.g. Thompson et al., 1996; Davies et al., 2000). However, a dominant culture may exist and how this culture is expressed varies within different hierarchical levels, different departments and with cultural differences among employees (Thompson et al., 1996; Bloor, 1999; Cooper, 2000; Sadri \& Lees, 2001). One department may value production over safety, profit over safety and vice versa. Likewise, senior management could have different priorities and cultures when compared to middle management and the operational level (Goffee \& Jones, 1996). The dominant culture should therefore be evident, so that employees 
identify with it, accept and embrace it (Sadri \& Lees, 2001). This non-homogeneity and complexity of an organisation's culture should be acknowledged. As such, a system approach is required to get an understanding of the prevailing culture. Moreover, based on organisational literature analysed, there is need to identify crucial elements, to use a triangulated methodology, to acknowledge the organisation's context, and to establish the mechanisms with which an organisation's culture influences personnel behaviour and the organisation's performance when evaluating an organisation's culture, and for meaningful FSculture research to be conducted.

Table 2.2: Key aspects derived from organisational culture literature essential to establish food safety culture research determinants

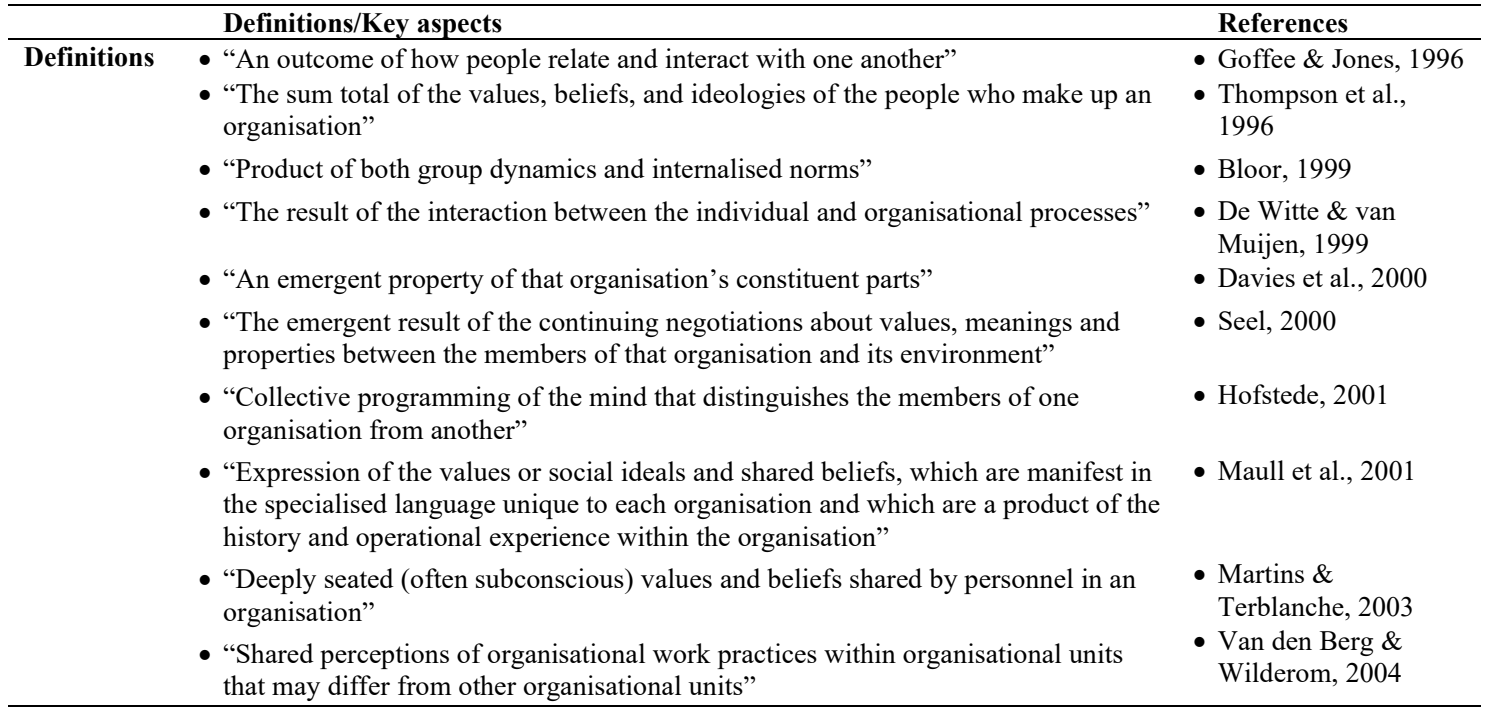

\section{Key aspects Organisational culture:}

- is developed through socialisation

- includes multiple levels:

- visible symbols and artefacts

- underlying assumptions and values
- Goffee \& Jones, 1996; Bloor, 1999;

Balmer \& Wilson, 2001;

Martins \& Terblanche, 2003;

Clark, 2002; Alvesson, 2012

- Bloor, 1999; Davies et al., 2000;

Balmer \& Wilson, 2001;

Martins \& Terblanche, 2003;

Alvesson, 2012 
- can have multiple subcultures

- evolves over time

- operates at different hierarchical levels (e.g. senior management, middle management, operational level)

- contributes to an organisation's overall performance

- influences employee behaviour

- encompasses:

- $\quad$ shared values, attitudes, knowledge and perceptions

- $\quad$ vision, leadership and management style, and communication system

- availability of facilities and resources

- organisation's context factors (e.g. national culture)

- needs both top-down and bottom-up approaches to change

- necessitates a system approach and use of a triangulated methodology
- Goffee \& Jones, 1996; Thompson et al., 1996; Bloor, 1999;

Davies et al., 2000; Sadri \& Lees, 2001;

Clark, 2002

- Bloor, 1999; De Witte \& van Muijen, 1999; Sadri \& Lees, 2001; Balmer \& Wilson, 2001

- Goffee \& Jones, 1996

- Sadri \& Lees, 2001; Martins \& Terblanche, 2003; Alvesson, 2012

- Line, 1999; Maull et al., 2001; Martins \& Terblanche, 2003; Van den Berg \& Wilderom, 2004

- Thompson et al., 1996; Hofstede, 1998;

Bloor, 1999; Parker \& Bradley, 2000; Maull et al., 2001; Sadri \& Lees, 2001; Martins \& Terblanche, 2003; Van den Berg \& Wilderom, 2004; Alvesson, 2012

- De Witte \& van Muijen, 1999; Bloor, 1999; Sadri \& Lees, 2001; Balmer \& Wilson, 2001; Martins \& Terblanche, 2003

- Martins \& Terblanche, 2003

- Thompson et al., 1996; De Witte \& van Muijen, 1999; Cooper; 2000; Martins \& Terblanche, 2003; Van den Berg \& Wilderom, 2004

- De Witte \& van Muijen, 1999

- Hofstede, 1998; Bloor, 1999; Martins \& Terblanche, 2003 


\subsection{Safety culture and its relationship with safety performance}

As highlighted in Figure 2.1, safety culture is a subcomponent of organisational culture, which focuses on and influences the safety performance of an organisation (Cooper, 2000). It refers to individuals', organisations' (characteristics of an organisation's arrangement e.g. procedures aimed at supporting personnel to appropriately execute work tasks) and work characteristics that influence safety (Cooper, 2000; Fernández-Muñiz et al., 2007; Luning \& Marcelis, 2009) and provides "contextual cues" which affect the way employees behave (Morrow et al., 2014). These "contextual" cues could be whether; management "walks the talk", a positive culture exists and safety is prioritised (Morrow et al., 2014).

Table 2.3 presents key definitions and key aspects in safety culture research that could be essential in FS-culture research. Safety culture is commonly defined as a social phenomenon (Glendon \& Stanton, 2000; Clarke, 2003), which focuses on human factors (Fleming \& Lardner, 1999; Guldenmund, 2010; Morrow et al., 2014) and technical aspects are regarded separately from safety culture (Guldenmund, 2010). However, a system approach (Skyttner, 2005), which considers human factors, technical aspects (INSAG, 1991; Reason, 1998; Cooper, 2000; Fernández-Muñiz et al., 2007), the processing operations (as shown in Figure $1)$, and the context within which an organisation operates should be adopted.

Various studies developed safety culture classification levels, which range from simple (e.g. good/poor, negative/positive) (HSE, 1999; Wiegmann et al., 2004) to comprehensive (e.g. a five stage classification: pathological, reactive, calculative, proactive and generative) safety culture (Parker et al., 2006; Hudson, 2007). The levels enable organisations to evaluate their prevailing safety culture and to implement appropriate interventions (Fleming, 2000; Foster \& Hoult, 2013). However, different parts of an organisation could possibly have different levels of culture at the same time (Fleming \& Lardner, 1999), which pose hurdles if an overall safety culture is to be established and if generic interventions are to be applied.

Understanding the crucial safety culture elements and defining measurable indicators is necessary to evaluate the prevailing safety culture. Common safety culture elements have been identified despite variations in wording. However, large variations are found in existing indicators (e.g. Singla et al., 2006; Wiegmann et al., 2004) posing challenges in synthesising indicators most suitable to measure safety culture. Moreover, most indicators do not clearly define what is being measured and do not clearly show how their assessment can depict safety 
culture (Fleming \& Lardner, 1999) creating the need to formulate indicators, which give a true reflection of the prevailing safety culture.

Ultimately, the goal for assessing safety culture is to give an indication of and to improve the organisation's safety performance (Morrow et al., 2014). Nevertheless, mixed reactions on the link between safety culture and safety performance exist (Mearns \& Flin, 1999; Morrow et al., 2014). However, Morrow et al. (2014), found a statistically significant correlation between safety culture, actual and self-reported behaviours and an organisation's safety performance, when measured concurrently and argued that clear-cut safety performance indicators are useful to measure safety performance. Various authors also proposed that a positive safety culture results in better employee and organisational performance (Fleming, 2000; Wiegmann et al., 2004; Parker et al., 2006; Fernández-Muñiz et al., 2007). It is therefore imperative to investigate the correlation of an organisation's safety culture with safety performance. However, this correlation is dependent upon how safety performance is defined, how and when safety culture and safety performance are measured, aspects of safety culture measured (Morrow et al., 2014), and the organisation's context and safety management system (Cooper, 2000; HSE, 2005). As such, the mechanisms with which safety culture relates to safety performance should be clear if a relationship between safety culture and safety performance is to be inferred. Since safety culture has been well investigated in other high risk fields such as occupational health and safety (e.g. HSE, 1999; Halligan \& Zecevic, 2011) and used as a basis for studying FS-culture (Griffith et al., 2010b) key safety culture aspects (Table 2.3) are highly useful to establish determinants for FS-culture research. 


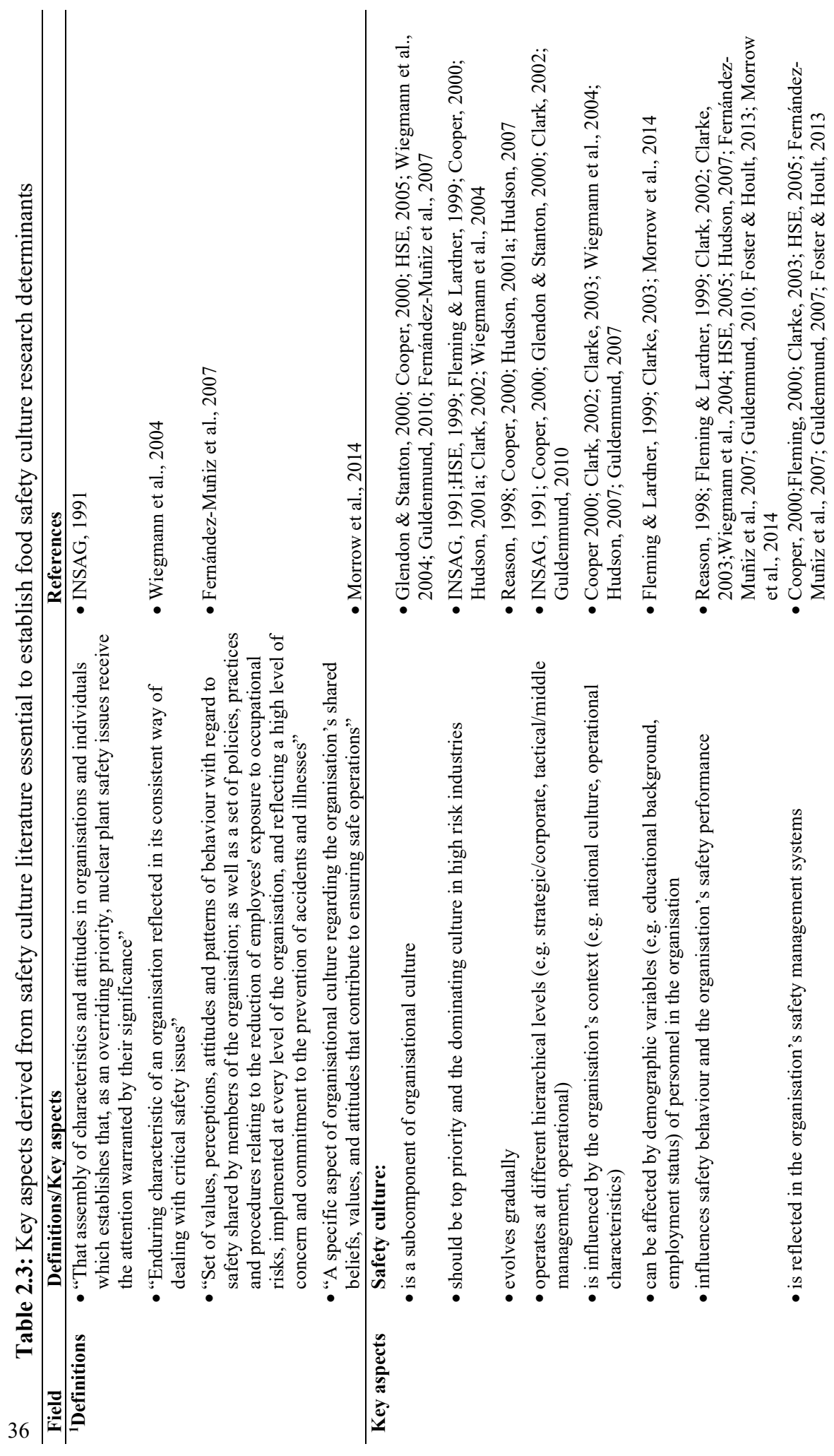



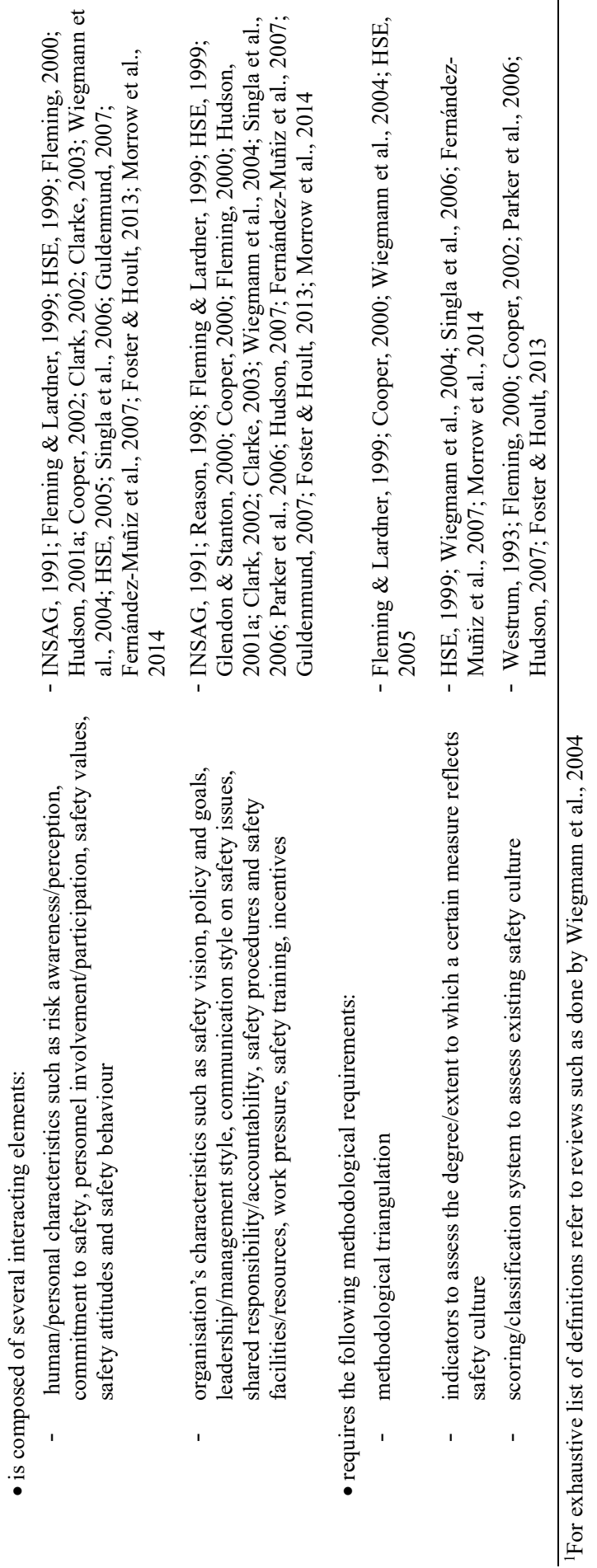


\subsection{Food Safety Management Systems and food safety culture}

Food safety management systems are defined in this study as "that part of a company's quality management system that is specifically aimed at controlling and ensuring that food safety requirements are met" (Luning \& Marcelis, 2009b; Jacxsens et al., 2010). Such systems are based on multiple public and private standards and are an important tool in realising safe and reliable food products. A FSMS can range from basic to comprehensive (FAO, 2007, Luning et al., 2008; Luning et al., 2009b), and from "end-of-pipeline" (reactive) approaches (as is evident in many transitioning countries) to "prevention-oriented" (proactive) approaches as is within the EU (Pederson \& Hernández, 2014; Luning et al., 2015) and Canada (e.g. the food safety enhancement program) (CFIA, 2014). For instance, food safety concerns in some transitioning countries are insufficiently addressed and enforced, multiple food safety control systems exist, and proper scientific risk assessments are lacking (e.g. FAO, 2007; Kussaga et al., 2014a) . In comparison, FSMS within the EU, Canada and the USA, are comprehensive and are a legal requirement (EC, 2004; FDA, 2011; CFIA, 2012).

At organisational level, a challenge faced by companies is on translating requirements of the public/private standards, and tailoring them for the company's specific context and production circumstances to assure food safety (FAO, 2007; Luning et al., 2011b; Sampers et al., 2012; Kirezieva et al., 2013b). FSMS are therefore elaborated differently within each organisation leaving room for "self-regulation" (Sampers et al., 2012; Kirezieva et al., 2015a). Moreover, the FSMS are enforced differently due to the different requirements of the public and private certification schemes. How the FSMS are elaborated and enforced results in variable performance of the implemented system (Sampers et al., 2012; Kirezieva et al., 2015a). However, De Boeck et al. (2015), emphasised that a "well elaborated and fit for purpose FSMS does not always guarantee the highest level of food safety and a stable food safety output". This is because other FS-culture factors (e.g. enabling conditions such as technological advancement, legal frameworks), actual employee behaviour, and other technological and managerial conditions within the establishment could influence the system safety output as well (FAO, 2007; Sawe et al., 2014). Furthermore, the character or status of an implemented FSMS is rooted in the prevailing FS-culture and a good FS-culture is key to the effectiveness of FSMS (Powell et al., 2011; Hayburn, 2014). The actual effectiveness is reflected in the ultimate system output i.e. safe and reliable foods (Sampers et al., 2010; Luning et al., 2011a). As such FS-culture research should consider FSMS characteristics and 
the concurrent analysis of food safety performance to understand the role of FS-culture on the system output.

\subsection{Current understanding of food safety culture}

FS-culture is a subcomponent of organisational culture that focuses on food safety and should be the dominating culture in food establishments (Yiannas, 2009; Griffith et al., 2010b; Powell et al., 2011; Ungku Fatimah et al., 2014b). Although no common definition has been established, Griffith et al. (2010b) defines FS-culture as the "aggregation of the prevailing constant learned shared attitudes, values and beliefs contributing to the hygiene behaviours used within a particular food handling environment". Various studies view FS-culture as how a group or an organisation handles food safety issues and considers the system as a whole (Yiannas, 2009; Powell et al., 2011). Studies therefore analyse behaviours that are demonstrated/practiced by employees (Nickell \& Hinsz, 2011; Wright et al., 2012; De Boeck et al., 2016), individual characteristics (e.g. values, attitudes, perceptions) (Griffith et al., 2010b; Ungku Fatimah et al., 2014b; Taylor et al., 2015), group characteristics (alignment in values, shared perceptions) (Powell et al., 2011) and the system output (e.g. De Boeck et al., 2015; De Boeck et al., 2016).

FS-culture studies identified common elements, which permeate FS-culture research. These elements include leadership, commitment, knowledge, training/competence, risk awareness, perceptions, employee confidence, management systems, employee involvement, accountability, communication, work pressure, environmental factors (e.g. infrastructure, equipment, tools), values and behaviour (e.g. Yiannas, 2009; Ball et al., 2010; Ungku Fatimah et al., 2014b; De Boeck et al., 2015). These elements are interdependent (Taylor, 2011; Wright et al., 2012). A few studies (e.g. Wright et al., 2012; De Boeck et al., 2015) established indicators, which aim to outline the extent/degree to which a given element reflects FS-culture. Limited research suggested classification levels, which range from a negative to a positive FS-culture and indicate the level of maturity of the FS-culture (e.g. Wright et al., 2012). However, no research has evaluated whether FS-culture evolves through these levels. Jespersen et al. (2016) further developed a behaviour-based food safety maturity model, which measures the status of an organisation's FS-culture, and according to the authors, needs further validation. 
In overall, FS-culture studies acknowledge the use of different disciplines to study FS-culture (e.g. Taylor, 2011; Jespersen et al., 2016). An analysis of existing FS-culture literature revealed the need to define key determinants required for conducting FS-culture research, if FS-culture research is to realise its potential.

\subsection{Overall discussion}

Analysis of existing literature revealed that FS-culture research is still fragmented and unsystematic and that there is need to establish a systematic way to conduct FS-culture research. By synthesising the findings from the literature reconsideration, we proposed FSculture research determinants, listed in Table 2.4, with the effort to provide a foundation upon which FS-culture research can be built.

Table 2.4: Proposed determinants of food safety culture research Proposed determinants to be taken into account in FS-culture research

FS-culture research should:

- acknowledge the national culture that an organisation operates in and the national cultures of the members in the organisations

- acknowledge that FS-culture influences food handler behaviour, which in turn influences the food safety performance of the organisation; focus on understanding the mechanisms

- recognise that FS-culture assessments should be adapted to the company's food risks and context

- recognise the hierarchical levels and FS-culture scopes that exist in organisations; food safety tasks and responsibilities differ at strategic, tactical and operational level

- include crucial elements in FS-culture assessments:

- employee characteristics, which include attitudes, perceptions, knowledge, risk awareness

- group characteristics, which include analysis of shared perceptions

- organisational and administrative characteristics, which include food safety vision, leadership, commitment, communication style, food safety/hygiene procedures, training, work pressure

- technical/technological facilities/resources, which include personal hygiene facilities, zoning, food safety and hygiene tools, equipment and facilities, sanitation, and maintenance

- food safety management system characteristics; design and assurance of crucial controls

- methodologically assess FS-culture by:

- $\quad$ using a systems approach; acknowledging the various sub-systems and the interlinks

- $\quad$ using indicators that focus on crucial aspects to be measured

- developing a classification system to enable differentiated assessment of the prevailing FS-culture

- $\quad$ using multiple methods (triangulated methodology) to enhance assessment validity

- measure the prevailing FS-culture since FS-culture evolves over time.

- measure FS-culture elements and actual food safety performance concurrently

- include evaluation of demographic variables

Current FS-culture research does not yet consider the national culture. FS-culture research therefore needs to investigate the influence of national culture on the prevailing FS-culture 
and should establish relevant national culture elements and their mechanisms of influence on the prevailing FS-culture. Moreover, to be able to generalise on what constitutes a good FSculture, there is need to address the fit of the FS-culture research strategies within different national cultures, since different cultures require different approaches, and different research tools are effective in different cultures/environments. We acknowledge that national culture is not the only context factor and that other external drivers such as sector values, customer/market requirements, economic climate and shareholder risks, influence an organisation's FS-culture, and research should be done on how these drivers affect an organisation's FS-culture.

Furthermore, FS-culture research needs to recognise and be specific to the hierarchical level(s) (e.g. the strategic, tactical and operational) being evaluated because personnel working at these levels are confronted with different food safety/hygiene tasks, responsibilities and decisions. For example, top management is responsible for defining the food safety vision, policy, and strategies and they decide on resource investments; quality assurance managers are responsible for designing, implementing and maintaining the FSMS; the shop floor, operators need to comply with food safety and hygiene procedures and rules. Actual decisions and behaviours at all levels contribute differently to actual product safety. Moreover, the evaluation (what and how should be measured?) of FS-culture and type of interventions that are applied will differ with the hierarchical level.

As emphasised in safety culture studies (e.g. Halligan \& Zecevic, 2011), FS-culture research should consider the company's food production context (also shown in Figure 2.1). This is because different products put different demands on an organisation's FS-culture depending on the production processes, company environment characteristics, and vulnerability of products to contamination. As such, FS-culture research should be adapted to the organisation's food risks and context characteristics rather than making sweeping generalisations across all food establishments. Although current FS-culture research addresses multiple FS-culture elements and acknowledges the interdependence of the elements, the possible causal relationships between the elements are not yet explicit. Moreover, the mechanisms with which FS-culture influences personnel behaviour and food safety performance, and whether and how FSMS reflect/influence the FS-culture of the organisation is not yet clear. In the available literature, considerable variance was found on current indicators. The indicators should clearly show how they depict an organisation's FS-culture. 
Moreover, the indicators should focus on the crucial aspects in the given context and must be evaluated (validated) on how well they give a measure of the prevailing FS-culture and food safety performance of the organisation, in view of the organisational hierarchical level being evaluated. Griffith (2013) suggested that indicators should be formulated in a way that they give a measure of how much food safety is prioritised, embedded, practiced, and shared among the staff.

This reconsideration revealed that culture evolves over time; is time-dependent. For this reason, FS-culture research should analyse the prevailing FS-culture, and this should be measured periodically. Research methodologies should therefore enable a structured analysis and a differentiated assessment of the prevailing FS-culture. As such, classification levels should be included in FS-culture research to enable a proper evaluation of the prevailing FSculture and to establish specific interventions/roadmaps to improve an organisation's FSculture. The levels should specify the scope, and the organisation's hierarchical level being evaluated. Furthermore, demographic variables (e.g. age, experience, qualifications) should be included in FS-culture research as they are part of the organisation's context that shapes an organisation's FS-culture. The literature analysed in this paper converges to the same message that a systems approach is necessary and should be adopted as it offers a holistic approach to FS-culture research and to the evaluation of the interaction, interdependence and interrelationships between FS-culture research elements.

\subsection{Conclusion and research recommendations}

This study derived key aspects from national, organisational and safety culture, and FSMS needed to identify the "determinants" for conducting FS-culture (Figure 2.1) research by drawing lessons from existing literature (synthesised in tables 2.1-3). Against the background of Figure 1, the study discussed the positioning of FS-culture within different disciplines resulting in the establishment of FS-culture research determinants from a broad, overall viewpoint. Major elements to consider in FS-culture research include organisational and administrative characteristics, technical facilities/resources, employee characteristics, group characteristics, crucial FSMS characteristics, and actual food safety performance (Table 2.4), with a focus on understanding the underlying relationships and mechanisms. Furthermore, the impact of national culture, the influence of a company's food risks and other context characteristics, and the hierarchical level(s) should be considered. Methodological requirements for FS-culture research should encompass the use of a systems approach, 
definition of measurable indicators, development of classification systems, and the use of a triangulated methodology. Further research will focus on developing a comprehensive diagnostic tool, including indicators and assessment grids to enable differentiated assessment of the prevailing FS-culture. We acknowledge that the list of FS-culture research determinants is not complete and further research could build up on these determinants. Further research also needs to identify internal and external drivers/triggers, which influence the prevailing FSculture. However, the complexity of FS-culture and its context specificity is acknowledged and makes it a challenging task to capture pertinent aspects with a "manageable assessment instrument" (Ungku Fatimah et al., 2014a). Moreover, reaching a consensus on the definition, elements, indicators, classifications, methodology and on what implies FS-culture is still a challenge. However, having the established FS-culture research determinants could bring clarity in FS-culture research and provide a useful starting point to the common understanding and research of FS-culture.

\section{Acknowledgements}

The authors are grateful to The Netherlands Fellowship Programmes (NFP) for financial support (Grant award number CF. 9421/2014) 



\section{Chapter 3}

\section{Food safety culture assessment using a comprehensive mixed-methods approach: A comparative study in dairy processing organisations in an emerging economy}

Published as: Nyarugwe, S. P., Linnemann, A., Nyanga, L. K., Fogliano, V., \& Luning, P. A. (2018). Food safety culture assessment using a comprehensive mixedmethods approach: A comparative study in dairy processing organisations in an emerging economy. Food Control, 84, 186-196. 


\begin{abstract}
Food safety challenges are a global concern especially in emerging economies, which are in the midst of developmental changes. The challenges are directly or indirectly related to the behaviour and decision-making of personnel, and to an organisation's food safety culture. This study evaluated the prevailing food safety culture in three Zimbabwean dairy companies of different size (multinational, large and medium) using a comprehensive mixed-methods approach. Four key elements were assessed, namely enabling conditions, employee characteristics, actual behaviour and microbial safety performance. Card-aided interviews provided data on enabling conditions, and questionnaires and storytelling on employee characteristics. Observations and microbial analysis assessed actual behaviour and microbial safety performance, respectively. The multinational company demonstrated a more proactive food safety culture compared to the other companies, which operated at an active level as exhibited by multiple inconsistencies in the enabling conditions and compliance behaviour. The large company had a moderate microbial safety performance even though it operated in a potentially risky situation, which could have been mitigated by the food safety management system. The medium-sized company had a poor microbial safety performance likely related to noncompliance with sanitation requirements, negative attitudes towards personal hygiene and an ambivalent attitude towards sanitation. Our study demonstrated the ability of the mixedmethods approach to assess and distinguish an organisation's prevailing food safety culture into identified classification levels (reactive, active, proactive). Specifically, storytelling elicited respondents to share stories, which reflected the food safety and hygiene control attitudes.
\end{abstract}




\subsection{Introduction}

Food safety is a global concern; the World Health Organisation (WHO) estimates that each year 600 million foodborne illness incidences occur worldwide (WHO, 2015). The highest burden of foodborne illnesses per population is in transitioning countries, particularly in Africa (WHO, 2015), as evidenced by inconsistent food safety (FAO, 2007; Kussaga et al., 2014a). Kussaga et al. (2014a) reported that $83 \%$ of the microbial cases, including dairy products, reported in African countries, exceed microbiological limits. This is worrisome since dairy products significantly contribute to the human diet and are consumed by all population groups (Chimboza \& Mutandwa, 2007; Papademas \& Bintsis, 2010). Additionally, dairy products are easily perishable (Demirbas et al., 2009) and are highly vulnerable to contamination (Chimuti et al., 2016; Papademas \& Bintsis, 2010). Therefore, the food industry and regulators are putting significant efforts on improving food safety management systems (FSMS) and food safety performance (Consumer Goods Forum (CGF), 2011; Kussaga et al., 2014a) in the dairy industry. However, FSMS are not always effective, as demonstrated by recurring food safety problems (e.g. Chimuti et al., 2016).

In transitioning countries such as Zimbabwe, deficiencies in food safety performance of dairy processing organisations have been attributed to outdated and/or poorly designed equipment, inadequate sanitation programs, restricted personal hygiene, unskilled/semi-skilled employees, and contaminated packaging material (Chimuti et al., 2016; Kussaga et al., 2014a; Macheka et al., 2013; Zimbabwe Economic Policy And Research Unit, 2014). These deficiences have been linked to an insufficient food safety culture (FS-culture) (Pennington, 2009) and are directly or indirectly related to decisions made by individuals in an organisation.

The role of individuals in food safety/FS-culture has been argued by various authors (e.g. De Boeck et al., 2017; Griffith, 2006). Individual characteristics (Griffith et al., 2010a; Fatimah et al., 2014b; Nyarugwe et al., 2016) influence decision-making behaviour and actual food safety practices (e.g. De Boeck et al., 2017; Pacholewicz et al., 2016; Sanny et al., 2010). Human behaviour contributes to food safety (De Boeck et al., 2015; Griffith et al., 2010b; Griffith, 2006) and has warranted the use and application of psychological models, behavioural frameworks and systems approaches, to assess and improve food safety (e.g. De Boeck et al., 2017; Griffith, 2006; Jespersen et al., 2016; Luning \& Marcelis, 2006, 2009a; Taylor, 2011). 
Griffith et al. (2010b) defined FS-culture as "shared attitudes, values and beliefs towards food safety behaviours that are routinely demonstrated in food establishments". FS-culture research, therefore, requires integrated analysis of personal/individual characteristics, organisational standards, practices/behaviour, FSMS and the context an organisation operates in (De Boeck et al., 2016; Griffith, 2006; Luning et al., 2011b; Nyarugwe et al., 2016; Powell et al., 2011). Since several elements are interlinked, using multiple methods in FS-culture assessments could enhance research validity (Nyarugwe et al., 2016). This study aims to get an insight into the prevailing (FS-culture) of dairy organisations in an emerging economy in view of their context characteristics using a mixed-methods approach.

\subsection{Material and Methods}

\subsubsection{Elements used for assessing prevailing FS-culture}

Four key elements (microbiological safety performance, actual behaviour, technological and organisational enabling conditions, and employee characteristics) were identified to systematically analyse an organisation's prevailing FS-culture. The elements were derived from previously validated organisational, safety and FS-culture studies (e.g. De Boeck et al., 2015; Fatimah et al., 2014b; Fleming, 2000; Glendon \& Stanton, 2000; Griffith et al., 2010a) based on a review done by Nyarugwe et al. (2016), and have been pretested in dairy companies in an explorative study (Nyarugwe, 2013).

The techno-managerial approach, i.e. concurrent analysis of technological and managerial factors (Luning \& Marcelis, 2006, 2009a), was used as a principal research approach. De Boeck et al., (2015) also distinguished two routes; the techno-managerial route (FSMS and organisation's context) and the human route (i.e. employees' shared perception of leadership, commitment, communication, resources and risk awareness). These routes provide a basis for FS-culture assessment and are considered to influence food safety behaviour and the microbial output (De Boeck et al., 2017).

Microbiological safety performance reflects the actual food safety performance as previously described by Jacxsens et al. (2010) and could be influenced by an organisation's FS-culture as demonstrated by De Boeck et al. (2016). Actual behaviour defines the actual execution of work practices (Van den Berg \& Wilderom, 2004) and is an outcome and reflection of the prevailing FS-culture. Enabling conditions are situational aspects of the system's environment aimed at supporting (when appropriate) personnel to appropriately execute work tasks. Both 
organisational and technological enabling conditions are interrelated and can be positive (support) or negative (hinder) employees to appropriately execute food safety or hygiene control tasks (Clayton et al., 2002; Luning \& Marcelis, 2006). The underlying assumption is that supportive conditions will enable more consistent compliance behaviour (Luning et al., 2011b; Pacholewicz et al., 2016; Sanny et al., 2010).

Employee characteristics describe an individual's attitudes, knowledge and perceptions of food safety and hygiene control (Nyarugwe et al., 2016). Individuals with the right attitude will seek to do things right especially when they perceive the organisation supports food safety (Griffith et al., 2010b; Pacholewicz et al., 2016; Yiannas, 2009). Moreover, employees' characteristics (e.g. perceptions, attitudes) are assumed to affect compliance behaviour (Chen et al., 2015; Luning \& Marcelis, 2006; Nyarugwe et al., 2016).

To operationalise the elements and assess the prevailing FS-culture, 25 indicators (i.e. crucial aspects) were defined for the four elements. Indicators give a measure of the actual situation (Kirezieva et al., 2013a) and define the extent to which FS-culture is prioritised, embedded, practiced and shared among staff (Griffith, 2013). The indicators enabled data to be collected and assessed with the mixed-methods approach (section 3.2.3). Indicators for microbiological safety performance measure actual food safety (e.g. De Boeck et al., 2015; Powell et al., 2011), while behaviour indicators measure actual practices displayed at critical steps and/or processes (Luning \& Marcelis, 2009a). For organisational conditions, the indicators leadership, communication, commitment, procedures, training and time were selected based on a review by Nyarugwe et al. (2016) and their potential contribution to food safety performance (De Boeck et al., 2015; Griffith et al., 2010b). For technological conditions, sanitation, protective clothing, handwashing facilities, zoning, hygiene design, and equipment maintenance were selected (Nyarugwe et al., 2016; Nyarugwe, 2013) as they are requisites for food safety and hygiene (Arendt et al., 2011; De Boeck et al., 2015; Wright et al., 2012). For employee characteristics, knowledge, attitudes and perceptions were selected based on a pretest and on previous studies (Nyarugwe et al., 2016; Powell et al., 2011; Van den Berg \& Wilderom, 2004). 


\subsubsection{Description of the comparative study}

\section{Characteristics of selected companies}

A comparative study was executed in three Zimbabwean dairy companies. The companies were selected based on size, level of implemented FSMS, variety of dairy products and willingness to participate in the research. The companies represent medium (company A), large (company B) and multinational (company C) companies. Company A (CA) employs an average of 120 employees, is currently working towards HACCP certification, and mainly produces a range of ice cream and yoghurts. Company B (CB) has about 400 employees, a Standards Association of Zimbabwe certified HACCP-based FSMS, and produces a wide variety of milk, ice cream and yoghurts. Company C (CC) has approximately 300 employees, a SGS (Société Générale de Surveillance) certified HACCP-based FSMS, and mainly produces a variety of milk.

\section{Characteristics of respondents}

Respondents were selected from the operations department, i.e. food handlers (machine operators, production attendants/packers and supervisors) and management (production controllers/managers, quality controllers/managers and food safety officers). This is because FS-culture research should recognise the hierarchical level of assessment as different levels are confronted with different responsibilities and decisions (Nyarugwe et al., 2016). Table 3.1 shows the respondents' profiles. Respondents were approached based on willingness to take part in the study. Respondents were locals and the local language (Shona) was used to explain or translate questionnaires, where necessary.

\subsubsection{Mixed-method data collection approach}

A mixed-methods approach was used to collect data since it provides a systematic and rigorous way to understand concepts (Creswell et al., 2011). Six methods were applied, i.e. microbial analysis, observations, card-aided interviews, questionnaires, storytelling and document analysis to collect information on the four key elements (section 3.2.1). Microbial analysis provided insight into the microbial safety of the dairy products as outsourced or analysed by the companies. Observations were used to assess actual behaviour and card-aided interviews to assess enabling conditions. Questionnaires and storytelling were used to collect data on employee characteristics, and document analysis to assess microbial safety performance records and actual behaviour. 
Table 3.1: Characteristics of respondents from the 3 Zimbabwean dairy companies

\begin{tabular}{lccc}
\hline Characteristics of respondents & CA & CB & CC \\
\hline Gender & 14 & 40 & 26 \\
Male & 10 & 3 & 2 \\
Female & 3 & 3 & 4 \\
Position & 21 & 40 & 24 \\
Managers & & & \\
Food handlers & 12 & 39 & 13 \\
Years in employment & 7 & 4 & 10 \\
$0-5$ & 5 & & \\
$6-10$ & & & 5 \\
$11-15$ & & 33 & 9 \\
15 and above & 24 & 10 & 19 \\
Type of employment & & & \\
Contract & 7 & 21 & 9 \\
Permanent & 17 & 22 & 19 \\
Educational level & & & \\
Tertiary & & & \\
Secondary & & & \\
\hline
\end{tabular}

Microbial analysis for food safety performance assessment

Salmonella sp. was selected as a food safety indicator and Staphylococcus aureus, coliforms/Escherichia coli as hygiene indicators based on Jacxsens et al. (2009). Researchers only collected samples from CA and CB because CC products were tested according to the company's protocols. Samples were collected at critical sampling locations (CSL's) (Table 3.2) over a period of 2 weeks. CSL's are "locations where microbial sampling provides information about the performance of core control strategies and loss of control at these locations could lead to food safety problems" (Jacxsens et al., 2009).

For CA and CB, 15 and 17 samples were collected, respectively and kept in either chilled (4$\left.6^{\circ} \mathrm{C}\right)$ or frozen $\left(-18^{\circ} \mathrm{C}\right)$ storage before analysis at the Government Analyst of Zimbabwe (CA samples), or at the Central Veterinary Laboratory (CB samples). For CC, samples were taken by employees at the filling and sealing CSL's, and analysed at the central laboratory daily. All laboratories are ISO17025 accredited.

A modified two class attribute sampling plan was used for Salmonella sp. and a three class attribute sampling plan for Salmonella sp. (Codex Alimentarius, 2004). The microbial analyses were according to the Official Microbiological Methods (FDA, 1998). Records for E.coli and coliforms, and customer complaints were analysed over a similar 3 month period to provide a uniform basis for comparing the three companies. Score zero was given when there was no indication of the specified food safety output, and scores 1,2 and 3 for a poor, moderate and good safety output, respectively, using the criteria of Jacxsens et al. (2010). 
Data was analysed using Microsoft Office Excel. Percentage non-conformance of products was calculated based on documents analysed.

Table 3.2: Microbiological sampling locations in companies A and B

\begin{tabular}{|c|c|c|}
\hline Company & CSL & Reasoning \\
\hline \multirow[t]{6}{*}{ A } & ${ }^{a}$ Cutting & $\begin{array}{l}\text { Product handling involved therefore personal hygiene is crucial to prevent } \\
\text { cross-contamination. }\end{array}$ \\
\hline & $\begin{array}{l}\text { a, b Cold room } \\
\text { storage }\end{array}$ & $\begin{array}{l}\text { Food handlers manually transfer unpackaged product to cold rooms using bare } \\
\text { hands. Moreover, products are left on wooden shelves (poor hygienic design) } \\
\text { risking cross-contamination. }\end{array}$ \\
\hline & a, b Vacuum & Products are manually packaged and left unsealed for long periods of time. \\
\hline & packaging & There is no further intervention step before sealing \\
\hline & $\begin{array}{l}{ }^{\mathrm{c}} \text { Filling and } \\
\text { sealing (before } \\
\text { sealing) }\end{array}$ & $\begin{array}{l}\text { Food handlers manually position packaging containers and seals increasing } \\
\text { product contamination risk. }\end{array}$ \\
\hline & $\begin{array}{l}{ }^{c} \text { Filling and } \\
\text { sealing (after } \\
\text { sealing) }\end{array}$ & $\begin{array}{l}\text { Packing material is improperly stored and could be a source for contamination. } \\
\text { There is no further intervention step. }\end{array}$ \\
\hline \multirow[t]{2}{*}{ B } & $\begin{array}{l}{ }^{\mathrm{d}} \text { Before sealing } \\
{ }^{\mathrm{d}} \text { Sealing/ } \\
\text { packaging }\end{array}$ & $\begin{array}{l}\text { Product coating is manually prepared and could result in cross-contamination. } \\
\text { Some areas of the sealing machine are not easily cleanable increasing } \\
\text { contamination risk. Packing material is not properly stored and could be a } \\
\text { contamination source. }\end{array}$ \\
\hline & $\begin{array}{l}\mathrm{e}, \mathrm{f} \text { Filling and } \\
\text { sealing }\end{array}$ & $\begin{array}{l}\text { Pasteurized product is manually inoculated potentially resulting in } \\
\text { contamination. Improper cleaning of the filling machine could result in cross- } \\
\text { contamination Packaging material is manually positioned and that requires } \\
\text { proper hygiene practices }\end{array}$ \\
\hline
\end{tabular}

The table shows samples taken by the researchers. *CSL refers to critical sampling location. a, b, c, d, e, f refers to product type from the companies. For CA, 5 samples were collected for product $\mathrm{a}, 5$ samples for product $\mathrm{b}$ and 5 samples for product c. For CB, 7 samples were collected for product d, and 5 samples each for products e and f.

Participatory observation to assess actual food handler behaviour, facility layout and equipment

Participatory observation, which entails the researcher being part of the group without informing group members that they are being observed, was done as it reduces the bias of the participants (Kumar, 2011; Zahle, 2012). Observations were randomly done by 2 researchers for 3 weeks in each company. For each observation period, the length and total people observed depended upon the activities. A checklist was developed as a guideline to evaluate the actual execution of food safety and hygiene tasks, and the organisation's facility layout and equipment, based on Codex Alimentarius (2003) and Lelieveld et al. (2014). Assessment criteria and the observation scoring system were modified from criteria developed by Nyarugwe (2013) and Pacholewicz et al. (2016). Where food safety and hygiene activities were not executed, incompletely executed or properly executed $\geq 80 \%$ of the time (Table 3.3 ), 
scores 1,2 or 3 were given, respectively. Where the facility layout or equipment did not comply, partially or fully complied with at least $80 \%$ of the stated requirements, scores 1,2 or 3 were given, respectively. To get an overall impression of actual employees' behaviour, the predominant behaviour observed was scored. For facility layout/equipment, the predominant observation was scored. Data was analysed using Microsoft Office Excel.

\section{Card-aided interviews to assess enabling conditions}

For each of the 11 enabling condition indicators, 3 cards were developed. Each card described a situation (Table 3.3) that corresponded with a concealed proactive (score 3), active (score 2) or reactive (score 1) food safety situation. To reduce bias, the cards were randomly arranged and given to the respondent. The interviewer guided each interviewee through each set of cards to ensure the interviewee understood each description, and selected a choice that reflected the company situation. The respondent was asked to justify the selection to verify that they clearly understood the questions. Responses were individually scored. Statistical analysis was performed using IBM SPSS version 22 for Windows to check the frequency and mode scores for each enabling condition.

\section{Questionnaires to assess employees' knowledge and perceptions}

To assess knowledge, a closed-ended questionnaire with 15 questions on food safety and hygiene was directed to food handlers. Both positive and negative questions were included to avoid bias (Kumar, 2011). Respondents could answer true, false or do not know. A correct answer scored 2 and an incorrect answer or do not know scored zero. The percentage of correct answers was calculated to obtain each respondent's percentage knowledge score. An arbitrary scale used by Pacholewicz et al. (2016) was used to interpret the overall scores. If $\geq 80 \%$ of the questions were correctly answered, score 3 (good) was given, between $51-79 \%$ score 2 (moderate) and $\leq 50 \%$, score 1 (poor).

For perceptions, a questionnaire with 6 open-ended questions on food safety and hygiene practices was used. Each response was evaluated to check the degree of alignment of food handlers' perceptions with company requirements. An arbitrary but explicitly defined scoring system was used. Scores 1, 2 or 3 were given, respectively, when food handler perceptions were aligned, partially/incompletely aligned or not aligned for at least $80 \%$ of the time with company requirements as defined in previous research (Nyarugwe, 2013). The frequency of 
responses with similar scores and the mode scores for both knowledge and perceptions were calculated using Microsoft Office Excel.

Table 3.3: Key aspects of a reactive, active and proactive FS-culture

\begin{tabular}{|c|c|c|c|}
\hline \multirow[t]{2}{*}{ Component } & \multicolumn{3}{|c|}{ Key aspects } \\
\hline & $\begin{array}{l}\text { Score } 1 \\
\text { (reactive FS-culture) }\end{array}$ & $\begin{array}{l}\text { Score } 2 \\
\text { (active FS-culture) }\end{array}$ & $\begin{array}{l}\text { Score } 3 \\
\text { (proactive FS-culture) }\end{array}$ \\
\hline $\begin{array}{l}\text { *Microbiologic } \\
\text { al safety } \\
\text { performance }\end{array}$ & $\begin{array}{l}\text { Poor performance } \\
\text { (noncompliance/conformance) - } \\
\text { minimal criteria used for } \\
\text { microbial safety performance } \\
\text { evaluation, and having various } \\
\text { food safety problems due to } \\
\text { different problems in the FSMS. }\end{array}$ & $\begin{array}{l}\text { Moderate performance (restricted } \\
\text { compliance/conformance - several } \\
\text { criteria used for microbial safety } \\
\text { performance evaluation and food } \\
\text { safety problems restricted to one } \\
\text { type of problem in the FSMS. }\end{array}$ & $\begin{array}{l}\text { Good performance (full } \\
\text { compliance/conformance) - } \\
\text { systematic evaluation of } \\
\text { microbial safety performance } \\
\text { using specific criteria and } \\
\text { having no food safety problems. }\end{array}$ \\
\hline $\begin{array}{l}\text { Actual food } \\
\text { safety and } \\
\text { hygiene control } \\
\text { behaviour }\end{array}$ & $\begin{array}{l}\text { High-risk behaviour due to } \\
\text { noncompliance with food safety } \\
\text { and hygiene control } \\
\text { requirements. Food safety and } \\
\text { hygiene practices are not } \\
\text { executed } \geq 80 \% \text { of the time. Risk } \\
\text { of cross-contamination is highly } \\
\text { likely to occur. }\end{array}$ & $\begin{array}{l}\text { Moderate-risk behaviour due to } \\
\text { partial compliance with food } \\
\text { safety and hygiene control } \\
\text { requirements. Food safety and } \\
\text { hygiene control practices are } \\
\text { executed wrongly/incompletely } \\
\geq 80 \% \text { of the time. Risk of cross- } \\
\text { contamination likely to occur. }\end{array}$ & $\begin{array}{l}\text { Low-risk behaviour due to full } \\
\text { compliance with food safety } \\
\text { and hygiene control } \\
\text { requirements. Food safety and } \\
\text { hygiene control practices } \\
\text { correctly and completely } \\
\text { executed } \geq 80 \% \text { of the time. } \\
\text { Risk of cross-contamination } \\
\text { highly unlikely to occur. }\end{array}$ \\
\hline $\begin{array}{l}\text { Enabling } \\
\text { conditions }\end{array}$ & $\begin{array}{l}\text { Reactive (lack of support/ } \\
\text { conditions are not enabling) - } \\
\text { acting only when there is a } \\
\text { situation that needs to be } \\
\text { controlled. Routine response to } \\
\text { inspection findings, } \\
\text { problems/incidents. Control is } \\
\text { mainly problem driven. }\end{array}$ & $\begin{array}{l}\text { Active (restricted support/ } \\
\text { conditions are enabling only to a } \\
\text { certain extent) - systems are in } \\
\text { place to manage the likelihood of } \\
\text { (cross) contamination and to } \\
\text { support food handlers' food } \\
\text { safety/hygiene control decisions }\end{array}$ & $\begin{array}{l}\text { Proactive (full support/ } \\
\text { conditions are enabling) - } \\
\text { thinking and acting in advance } \\
\text { of anticipated problems. Focus } \\
\text { is on prevention of (cross) } \\
\text { contamination }\end{array}$ \\
\hline Kno & $\begin{array}{l}\text { Inadequate knowledge- complete } \\
\text { lack of knowledge in majority of } \\
\text { food safety issues and unable to } \\
\text { explain the reasoning behind } \\
\text { majority of food safety } \\
\text { requirements. }\end{array}$ & $\begin{array}{l}\text { Moderate knowledge- incomplete } \\
\text { knowledge in food safety issues } \\
\text { and inability to explain the } \\
\text { reasoning behind certain food } \\
\text { safety requirements. }\end{array}$ & $\begin{array}{l}\text { Good knowledge- ample } \\
\text { knowledge in food safety issues } \\
\text { required of them and capable of } \\
\text { explaining the reasoning behind } \\
\text { each food safety requirement. }\end{array}$ \\
\hline Perceptions & $\begin{array}{l}\text { Non-aligned- employee } \\
\text { perceptions incorrect and not } \\
\text { aligned with the company's food } \\
\text { safety and hygiene control } \\
\text { requirements }\end{array}$ & $\begin{array}{l}\text { Partially aligned- employee } \\
\text { perceptions partially/incompletely } \\
\text { aligned with the company's food } \\
\text { safety and hygiene control } \\
\text { requirements }\end{array}$ & $\begin{array}{l}\text { Fully aligned- employees have } \\
\text { appropriate perceptions aligned } \\
\text { with the company's food safety } \\
\text { and hygiene control } \\
\text { requirements }\end{array}$ \\
\hline Attitude & $\begin{array}{l}\text { Weak and negative attitude- } \\
\text { negative predisposition toward } \\
\text { compliance with food } \\
\text { safety/hygiene requirements. } \\
\text { Employees have no regard for } \\
\text { food safety/hygiene issues unless } \\
\text { compelled to }\end{array}$ & $\begin{array}{l}\text { Ambivalent attitude- uncertain } \\
\text { predisposition to comply with } \\
\text { food safety/ hygiene requirements. } \\
\text { Employees perform adequately } \\
\text { only when circumstances are } \\
\text { appropriate }\end{array}$ & $\begin{array}{l}\text { Strong and positive attitudes- } \\
\text { positive predisposition to } \\
\text { comply with food } \\
\text { safety/hygiene requirements } \\
\text { under all circumstances. } \\
\text { Employees always maintain } \\
\text { adequate performance }\end{array}$ \\
\hline Prevailing FS- & Reactive (negative FS-culture)- & Active (intermediate FS-culture)- & Proactive (positive FS-culture)- \\
\hline
\end{tabular}




\begin{tabular}{llll}
\hline culture & $\begin{array}{l}\text { low support and little or no } \\
\text { regard towards the importance of } \\
\text { food safety }\end{array}$ & $\begin{array}{l}\text { incomplete regard and restricted } \\
\text { support towards food safety }\end{array}$ & $\begin{array}{l}\text { high regard and complete } \\
\text { support towards food safety }\end{array}$ \\
\hline
\end{tabular}

*For microbiological safety performance, a score zero (absence) was given and refers to a situation were no food safety performance evaluation is carried out, and/or that the specific food safety performance information is not known.

\section{Storytelling to assess employees' attitudes}

Employee attitudes were assessed using storytelling as this method enhances understanding of specific contexts, ensures active participation and encourages researcher/participant interaction (Banks, 2012). Moreover, storytelling could give an indication of employees' predisposition to respond in a positive or negative way to food safety and hygiene control. Eight stories on food safety and hygiene were formulated. These stories were hypothetical scenarios formulated to probe and stimulate respondents to identify situations and to tell versions of their own stories, as seen and/or experienced from the organisation, that could give an indication of the attitude of the organisation's personnel. The stories were developed based on Adamson et al. (2006), who indicated that a good story should " inspire and combine conflict, suspense, symbols, characters to capture one's imagination and provide meaning". At the end of each story, questions were posed to check food handlers' opinion on the attitude displayed; whether they could identify with the attitude in their organisation and whether they had similar stories and/or experiences.

The stories were written on a card and read out to a small group of (at the most 8) employees. Since a group of respondents was required each time, they were asked to come outside working hours and were given US\$ 5 each to cater for transport and food. The common interpretation of the attitude by the group on the story told and stories that the respondents shared were scored by 2 researchers. If for at least $80 \%$ of the responses, a negative, ambivalent/uncertain or positive predisposition towards compliance with personal hygiene, sanitation and crucial process parameters was evident, scores 1,2 or 3 were given, respectively (Table 3). The frequency and mode scores were calculated using Microsoft Office Excel. 
Document analysis to assess actual food safety and hygiene practices, microbiological safety performance and equipment maintenance

A checklist was developed to analyse records/documents for equipment maintenance, sanitation activities, control of crucial process parameters and microbial analysis. Records spanning 12 months were analysed to get an overview of the organisation's activities over a period of time. Information obtained was used to verify and explain the patterns observed for specific elements. Scores 1, 2 or 3 were given for non- (absence), partial (available but with gaps), and full compliance with the set criteria.

\section{Characteristics of prevailing FS-culture}

Table 3.3 shows scores used to assess the companies' prevailing FS-culture. Three classification levels, i.e. proactive, active and reactive levels (modified from Parker et al., 2006), were distinguished. For microbial safety performance, four stereotype situations that reflect no indication of, poor, moderate and good food safety performance were defined (Jacxsens et al., 2010).

\subsection{Results and Discussion}

\subsubsection{Prevailing FS-culture}

Figure 3.1 shows scores used to determine the companies' FS-culture; the greater the surface area, the more proactive the FS-culture. Score 2 predominated in CA and CB for employee characteristics and enabling conditions indicating that both companies demonstrated an active prevailing FS-culture. For CC score 3.3 predominated indicating a proactive prevailing FSculture. This implies that food safety and hygiene control was not always regarded as important in $\mathrm{CA}$ and $\mathrm{CB}$, whereas in $\mathrm{CC}$ food safety was consistently regarded as highly important i.e. food safety and hygiene control were prioritised. Our findings are consistent with De Boeck et al. (2016) who found that food safety climate scored higher for larger, centrally managed organisations. 

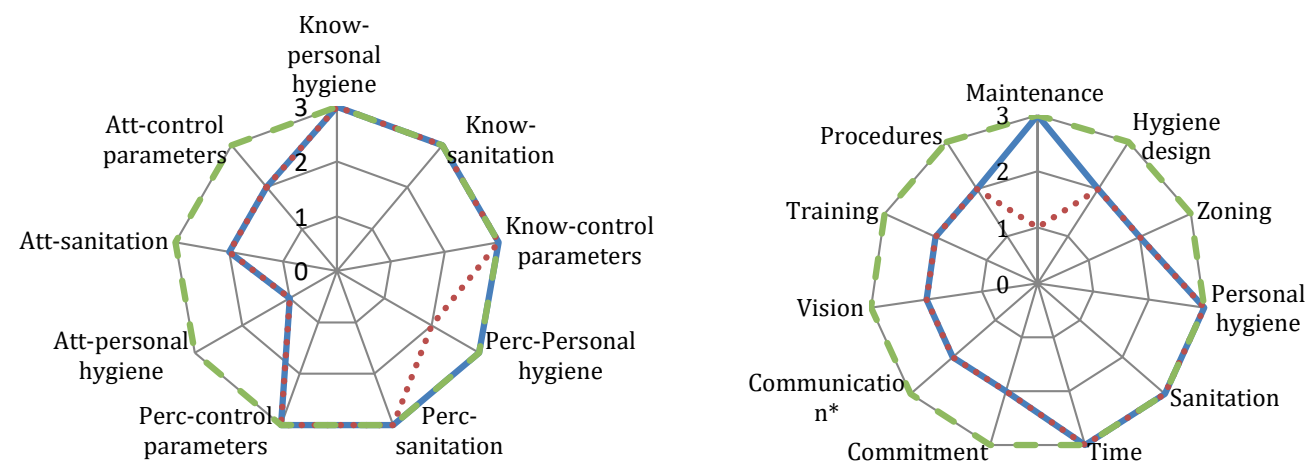

Figure 3.1: Web diagrams showing an overview of overall scores for enabling conditions and employee characteristics for $C A, C B$ and CC used to give an indication of the organisation's prevailing FS-culture.

Interpretation of scores for each key element is given in Table 3. Know $=$ knowledge, Perc $=$ perceptions, Att $=$ attitudes. A: Personal characteristics; B: Enabling conditions<smiles>[Mg]</smiles>

$---\mathrm{CC}$

\subsubsection{Microbiological safety performance}

Products in all 3 companies tested negative for Salmonella. S. aureus was also absent in CB and $\mathrm{CC}$ but was present in CA at 5 ( 2 cold room storage and 2 vacuum packaging points, and 1 filling and sealing step) of the 7 CSL's (Table 3.2). Document analysis showed that coliforms and E. coli were present in CA (Figure 3.2), which is consistent with actual product testing on hygiene performance. For $\mathrm{CB}$, compliance to criteria for coliforms was at least $93 \%$ and for CC compliance to E. coli criteria was $100 \%$.

Customer complaint records revealed that complaints for $\mathrm{CA}$ and $\mathrm{CB}$ were restricted to quality problems and for $\mathrm{CC}$ there were no complaints. In overall, the microbial safety performance for CC was good (score 3) compared to CA (score 1) and CB (score 2). CC's good performance could be because of the organisation's low product riskiness and the wellelaborated certified FSMS as also established by De Boeck et al. (2016) and Kussaga et al. (2015). Moreover, the company had a comprehensive complaints system and a crisis management protocol in place, in case of food safety incidences. De Boeck et al. (2016), also found that companies with a high food safety climate score and a well elaborated FSMS had a better microbial safety performance. Analysis of data on actual behaviour, enabling conditions 
and employee characteristics could provide further explanations of the food safety performance differences.

\section{Percentage compliance of products based on microbial records}

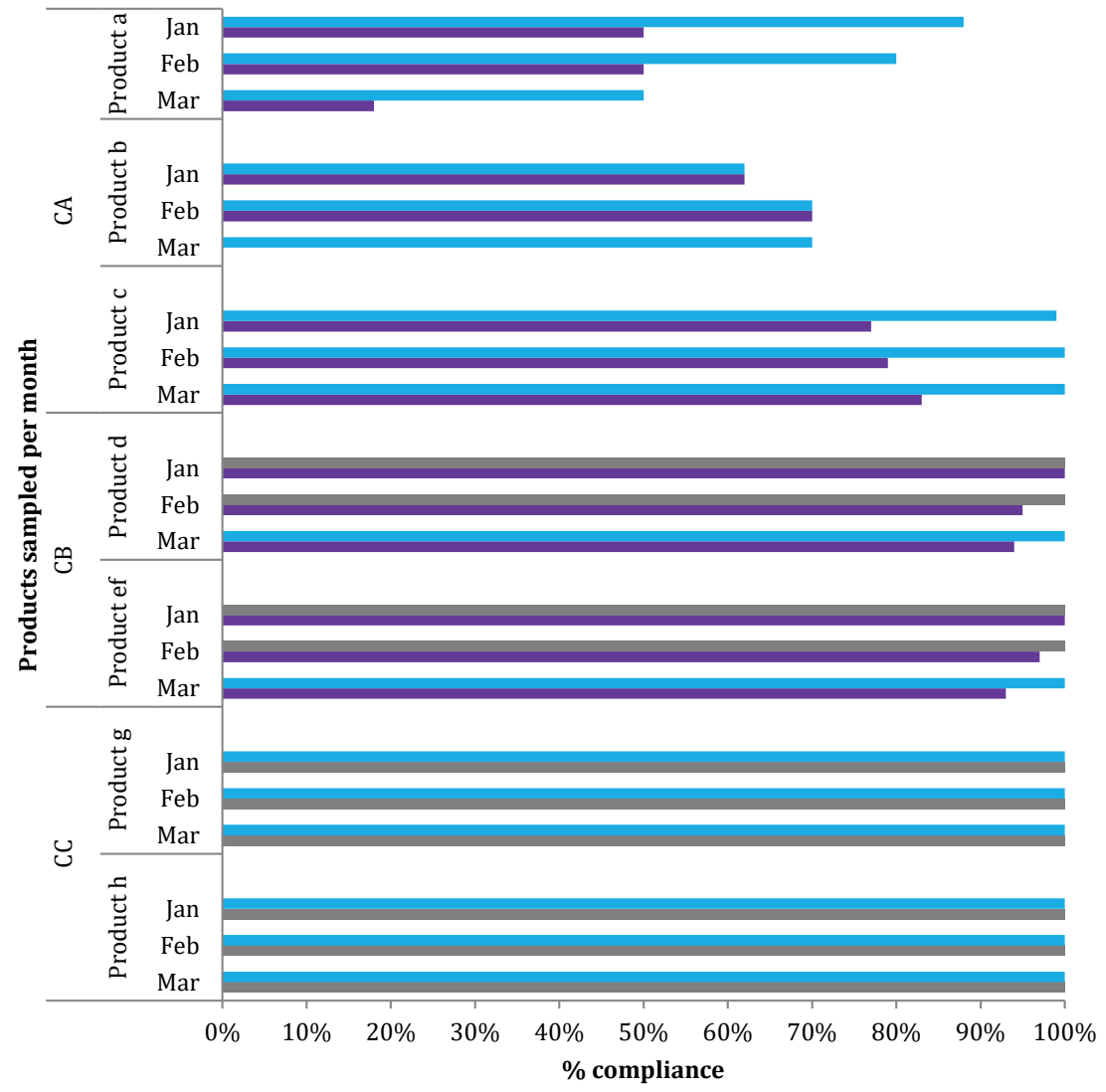

Figure 3.2: Compliance of products with microbiological criteria in companies $A, B$ and $C$ based on analysis of company records on hygiene performance.

Blue: E.coli, Purple: Coliforms, Grey: Analysis not done.

\subsubsection{Actual food safety and hygiene behaviour}

Table 3.4 shows that CA partially complied (score 2; moderate-risk) with most behaviour parameters with an exception of health status, which scored 3 (low-risk) and sanitation practices, which scored 1 (high-risk) as food handlers did not execute sanitation activities at least $80 \%$ of the time. $\mathrm{CB}$ shows a more diverse pattern as some activities were well performed (score 3), i.e. correct cleaning compounds used and efficacy checked, whereas 
handwashing and corrective actions scored 1 as a majority of employees did not wash their hands or follow the whole handwashing procedure and adjusted process parameters without reporting the corrective action taken. Furthermore, in $\mathrm{CB}$, most personal hygiene activities scored 2, as employees predominantly exhibited moderate-risk behaviour. Although no major microbial safety problems were observed, the multiple inconsistencies in compliance behaviour could imply potential risks in the organisation's microbial safety performance. CC showed a homogenous pattern as score 3 was consistently obtained since personnel strictly adhered to all food safety and hygiene control requirements (e.g. "handwashing is a culture in this company"). If employees perceive that their organisations treat them well and provide the enabling climate, they are more inclined to respond with positive work attitude and behaviour (Lee et al., 2013). Likewise, Pacholewicz et al. (2016) found that consistent food safety and hygiene compliance behaviour was reflected in better product safety performance.

\subsubsection{Supportiveness of enabling conditions}

Data for enabling conditions (Table 3.5) for CA and CB show a diverse pattern because there was no clear consensus amongst the food handlers on how the current enabling conditions supported them in executing their tasks, whereas data for $\mathrm{CC}$ show a homogenous pattern (score 3). In both $\mathrm{CA}$ and $\mathrm{CB}$, technological conditions such as hygienic design and zoning, and a majority of the organisational conditions (commitment, vision, training and procedures) scored 2 (restricted support) as compared to CC, where all enabling conditions were considered to be supportive (score 3).

Both CA and CB had similar overall mode scores for the provided enabling conditions with the exception of maintenance, which was more supportive in CA compared to CB where it was reactive and not supportive (score 1) as it was frequently triggered by breakdowns ("maintenance is carried out when machines are down completely"). Likewise, previous studies in dairy companies of transitioning countries found equipment maintenance to be reactive (Kussaga et al., 2015). For CC, equipment maintenance was proactive as the organisation had a structured, preventive program regularly monitored by experts and maintenance was periodically done ("we don't mind shutting down the plant to carry out maintenance"). 
Table 3.4: Mode scores for employees' actual behaviour for executing different food safety and hygiene tasks

\begin{tabular}{|c|c|c|c|}
\hline & $\begin{array}{l}\mathbf{C A} \\
\mathbf{n}=24\end{array}$ & $\begin{array}{l}\text { CB } \\
n=38\end{array}$ & $\begin{array}{l}\mathbf{C C} \\
\mathbf{n}=10\end{array}$ \\
\hline Indicator & Mode & Mode & Mode \\
\hline \multicolumn{4}{|l|}{ Actual personal hygiene behaviour } \\
\hline $\begin{array}{l}\text { Maintenance of high degree of personal cleanliness } \\
\text { (protective clothing, hair covers, footwear, hand gloves) } \\
\text { - Handwashing practices }\end{array}$ & 2 & 2 & 3 \\
\hline $\begin{array}{l}\text { Handwashing behaviour before and after crucial activities, } \\
\text { e.g. high risk areas, before starting work, after blowing } \\
\text { nose, visiting the toilet and handling waste } \\
\text { - Handwashing steps }\end{array}$ & 2 & 1 & 3 \\
\hline \multicolumn{4}{|l|}{ - Personal habits } \\
\hline $\begin{array}{l}\text { Personal hygiene habits e.g. (wearing jewellery, chewing } \\
\text { gum, use of mobile phones or blowing nose during } \\
\text { processing }\end{array}$ & 2 & 2 & 3 \\
\hline $\begin{array}{l}\text { Handling of health issues i.e. coughing/sneezing, illness, } \\
\text { exclusion of those sick and with open lesions/wounds in } \\
\text { food processing areas }\end{array}$ & 3 & 2 & 3 \\
\hline \multicolumn{4}{|l|}{ Actual execution of sanitation activities } \\
\hline - Following cleaning and disinfection procedures & 1 & 2 & 3 \\
\hline - Correct cleaning compounds & 1 & 3 & 3 \\
\hline - Correct cleaning tools & 1 & 2 & 3 \\
\hline \multirow{2}{*}{$\begin{array}{l}\text { - Sanitation activities and/or efficacy monitored } \\
\text { Overall score sanitation activities }\end{array}$} & 2 & 3 & 3 \\
\hline & 1 & $2 *$ & 3 \\
\hline \multicolumn{4}{|l|}{ Actual control of process parameters } \\
\hline - Appropriateness of monitoring of crucial parameters & 2 & 2 & 3 \\
\hline from required levels & 2 & 1 & 3 \\
\hline \multicolumn{4}{|l|}{ Overall score control of process parameters } \\
\hline & 2 & $2 *$ & 3 \\
\hline
\end{tabular}

${ }^{*}$ Overall score obtained from further checklist sub-parameters in the event that checklist criteria have an equal scoring. Score $1=$ noncompliance (food safety and hygiene practices are not executed $\geq 80 \%$ of the time), $2=$ partial compliance (incomplete execution $\geq 80 \%$ of the time), $3=$ full compliance (correct and complete execution $\geq 80 \%$ of the time)

Closer inspection of the frequency scores shows that for various enabling conditions e.g. personal hygiene and training (Table 3.5), there was no clear distinction on the extent of supportiveness of the provided conditions. For example, the diverse assignment of scores for training in CA could be attributed to the company's initiative towards HACCP training at the time of assessment. This prompted some respondents to have a positive bias towards training whereas others stated unstructured training to be the norm. In CB, some respondents also had a positive bias because of the current occupational safety training, whereas others highlighted 
training was unstructured. However, in CC training was tailored to individual needs as there was a competence and development matrix to identify training needs.

Table 3.5: Frequency of individual scores and mode scores for the enabling conditions

\begin{tabular}{|c|c|c|c|c|c|c|c|c|c|c|c|c|c|}
\hline \multirow{4}{*}{ Indicator } & & \multicolumn{9}{|c|}{ Frequencies of scores from respondents } & \multicolumn{3}{|c|}{ Mode $^{b}$} \\
\hline & & \multicolumn{3}{|c|}{$\mathrm{CA}(\mathrm{n}=24)$} & \multicolumn{3}{|c|}{ CB $(n=43)$} & \multicolumn{3}{|c|}{$\mathrm{CC}(\mathrm{n}=28)$} & \multirow[t]{3}{*}{ CA } & \multirow[t]{3}{*}{ CB } & \multirow[t]{3}{*}{$\mathrm{CC}$} \\
\hline & & $\mathbf{1}^{\mathbf{a}}$ & 2 & 3 & 1 & 2 & 3 & 12 & 23 & 3 & & & \\
\hline & \multicolumn{10}{|l|}{ Respondents } & & & \\
\hline \multicolumn{14}{|c|}{ Technological enabling conditions } \\
\hline \multirow[t]{3}{*}{ Maintenance } & Managers & & 3 & & 1 & 3 & 2 & & & 4 & 2 & 2 & 3 \\
\hline & Food handlers & 4 & 6 & 11 & 24 & 10 & 3 & & & 24 & 3 & 1 & 3 \\
\hline & Overall score & & & & & & & & & & $3^{c}$ & $\mathbf{1}$ & 3 \\
\hline \multirow[t]{3}{*}{ Hygiene design } & Managers & & 2 & 1 & 1 & 4 & 1 & & & 4 & 2 & 2 & 3 \\
\hline & Food handlers & 1 & 15 & 5 & 3 & 23 & 11 & & 22 & 22 & 2 & 2 & 3 \\
\hline & Overall score & & & & & & & & & & 2 & 2 & 3 \\
\hline \multirow[t]{3}{*}{ Zoning } & Managers & 1 & 2 & & & 4 & 2 & & & 4 & 2 & 2 & 3 \\
\hline & Food handlers & & 16 & 5 & 1 & 32 & 4 & & & 24 & 2 & 2 & 3 \\
\hline & Overall score & & & & & & & & & & 2 & 2 & 3 \\
\hline Personal & Managers & & 2 & 1 & & 3 & 3 & & & 4 & 2 & $2 / 3 *$ & 3 \\
\hline \multirow[t]{2}{*}{ hygiene } & Food handlers & 1 & 8 & 12 & 4 & 14 & 19 & & 12 & 23 & 3 & 3 & 3 \\
\hline & Overall score & & & & & & & & & & $3^{\mathrm{c}}$ & $\mathbf{3}^{\mathbf{c}}$ & 3 \\
\hline \multirow[t]{3}{*}{ Sanitation } & Managers & & 2 & 1 & 1 & 1 & 4 & & & 4 & 2 & 3 & 3 \\
\hline & Food handlers & 2 & 5 & 14 & 3 & 14 & 20 & & & 24 & 3 & 3 & 3 \\
\hline & Overall score & & & & & & & & & & 3 & 3 & 3 \\
\hline \multicolumn{14}{|c|}{ Organisational enabling conditions } \\
\hline \multirow[t]{3}{*}{ Time } & Managers & & 1 & 2 & 1 & 1 & 4 & & & 4 & 3 & 3 & 3 \\
\hline & Food handlers & & 5 & 16 & 4 & 13 & 20 & & & 24 & 3 & 3 & 3 \\
\hline & Overall score & & & & & & & & & & 3 & 3 & 3 \\
\hline \multirow[t]{3}{*}{ Commitment } & Managers & & 2 & 1 & & 5 & 1 & & & 4 & 2 & 2 & 3 \\
\hline & Food handlers & 2 & 10 & 9 & 6 & 26 & 5 & & 22 & 22 & 2 & 2 & 3 \\
\hline & Overall score & & & & & & & & & & $2^{c}$ & 2 & 3 \\
\hline \multirow[t]{3}{*}{ Communication } & Managers & & 2 & 1 & & 3 & 3 & & & 4 & 2 & $2 / 3 *$ & 3 \\
\hline & Food handlers & & 10 & 11 & 5 & 16 & 16 & & 12 & 23 & 3 & $2 / 3 *$ & 3 \\
\hline & Overall score & & & & & & & & & & $2 / 3 *$ & $2 / 3 *$ & 3 \\
\hline \multirow[t]{3}{*}{ Vision } & Managers & & 3 & & 1 & 2 & 3 & & & 4 & 2 & 3 & 3 \\
\hline & Food handlers & & 10 & 11 & & 29 & 8 & & 12 & 23 & 3 & 2 & 3 \\
\hline & Overall score & & & & & & & & & & $2^{\mathrm{c}}$ & 2 & 3 \\
\hline \multirow[t]{3}{*}{ Training } & Managers & & 3 & & 1 & 5 & & & & 4 & 2 & 2 & 3 \\
\hline & Food handlers & 1 & 9 & 11 & 19 & 18 & & & & 24 & 3 & 1 & 3 \\
\hline & Overall score & & & & & & & & & & $2^{\mathrm{c}}$ & $2^{\mathrm{c}}$ & 3 \\
\hline \multirow[t]{3}{*}{ Procedures } & Managers & & 3 & & & 3 & 3 & & & 4 & 2 & $2 / 3 *$ & 3 \\
\hline & Food handlers & 1 & 12 & 8 & 6 & 21 & 10 & & 22 & 22 & 2 & 2 & 3 \\
\hline & Overall score & & & & & & & & & & 2 & 2 & 3 \\
\hline
\end{tabular}

${ }^{\text {a }}$ Scores 1, 2, 3 correspond with lack of, restricted and full support

Overall scores are in bold

${ }^{\mathrm{b}}$ Mode scores derived from total scores of respondents

${ }^{\mathrm{c}}$ Overall score not clearly distinctive (differences between scores $\leq 5$ )

* Equal scores assigned

For communication, a clearly divided opinion (equal scores assigned) on its supportiveness was evident (Table 3.5). Some respondents in CA considered communication lines to be open, whereas others cited lack of communication tools, e.g. infosheets. In CB, some respondents considered the communication system to be advanced because of the existing information 
sharing software, whereas others cited limited opportunities for feedback and channels to reach supervisors. A study by Fatimah et al. (2014a) also showed a divided opinion on communication with some respondents appreciating the communication style and others pointing at its inconsistencies. The varied responses could be because the enabling conditions are as perceived by employees and individuals could over- or underestimate the supportiveness of the conditions due to i.e. job stress and conscientiousness (De Boeck et al., 2015). For CC, additional communication tools were clearly visible in all locations, which might have reinforced the good food safety practices. Chapman et al. (2010) also found that infosheets positively influence hygiene behaviour, which underpins the importance of food safety communication strategies for compliance behaviour.

The inconsistencies in perceived supportiveness of enabling conditions in CA could have hindered compliance to food safety and hygiene control. For example, respondents indicated personal hygiene requirements were not always available and adequate. Moreover, equipment was difficult to clean, which confirms findings by the Zimbabwe Economic Policy And Research Unit (2014), who found that hybrid and self-fabricated equipment is sometimes used in Zimbabwe and could be a hindrance to effective sanitation. Furthermore, some respondents perceived management commitment as less supportive since according to them, some managers openly violated hygiene requirements. Chen et al. (2015) and Lee et al. (2013) suggested managers commitment as an important driver to food safety as it motivates employees to appropriately execute their tasks. Moreover, Arendt et al. (2011) posited that willingness of employees to follow safe food behaviour is shown when employees observe superiors following safe food practices.

Also, for $\mathrm{CB}$, lack of consensus, as not all food handlers perceived the enabling conditions to be supportive, could have resulted in the moderate-risk behaviour. Remarks such as "some machines are difficult to clean", "it has been 3 years since I joined the company and have not seen any training", "handwashing facilities are crowded" and "it can take two days to replace sanitisers" suggest a potentially risky situation. Fatimah et al. (2014a) indicated that supportive environmental conditions, i.e. resources, enable and prompt food safety practices and that if not functioning properly or inadequate, do not support safe food practices. Moreover, De Boeck et al., (2017) established that food safety behaviour could be influenced by FS-culture elements and could shape the organisation's FS-culture. 
In CA, some food handlers scored different from the managers e.g. for maintenance food handlers scored 3 as they were inclined towards proactive maintenance whereas managers scored 2 as they perceived it as active, but the number of managers is comparatively small. For CB, managers scored 2 or 3 for maintenance whereas food handlers mainly scored 1 . Findings are consistent with De Boeck et al., 2015 who observed that mangers and food handlers were not always on the same wavelength. The discrepancies could affect trust and loyalty, which in turn could influence attitudes and actual behaviour (Cogliser et al., 2009; De Boeck et al., 2016). In comparison, both managers and food handlers in CC similarly perceived the enabling conditions and unanimously agreed that the organisation was focused on preventing food safety problems.

\subsubsection{Employee characteristics: knowledge, perceptions and attitude}

The mode scores show that respondents in all three companies scored 3 (Table 3.6) on all indicators related to knowledge of food safety and hygiene control. However, sufficient knowledge of respondents in both CA and CB did not always translate into good behaviour, which is consistent with findings by Arendt et al. (2011), Fatimah et al. (2014b) and Jianu and Chiş (2012). There is need to understand what motivates personnel to correctly execute food handling practices.

Ko (2013) established that attitudes mediate the relationship between actual practices and knowledge. Moreover, optimistic bias, where personnel know the correct procedure but consider or perceive the inherent risk to less likely occur to them, could explain the discrepancy between knowledge and behaviour (da Cunha et al., 2014). Interestingly, this is not the case for $\mathrm{CC}$ employees as quizzes to assess knowledge were periodically held and winners were awarded, all in the effort to make sure employees had good knowledge.

All three companies mainly scored 3 (mode score) for indicators on perceptions towards food safety and hygiene practices (Table 3.6) as respondents' perceptions completely aligned with organisational requirements. Findings are consistent with Fatimah et al. (2014b) where employees largely perceived food safety as being practiced within the organisation. An exception was perceptions on personal hygiene requirements in $\mathrm{CB}$ where respondents' perceptions did not always align with organisational requirements (score 2). This was mainly because of the handwashing procedure, e.g. the time for rubbing hands after applying soap varied from 15 seconds to 5 minutes. This result corroborates findings by Jianu and Chiş 
(2012), where food handlers did not know all the appropriate handwashing steps, which could explain the observed handwashing behaviour (Table 3.4).

Table 3.6: Frequency of individual scores and mode scores for knowledge, perceptions and attitude

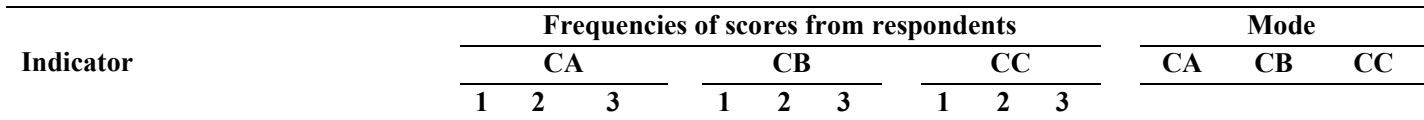

Knowledge of food safety and hygiene control

- Personal hygiene requirements $12 \quad 18$ 40 325 3 (protective clothing, hand gloves, hair covers, face masks, fingernails, handwashing, illness)

- Sanitation activities (sanitation procedures, cleaning methods, cleaning efficacy, cleaning tools, order of cleaning)

- Control of crucial process parameters (temperature, time, calibration, post pasteurisation)

Perceptions towards food safety practices

- Personal hygiene practices (appropriate handwashing, personal cleanliness, use of protective wear, reporting of health issues)

- Sanitation activities (appropriate removal of soil)

- Control of crucial process parameters (appropriate time and temperature control practices, and corrective actions)

Attitude towards compliance to procedures

Personal hygiene practices $3 \quad 21$

$\begin{array}{lllll}43 & 15 & \mathbf{3 ( 1 )} & \mathbf{3 ( 1 )} & \mathbf{3 ( 3 )} \\ 43 & 15 & \mathbf{3 ( 2 )} & \mathbf{3 ( 2 )} & \mathbf{3 ( 3 )} \\ 43 & 8^{*} & \mathbf{3 ( 2 )} & \mathbf{3 ( 2 )} & \mathbf{3 ( 3 )}\end{array}$

Control of crucial process parameters

7

6*

Scores 1, 2, 3 for (1) knowledge correspond with inadequate (complete lack of), moderate (incomplete) and good (ample) knowledge on food safety and hygiene issues, (2) perceptions with non-, partial and full alignment, at least $80 \%$ of the time, with company requirements, (3) attitudes with negative, ambivalent and positive attitude. For knowledge $\mathrm{n}=21$ for $\mathrm{CA}, \mathrm{n}=40$ for $\mathrm{CB}$ and $\mathrm{n}=28$ for $\mathrm{CC}$. For perceptions $\mathrm{n}=10$ for $\mathrm{CA}, \mathrm{n}=10$ for $\mathrm{CB}$ and $n=7$ for CC. For attitude $n=24$ for CA, $n=43$ for $C B$ an $n=15$ for CC.

* Respondents less than $\mathrm{n}$ as they indicated that questions were not applicable to them

${ }^{a}$ Mode scores given are those for the common interpretation of stories told by the researchers and in brackets the predominant attitude scored for the stories shared by food handlers. 
Except for $\mathrm{CC}$ and for personal hygiene in $\mathrm{CB}$, perceptions did not translate to actual behaviour. This discrepancy might be related to respondents' characteristics, perceived supportiveness of enabling conditions, and individual preferences, beliefs, attitudes and values. Taylor (2011) acknowledged that a person's family/social background (e.g. societal norms) can influence how someone perceives and responds to organisational food safety requirements, as expressed in work practices, and can be encouraged or discouraged by an organisation's values. The limited number of respondents on perceptions limits us in drawing strong conclusions, since respondents not involved in the work activities declined to answer.

Mode scores for attitudes towards food safety and hygiene control (Table 3.6) differed between the respondents' interpretation of the attitude in the stories told by the researchers and the actual (as shown in brackets) attitude judged from stories told by respondents of actual situations typical to their organisation. In CA and CB, all scores were lower (score 1 for personal hygiene practices, and score 2 for sanitation activities and control of crucial process parameters when they were assigned based on the actual attitude. On the contrary, CC consistently scored 3 for both mode scores. Food handlers' negative attitudes towards compliance with personal hygiene practices for CA and CB (Table 3.6) were reflected in stories such as "some people are negligent because they are in a hurry to close from work", "changing rooms are not safe, so we carry our valuables e.g. phones, jewellery with us into the production area" and "sometimes people clean without detergents". Some respondents attributed the negative attitude to unclear personal hygiene requirements. Moreover, financial constraints were frequently mentioned as a driver for risky decisions and risk-taking behaviour such as cutting corners, which is corroborated by Fatimah et al. (2014a). The negative personal hygiene attitude could also explain the handwashing behaviour in $\mathrm{CB}$ since attitude has been identified as a predictor of hand hygiene behaviour (Clayton \& Griffith, 2008). Ambivalent attitudes towards sanitation activities and control of crucial process parameters could have triggered the insufficient adoption of food safety practices as also found in studies by da Cunha et al. (2014) and Ko (2013). In CC, respondents' attitudes were demonstrated by clear ownership of the products and attachment to the organisation. This was corroborated by common responses such as "...because we want the job, we keep the rules", "it won't happen here", "it is better to do the right things" and "it is better to miss an appointment than shortcut the process". 


\subsubsection{Mixed-methodology approach}

The card-aided interview approach guided respondents to select the situation that best reflected the organisation and was useful to get in-depth understanding behind the choices. However, terms used were sometimes perceived to be too technical resulting in more time (i.e. 30 minutes to 1 hour) spent with the respondent. It could be advantageous to translate the cards into the local language and add pictures (Chapman et al., 2010) to help understand some parameters, i.e. zoning, thus limiting the influence of the researcher. Storytelling was able to elicit food handlers to share more stories, which helped to understand the attitudes. Stories offer researchers an entry point to getting insights in an organisation's culture (Boyce, 1996). Chapman et al. (2010) used storytelling to generate dialogue and the method was effective as an intervention tool to positively influence food safety practices. A downside to storytelling could be the social desirability bias. Respondents could therefore put their thoughts on paper rather than airing them out in the group. A timestamp is also required since some stories could have happened years back and the situation could have improved over time, thus not reflecting current trends.

Observations provided information on the actual behaviour and status of equipment/facilities, and have been advocated as a reliable measure of FS-culture as they capture actual practices in their actual context (Chapman et al., 2010) and are not dependent on self-reported practices but can be independently and objectively assessed (Powell et al., 2011). Organisations were observed as units. It is recommended to observe an individual's behaviour in a next study as compared to organisational behaviour to get a more accurate insight of actual behaviour. Questionnaires have been successfully used in existing FS-culture research (e.g. De Boeck et al., 2016; Fatimah et al., 2014b). Document analysis gave a clearer picture of what had been on the ground for a longer period of time, which is consistent with Powell et al. (2011). All companies had samples analysed at accredited laboratories, which is consistent with the assessment done by Kussaga et al. (2015). The microbial results should be interpreted with caution due to the sample size and limitations placed by the organisations on actual microbial analysis.

Overall, the mixed-methods approach was suitable to get an in-depth understanding of FSculture. The approach encourages multi-level analysis, enables one to take a multi-faceted view of FS-culture, and to establish relationships between the context, behaviour and individual characteristics (Cooper, 2000). Moreover, the methodology enables assessment of 
the external validity of the FS-culture construct through a "within-methods triangulation approach" and "between-method validation process". Within-methods involves crosschecking each method used for consistency and reliability (Cooper, 2000). Between-method validation involved comparisons between the different constructs, i.e. prevailing FS-culture, actual behaviour and performance. However, the approach was quite elaborate but time consuming. To get a quick overview of the FS-culture with a less demanding process, an organisation can use a self-assessment tool.

\subsection{Conclusions and suggestions for future research}

Comparison of the results obtained from the microbiological safety performance of the three dairy companies in this study are in agreement with the outcomes of the data on actual food handler behaviour, enabling conditions and employee characteristics. Firstly, this clearly supports the suitability and validity of the proposed mixed-methods approach used to assess FS-culture in the present study. Secondly, it enables an organisation to have an understanding of its prevailing FS-culture, which provides guidelines on measures to improve performance. The identified levels (reactive, active and proactive) were able to distinguish the prevailing FS-culture. Bottlenecks (scores 1, 2 or where respondents lacked consensus) were therefore identified. There is need to intervene at these bottlenecks as these could accumulate or gradually worsen and could lead to major consequences in food safety (Nayak \& Waterson, (2016). Moreover, studies should add weight factors to the FS-culture indicators as the indicators could have differently contributed to food safety performance. To reach a proactive level, appropriate roadmaps for tackling the identified bottlenecks should elaborate FS-culture specific interventions, point the where, what and how to improve the FS-culture (Hudson, 2007) and be assessed over time to assure their effectiveness to FS-culture improvement. Though having a proactive FS-culture is sufficient, an enlightened (well-advanced) FS-culture would be ideal. However, the paradigm stating that the more enlightened the FS-culture, the better the performance, could be over-the-top and FS-culture paranoia will make operations time consuming and rigid, and workers could lose motivation resulting in performance losses. Pidgeon (1998) acknowledged the paradox of safety culture, where it could both act as a "precondition to safe operations (illuminating hazards) and for oversight of incubating (deflecting attention) hazards." As such, risk-based auditing for management of key food safety risks could be a tool useful in FS-culture as it allows spot checks and focuses on areas of risk (Albersmeier et al., 2009). Future studies should also consider chemical safety as existing studies primarily focus on microbiological safety. 
The study was done in 3 dairy companies of 1 country and since FS-culture is context specific (Fatimah et al., 2014a; Nyarugwe et al., 2016), generalisations cannot be inferred across food establishments and countries as sector specific characteristics and national culture can influence the FS-culture. Future research needs to study the national culture influence, and research in food establishments in several countries is required.

\section{Acknowledgements}

This research was supported by The Netherlands Fellowship Programmes (NFP) (Grant award number CF. 9421/2014). The authors thank James Ledo for assistance with data collection and the participants for their time and support. 
Food safety culture assessment using a comprehensive mixed-methods approach: A comparative study in dairy processing organisations in an emerging economy 



\section{Chapter 4}

\section{Prevailing food safety culture in companies operating in a transition economy- does product riskiness matter?}

Published as: Nyarugwe, S. P., Linnemann, A. R., \& Luning, P. A. (2020). Prevailing food safety culture in companies operating in a transition economy - Does product riskiness matter? Food Control, 107, 106803. 


\begin{abstract}
Food safety outbreaks are recurrent events, which regularly cost human lives. Food safety goes beyond food safety management systems; an organisation's prevailing food safety culture, and its internal and external environment must also be considered. This study introduces a research framework to analyse crucial food safety culture elements, and characteristics of the internal (i.e. food safety program, product riskiness, and vulnerability of food production system) and the external company environment (i.e. national values and food safety governance characteristics). We hypothesised that companies producing high-risk products are more likely to demonstrate a proactive food safety culture. We used the framework to assess nine companies producing low, medium, and high-risk products in Zimbabwe, as a case of a transition economy. Results showed no direct relationship between product riskiness and food safety culture, which negated our hypothesis. Other variables explored in this study could have moderated the relationship. We found that the vulnerability (i.e. susceptibility to microbial contamination) of the food production system could be associated with an organisation's food safety culture. Moreover, the external environment could have shaped the prevailing food safety culture. In particular, food safety governance and national values seem to be reflected in the way food safety was prioritised, food safety programs were designed and implemented, the prevailing food safety culture, and the observed food safety behaviour. Further research could investigate the role of the external environment in an organisation's food safety culture by evaluating companies in countries operating with different food safety governance approaches and national values.
\end{abstract}

Keywords:

Food safety culture assessment; food safety governance; national culture; external company environment, food safety program 


\subsection{Introduction}

Food safety continues to be a challenge as demonstrated by recurring food safety outbreaks (Centers for Disease Control and Prevention (CDC), 2018; European Food Safety Authority and European Centre for Disease Prevention Control, 2018), despite investments in food safety management systems (FSMS) (i.e. in infrastructure, equipment and documentation), food safety regulations, training and auditing. The recurrence of these outbreaks is more prominent in transition economies (World Health Organization, 2015), where a third of the global foodborne-related deaths occur (WHO, 2016). These economies face difficulties in the adoption of FSMS (Griffith et al., 2017; Macheka et al., 2013; Nanyunja et al., 2015) as well as in the assurance of food safety (Kussaga et al., 2013). In 2017-2018, a Listeriosis outbreak emanating from a meat processing company in South Africa resulted in 978 illnesses and 183 deaths, putting 15 countries at risk (World Health Organization, 2018), thus revealing deficiencies in the core control and assurance activities such as lack of preventive measures, monitoring systems to detect pathogens, verification activities, and lack of hygiene training (Boatemaa et al., 2019). Most outbreaks are anecdotal as there are often no structured systems to report cases (Kussaga et al., 2014a; WHO, 2015).

In addition to proper design and implementation of FSMS, the human dimension, e.g. perceptions, decision-making, and actual execution of food safety and hygiene tasks, has been found to influence the food safety performance of an organisation (e.g. De Boeck et al., 2015; Griffith et al., 2017; Fatimah et al., 2014b; Nyarugwe et al., 2018). Recent studies have therefore stressed the importance of food safety culture (FS-culture) in food safety performance (De Boeck et al., 2018; De Boeck et al., 2019; Jespersen et al., 2017; Manning, 2018; Nayak \& Taylor, 2018; Nyarugwe et al., 2016). Food companies nowadays attempt to create and sustain a culture of food safety, evidenced by efforts of e.g. Campden BRI (Emond \& Taylor, 2018) and the Global Food Safety Initiative's position paper on FS-culture (GFSI, 2018). This is because in the midst of persistent food safety challenges and globalisation, food safety should go beyond fulfilling regulatory requirements to "live within the company's culture" (GFSI, 2018).

However, ensuring food safety is more complex and may go beyond a company FS-culture as advocated previously (Nyarugwe et al., 2018). It should incorporate the external environment in which the company operates, such as national values and food safety governance (GFSI, 2018; Taylor, 2011). De Boeck et al. (2016) suggested that not only the technological and 
managerial factors reflect an organisation's FS-culture but also the human factors and the environment, in which a company operates. Moreover, Donaldson (2001), and Sousa and Voss (2008) indicated that an organisation's performance varies with differences in the organisation's situation like company size, environment and strategy, based on the contingency theory principles. De Boeck et al. (2017), Fatimah et al. (2014a), and Taylor (2011) also confirmed the importance of the environment or context to the FS-culture of a company.

Other studies have discussed the importance of context in relation to FSMS performance (Herath et al., 2007; Kirezieva et al., 2013b; Luning et al., 2011). Context refers to a broader concept, which encompasses characteristics of the external company environment and characteristics of the products, process and chain environment as described by Kirezieva et al. (2015a) and Luning et al. (2011). Kirezieva et al. (2013) proposed that the context puts demands on the design and operation of FSMS. Luning et al. (2011) identified product riskiness as one of the context factors and indicated that companies with a high-risk context are typified by a high vulnerability to food safety problems and need to have advanced control and assurance activities when compared with those with a low-risk context. Moreover, empirical studies demonstrated that companies operating with more vulnerable food products and food processes have a higher chance of food safety issues if their food safety system is not well developed (e.g. Luning et al., 2015; Sampers et al., 2012). Studies also showed that companies place stricter requirements and greater priority on food safety in production of high-risk products (e.g. meat and dairy) than for other products as high-risk products are potentially hazardous if processed under non-conforming circumstances (e.g. De Boeck et al., 2018a; Herath et al., 2007; Jacxsens et al., 2015; Karaman et al., 2012). Moreover, authors argued that companies with a more vulnerable context (i.e. product, process and supply chain characteristics, which indicate riskiness of the situation and that could affect food safety) need to provide better organisational support to enable consistency in decision-making (Kussaga et al., 2013; Luning et al., 2011).

Furthermore, Nyarugwe et al. (2016) discussed the need to adapt FS-culture to a company's food risks and context, as has been done in FSMS performance and in safety culture studies (e.g. Flin, 2007). To the best of our knowledge, no empirical studies have investigated if companies' food safety risks are reflected in the prevailing FS-culture and whether companies operating with more risky products and processes possess a more pro-active FS-culture. We 
postulate that companies working with high-risk food products possess a pro-active FSculture.

Besides product riskiness, the broad national context (i.e. external company environment), particularly food safety governance (i.e. characteristics of the regulatory environment and enforcement practices), plays a role in food safety performance (Kirezieva et al., 2015a; Kussaga et al., 2013; Nanyunja et al., 2015). Several authors also hypothesised that food safety governance could shape the FS-culture of an organisation (De Boeck et al., 2017; Taylor, 2011). In many transition economies, food safety legislation and its enforcement are weak and underdeveloped (Kirezieva et al., 2015b; Kussaga et al., 2014a; Kussaga et al., 2013; Nanyunja et al., 2015), which could constrain the development of FSMS and negatively impact FS-culture. This study therefore aims to investigate whether food companies operating under the same national context but varying in product riskiness differ in their prevailing FSculture. As a case study we used Zimbabwe, where the food safety governance system is fragmented (i.e. consists of multiple actors in food safety governance leading to overlaps or oversights in food safety control), lacks a clear enforcement strategy, and authorities act independently and uncoordinated, except when faced with food safety challenges (e.g. Macheka et al., 2013; Pswarayi et al., 2014).

\subsection{Food safety culture research framework}

Figure 4.1 shows the FS-culture research framework extended from Nyarugwe et al. (2018), used to analyse an organisation's prevailing FS-culture within its national context. Development of this FS-culture research framework was founded on the contingency theory, the food quality functions model and principles of the techno-managerial approach, i.e. concurrent analysis of technological and managerial factors that can have an influence on food safety (Luning \& Marcelis, 2007; Luning \& Marcelis, 2006; Sousa \& Voss, 2008). The figure shows elements, which include: organisational and technological enabling conditions, employee characteristics, food production characteristics, food safety output, and the internal and external company environment. Enabling conditions and employee characteristics reflect an organisation's FS-culture. Enabling conditions include technological and organisational conditions that measure the supportiveness of the company's technological and managerial environment to food handlers when executing their work tasks (Luning et al., 2011; Nyarugwe et al., 2018). Regarding employee characteristics, food safety, hygiene and risk perceptions, and attitudes of food handlers were assessed. Perceptions measure how personnel 
evaluate and ascribe meaning to their work environment (De Boeck et al., 2015). Attitude has been proposed as one of the predictors of intention to comply with food safety and hygiene requirements and intention as an influencer of actual behaviour (Ajzen, 1991; Clayton \& Griffith, 2008; Manning, 2018b; Young et al., 2018). With actual behaviour, we measure actual compliance to food safety related activities as behaviour reflects an organisation's FSculture (De Boeck et al., 2017; Nyarugwe et al., 2018). Food safety output gives an indication of actual food safety performance as an outcome of the FSMS (Jacxsens et al., 2010). Above elements and their associated indicators (i.e. crucial aspects) were identified from previously validated studies (e.g. De Boeck et al., 2016; Fatimah et al., 2014a; Jacxsens et al., 2010; Nyarugwe et al., 2018).

Fatimah et al. (2014a) denoted company characteristics as operational characteristics including management system, size and product type, which all could influence an organisation's FS-culture. In our study, food production characteristics (i.e. product riskiness and vulnerability) were incorporated in addition to company characteristics (including size, product type and organisational structure) to typify the internal company environment. Moreover, food safety performance was included as Luning et al. (2011) suggested food safety performance to not only depend on FSMS performance but also on the system's context with the assumption that product riskiness is a determinant of food safety performance. The food safety program was furthermore incorporated in the framework as a FSMS has been indicated as part of FS-culture assessments (De Boeck et al., 2016; Griffith et al., 2017; Nyarugwe et al., 2016).

Additionally, the framework shows national values and food safety governance as part of the broad national context used to typify the external company environment. In this study, national values characterise the national culture based on the Hofstede cultural dimensions i.e. power distance, individualism vs collectivism, masculinity vs femininity, uncertainty avoidance, long vs short-term orientation, and indulgence vs restraint (Hofstede et al., 2010). The food safety governance approach (i.e. characteristics of legal framework and enforcement practices) was assessed as it shapes an organisation's food safety system and the way it is implemented (Kirezieva et al., 2015a; Rouvière \& Caswell, 2012), which possibly reflects the FS-culture. 
External company environment

\section{National values}

- Power Distance

- Individualism vs collectivism

- Masculinity vs Femininity

- Uncertainty avoidance

- Long-term vs short-term orientation
Food safety governance approach

- Legal framework characteristics

- Enforcement practices

- Public/private standards

\section{Internal companv environment}

- Company characteristics

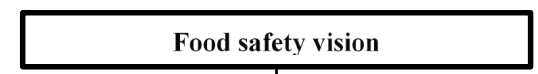

Setting priorities

$\frac{1}{1}$

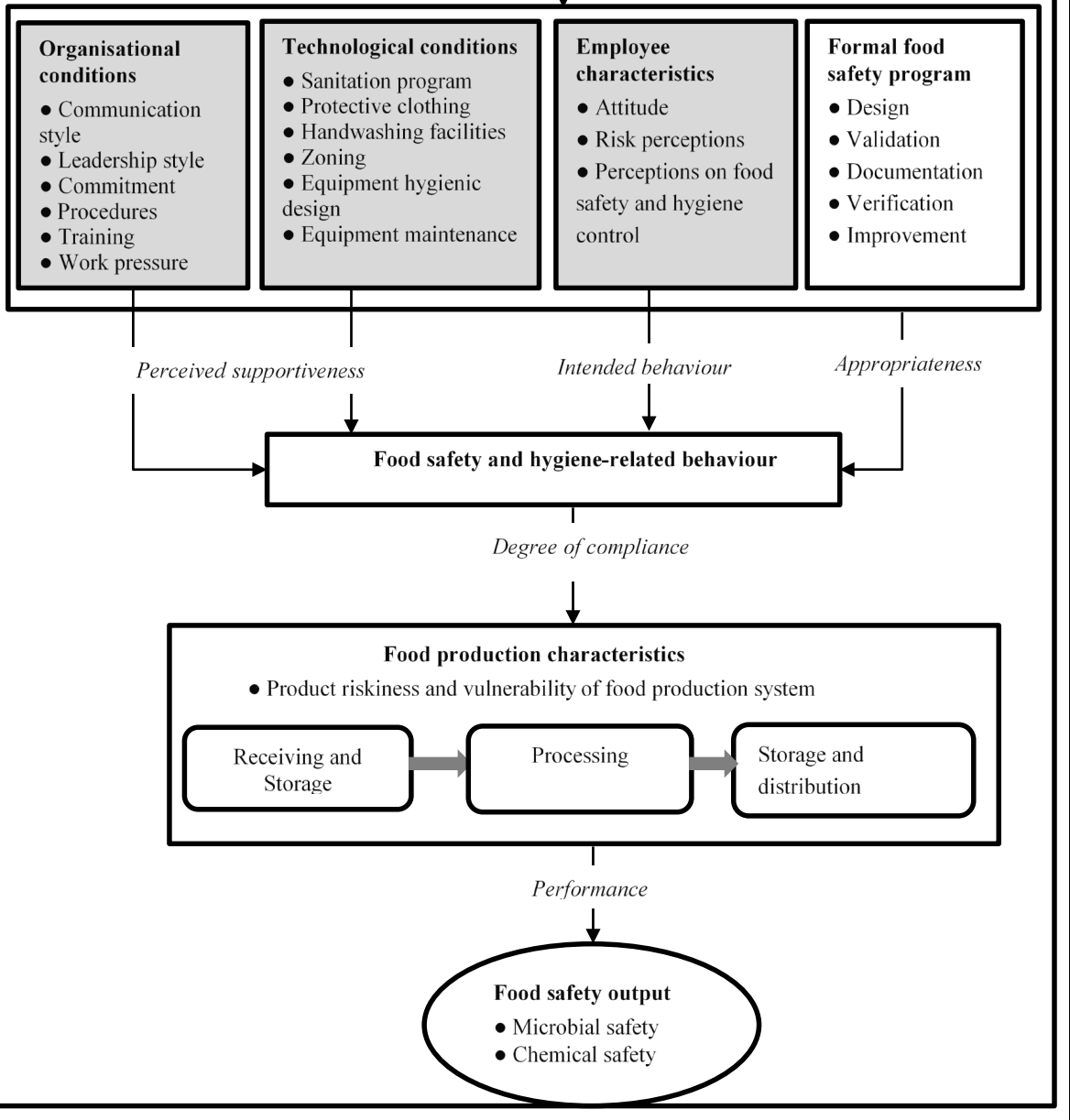

Figure 4.1:Research framework to analyse prevailing FS-culture of a company within its environmental context. In grey are the elements used to give an indication of an organisation's prevailing FS-culture from a food handler's perspective. 


\subsection{Materials and methods}

\subsubsection{Study design}

\section{Selection of respondents}

The study was carried out between July 2017 and September 2018 in nine Zimbabwean food companies coded L1-3, M1-2 and H1-4 for confidentiality reasons. The companies differed in level of product riskiness (low-L, medium-M, and high-risk-H), product type (dairy, meat, juices and cordials, baked goods, fresh vegetables), and company size (small to large). Small to medium companies employ more than 10 but less than 250 people with an annual turnover of EUR 50 million and balance sheet not exceeding EUR 43 million (European Union Commission, 2003). Dairy and meat companies were classified as high-risk, and vegetables and baked goods as low-risk (Dora et al., 2013; Jacxsens et al., 2015; Karaman et al., 2012). Medium-risk companies produced cordials and pasteurised juices. Companies and respondents were selected based on their willingness to participate. In the study, different types of respondents were interviewed. Food handlers (i.e. machine operators, production attendants, packers and supervisors) were randomly selected by the researchers from the production floor (according to Nyarugwe et al., 2018) to obtain the maximum participants within the allowable time. In each company, the quality assurance (QA) manager was interviewed. Three food safety authorities, one from a private certification body (coded as FSA1), and two from governmental bodies (FSA2 and FSA3), were also interviewed. FSA1 operated at the managerial level whilst the others operated at the directorship level. All received information about the research background and a guarantee of confidentiality. Table 4.1 summarizes respondent characteristics.

\section{Design of empirical study}

The empirical study design consisted of one part to typify internal and external company characteristics that could shape the FS-culture of an organisation and another part to assess the FS-culture elements that give an insight into the prevailing FS-culture. Questionnaires were used to collect data on external company characteristics (national values, food safety governance) and internal company characteristics. Interviews were also used to assess food safety governance. To assess the prevailing FS-culture, a mixed-methods approach, which involved triangulation of research methods, was used as recommended in other studies (De Boeck et al. (2018b) and Jespersen and Wallace (2017). The approach included interviews, card-aided interviews, questionnaires, participatory observations, and document analysis as previously developed (Nyarugwe et al., 2018). 
Some methods, such as storytelling to assess the prevailing FS-culture, were slightly modified (sections 2.2.3.1 to 2.2.3.4) based on recommendations from a previous study (Nyarugwe et al., 2018). Two research assistants from the University of Zimbabwe, who were trained in conducting the FS-culture assessments, assisted in data collection. In each company, data was collected for a period of 1 week as that was the maximum time the companies allowed.

Table 4.1: Characteristics of company respondents

\begin{tabular}{|c|c|c|c|c|c|c|c|c|c|}
\hline & \multicolumn{9}{|c|}{ Companies } \\
\hline & \multicolumn{3}{|c|}{ Low-risk } & \multicolumn{2}{|c|}{ Medium- risk } & \multicolumn{4}{|c|}{ High-risk } \\
\hline & ${ }^{1} \mathbf{L 1}$ & L2 & L3 & M1 & M2 & H1 & H2 & H3 & H4 \\
\hline \multicolumn{10}{|c|}{ Respondents profile } \\
\hline \multicolumn{10}{|c|}{ Gender } \\
\hline Male & 25 & 26 & 1 & 27 & 24 & 25 & 25 & 21 & 10 \\
\hline Female & 1 & 2 & 9 & 5 & 1 & 0 & 0 & 1 & 2 \\
\hline \multicolumn{10}{|l|}{ Age } \\
\hline Below 26 & 3 & 2 & 3 & 2 & 1 & 6 & 7 & 6 & 5 \\
\hline $26-30$ & 8 & 1 & 4 & 10 & 2 & 10 & 5 & 7 & 1 \\
\hline $31-35$ & 7 & 1 & 1 & 8 & 5 & 6 & 5 & 4 & 4 \\
\hline $36-40$ & 3 & 5 & 0 & 2 & 4 & 3 & 4 & 2 & 1 \\
\hline $41-45$ & 1 & 6 & 1 & 3 & 3 & 1 & 2 & 1 & 0 \\
\hline $46-50$ & 0 & 6 & 0 & 4 & 4 & 0 & 2 & 2 & 0 \\
\hline 50 and above & $2 *$ & 7 & 1 & $1^{*}$ & $5 *$ & 0 & 0 & 0 & 1 \\
\hline \multicolumn{10}{|l|}{ Position } \\
\hline Managers & 1 & 1 & 1 & 1 & 1 & 1 & 1 & 1 & 1 \\
\hline Food handlers & 25 & 27 & 9 & 31 & 24 & 24 & 24 & 21 & 11 \\
\hline \multicolumn{10}{|l|}{$\begin{array}{l}\text { Years in } \\
\text { employment }\end{array}$} \\
\hline$<1$ & 2 & 2 & 0 & 4 & 2 & 4 & 12 & 10 & 2 \\
\hline $1-5$ & 11 & 5 & 9 & 12 & 5 & 16 & 8 & 12 & 8 \\
\hline $6-10$ & 9 & 0 & 1 & 6 & 6 & 5 & 5 & 0 & 2 \\
\hline $11-15$ & 2 & 0 & 0 & 2 & 2 & 0 & 0 & 0 & 0 \\
\hline $16-20$ & $1 *$ & 9 & 0 & 4 & 2 & 0 & 0 & 0 & 0 \\
\hline 21 and above & 0 & 12 & 0 & 2 & $7 *$ & 0 & 0 & 0 & 0 \\
\hline \multicolumn{10}{|l|}{$\begin{array}{l}\text { Type of } \\
\text { employment }\end{array}$} \\
\hline Contract & 23 & 4 & 9 & 9 & 10 & 15 & 17 & 16 & 2 \\
\hline Permanent & 3 & 24 & 1 & 23 & 15 & 10 & 8 & 6 & 10 \\
\hline \multicolumn{10}{|l|}{$\begin{array}{l}\text { Educational } \\
\text { level }\end{array}$} \\
\hline Primary & 0 & 2 & 3 & 0 & 5 & 0 & 0 & 2 & 4 \\
\hline Secondary & 24 & 23 & 6 & 12 & 16 & 23 & 21 & 17 & 4 \\
\hline Tertiary & 2 & 3 & 1 & $17 *$ & $3 *$ & 2 & 4 & 3 & 4 \\
\hline \multicolumn{10}{|l|}{ Nationality } \\
\hline Zimbabwean & 26 & 28 & 10 & 32 & 25 & 26 & 25 & 22 & 12 \\
\hline $\begin{array}{l}\text { Non- } \\
\text { Zimbabwean }\end{array}$ & 0 & 0 & 0 & 0 & 1 & 0 & 0 & 0 & 0 \\
\hline
\end{tabular}

${ }^{1} \mathrm{~L} 1, \mathrm{M} 1 \ldots$ refers to the names of the companies.

*Some respondents chose not to respond

\subsubsection{Data collection}

\section{Assessment of external company environment}

Food handlers received the values survey module (VSM), a questionnaire developed by

Hofstede et al. (2013) to characterise national values, as the assessment had not yet been fully 
done for Zimbabwe. Questions to typify the food safety governance approach were developed by the researchers based on previous research (Kirezieva et al., 2015a), adapted to fit the context of emerging economies based on previous findings (Kussaga et al., 2014a) and directed to food safety authorities and QA managers. The questionnaires consisted of both open and closed questions on characteristics of the legal framework, enforcement practices, and private enforcement. All questionnaires, except for the VSM, had three answer categories reflecting unsupportive, restricted support, and supportive, which correspond with scores 1, 2, and 3 , respectively.

\section{Assessment of internal company environment}

Questionnaires were developed to assess, from the QA manager's perspective, the internal company environment, which included vulnerability of the product and production characteristics, and the organisation's food safety vision, company characteristics and formal food safety program. One questionnaire comprised closed questions to characterise vulnerability (modified from Luning et al., 2011). Vulnerability reflects the perceived riskiness in the context (Sawe et al., 2014), encompassing, in the current study, the inherent product and production characteristics. The other questionnaire comprised both closed and open questions to assess company characteristics and the formal food safety program. All questions had answer categories characterising a reactive, active, and proactive FS-culture, which correspond with scores 1,2 , and 3, respectively. Vulnerability and assigned food safety performance scores were based on Sampers et al. (2012) and Jacxsens et al. (2010). Scores were also assigned for the formal food safety program using the same approach.

\section{Assessment of organisational and technological enabling conditions}

Card-aided interviews were used to assess food handlers' perceptions of the organisation's technological and organisational enabling conditions (Figure 4.1) as described in Nyarugwe et al. (2018). For each enabling condition, three cards providing descriptions reflecting characteristics of a reactive, active, and proactive FS-culture (scores 1, 2, 3, respectively) were given to respondents. This supported the respondents to choose the situation that best described the organisation's supportiveness to food safety and hygiene. The cards were given random letters and numbers and the combinations of letter and number chosen by the food handlers were recorded on a separate answer sheet together with the respondent's justification of the selected response. Each interview lasted for 20 to $45 \mathrm{~min}$, depending on the 
respondent's ability to use English for communication, with the local language (Shona) used where translation was required.

\section{Assessment of employee characteristics}

Following the card-aided interviews, food handlers received a FS-culture self-assessment questionnaire. The questionnaire included demographic variables, operating characteristics, and employee characteristics. The employee characteristics section consisted of closed and open questions to: (1) evaluate attitudes towards food safety and hygiene control, (2) assess risk perceptions, (3) analyse perceived appropriateness of personal hygiene practices, crucial control and sanitation practices, and (4) assess intended food safety and hygiene control behaviour. The questionnaire was modified from our previous study (Nyarugwe et al., 2018) by including risk perceptions and intended behaviour. Most food handlers completed their own questions with a few requiring assistance from the researchers in translating the questionnaires. The questionnaire comprised three answer categories reflecting reactive, active, and proactive FS-culture, which correspond with scores 1, 2, and 3, respectively. Exceptions were the food safety and hygiene perceptions where the chosen responses were classified as reactive, active or proactive.

\section{Assessment of actual behaviour}

An observation checklist was used to assess food handler behaviour based on guidelines previously described by Nyarugwe et al. (2018). The checklist contained three sections, namely on personal hygiene, actual sanitation practices, and actual control of crucial process parameters. For each section, the observer classified the observations into non-, partial, or full compliance corresponding with scores 1, 2, and 3, respectively. Two researchers randomly and independently observed the same person. The duration varied depending on, e.g., work area, tasks, and product or process requirements. Participatory observation, where the researchers integrate themselves within a group without informing group members that they are being observed, was done to observe actual execution of work tasks by the food handlers, as described by Kawulich (2005).

\section{Assessment of food safety output}

A checklist was developed to systematically analyse records for microbial trends, and type of microbial and hygiene-related complaints based on Nyarugwe et al. (2018). Analysed records covered a period of eight months to get insight into the companies' activities over a longer 
period. This period was the same for all companies. Companies were scored 1, 2 or 3, depending on whether records indicated multiple problems, restricted or no food safety problems. This was associated with respectively a reactive, active, or proactive FS-culture. Additionally, food safety key performance indicators were assessed through questions on food safety directed to the QA manager, as previously described by Jacxsens et al. (2010). Food safety performance indicators are useful to give a first indication of the microbial food safety performance as a measure of the food safety output without actual microbial analysis, as demonstrated by Jacxsens et al. (2010). These authors suggested that food companies that evaluate their performance in a structured way and according to very strict and specific criteria, will have a better insight in their actual microbial food safety performance because "food safety problems will be more systematically detected".

\subsubsection{Data interpretation and analyses}

\section{Data interpretation}

For each of the assessed elements and their associated indicators, situational descriptions and scores that reflect a reactive, active, and proactive FS-culture were defined to interpret data obtained from the multiple data collection methods with the exception of national values. Table 4.2 shows the overall characteristics to define these descriptions and assign scores. The assigned scores were used for both data and statistical analyses.

Table 4.2: Overall characteristics of the FS-culture elements and the internal and external environment used to typify the prevailing FS-culture and the company environment extended from Nyarugwe et al. (2018)

\begin{tabular}{|c|c|c|c|}
\hline *Element & $\begin{array}{l}\text { Score } 1 \text { (typifying reactive FS- } \\
\text { culture) }\end{array}$ & Score 2 (typifying active FS-culture) & $\begin{array}{l}\text { Score } 3 \text { (typifying proactive FS- } \\
\text { culture) }\end{array}$ \\
\hline \multicolumn{4}{|c|}{ External company environment } \\
\hline $\begin{array}{l}{ }^{a} \text { Food safety } \\
\text { governance }\end{array}$ & $\begin{array}{l}\text { Unsupportive i.e. Out-of-date, } \\
\text { unusable, generic food safety } \\
\text { standards which leave much room } \\
\text { for interpretation or punitive } \\
\text { enforcement practices or ad hoc } \\
\text { inspections and audits are done only } \\
\text { when problems occur }\end{array}$ & $\begin{array}{l}\text { Restricted support i.e. relevant food } \\
\text { safety standards, usable to some } \\
\text { extent and are prescriptive. Partially } \\
\text { facilitative enforcement practices. } \\
\text { Structured inspections and audits done } \\
\text { on a regular basis }\end{array}$ & $\begin{array}{l}\text { Supportive i.e. up-to-date food } \\
\text { safety standards. Facilitative } \\
\text { enforcement practices. Inspections } \\
\text { and audits done on a defined } \\
\text { frequency and are risk-based }\end{array}$ \\
\hline \multicolumn{4}{|c|}{ Internal company environment } \\
\hline $\begin{array}{l}{ }^{\mathrm{a}} \text { Company } \\
\text { characteristics }\end{array}$ & $\begin{array}{l}\text { Unsupportive e.g. Low workforce } \\
\text { quality (related to food safety } \\
\text { competence) with high employee } \\
\text { turnover. Lack of or unclear } \\
\text { organizational structure }\end{array}$ & $\begin{array}{l}\text { Constrained e.g. Constrained } \\
\text { workforce quality with variable } \\
\text { workforce composition. Restricted } \\
\text { organizational structure }\end{array}$ & $\begin{array}{l}\text { Supportive e.g. High workforce } \\
\text { quality with low turnover and a } \\
\text { clear organizational structure }\end{array}$ \\
\hline $\begin{array}{l}{ }^{a} \text { Formal food } \\
\text { safety program }\end{array}$ & $\begin{array}{l}\text { Non-existent or if it exists is not } \\
\text { formally written, is unstructured, } \\
\text { and not verified or validated }\end{array}$ & $\begin{array}{l}\text { Improperly implemented. Based on } \\
\text { experience and in-house or general } \\
\text { knowledge, partially digital, updates } \\
\text { are ad hoc, restricted access, } \\
\text { verified/validated based on in-house } \\
\text { knowledge }\end{array}$ & $\begin{array}{l}\text { Properly implemented Science- } \\
\text { based, digital, decentralised, } \\
\text { always updated, verified based on } \\
\text { scientific sources and validated } \\
\text { based on rigorous analysis by } \\
\text { independent experts }\end{array}$ \\
\hline
\end{tabular}




\begin{tabular}{|c|c|c|c|}
\hline \multicolumn{4}{|l|}{ Vulnerability } \\
\hline $\begin{array}{l}\text { Product } \\
\text { characteristics }\end{array}$ & $\begin{array}{l}\text { High chance on chemical and } \\
\text { microbial contamination, and } \\
\text { growth or survival of pathogens }\end{array}$ & $\begin{array}{l}\text { Potential contamination and likely } \\
\text { chance for growth or survival of } \\
\text { pathogens }\end{array}$ & $\begin{array}{l}\text { Low chance of contamination and } \\
\text { growth or survival of pathogens }\end{array}$ \\
\hline $\begin{array}{l}\text { Process } \\
\text { characteristics }\end{array}$ & $\begin{array}{l}\text { Highly susceptible to cross } \\
\text { contamination }\end{array}$ & $\begin{array}{l}\text { Potentially susceptible to cross } \\
\text { contamination }\end{array}$ & $\begin{array}{l}\text { Unlikely to be susceptible to cross } \\
\text { contamination }\end{array}$ \\
\hline \multicolumn{4}{|c|}{ Enabling conditions } \\
\hline $\begin{array}{l}\text { Technological } \\
\text { and } \\
\text { organisational } \\
\text { conditions }\end{array}$ & $\begin{array}{l}\text { Reactive (lack of support/conditions } \\
\text { are not enabling) - acting only when } \\
\text { there is a situation that needs to be } \\
\text { controlled. Routine response to } \\
\text { inspection findings, problems/ } \\
\text { incidents. Control is mainly problem } \\
\text { driven. }\end{array}$ & $\begin{array}{l}\text { Active (restricted support/ conditions } \\
\text { are enabling only to a certain extent) - } \\
\text { systems are in place to manage the } \\
\text { likelihood of (cross) contamination } \\
\text { and to support food handlers' food } \\
\text { safety/hygiene control decisions }\end{array}$ & $\begin{array}{l}\text { Proactive (full support/ conditions } \\
\text { are enabling) - thinking and acting } \\
\text { in advance of anticipated problems. } \\
\text { Focus is on prevention of (cross) } \\
\text { contamination }\end{array}$ \\
\hline \multicolumn{4}{|c|}{\begin{tabular}{|l} 
Employee characteristics \\
\end{tabular}} \\
\hline Attitude & $\begin{array}{l}\text { Weak and negative attitude-negative } \\
\text { predisposition toward compliance } \\
\text { with food safety/hygiene } \\
\text { requirements. Employees have no } \\
\text { regard for food safety/hygiene issues } \\
\text { unless compelled to }\end{array}$ & $\begin{array}{l}\text { Ambivalent attitude- uncertain } \\
\text { predisposition to comply with food } \\
\text { safety/ hygiene requirements. } \\
\text { Employees perform adequately only } \\
\text { when circumstances are appropriate }\end{array}$ & $\begin{array}{l}\text { Strong and positive attitudes- } \\
\text { positive predisposition to comply } \\
\text { with food safety/hygiene } \\
\text { requirements under all } \\
\text { circumstances. Employees always } \\
\text { maintain adequate performance }\end{array}$ \\
\hline $\begin{array}{l}\text { a Risk } \\
\text { perceptions }\end{array}$ & $\begin{array}{l}\text { Inadequate - complete lack of } \\
\text { awareness in the risk posed on a } \\
\text { majority of food safety and hygiene } \\
\text { issues. }\end{array}$ & $\begin{array}{l}\text { Moderate - incomplete awareness on } \\
\text { the risk posed on some food safety } \\
\text { and hygiene. }\end{array}$ & $\begin{array}{l}\text { Good - ample awareness on the risk } \\
\text { posed on a majority of the food } \\
\text { safety and hygiene issues. }\end{array}$ \\
\hline $\begin{array}{l}\text { Food safety and } \\
\text { hygiene } \\
\text { perceptions }\end{array}$ & $\begin{array}{l}\text { Non-aligned- employee perceptions } \\
\text { incorrect and not aligned with the } \\
\text { company's food safety and hygiene } \\
\text { control requirements }\end{array}$ & $\begin{array}{l}\text { Partially aligned- employee } \\
\text { perceptions partially/incompletely } \\
\text { aligned with the company's food } \\
\text { safety and hygiene requirements }\end{array}$ & $\begin{array}{l}\text { Fully aligned- employees have } \\
\text { appropriate perceptions aligned } \\
\text { with the company's food safety and } \\
\text { hygiene control requirements }\end{array}$ \\
\hline $\begin{array}{l}{ }^{a} \text { Intended } \\
\text { behaviour }\end{array}$ & $\begin{array}{l}\text { High-risk due to high inclination to } \\
\text { engage in risky behaviour (i.e. not to } \\
\text { comply with food safety and } \\
\text { hygiene control practices } \geq 80 \% \text { of } \\
\text { the time). }\end{array}$ & $\begin{array}{l}\text { Moderate-risk due to moderate } \\
\text { inclination to engage in risky } \\
\text { behaviour (i.e. to incompletely } \\
\text { comply with food safety and hygiene } \\
\text { control practices } \geq 80 \% \text { of the time). }\end{array}$ & $\begin{array}{l}\text { Low-risk due to high inclination to } \\
\text { engage in non-risky behaviour (i.e. } \\
\text { to comply with food safety and } \\
\text { hygiene control practices } \geq 80 \% \text { of } \\
\text { the time). }\end{array}$ \\
\hline \multicolumn{4}{|c|}{ Actual Behaviour } \\
\hline $\begin{array}{l}\text { Actual food } \\
\text { safety and } \\
\text { hygiene control } \\
\text { behaviour }\end{array}$ & $\begin{array}{l}\text { High-risk due to noncompliance } \\
\text { with food safety and hygiene control } \\
\text { requirements. Food safety and } \\
\text { hygiene practices are not executed } \\
\geq 80 \% \text { of the time. Risk of cross- } \\
\text { contamination is highly likely to } \\
\text { occur. }\end{array}$ & $\begin{array}{l}\text { Moderate-risk due to partial } \\
\text { compliance with food safety and } \\
\text { hygiene control requirements. Food } \\
\text { safety and hygiene control practices } \\
\text { are executed wrongly/incompletely } \\
\geq 80 \% \text { of the time. Risk of cross- } \\
\text { contamination likely to occur. }\end{array}$ & $\begin{array}{l}\text { Low-risk due to full compliance } \\
\text { with food safety and hygiene } \\
\text { control requirements. Food safety } \\
\text { and hygiene control practices } \\
\text { correctly and completely executed } \\
\geq 80 \% \text { of the time. Risk of cross- } \\
\text { contamination highly unlikely. }\end{array}$ \\
\hline \multicolumn{4}{|c|}{ Food safety output } \\
\hline $\begin{array}{l}\text { Food safety } \\
\text { performance }\end{array}$ & $\begin{array}{l}\text { Poor food safety performance } \\
\text { (noncompliance/conformance) - } \\
\text { minimal criteria used for food safety } \\
\text { performance evaluation, and having } \\
\text { various food safety problems due to } \\
\text { different problems in the FSMS }\end{array}$ & $\begin{array}{l}\text { Moderate food safety performance } \\
\text { restricted compliance/conformance) - } \\
\text { several criteria used for food safety } \\
\text { performance evaluation and food } \\
\text { safety problems restricted to one type } \\
\text { of problem in the FSMS. }\end{array}$ & $\begin{array}{l}\text { Good food safety performance (full } \\
\text { compliance/conformance) - } \\
\text { systematic evaluation of food } \\
\text { safety performance using specific } \\
\text { criteria and having no food safety } \\
\text { problems. }\end{array}$ \\
\hline
\end{tabular}

${ }^{a}$ Extended from Luning et al. (2011a); Nyarugwe et al. (2018)

*For national values, typification is based on Hofstede et al. (2010)

Scores for technological and organisational enabling conditions, employees' food safety, hygiene and risk perceptions, attitudes, and intentions were used to gain insight into the overall prevailing FS-culture (Nyarugwe et al., 2018). Score 1 indicated low support and little or no regard towards the importance of food safety. Score 2 reflected an incomplete regard and restricted support and score 3 a high regard and complete support towards food safety. These scores reflected a reactive, active and proactive FS-culture, respectively. 


\section{Data analysis and statistical analysis}

Microsoft Office Excel was used to calculate the percentage non-conformance of food products to microbiological criteria and the percentage of microbiological and quality complaints (Nyarugwe et al., 2018) related to the food safety output (Figure 4.1). For national values, index scores were calculated from the five-point Likert scale based on Hofstede and Minkov (2013) and used to determine the predominant cultural dimensions in the country, as well as to give an indication of the external company environment. For the food safety governance approach, which was also used to give an indication of the external company environment, assigned scores of each of the three food safety authorities and eight QA managers were entered into IBM SPSS software version 25.0 (2017) and frequencies calculated for the two groups to check for alignment in responses between the QA managers and food safety authorities.

The assigned scores of each respondent for the nine companies were also entered into IBM SPSS software version 25.0. Frequencies and mode scores were calculated per company for the organisational and technological enabling conditions, and employee characteristics reflecting an organisation's prevailing FS-culture and for actual food handler behaviour, i.e. food safety and hygiene-related behaviour (Figure 4.1). The mode scores were used to designate the prevailing FS-culture and find possible associations between actual behaviour and the FS-culture variables using multiple linear regression, where findings were considered statistically significant if the p-value $<0.05$. The forward selection method was used (Alexopoulos, 2010).

\subsection{Results}

\subsubsection{Characteristics of the company environment}

\section{i. External company environment}

\section{National values}

Hundred and ninety food handlers completed the Hofstede questionnaire (VSM). Data (Table 4.3) indicated that Zimbabweans have a high (68.6) power distance (PD) depicting a culture where inequality exists. The low score on long-term orientation (18.3) shows a culture that focuses on prevailing issues in the short-term, and an intermediate score for uncertainty avoidance (57.2) was given as no clear preference was depicted. Additionally, low scores on individualism (38.7) and masculinity (8.3) dimensions shows that the Zimbabwean culture is typified by collectivism and femininity. 
Table 4.3: Scores for national values based on the value surveys module

\begin{tabular}{ll}
\hline Cultural Dimension & Score \\
\hline Power distance & 68.6 (high power distance) \\
Individualism & 38.7 (collectivism) \\
Masculinity & 8.3 (femininity) \\
Unceratinity Avoidance & 57.2 (intermediate) \\
Long-Term Orientation & 18.3 (short-term orientation \\
Indulgence vs restaint & 61.8 (indulgence) \\
\hline Based on 190 respondents & \\
Interpretations based on Hofstede et al. (2010) where a high score on power distance refers to high power distant cultures and \\
low score refers to low power distant cultures. Low scores on individualism, masculinity, uncertainty avoidance, long-term \\
orientation and indulgence refer to collectivist, feminine, low uncertainty avoidance, short-term oriented and restrained \\
cultures whereas high scores refer to individualistic, masculine, high uncertainty avoidance, long-term orientation and \\
indulgent cultures. Intermediate scores indicate no preference.
\end{tabular}

\section{Food safety governance approach}

Table 4.4 shows results for the food safety governance approach from the FSAs and QA managers' perspectives. Only on the specificity of food safety regulations and type of assessments did both FSAs and QA managers have aligned perspectives. Both perceived food safety regulations to be unsupportive (score 1) and type of assessments as either unsupportive or supportive (score 3). Both authorities and QA managers agreed that the legislation was written in general terms, leaving room for different interpretations. Interestingly, authorities indicated the status of food safety regulations as reactive, whilst companies perceived it to provide restricted support (score 2) except for M1, which was aligned with the authorities.

Overall, both described the food safety governance approach as fragmented, without clear structures of authority, and somewhat punitive with outdated and generic legislation. Moreover, legislation was only available upon request as mentioned by authorities:

"If you don't know that legislation or updates have been gazetted then you will be in the dark as legislation is upon request and at times you have to go and buy it”.

\section{ii. Internal company environment}

\section{Company characteristics}

Table 4.5 shows the data to typify the internal company environment. At least five companies produced for export, whilst the rest produced for local markets. Those producing for the export market mostly had implemented HACCP and/or private standards, but companies producing for the local market did not have a certified FSMS. Overall, there were no distinct differences between the low, medium, and high-risk companies regarding the other characteristics. The only difference was that most low and medium-risk companies (4/5) 
exported some of their products, whereas most high-risk companies (3/4) mainly produced for the local market.

Table 4.4: Frequency of scores for the food safety governance approach from the food safety authorities and QA managers perspective

\begin{tabular}{|c|c|c|c|c|c|c|c|}
\hline \multirow{2}{*}{$\begin{array}{l}\text { Characteristics } \\
\text { Score }\end{array}$} & \multicolumn{3}{|c|}{$\begin{array}{l}\text { Food safety } \\
\text { authorities } \\
(\mathrm{N}=3)\end{array}$} & \multicolumn{3}{|c|}{$\begin{array}{l}\text { QA } \\
\text { managers } \\
(\mathrm{N}=8)\end{array}$} & \multirow[t]{2}{*}{ Qualitative Data } \\
\hline & 1 & 2 & 3 & 1 & 2 & 3 & \\
\hline $\begin{array}{l}\text { Status of food } \\
\text { safety regulations }\end{array}$ & 3 & & & 2 & 6 & & $\begin{array}{l}\text { Food safety authorities unanimously agreed on food safety } \\
\text { regulations being out-of-date and unusable. Majority of } \\
\text { companies indicated regulations as relevant and useful to a } \\
\text { certain extent. Only M1, an international company was } \\
\text { aligned with the food safety authorities }\end{array}$ \\
\hline $\begin{array}{l}\text { Specificity of food safety } \\
\text { regulations }\end{array}$ & 2 & 1 & & 5 & 2 & 1 & $\begin{array}{l}2 / 3 \text { Food safety authorities emphasised that food safety } \\
\text { regulations are written in general terms and leave much room } \\
\text { for interpretation, and a majority of the QA managers } \\
\text { perceived so too. }\end{array}$ \\
\hline $\begin{array}{l}\text { Enforcement } \\
\text { practices }\end{array}$ & 3 & & & 4 & 4 & & $\begin{array}{l}\text { Food safety authorities unanimously stressed that they } \\
\text { penalized those who did not comply. Whilst some QA } \\
\text { managers agreed with the food safety authorities, others felt } \\
\text { that the food safety authorities provided assistance e.g. } \\
\text { reference standards, training. }\end{array}$ \\
\hline Type of assessments & 2 & & 1 & 4 & & 4 & $\begin{array}{l}\text { Inspections were done by two food safety authorities } \\
\text { However, the other also provides } 3^{\text {rd }} \text { party audits. Some QA } \\
\text { managers scored } 1 \text { or } 3 \text {, in alignment with food safety } \\
\text { authorities. }\end{array}$ \\
\hline
\end{tabular}

Scores 1, 2, 3 represent unsupportive, restricted support and supportive respectively. The food safety authorities were from 3 different institutions and the QA managers were from 8 different companies as 1 QA manager mentioned they did not know the answers.

\section{Formal food safety program}

Table 4.5 also shows results of the assessment of the formal food safety program. Only M1, an international company, scored 3 as they had a well-designed food safety program and were FSSC certified. Even though $\mathrm{H} 3$ and $\mathrm{H} 4$ produce high-risk products, they overall scored 1 as they did not have any formal food safety program. Only H1 scored 2 overall, with a score 2 for design, documentation and verification and score 1 for validation as it was not done. Also, L2 scored overall 2; they designed their FSMS based on ISO22000 but were not certified. The other companies overall scored 1_2, because of poor design, and/or lack of validation, limited verification and poor documentation. 
Table 4.5: Company characteristics, food safety program and vulnerability of food production system as assessed for the low, medium and high-risk food companies

\begin{tabular}{|c|c|c|c|c|c|c|c|c|c|}
\hline \multirow[b]{3}{*}{$\begin{array}{l}\text { Internal company } \\
\text { environment }\end{array}$} & \multicolumn{8}{|c|}{ Company } & \multirow[b]{3}{*}{ H4 } \\
\hline & \multirow[b]{2}{*}{ L1 } & \multicolumn{2}{|l|}{ Low-risk } & \multicolumn{2}{|l|}{ Medium-Risk } & \multicolumn{3}{|c|}{ High-risk } & \\
\hline & & $\mathbf{L 2}$ & $\mathbf{L 3}$ & M1 & M2 & H1 & H2 & $\mathbf{H 3}$ & \\
\hline \multicolumn{10}{|l|}{$\begin{array}{l}\text { Company } \\
\text { Characteristics } \\
\end{array}$} \\
\hline Product type & Baked & Baked & $\begin{array}{l}\text { Vegetab } \\
\text { les }\end{array}$ & $\begin{array}{l}\text { Juice, } \\
\text { cordials }\end{array}$ & Juice & Dairy & Dairy & $\begin{array}{l}\text { Meat, } \\
\text { Pastries }\end{array}$ & Dairy \\
\hline Company size ${ }^{a}$ & M & $\mathrm{L}$ & $\mathrm{S}$ & $\mathrm{L}$ & M & M & M & $\mathrm{S}$ & $\mathrm{S}$ \\
\hline Local or export products & Local & Export & Export & Export & Export & Export & Local & Local & Local \\
\hline FSMS implemented & None & $\begin{array}{l}\text { ISO } \\
22000, \\
\text { ISO/TS } \\
22002\end{array}$ & $\begin{array}{l}\text { Global } \\
\text { Gap }\end{array}$ & $\begin{array}{l}\text { FSSC 22000, } \\
\text { ISO 22002-4: } \\
2013\end{array}$ & НACCP & $\begin{array}{l}\text { ISO } \\
22000: 2005, \\
\text { ISO/TS } \\
22001: 2009\end{array}$ & HACCP & None & None \\
\hline FSMS certified & None & None & $\begin{array}{l}\text { Global } \\
\text { Gap }\end{array}$ & $\begin{array}{l}\text { FSSC } \\
22000: 2005\end{array}$ & None & $\begin{array}{l}\text { ISO } \\
22000: 2005\end{array}$ & None & None & None \\
\hline Type of ownership & Private & Private & Private & Private & Private & Private & Private & Private & Private \\
\hline Organisational structure $^{\mathrm{b}}$ & Central & Decentral & Central & Decentral & Central & Central & Central & Central & Central \\
\hline \multicolumn{10}{|l|}{ Food Safety Program } \\
\hline Design (sources) & 2 & 3 & & 3 & 2 & 2 & 1 & 1 & 1 \\
\hline Validation & 1 & 2 & & 3 & 2 & 1 & 2 & 1 & 1 \\
\hline $\begin{array}{l}\text { Formal documentation } \\
\text { (characteristics, updating, } \\
\text { accessibility) }\end{array}$ & 1 & 1 & & 3 & 1 & 2 & 1 & 1 & 1 \\
\hline Verification & 2 & 1 & & 3 & 1 & 2 & 2 & 1 & 1 \\
\hline Overall assigned score $^{c}$ & $1 \_2$ & 2 & $*$ & 3 & $1 \_2$ & 2 & $1 \_2$ & 1 & 1 \\
\hline \multicolumn{10}{|l|}{$\begin{array}{l}\text { Vulnerability of food } \\
\text { production system } \\
\text { Product characteristics }\end{array}$} \\
\hline Type of raw materials & 1 & 1 & 1 & 2 & 1 & 3 & 3 & 3 & 3 \\
\hline Raw material storage & 2 & 1 & 1 & 3 & 1 & 3 & 3 & 3 & 3 \\
\hline Product properties & 1 & 1 & 3 & 1 & 1 & 3 & 3 & 3 & 3 \\
\hline Product heat treatment & 2 & 1 & 1 & 2 & 2 & 3 & 2 & 2 & 3 \\
\hline Final product packaging & 1 & 2 & 1 & 2 & 2 & 2 & 2 & 2 & 2 \\
\hline $\begin{array}{l}\text { Overall score product } \\
\text { characteristics } \\
\text { Production } \\
\text { Characteristics }\end{array}$ & $1 \_2$ & 1 & $1 \_2$ & 2 & $1 \_2$ & 3 & $2 \_3$ & $2 \_3$ & 3 \\
\hline Intervention steps & 1 & 2 & 1 & 2 & 2 & 1 & 1 & 2 & 2 \\
\hline Process characteristics & 1 & 3 & 3 & 1 & 3 & 1 & 1 & 3 & 2 \\
\hline Process design & 1 & 3 & 1 & 2 & 1 & 3 & 2 & 2 & 2 \\
\hline $\begin{array}{l}\text { Overall score production } \\
\text { characteristics }\end{array}$ & 1 & $2 \_3$ & $1 \_2$ & $1 \_2$ & 2 & $1 \_2$ & $1 \_2$ & $2 \_3$ & 2 \\
\hline Overall assigned score & 1 & 1_2 & 1_2 & 2 & 1_2 & $2 \_3$ & $2 \_3$ & $2 \_3$ & $2 \_3$ \\
\hline
\end{tabular}

${ }^{\text {a }} \mathrm{S}, \mathrm{M}, \mathrm{L}$ refers to Small, Medium or Large companies

${ }^{\mathrm{b}}$ Central refers to centralised and Decentral to decentralised

${ }^{\mathrm{c}}$ Assigned Scores based on Luning et al. (2011a) and Sampers et al. (2012), If the mean score was between 1 and 1.2 then assigned score 1, between 1.3 and 1.7 (assigned score 1_2), between 1.8 and 2.2 (2), between 2.3 and 2.7 (2 3), and between 2.8 and 3.0 (3). Scores 1, 2, 3 for the food safety program respectively represent unsupportive, restricted support, supportive. For vulnerability of the food production system, scores 1, 2 and 3 respectively refer to high, potential and unlikely susceptibility to contamination.

* not evaluated as person responsible was not available. 


\section{Vulnerability of food production system}

Assigned scores (Table 4.5) to determine the vulnerability of the food production system overall confirmed that L1, L2 and L3, were low-risk, M1, M2 were medium-risk, and H1, H2, H3 and H4 were high-risk companies. However, even though companies produced similar products with similar riskiness, companies sometimes differed in the specific product and production characteristics, which means they actually differed in vulnerability. For example, L1, L2 and L3 differed in raw material storage requirements and degree of automation.

\subsubsection{Food safety output}

Table 4.6 shows that better performing companies (H2, M1, M2 and L1) had a moderate (score 2) to good (score 3) food safety performance. Companies H3, H4, and L1, L2, L3 did not perform any food safety (microbial or chemical) analysis, even though H3 and H4 produced high-risk products. All these companies, except for L2, did not have a complaints system in place, questioning how they control the food safety performance of their products. Companies $\mathrm{H} 1$ and $\mathrm{H} 2$, producing similar high-risk products, performed similarly, with the exception of the complaints system, which was absent in H2. Results from the analysis of the microbial data and customer complaints were mostly consistent with the food safety performance level as indicated by the QA manager using the FS-output questionnaire (Table 4.6). However, the QA managers in $\mathrm{H} 4, \mathrm{H} 3$, and $\mathrm{L} 1$ assigned higher scores for the performance of their system, which was not corroborated by the actual data on food safety and hygiene performance in their documents.

\subsubsection{Prevailing FS-culture}

\section{i. Enabling conditions}

Figure 4.2 shows scores for the organisational and technological conditions used in assessing the prevailing FS-culture based on card-aided interviews with the food handlers. H1, M1, and L1 predominantly scored 3 for most of the technological and organisational conditions, signifying that these companies, which differ in product riskiness, were all supportive to food safety and hygiene. H2, H3, M2, and L2, also differing in product riskiness, predominantly scored 2, indicating restricted support, whereas H4 and L3 mostly scored 1, demonstrating lack of support. Of interest was that most companies, regardless of their level of product riskiness, scored 3 for the communication system and adequacy of time (both organisational conditions), as they had good communication systems and had sufficient time for food safety and hygiene activities. However, some food handlers raised concerns, e.g. in H3, a food 
handler said: "Sometimes there isn't enough time as the demand will be so high. It will be "hurry, hurry" as orders will be supposed to be dispatched..., ... We then have insufficient time for hygiene tasks but sometimes it is sufficient when we have less orders".

Table 4.6: Assigned scores for food safety output

\begin{tabular}{|c|c|c|c|c|c|c|c|c|c|}
\hline \multirow[b]{3}{*}{ Characteristics } & \multicolumn{8}{|c|}{ Company } & \\
\hline & \multicolumn{3}{|c|}{ Low-risk } & \multicolumn{2}{|c|}{ Medium-Risk } & \multicolumn{4}{|c|}{ High-risk } \\
\hline & L1 & $\mathbf{L 2}$ & $\mathbf{L 3}$ & M1 & M2 & H1 & $\mathbf{H 2}$ & $\mathbf{H 3}$ & H4 \\
\hline \multicolumn{10}{|l|}{ Food Safety Performance Indicators } \\
\hline \multicolumn{10}{|l|}{ External food safety performance indicators } \\
\hline FSMS evaluation & 2 & & & 3 & 1 & 2 & 2 & 1 & 2 \\
\hline Seriousness of remarks of FSMS evaluation & 3 & & & 2 & 1 & 1 & 1 & & 1 \\
\hline Customer complaints-microbial & 3 & 3 & & 2 & 3 & 2 & 2 & 2 & 3 \\
\hline Customer complaints- hygiene & 2 & 1 & & 3 & 3 & 1 & 3 & 3 & 3 \\
\hline \multicolumn{10}{|l|}{ Internal food safety performance indicators } \\
\hline Product sampling & 2 & 1 & & 3 & 3 & 3 & 3 & 3 & 2 \\
\hline Judgement criteria & 3 & 1 & & 3 & 3 & 3 & 3 & 1 & 2 \\
\hline Hygiene and pathogen non-conformities & 3 & 1 & & 1 & 2 & 1 & 2 & 1 & 1 \\
\hline Overall assigned score ${ }^{\text {ab }}$ & 2_3 & 1 & * & 2_3 & 2_3 & 2 & 2_3 & 1_2 & 2 \\
\hline \multicolumn{10}{|l|}{ Actual food safety and hygiene performance } \\
\hline Microbial Analysis -Yeasts and Moulds ${ }^{\mathrm{cd}}$ & $\mathrm{X}$ & $\mathrm{X}$ & $\mathrm{X}$ & 100 & $86-100$ & $59-61$ & $61-63$ & $\mathrm{X}$ & $\mathrm{X}$ \\
\hline Microbial Analysis - Coliforms ${ }^{\text {cd }}$ & $\mathrm{X}$ & $\mathrm{X}$ & $\mathrm{X}$ & 100 & $10-86$ & $87-97$ & $88-95$ & $\mathrm{X}$ & $\mathrm{X}$ \\
\hline Quality complaints ${ }^{\mathrm{ce}}$ & $X$ & 100 & $\mathrm{X}$ & 71 & 100 & 34 & $X$ & $X$ & $\mathrm{X}$ \\
\hline Microbial safety complaints ${ }^{\mathrm{ce}}$ & $\mathrm{X}$ & 0 & $\mathrm{X}$ & 29 & 0 & 66 & $\mathrm{X}$ & $\mathrm{X}$ & $\mathrm{X}$ \\
\hline
\end{tabular}

${ }^{\mathrm{a} A s s i g n e d ~ S c o r e s,}{ }^{\mathrm{b}}$ If the mean score was between 1 and 1.2 then assigned score 1 , between 1.3 and 1.7 (assigned score 1_2), between 1.8 and 2.2 (2), between 2.3 and 2.7 (2_3), and between 2.8 and 3.0 (3) (Jacxsens et al., 2010 ), ${ }^{\mathrm{c}}$ Document analysis, ${ }^{\mathrm{d}} \%$ product conformance to microbial requirements, ${ }^{\mathrm{e}} \%$ complaints related to quality or microbial safety, * not evaluated as person responsible was not available. X-not done at the company. Score $1=$ poor, 2 moderate, 3 good.

Regarding the training program, food handlers in most high-risk companies perceived training to be generic (score 1), whereas in most low and moderate-risk companies these scored 2 and 3. For the technological conditions, handwashing facilities mostly scored 3, as food handlers perceived them to be enabling in all the companies. In contrast, food handlers in most highrisk companies $(\mathrm{H} 2, \mathrm{H} 3, \mathrm{H} 4)$ regarded the protective clothing to be inadequate (score 1), whereas food handlers in most low and moderate-risk companies regarded protective clothing to be adequate (score 3) except for L1, which scored 1. The low score (1) was attributed to the lack of additional protective clothing such as face masks, gloves, and cold-room suits required in the high-risk companies. Food handlers stated: "Protective clothing is not adequate, we have one set only..., There is no protective clothing, we use our own..., What we have is torn" 


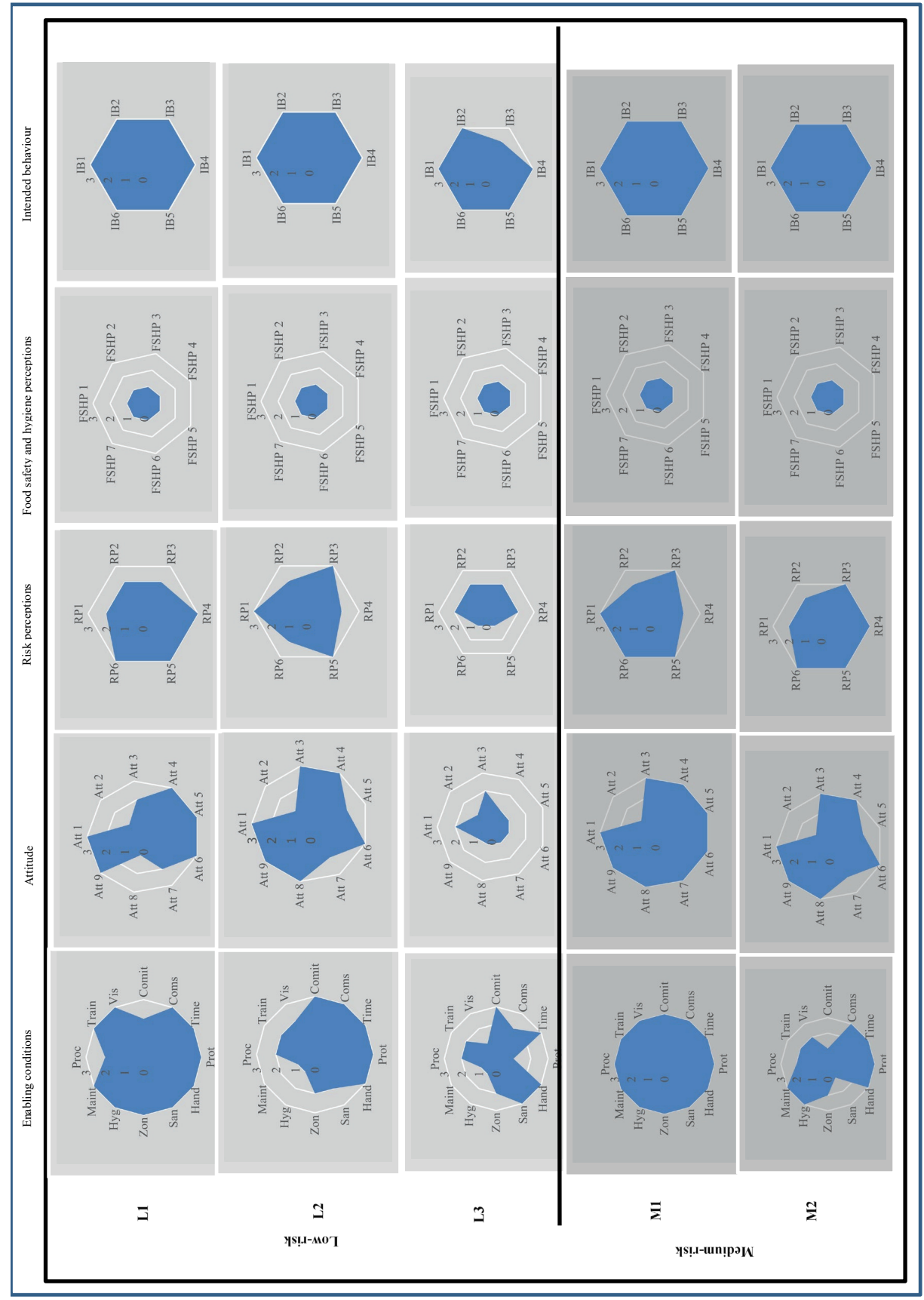



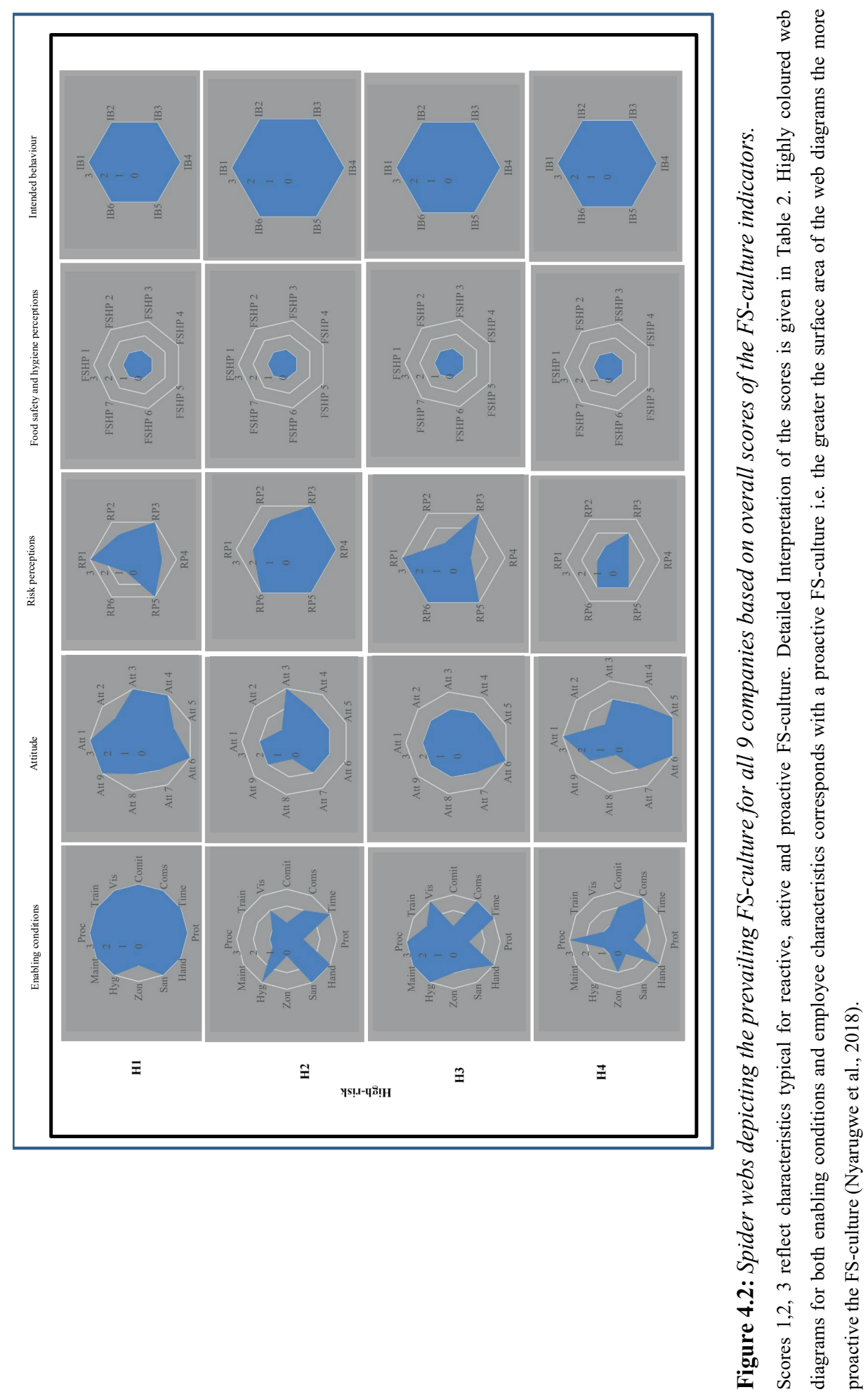
Food handlers in most low-risk companies (L2, L3) perceived equipment to be not hygienically designed (score 1) and equipment maintenance to be generally breakdown related (score 1). Food handlers in $\mathrm{H} 2, \mathrm{H} 4$ also mentioned breakdown maintenance to be prominent as illustrated in the text below:

"They fix machines when told..., If a machine does not have a problem, it is not fixed/serviced"

\section{ii. Employee characteristics}

\section{Attitude}

Figure 4.2 also presents results of the assessment of employee attitudes. Food handlers in L2, M1, and M2 predominantly scored 3, signifying strong and positive attitudes towards the food safety and hygiene tasks. Most food handlers in $\mathrm{H} 1$ and $\mathrm{L} 1$ also had positive attitudes, although some showed ambivalence (score 2), indicating an uncertain predisposition to comply with food safety and hygiene requirements. For H2 and H3, food handlers had ambivalent attitudes, and in L3 they even had a negative attitude (score 1), reflected in the lack of regard for food safety/hygiene issues unless compelled to.

With respect to handwashing requirements, food handlers in most companies (7/9) had negative attitudes (score 1), except in $\mathrm{H} 1$ and $\mathrm{H} 3$ were food handlers demonstrated ambivalent attitudes. Of concern was the attitude towards cleaning and sanitation of food handlers in all high-risk companies, L1 and L3 as these were mostly ambivalent.

\section{Risk perceptions}

Figure 4.2 shows the results of the risk perception assessment. Food handlers in 2 out of 4 high-risk companies $(\mathrm{H} 2, \mathrm{H} 3)$ revealed appropriate risk-perceptions (score 3), signifying that they were sufficiently aware of the risks posed on consumers by food safety and hygiene issues. Results also show that food handlers in both medium-risk companies predominantly scored 3. On the contrary, H1, H4 and all low risk companies predominantly scored 1 and 2, which reflects that their food handlers lack or have an inadequate perception of the food safety and hygiene risks.

With respect to the perceptions towards their safety and hygiene tasks, food handlers in all companies consistently scored 2 for risk perceptions regarding working while wearing jewellery. Moreover, in most companies (7/9), (except L3 and H4), food handlers revealed 
ample awareness (score 3) of the risks of microbial contamination when appropriate corrective actions were not followed. Likewise, food handlers in high and medium-risk companies demonstrated ample awareness (score 3) of the risks associated with inadequately sanitizing equipment when compared to L1, L3 and H4 (score 2), which demonstrated inadequate awareness.

\section{Food safety and hygiene perceptions}

Results in Figure 4.2 show a mode score of 1 on food safety and hygiene perceptions for all companies. This indicates that food handlers in all companies had incorrect food safety and hygiene perceptions, which were not aligned with company requirements.

\section{Intended behaviour}

Food handlers in all companies predominantly scored 3 on intended behaviour (Figure 4.2). This implies that food handlers were strongly inclined not to engage in risky behaviour. An exception was L3, where food handlers were moderately inclined to engage in risky behaviour regarding the control of crucial parameters (score 2).

\subsubsection{Actual behaviour}

Table 4.7 shows mode scores for actual food handler behaviour. Food handlers in H1, M1, and L1 correctly executed all personal hygiene, sanitation, and crucial process control requirements (score 3). However, results indicate that food handlers in all other high-risk companies $(\mathrm{H} 2, \mathrm{H} 3, \mathrm{H} 4)$ did not follow multiple personal hygiene requirements (score 1). Likewise, food handlers in L2 and M2 did not execute multiple personal hygiene requirements (score 1), and food handlers in L2 performed all sanitation activities inadequately (score 2); two companies, H4 and M2, had a cleaning department and dedicated cleaning staff and these practices were not observed as the study was restricted to food handlers in direct contact with food. 
Table 4.7: Mode scores for actual execution of personal hygiene behaviour, sanitation activities and control of process parameters

\begin{tabular}{|c|c|c|c|c|c|c|c|c|}
\hline \multirow[b]{3}{*}{ Observed behaviour } & \multicolumn{7}{|c|}{ Company } & \\
\hline & \multicolumn{2}{|c|}{ Low-risk } & \multicolumn{2}{|c|}{$\begin{array}{l}\text { Medium- } \\
\text { Risk }\end{array}$} & \multicolumn{4}{|c|}{ High-risk } \\
\hline & $\begin{array}{l}\text { L1 } \\
{ }^{\mathbf{c}} \mathbf{N}= \\
\mathbf{1 0}\end{array}$ & $\begin{array}{l}\text { L2 } \\
\mathbf{N}= \\
27\end{array}$ & $\begin{array}{l}\text { M1 } \\
\mathrm{N}= \\
23\end{array}$ & $\begin{array}{l}\text { M2 } \\
\mathbf{N}= \\
\mathbf{9}\end{array}$ & $\begin{array}{l}\mathrm{H1} \\
\mathrm{N}= \\
10\end{array}$ & $\begin{array}{l}\mathrm{H} 2 \\
\mathrm{~N}= \\
16\end{array}$ & $\begin{array}{l}\mathrm{H3} \\
\mathrm{N}= \\
\mathbf{1 0}\end{array}$ & $\begin{array}{l}\mathrm{H4} \\
\mathrm{N}= \\
10\end{array}$ \\
\hline \multicolumn{9}{|l|}{ Actual Behaviour } \\
\hline $\begin{array}{l}\text { Actual execution of personal hygiene behaviour } \\
\text { - Maintenance of high degree of personal cleanliness } \\
\text { - Hand washing practices }\end{array}$ & $\begin{array}{l}3 \\
3\end{array}$ & $\begin{array}{l}3 \\
2\end{array}$ & $\begin{array}{l}3 \\
3\end{array}$ & $\begin{array}{l}3 \\
1\end{array}$ & $\begin{array}{l}3 \\
3\end{array}$ & $\begin{array}{l}3 \\
1\end{array}$ & $\begin{array}{l}3 \\
2\end{array}$ & $\begin{array}{l}3 \\
1\end{array}$ \\
\hline - Hand washing steps & 3 & 1 & 3 & 1 & 3 & 1 & 1 & 1 \\
\hline - Personal habits & 3 & 1 & 3 & 1 & 3 & 1 & 1 & 1 \\
\hline Overall score personal hygiene practices & 3 & 1 & 3 & 1 & 3 & 1 & 1 & 1 \\
\hline \multicolumn{9}{|l|}{ Actual execution of sanitation activities } \\
\hline - Following procedures for cleaning and disinfection & 3 & 2 & 3 & * & 3 & 3 & 2 & * \\
\hline - Correct cleaning compounds used & 3 & 2 & 3 & & 3 & 3 & 2 & \\
\hline - Correct cleaning tools used & 3 & 2 & 3 & & 3 & 3 & 2 & \\
\hline $\begin{array}{l}\text { - Sanitation activities and/or efficacy monitored with microbiological } \\
\text { sampling }\end{array}$ & 3 & 2 & 3 & & 3 & 3 & 2 & \\
\hline Overall score sanitation activities & 3 & 2 & 3 & & 3 & 3 & 2 & \\
\hline \multicolumn{9}{|l|}{ Actual control of process parameters } \\
\hline $\begin{array}{l}\text { - Appropriateness of monitoring time-temperature parameters during } \\
\text { processing }\end{array}$ & 3 & 3 & 3 & 3 & 3 & 3 & a & 3 \\
\hline $\begin{array}{l}\text { - Corrective actions taken when time-temperature parameters deviate } \\
\text { from required levels }\end{array}$ & 3 & 3 & 3 & 2 & 3 & 3 & 2 & 2 \\
\hline Overall score control of process parameters & 3 & 3 & 3 & 2 & 3 & 3 & 2 & 2 \\
\hline
\end{tabular}

${ }^{a}$ Monitoring done by QC and not food handlers, *These were designated cleaners from the company's own cleaning department who were not part of food handlers, ${ }^{\mathrm{c}} \mathrm{N}$ is for observed food handlers. Score $1=$ non-compliance, $2=$ partial compliance, and 3 = full compliance.

\subsubsection{Statistical analysis}

Multiple linear regression (Table 4.8) shows which FS-culture variables significantly $(\mathrm{p}<$ 0.05 ) contributed to actual food handler behaviour and statistical associations. Training, time, protective clothing, sanitation, handwashing perceptions, attitude on control of crucial parameters, and intended corrective action behaviour explained $61 \%$ (adjusted $\mathrm{R}^{2}=0.607$ ) of the variation of the actual personal hygiene behaviour. With actual sanitation behaviour as the dependent variable, time, sanitation, protective clothing, hygiene design, risk perceptions (on handwashing and corrective actions), perceptions on sanitation efficacy and intended personal hygiene behaviour explained $51.4 \%$ of the variance. Commitment, sanitation practices, maintenance, protective clothing, perceptions on handwashing and execution of corrective actions, and intended behaviour towards corrective actions for sanitation explained $43 \%$ (adjusted $\mathrm{R}^{2}=0.430$ ) of the variation for actual control of crucial process parameters 
Table 4.8: Possible determinants of actual personal hygiene, sanitation and control of crucial process parameters.

\begin{tabular}{|c|c|c|c|c|c|c|}
\hline \multirow[b]{2}{*}{ Characteristics } & \multicolumn{2}{|c|}{ Personal hygiene } & \multicolumn{2}{|c|}{ Sanitation activities } & \multicolumn{2}{|c|}{$\begin{array}{c}\text { Control of Crucial } \\
\text { Parameters }\end{array}$} \\
\hline & $\begin{array}{c}\text { Standardised } \\
\text { Coefficients } \\
\text { Beta, } \beta \\
\end{array}$ & $\begin{array}{l}\text { Significance } \\
(\mathrm{p}<0.05)\end{array}$ & $\begin{array}{c}\text { Standardised } \\
\text { Coefficients } \\
\text { Beta, } \beta \\
\end{array}$ & $\begin{array}{l}\text { Significance } \\
(\mathbf{p}<0.05)\end{array}$ & $\begin{array}{c}\text { Standardised } \\
\text { Coefficients } \\
\text { Beta, } \beta \\
\end{array}$ & $\begin{array}{c}\text { Significance } \\
(\mathbf{p}<0.05)\end{array}$ \\
\hline \multicolumn{7}{|c|}{$\begin{array}{l}\text { Organisational and Technological } \\
\text { enabling conditions }\end{array}$} \\
\hline Training & 0.375 & 0.00 & - & - & - & - \\
\hline Commitment & - & - & - & - & 0.224 & 0.03 \\
\hline Time & -0.354 & 0.00 & -0.282 & 0.01 & - & - \\
\hline Protective clothing & 0.410 & 0.00 & 0.455 & 0.00 & 0.232 & 0.03 \\
\hline Sanitation & 0.301 & 0.00 & 0.263 & 0.04 & 0.353 & 0.00 \\
\hline Hygiene design & - & - & 0.214 & 0.018 & & - \\
\hline Maintenance & & & & & -4.94 & 0.00 \\
\hline Employee Characteristics & & & & & & \\
\hline $\begin{array}{l}\text { Attitude on corrective actions } \\
\text { on crucial parameters }\end{array}$ & 0.206 & 0.02 & - & - & - & - \\
\hline $\begin{array}{l}\text { Risk perception on } \\
\text { handwashing }\end{array}$ & - & - & -0.359 & 0.00 & - & - \\
\hline $\begin{array}{l}\text { Risk perceptions on } \\
\text { corrective actions for crucial } \\
\text { parameters }\end{array}$ & - & - & 0.279 & 0.03 & - & - \\
\hline $\begin{array}{l}\text { Perceptions on handwashing } \\
\text { procedure }\end{array}$ & 0.280 & 0.00 & - & - & 0.189 & 0.022 \\
\hline $\begin{array}{l}\text { Perceptions on corrective } \\
\text { actions for crucial parameters }\end{array}$ & - & - & - & - & 0.197 & 0.013 \\
\hline $\begin{array}{l}\text { Perceptions on sanitation } \\
\text { efficacy checks }\end{array}$ & - & - & 0.201 & 0.013 & - & - \\
\hline $\begin{array}{l}\text { Intended personal hygiene } \\
\text { behaviour }\end{array}$ & - & - & -0.437 & 0.00 & - & - \\
\hline $\begin{array}{l}\text { Intended correction action } \\
\text { behaviour }\end{array}$ & 0.201 & 0.02 & - & - & - & - \\
\hline $\begin{array}{l}\text { Intended corrective actions on } \\
\text { sanitation requirements }\end{array}$ & - & - & - & - & -0.227 & 0.02 \\
\hline
\end{tabular}

Only significant determinants are indicated in this table. Adjusted $\mathrm{R}^{2}$ values were $0.607,0.514$, and 0.430 for possible determinants of personal hygiene behaviour, sanitation activities and control of crucial parameters respectively

\subsection{Discussion}

\subsubsection{Prevailing food safety culture as related to product riskiness}

This study investigated whether companies differing in product riskiness (low, medium and high) exhibit differences in their prevailing FS-culture, assuming that high-risk companies are more likely to have a proactive FS-culture. However, our results indicated that companies exhibited different FS-cultures, regardless of product riskiness. More specifically, our findings showed that for high-risk companies, only $\mathrm{H} 1$ reflected a proactive FS-culture. On the contrary, $\mathrm{H} 2$ and $\mathrm{H} 3$ showed an active, and $\mathrm{H} 4$ a reactive prevailing FS-culture (Figure 4.2). Concerning medium-risk companies, M1 revealed a proactive FS-culture as food handlers highly regarded food safety and hygiene issues, whereas M2 exhibited an active FSculture as enabling conditions were not always supportive. With respect to the low-risk 
companies, L1 showed a proactive FS-culture as the company and food handlers highly prioritised food safety and hygiene (predominantly score 3), whereas L2 and L3, respectively, depicted an active and a reactive FS-culture as scores implied restricted (score 2) or low (score 1) support for food safety. These findings are corroborated by De Boeck et al. (2018a), who did not find a significant correlation between food safety climate and food sector (i.e. foods of animal and non-animal origin), although they did not specify product riskiness.

Our data for companies operating in a transition economy indicate that the prevailing FSculture cannot be attributed to product riskiness alone. This could be because in a transition economy, companies inevitably operate in a constantly changing external environment. Other variables explored in this study could have moderated the relationship between product riskiness and FS-culture, which will be further discussed.

\subsubsection{Common characteristics in the prevailing FS-culture of participating companies}

The nine companies showed several similarities in the assessed FS-culture elements. The most obvious similarities were related to the food safety and hygiene perceptions (Figure 4.2), which were incorrect (score 1) and not aligned with company specifications. It could be because some companies (H3, H4 and L1) had no written procedures for personal hygiene. For example, $\mathrm{H} 4$ did not have food safety programs or specific personal hygiene and sanitation procedures. Moreover, H3, H4, L1, L2, and L3 did not perform hygiene checks (Table 4.6), which could also explain the incorrect perceptions. Regardless of incorrect perceptions, food handlers in all companies were strongly inclined not to engage in risky behaviour (Figure 4.2) as all companies predominantly scored 3. Food handlers who highly perceive their organisation to be supportive to food safety, are more inclined to execute work tasks as required (Griffith et al., 2010a), which was not the case in this study. Even though food handlers were inclined to execute work tasks as required, only food handlers in companies H1, M1 and L1, which had a proactive FS-culture, actually executed work tasks as required as compliance behaviour predominantly scored 3 (Table 4.7).

Regarding the enabling conditions, we also found similarities among the companies. Food handlers in most companies (7/9) perceived the food safety communication system as supportive (score 3) (Figure 4.2). Communication is crucial for organisational effectiveness as it enhances understanding of food safety information (De Boeck et al., 2015; Griffith et al., 2010a; Griffith et al., 2017). However, food handlers mentioned that there were no checks to 
verify whether the information was understood. Griffith et al. (2017) found checks and assessments necessary to ensure effectiveness of communication, which could explain the inadequacies in observed tasks. Food handlers also perceived time as sufficient as companies maintained a good balance between production, and food safety and hygiene activities (Figure 4.2). Time is a crucial factor to consider in assuring FS-culture. Findings by Fatimah et al. (2014a) stressed that time affects compliance to food safety practices. Handwashing facilities were also considered to be adequate and food handlers were satisfied with them (Figure 4.2). On the contrary, most food handlers had incorrect handwashing perceptions and incorrectly washed their hands in actual practice (Table 4.7), which could be caused by inadequate training and or ambivalent attitudes (Figure 4.2). Statistical analysis proved $(\mathrm{p}<0.05)$ handwashing perceptions to be a determinant of actual hygiene behaviour.

\subsubsection{Prevailing FS-culture and food safety output}

Some associations between the prevailing FS-culture and food safety and hygiene performance were observed. For M1, we found that the positive FS-culture was associated with a good food safety performance. Also, the reactive FS-culture in H3 and L3 was consistent with the poor food safety performance in these companies. Both De Boeck et al. (2016) and Nyarugwe et al. (2018) reported that companies with a positive FS-culture and a well-elaborated FSMS had a better microbiological safety performance. However, in other companies the prevailing FS-culture was not necessarily reflected in the food safety performance, e.g. H4 had a reactive FS-culture (Figure 4.1) and a moderate food safety performance (Table 4.6), L2 with an active FS-culture showed a poor food safety performance, and $\mathrm{H} 1$ with a proactive FS-culture had a moderate food safety performance. Findings are consistent with Nyarugwe et al. (2018), who also found that the prevailing FSculture in some companies was not associated with food safety performance due to, e.g. extent of supportiveness of the company to food handlers when executing their tasks, i.e. whether the organisational and technological conditions enabled or hindered food handlers to appropriately execute their food safety tasks. In addition, the attitudes of the food handlers, alignment in perceptions of the food handlers, absence/presence of complaint systems and microbial analysis, and product sampling were also found to have influenced this association. M1 was the only international company and showed a proactive FS-culture. This finding is corroborated by our previous study (Nyarugwe et al., 2018), where a subsidiary of a multinational company also had a proactive FS-culture and performed better than companies operating within country boundaries. We therefore suggest to compare local versus 
multinational companies as a determining factor. Our reasoning is that although these multinationals adapt to the organisation's national culture, they tend to keep the national culture of the headquarters as a frame of reference (Ghemawat \& Reiche, 2011; Hofstede et al., 2010).

\subsubsection{Internal company characteristics}

\section{Prevailing FS-culture in view of companies' food safety program}

Nowadays, companies are expected to have a food safety program in place to show their measures to manage food safety issues. In our study, most companies (6/9) did not have an established certified system. The majority implemented some form of food safety program, but most were evaluated as low to moderate because of inadequacies or constraints in design, validation, verification and or documentation (Table 4.5). Surprisingly, some exporting companies also did not have a sufficient program, and if they had one, they did not meet microbial specifications or check for food safety and hygiene performance, which is a prerequisite in FSMS (Table 4.6). This questions the utility of audits and inspections, as in the past, companies with certified FSMS have recorded inconsistences in microbial safety and reported food safety outbreaks (Powell et al., 2013). Moreover, De Boeck et al. (2015) found that having a FSMS is no guarantee of a good FS-culture and food safety performance.

Furthermore, we observed that large companies (M1, L2) implemented ISO22000/ FSSC22000 and that the exporting companies (H1, M1, M2, L2, L3) had some form of implemented or certified food safety program (Table 4.6). This could have prompted companies to depend on their programs to mitigate food safety issues. Moreover, we found that low-risk companies did not check for food safety performance (Table 4.6). This leads us to postulate that the large, exporting and low-risk companies could have been complacent, which might explain why we did not find differences in the prevailing FS-culture between the companies. The Consumer Goods Forum (CGF) ( 2011) indicated that complacent companies are often not rigorous, as they believe in their systems. This could negatively impact the prevailing FS-culture.

\section{Prevailing FS-culture in relation with food production system vulnerability}

In our study, companies with products belonging to the same risk category (low, medium, high) differed in the degree of vulnerability of their food production system (Table 4.5). Thus, companies within the same risk category were not homogeneous, which could have 
contributed to the absence of distinct differences between the prevailing FS-culture and product riskiness. For example, even though M1 and M2 both produced medium-risk products, M1 applied stricter storage conditions for raw materials and the process was fully automated, whereas M2 had too much product handling. The companies also differed in their actual production characteristics as M1 produced cordials and fruit juices made from concentrates, and M2 produced fruit juices and concentrates made from fresh fruit. Sawe et al. (2014) found that the actual product and production characteristics of companies processing similar products, i.e. fresh produce, differed due to differences in product variety, initial raw materials, final product composition, process conditions and intervention strategies. These differences prompted companies to adopt dissimilar processing conditions to suit their production circumstances. Companies in the same product riskiness category could have therefore addressed food safety concerns differently to match their production circumstances, thus attributing to differences in the prevailing FS-culture amongst the companies.

Furthermore, we found in our study that companies with less vulnerable production systems do not necessarily have a reactive FS-culture as companies differing in the degree of vulnerability of the food production system differed in the prevailing FS-culture. For example, L1 had the least vulnerable production system but had a proactive FS-culture (Table 4.5, Figure 4.2). L2, L3 and M2 also showed less vulnerable production systems and exhibited an active, reactive and active FS-culture, respectively. A reactive situation is unwanted for all levels of system vulnerability because it implies that action is only taken when there is a situation that needs to be controlled, i.e. corrective actions are only done when a problem has already occurred as also defined by Wright et al. (2012).

\section{Prevailing FS-culture in relation with other company characteristics}

Regarding other company characteristics, we observed that most companies (6/9) employed contract workers (Table 4.1). This could cause a high employee turnover, which is characteristic for a high-risk organisation situation (Luning et al., 2011b). The importance of a stable workforce composition for proper execution of food safety and hygiene has been stated before (Bas et al., 2007; Walker et al., 2003). Contract workers, except in M1, were considered to be temporarily affiliated with the companies. The companies sometimes did not invest in their training, incentives, and protective clothing, which could have also influenced food handler perceptions on the prioritization of food safety and hygiene in the companies. Findings were corroborated by regression analysis where training, commitment and protective 
clothing were found to be predictors $(\mathrm{p}<0.05)$ of food handler behaviour. Subcultures could have been created as employees might have felt segregated because of the unequal treatment. Furthermore, during interviews it became clear that support functions of engineering and accounting were often highlighted as bottlenecks to food safety progression evidenced by the following statements:

"When we request for example hand towels, or new sinks, finance always gives us a hard time..., Machine spares are not being bought...", “When machines are broken down, they can go 24 hours without running..., When we request something to be fixed, they are not active, unless there is complete breakdown".

Based on our findings, both employee segregation and departmentalisation could have created subcultures. According to Cooper (2000), subcultures form around or emerge from functional roles/groups and hierarchical levels. Moreover, subcultures have been observed to oppose, support or interact with the prevailing FS-culture by either constraining or enabling it (Manning, 2017).

\subsubsection{External company characteristics}

Food safety governance

Manning (2017) mentioned that an organisation's FS-culture is not isolated as it is interlinked with the external company environment. In our study, we observed that the Zimbabwean legislation and enforcement practices were inadequate (Table 4.4), which was reflected in how some companies (H4, H3 and L1) operated without a food safety program and did not check for compliance to food safety and hygiene requirements (Table 4.5). Moreover, for all companies except for M1, the food safety programs were inadequately designed and implemented due to inadequate support from the FSAs, evidenced by the out-of-date, unusable legislation, which was also written in general terms, i.e. non-specificity, thus leaving room for different interpretations by the companies (Table 4.4). FSAs also indicated that they did not provide assistance to companies in cases of non-conformance as they lacked the resources to do so and QA managers stated that inspections were not regularly done. The nonspecificity of the regulations and inconsistencies in assessments could explain why some companies did not check for food safety performance. Findings are consistent with Pswarayi et al. (2014) and Macheka et al. (2013) who found inconsistencies in inspection services, with some companies going two years without inspection, food monitoring, and information or 
training by food safety authorities. Pswarayi et al. (2014) also found that the country lacked the required resources to properly monitor food safety performance.

Non-alignment of authorities and companies in food safety governance shows the inadequacy to support companies to practice and prioritise food safety. This probably contributed to differences in how companies managed food safety issues and could probably explain the prevailing FS-culture in the companies. For example, lack of adequate enforcement could have resulted in inadequate food safety and hygiene training, inadequate protective clothing that was sometimes unfit-for-purpose (e.g. torn), and equipment, which was inadequately designed for hygienic purposes (e.g. L2, L3) and poorly maintained (e.g. H2, H4).

Nayak and Waterson (2016), and Powell et al. (2011) highlighted that complacency could also emanate from the attitude at regulatory level, i.e. food safety authorities, where we observed that the food safety governance approach was unsupportive or provided restricted support to the companies. Our study seems to fit with the context of many transition economies, where companies operate within the confines of deficient food safety governance approaches. A study by Kussaga et al. (2014a) on the status of the FSMS in various African countries corroborates our findings. This questions whether a study in a transition economy is decisive and can be generalised. This is because legislation in established economies such as the EU, Canada and the USA is more developed, uniform, proactive and a legal requirement (e.g. CFIA, 2012; EC, 2004; FDA, 2011). However, even in countries with similar prescribed legislation, enforcement strategies can differ (Kirezieva et al., 2015a). Our findings on food safety performance, food safety programs and characteristics of the prevailing FS-culture seem therefore consistent with our findings on the food safety governance approach.

\section{National values}

National values could also have explained our findings as the cultural dimensions were also reflected in the prevailing FS-culture, actual food safety and hygiene behaviour, and the food safety governance approach. This could be because individuals bring different beliefs, values, and attitudes to the workplace as reflected in their national culture (Lok \& Crawford, 2004). Moreover, organisational culture studies have shown that operating in ways that are congruent with the cultural context can improve an organisation's performance (Burke et al., 2008; Lok \& Crawford, 2004). The current study showed that Zimbabweans have a higher power distance (PD), where inequality exists, demonstrated by the centralisation of most companies 
(Table 4.5). Food handlers were therefore limited in decision-making, as they indicated that decisions were made by management and they were told what to do. Moreover, food handlers were not free to approach their bosses. The onus was on management to prioritise food safety and support food handlers in executing their food safety and hygiene tasks. Wallace (2009) mentioned that a consultative management style coupled with information sharing evidenced in low PD could be more suitable in a food safety environment. However, proactiveness by key management in high PD environments could also be effective. Countries with a high PD score are expected to have a low score on individualism (Hofstede et al., 2010), which was indeed the case in our study. Hence, Zimbabweans are perceived to have collectivist culture, which was reflected in, for example, the food safety and hygiene training, which was done collectively as a group. Results are consistent with Seymen and Bolat (2010), who suggested that in collectivist cultures, training is focused at group level as it is considered most effective.

As a nation with a slight preference for avoiding uncertainty, Zimbabweans are risk-averse, only expressive to a certain extent and are not keen on accepting new ideas and responsibilities. As uncertainty avoidance cultures dislike ambiguous situations and prefer structured organisations with clear rules and regulations (Burke et al., 2008), this might explain the food safety and hygiene perceptions (Figure 4.2), which were mostly incorrect and not aligned with company specifications as some companies did not have food safety programs (e.g. H4) and clearly written procedures (e.g. H3 and L1). A low score on the masculinity dimension indicated that Zimbabweans are feminine, which means that they are less assertive when compared to masculine cultures that are assertive, success-oriented and focus on getting the job done (Hofstede et al., 2010; Seymen \& Bolat, 2010), and which could explain the restricted technological and organisational support given by a majority of the companies to the food handlers (Figure 4.2). Moreover, feminine cultures rely on consensusbased decision-making, which was not the case in our study as decision-making was centralised. This possibly explains the incorrect food safety and hygiene perceptions, and the attitudes in most companies, where food handlers demonstrated negative to ambivalent attitudes except for L2, M1, and M2. Wallace (2009) suggested that femininity could be beneficial to achieving food safety as the ability to work in teams, which is characteristic of feminine cultures is essential for good food safety performance.

Zimbabweans are also short-term oriented, which is consistent with Hofstede et al. (2010). In short-term oriented cultures, organisations are likely to provide temporary measures to 
address food safety concerns (Taylor, 2011). This is reflected in the fact that most companies (6/9) did not have certified food safety programs in place to mitigate unexpected risks. Moreover, the FSAs had outdated and generic food safety legislation, which provided restricted support to companies. Harvey et al. (2000) had similar findings on national values of Zimbabweans, although they studied managers. Even though the companies operated within the confines of one country, differences could occur because organisations also have their own unique cultural traits (Seymen \& Bolat, 2010). Moreover, the political and economic situation during the period of study was unstable. This could also have influenced perceptions and attitudes of respondents, and the way companies prioritised food safety in addition to actual behaviour. In general, a politically, economically and sociotechnically balanced environment is of importance to the decisive operation and performance of any business entity (Asdullah et al., 2015).

\subsubsection{Methodological considerations, limitations and research recommendations}

Perceptions of respondents were evaluated to assess the prevailing FS-culture because individuals use perceptual cues to infer and make decisions about their environmental circumstances. However, individuals may perceive the same thing differently (Robbins \& Coulter, 2007), and food handlers could have given socially desirable answers, a bias we need to acknowledge (Jespersen et al., 2017b; Krumpal, 2013).

Although statistical analysis showed associations between some FS-culture variables and actual behaviour, some determinants appeared to be endogenous. This could be because subindicators were considered as equally contributing to the indicators. Further studies should consider only the most relevant sub-indicators and add weight factors to enhance robustness of associations. We acknowledge that only a few companies representing each level of riskiness agreed to participate in the research. More companies should be assessed to draw strong conclusions on the correlations between product riskiness and FS-culture. Further studies should also assess matched companies in terms of product and process vulnerability in addition to product riskiness to avoid the influence of other factors. Our study was restricted to food handlers. Further studies should also include other groups like the cleaning and equipment maintenance departments, as these could also give an indication of an organisation's FS-culture. Our findings on national values and food safety governance were used to explain some characteristics of the prevailing FS-culture. Comparison of companies 
operating in different countries is needed to be able to determine a statistical correlation with the prevailing FS-culture.

In assessing national culture, a comparison with other countries with matched samples is advocated. Our findings were limited to one transition country and gave insights in the prevailing FS-culture and possible influence of the company external environment as a basis for improvement policies that could fit the possibilities in transition economies. For the findings to be generalised, more research is needed in other countries differing in food safety governance approach and national values. The political, economic, and sociotechnical environment must be considered in FS-culture assessments as it may influence the way food safety is prioritised and perceived.

\subsection{Conclusions}

Assessment of the prevailing FS-culture in nine companies operating in a transition economy revealed no direct relationship between product riskiness and the organisation's prevailing FS-culture. Each company had its own prevailing FS-culture governed by the extent of supportiveness of enabling conditions and the characteristics of employees. Our study indicated that the external company environment was reflected in the food safety performance, food safety programs and characteristics of the prevailing FS-culture, and could have possibly shaped the way companies prioritised food safety and how food handlers behaved. Findings showed that food safety governance, a characteristic of the external environment, was inadequate and consistent with the way companies prioritised food safety, which was also inadequate, i.e. food safety programs in multiple companies were unsatisfactory. Moreover, findings on national values revealed that the cultural dimensions used to typify the external company environment were in line with and could have possibly explained the food safety governance approach, food safety programs, and characteristics of the prevailing FS-culture such as the supportiveness of the organisational and technological conditions (e.g. food safety and hygiene training, and management commitment), employee characteristics (i.e. attitude, and food safety and hygiene perceptions). Based on our findings companies need to consider these factors in their external company environment as the ability to adapt to the external company environment could be beneficial for food safety. The outcome of our findings contributes to understanding an organisation's prevailing FS-culture from a systems perspective. Our study did not show to what extent this external company environment influences FS-culture, which requires further elaboration by evaluating 
companies operating in countries differing in national values and food safety governance approach.

\section{Acknowledgements}

This work was supported by the Netherlands Fellowship Programmes (NFP) (Grant award number H4. 9421/2014). The authors thank the interviewees for support, Prof. Dr V. Fogliano for his valuable input, and Dr L. Macheka and Dr L.K. Nyanga for assistance with contacting respondents. 



\section{Chapter 5}

\section{An intercontinental analysis of food safety culture in view of food safety governance and national values}

Published as: Nyarugwe, S. P., Linnemann, A. R., Ren, Y., Bakker, E.-J., Kussaga, J. B., Watson, D., Fogliano, V., \& Luning, P. A. (2020). An intercontinental analysis of food safety culture in view of food safety governance and national values. Food Control 


\begin{abstract}
Taking food safety culture into account is a promising way to improve food safety performance in the food industry. Food safety culture research is expanding from an organisational perspective to include characteristics of the internal and external company environment. In this study, the prevailing food safety culture in 17 food companies from four countries on three continents (Africa, Asia and Europe) was assessed in view of food safety governance and national values. The internal environment characteristics, i.e. food safety vision, food safety program and food production system vulnerability, were also assessed. Statistical analysis revealed little variation in FS-culture scores between the companies within the same country. Overall the FS-culture for Greek and Zambian companies was scored proactive, while for Chinese and Tanzanian companies an active score was achieved. Both the internal and external company environment seemed to influence the prevailing FS-culture. Cluster analysis showed that Tanzanian and Zambian companies exhibited similarities in the implementation of food safety programs, and in their national values and food safety governance as compared to Greece and China. Food safety governance was reflected in the food safety programs and supportiveness of the organisation to food safety and hygiene. All cultural dimensions were correlated with risk perceptions, with masculinity and long-term orientation also significantly correlated with the enabling conditions and attitude. Understanding how national values and food safety governance approaches differently influence food safety culture is expected to enable formulation of best approaches tailored for companies operating in countries with different company environments, to improve food safety performance.
\end{abstract}

Keywords:

Food safety culture assessment; food safety program; national values; food safety governance; food safety performance 


\subsection{Introduction}

Best approaches to improve food safety performance urgently need to be identified in view of existing food safety concerns (Kamau Njage et al., 2017). Research on food safety has therefore increased attention on food safety culture (FS-culture) as a measure to improve food safety performance (De Boeck et al., 2015; Fatimah et al., 2014b; Griffith et al., 2010b; Powell et al., 2011; Nyarugwe et al., 2018). To date, much of the research has been focused on the assessment of FS-culture and food safety climate within the internal company environment (e.g. De Boeck et al., 2016; Jespersen et al., 2016; Nyarugwe et al., 2018). However, Nyarugwe et al. (2016) and Taylor (2011) acknowledged national culture as a key determinant for conducting FS-culture research as all organisations, whether national or multinational, inevitably operate within a specific national culture context. Moreover, several authors proposed that characteristics of the external environment, such as national values, could have a significant role in shaping organisational culture, and influencing the operation and performance of organisations (Lok \& Crawford, 2004; Newman \& Nollen, 1996). Meshkati (1995) concluded that an organisation's safety culture interacts with its environment and therefore should be considered in the context of national culture. However, the role of the external business environment, encompassing national values and food safety governance, in shaping the prevailing FS-culture of an organisation has been scarcely studied (e.g. Nyarugwe et al., 2020).

National culture is that "collective programming of the mind that distinguishes the members of one group or category (nation) of people from others" (Hofstede et al., 2010). Hofstede defined six cultural dimensions i.e. power distance, individualism, masculinity, uncertainty avoidance, long-term orientation and indulgence (Hofstede et al., 2010), which have been widely used to assess differences in national values and to investigate the role of national values in an organisation's safety performance (e.g. Newman \& Nollen, 1996; Noort et al., 2016; Van Oudenhoven, 2001). The first dimension, power distance (PD) measures the degree of inequality between employees and their bosses. In high PD cultures, decision-making is centralised, and in a low PD culture, decision-making is consultative and decentralised. Individualism distinguishes individualistic societies, where self-interests prevail over the group and collectivistic societies, where group interests prevail. Masculine cultures are characterised by people who are assertive whereas feminine cultures are characterised by modesty and valuing relationships (Hofstede et al., 2010). Uncertainty avoidance (UA) measures the degree to which people feel threatened by ambiguity. In high UA cultures, 
people avoid ambiguous situations and are more expressive, and in low UA cultures, people are less expressive. In long-term oriented cultures, long-term planning and goals are evident, whereas, in short-term oriented cultures, the focus is on prevailing issues. The last dimension, indulgence measures the "tendency to allow relatively free gratification" whereas the opposite i.e. restraint reflects suppressed gratification. Wallace (2009), Taylor (2011) and Nyarugwe et al. (2020) proposed that these dimensions could potentially influence the performance of an organisation's food safety management system (FSMS) and prevailing FSculture.

In addition to being reflected in the way people behave, e.g. at work, national values are also reinforced by government policies and national legislation (Van Oudenhoven, 2001). For example, the EU, has developed extensive legislation (EC, 2004) to assure food safety when compared to countries in sub-Saharan Africa, where legislation is usually still outdated and poorly enforced (Kussaga et al., 2014a; Morse et al., 2018; Nguz, 2007). However, within the EU, member states also have different enforcement practices, leaving room for industrial selfregulation (Caduff \& Bernauer, 2006; Jacxsens et al., 2015; Kirezieva et al., 2015b). Companies, therefore, adopt and implement different public and private standards, which they need to conform to, to remain competitive and to gain market access (Fulponi, 2006; Jacxsens et al., 2011; Luning et al., 2009a). These public legislation, private standards, and public and private enforcement practices, typically describe food safety governance (Kirezieva et al., 2015b). Food safety governance issues such as legal frameworks, enforcement philosophies, strategies, and practices can mould FSMS design and operation (Kirezieva et al., 2015b; Sampers et al., 2012) and therefore need to be studied in FS-culture assessments as they could also influence the prevailing FS-culture of organisations.

In a previous study (Nyarugwe et al., 2020), a FS-culture research framework was developed to enable the analysis of an organisation's FS-culture within its national context. The prevailing FS-culture was assessed in view of the internal and external company characteristics. The results of that study implicated that the external environment of a company could have a role in the prevailing FS-culture of an organisation. However, this assumption could not be confirmed as the analysis was confined to companies in one country. Therefore, the objective of this study was to evaluate the role of food safety governance and national values in the prevailing FS-culture of organisations by investigating the FS-culture in 
food companies from different countries differing in national values and the food safety governance approach.

\subsection{Materials and Methods}

\subsubsection{Study design}

Ethical approval was granted by the Wageningen University Social Sciences Ethics Committee (SEC) before conducting the research (see supplementary material S1).

\section{Selection of respondents}

The study was conducted in four countries, namely China, Greece, Tanzania, and Zambia. The focus was on countries from different continents were national values and the food safety governance approaches were expected to be different on the basis of Hofstede et al. (2010) and Kirezieva et al. (2015a). In each of the countries, companies producing high-risk products (mostly dairy companies) were chosen because of their high susceptibility to microbial contamination (Qian et al., 2011). Companies with at least 10 employees (European Union Commission, 2003) were selected, as approximately 10 food handlers and 1 QA manager were required for the interviews.

Companies were invited to participate in the study via email, LinkedIn and ResearchGate. Local researchers in the participating countries who were committed and knowledgeable in the research field facilitated the acquisition of respondents through visits, emails, and telephone calls. Participation was voluntary, and countries, companies, and respondents were selected based on their willingness to participate. In total 17 companies participated, namely five from China (C1-C5), four from Greece (G1-G4), five from Tanzania (T1-T5) and three from Zambia (Z1-Z3). Characteristics of these companies and the respondents thereof are presented in Table 5.1.

\section{Research framework}

Figure 5.1 shows the framework used to analyse an organisation's prevailing FS-culture within its company environment. It shows elements used to analyse an organisation's prevailing FS-culture i.e. organisational and technological enabling conditions and employee characteristics, and the internal company environment (i.e. food safety vision, vulnerability of food production system and food safety program). 


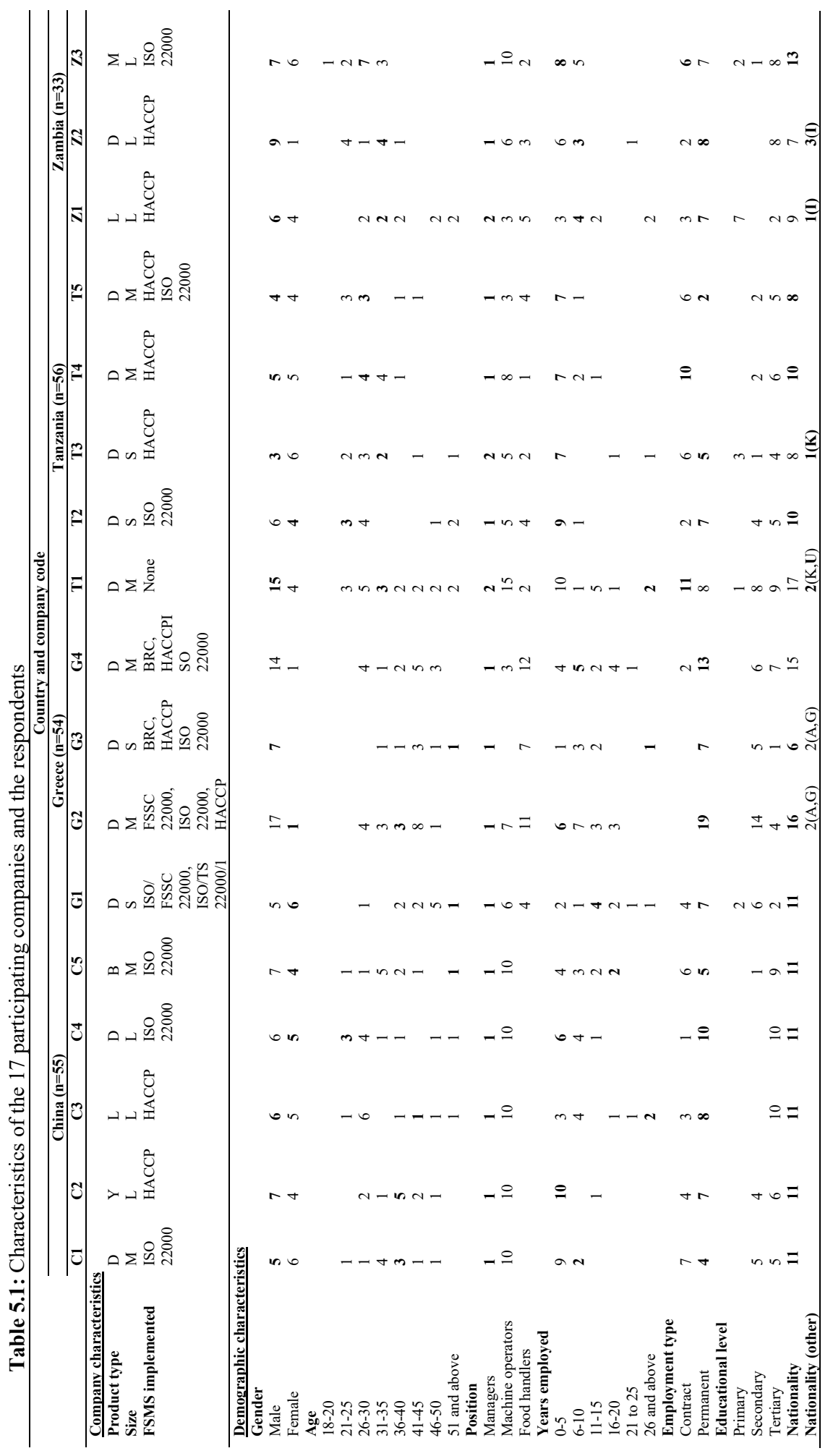


C1, G1, T1, Z1 ...etc. refers to companies in China, Greece, Tanzania and Zambia, respectively For product type, $\mathrm{D}=$ dairy products, $\mathrm{Y}=$ yoghurt, $\mathrm{L}=$ liquid milk, $\mathrm{B}=$ baby formula, $\mathrm{M}=$ meat For company size, $\mathrm{S}=$ small, $\mathrm{M}=$ medium and $\mathrm{L}=$ large

For nationality, $\mathrm{A}=$ Albanian, $\mathrm{G}=$ German, $\mathrm{K}=$ Kenyan, $\mathrm{U}=\mathrm{Ugandan}$ and $\mathrm{I}=\mathrm{Indian}$

In bold, QA managers data included

It also shows elements used to analyse the external company environment i.e. national values and food safety governance approach. For each element, variables used to collect essential aspects of the elements and subsequently give an indication of the actual situation in the assessed companies are given. Nyarugwe et al. (2018) and Nyarugwe et al. (2020) provide detailed descriptions of the elements and their assessment.

\subsubsection{Data on national values}

The country comparisons accessed from Hofstede Insights (https://www.hofstedeinsights.com) were used to typify the national values (Hofstede et al., 2010).

\subsubsection{Questionnaires}

Two questionnaires, one for the quality assurance (QA) managers and one for the food handlers were designed based on a previous FS-culture research framework and previously validated studies (Nyarugwe et al., 2018; Nyarugwe et al., 2020). The questionnaires were modified, translated, and tested to suit the purpose of an online survey. Modifications were mainly methodological, such as the replacement of the card-aided by closed questions. The questionnaires could be filled out through a link to an online survey (SurveyMonkey®). The English version was translated into Swahili, Greek and Chinese by native speaking researchers with expertise in the research field. For China, the questionnaires were disseminated through Wenjuanxing, a Chinese online survey system (https://www.wjx.cn/). Occasionally questionnaires were downloaded and manually disseminated when this was more convenient for respondents. 


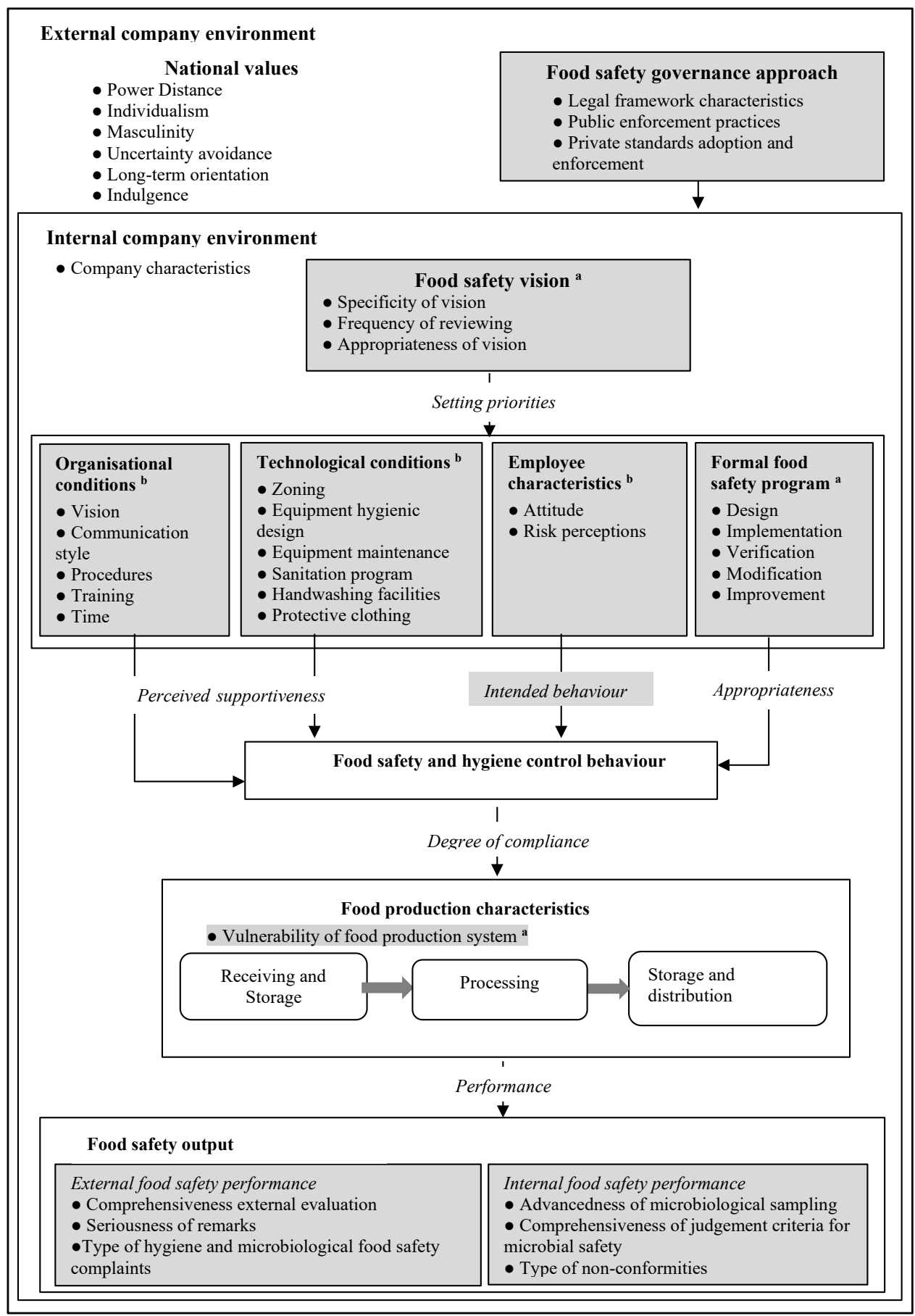

Figure 5.2: Structure of the framework to analyse prevailing FS-culture of a company within its environmental context. Adapted from Nyarugwe et al., (2020) 
In grey are the elements measured in this study

${ }^{a}$ Elements used to measure the internal company characteristics

${ }^{b}$ Elements and variables used to assess an organisation's prevailing FS-culture

Food handlers' questionnaire was used to assess the FS-culture variables and intended behaviour

QA managers questionnaire was used to assess the internal and external company environment, and the food safety output.

\section{Questionnaire for QA managers}

The questionnaire for QA managers consisted of open questions for company characteristics and demographic variables such as type of products and nationality, and closed questions on the vulnerability of product and production characteristics, food safety vision, formal food safety program, food safety governance, and food safety performance indicators. The questionnaires contained questions to check for reliability, i.e. consistency in responses. Closed questions described implied proactive (score 3), active (score 2) and reactive (score 1) situations, with the answer categories randomised to avoid response bias. For vulnerability of product and production characteristics, scores 1, 2 or 3, respectively indicated a high, potential and unlikely susceptibility to (cross) contamination. Scores 1, 2 or 3 were also given when food safety vision, food safety program and food safety governance were unsupportive, partially supportive or fully supportive, respectively. If the food safety performance indicators scored 1, 2, 3, then the scores reflected poor, moderate and good food safety performance, respectively. Data on vulnerability, food safety program and food safety performance indicators were entered into a database designed in Microsoft Office Excel 2016 and interpreted based on Jacxsens et al. (2010) and Luning et al. (2011a). If the mean score was between 1 and 1.2 the assigned score was 1 , between 1.3 and $1.7\left(1 \_2\right)$, between 1.8 and 2.2 (2), between 2.3 and 2.7 (2_3), and between 2.8 and 3.0 score 3 was given. Predominant scores were used to get an overall impression of the food safety governance and food safety vision.

\section{Food handlers' questionnaire}

The food handlers' questionnaire comprised six sections, including general characteristics of the individual, attitudes, risk perceptions, organisational support, technological support and intended behaviour. Questions pertaining to general characteristics were both open (regarding e.g. type of products, job title, nationality of birth and current nationality) and closed (concerning employment status, number of years employed, the highest level of education and gender). Statements on attitudes, and organisational and technological support were rated on a 5-point Likert scale ranging from not at all true, slightly true, moderately true, very true and completely true. The questions were based on how true they were in a food handler's job 
position (for attitudes) or how accurate they reflected the company situation (for organisational and technological support conditions). Statements on risk perceptions were scored from not at all likely, slightly likely, moderately likely, very likely to completely likely to happen, depending on how likely an individual perceived the food safety and hygiene risks to occur. A higher score on the Likert scale for positive statements, meant the highest possible agreement with the statement and corresponded with a more proactive situation in the company. The opposite was true for negative statements. In our study design, scores 1 and 2 on the descriptive Likert scale corresponded with a reactive situation (score 1), score 3 with an active situation (score 2), and scores 4 and 5 with a proactive situation (score 3 ). Scores were therefore reassigned accordingly before statistical analysis. Intended behaviour questions were closed, whereby scores 1,2 and 3 indicated a high, moderate, and low inclination towards risky behaviour, respectively. Reassigned scores of each respondent were used in the analyses.

\section{Pretesting of questionnaires}

As a first check on the understandability, adequacy, consistency, and completeness, both questionnaires were pretested by food safety scientists, QA managers, and students with a food safety background. Fifteen people willingly pretested the food handler questionnaire and nine the QA managers questionnaire. The process was iterative until the questionnaires were finalised. As a further check, the questionnaires were also pretested in one high-risk company, namely a dairy processing company in Malawi, where one QA manager and seven food handlers responded.

\subsubsection{Statistical analyses}

For each respondent $(n=181)$ in each of the 17 companies, the assigned scores for the FSculture variables (i.e. enabling conditions, attitudes, risk perceptions, intended behaviour), and the internal and external environment were entered into IBM SPSS software version 25.0 (2017). Descriptive statistics were performed to determine the frequencies, mean, and mode scores for calculating the prevailing FS-culture for all the companies. ANOVA (post hoc: Tukey) was performed to find statistical differences between companies and countries. Pearson correlation was used to describe the strength of association between the prevailing FS-culture and the company environment characteristics. A hierarchical cluster analysis was performed based on the individual scores for each of the FS-culture variables, and the scores for the internal and external company environment. The hierarchical cluster analysis was 
performed using Ward's method and the squared Euclidean method (Sarstedt \& Mooi, 2014). This method minimises variance within a cluster and keeps the clusters homogeneous. Differences between the mean scores for the indicators used in the three clusters were analysed using the Kruskal-Wallis nonparametric test, with the significance of results established at $\mathrm{p}<0.05$.

\subsection{Results}

\subsubsection{Prevailing FS-culture}

Our study yielded a total of 181 responses, which were used to analyse the prevailing FSculture in the 17 participating companies. To give an overall impression of the prevailing FSculture in each company, Table 5.2 shows mean scores for the enabling conditions and employee characteristics used to determine the prevailing FS-culture of the companies. Table 5.2 shows that both technological and organisational enabling conditions in China and Greece predominantly scored 3, indicating that the companies were fully supportive to food handlers in enabling them to execute their tasks appropriately. For both countries, score 3 was also predominant for attitudes, indicating positive attitudes, which reflect a strong and positive predisposition by the food handlers to always comply with food safety and hygiene requirements. An exception was the attitude for monitoring process temperature where Chinese companies scored 1 and Greece companies scored 2, which was indicative of negative and ambivalent attitudes, respectively. Interestingly, Chinese companies scored 1 on most risk perceptions, except for process temperature monitoring, revealing a lack of awareness about the risks posed by a majority of food safety and hygiene issues. In Greece, companies mainly scored 2 for risks pertaining to sanitation, as food handlers were moderately aware of the risks.

In Tanzanian companies, both enabling conditions and employee characteristics predominantly scored 2, reflecting restricted support of the enabling conditions, and ambivalent attitudes (uncertain predisposition) and moderate risk perceptions. For Zambia, companies mostly scored 3 for both enabling conditions and employee characteristics, indicating that food safety and hygiene were prioritised. 


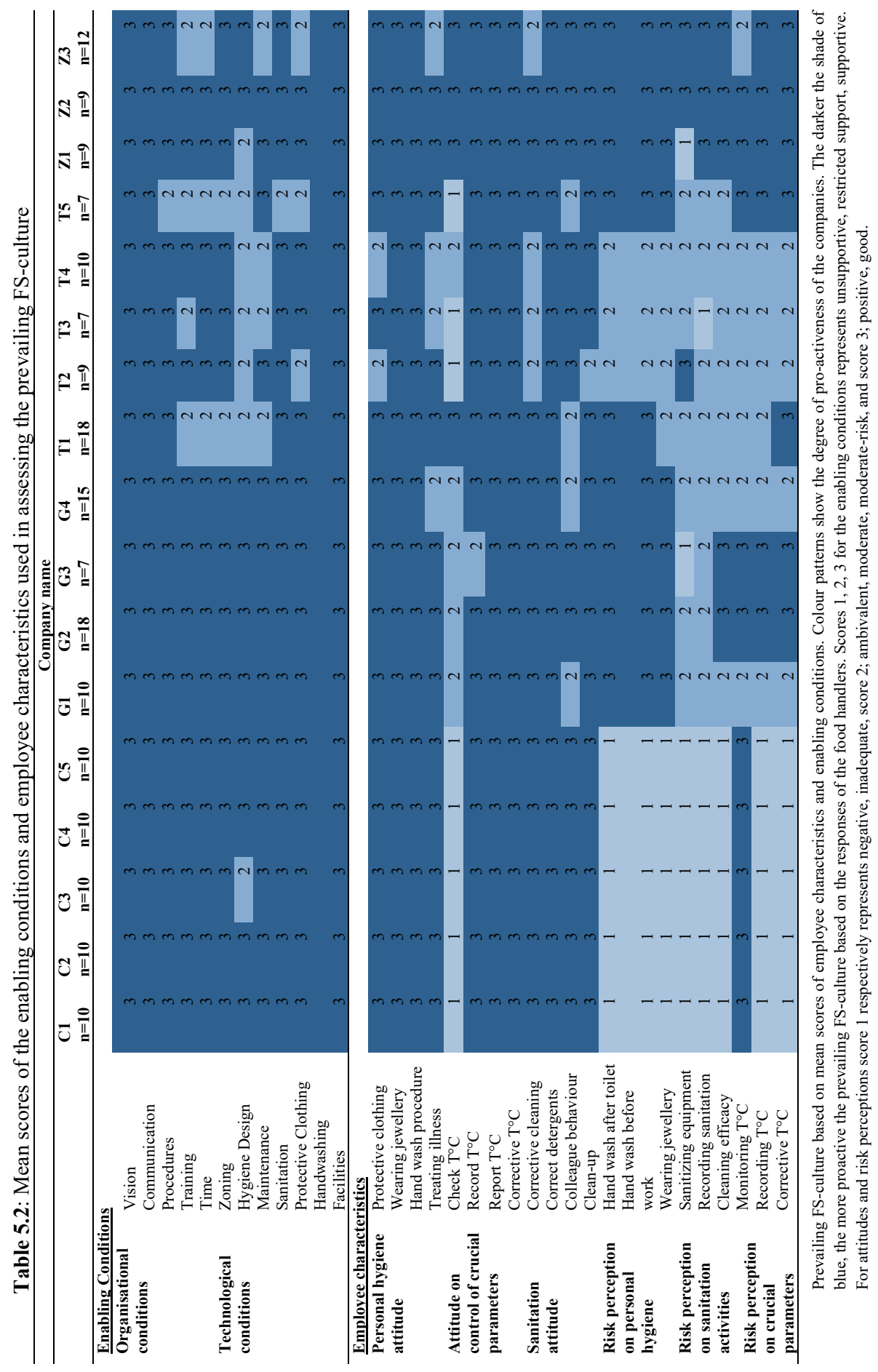


Based on the general patterns in Table 5.2, Chinese companies were assigned an overall score 2, implying an active prevailing FS-culture; not a score 3 because food safety and hygiene were not always regarded as important. Tanzania also reflected an active FS-culture (overall score 2). Both Greece and Zambia overall scored 3, indicating a proactive prevailing FSculture as companies in both countries demonstrated that they mostly prioritised food safety and hygiene.

The ANOVA (post hoc: Tukey) (Figure 5.2) was performed on the mean scores of FS-culture variables per company to assess whether differences implied in Table 5.2 were statistically significant. Statistical analysis revealed that differences in FS-culture scores between companies within the same country were not statistically significant, indicating little variation between the companies. At country level, there were no statistical differences between China and Tanzania, nor between Greece and Zambia. However, the Chinese and Tanzanian companies’ FS-culture scores significantly differed from Greece and Zambia.

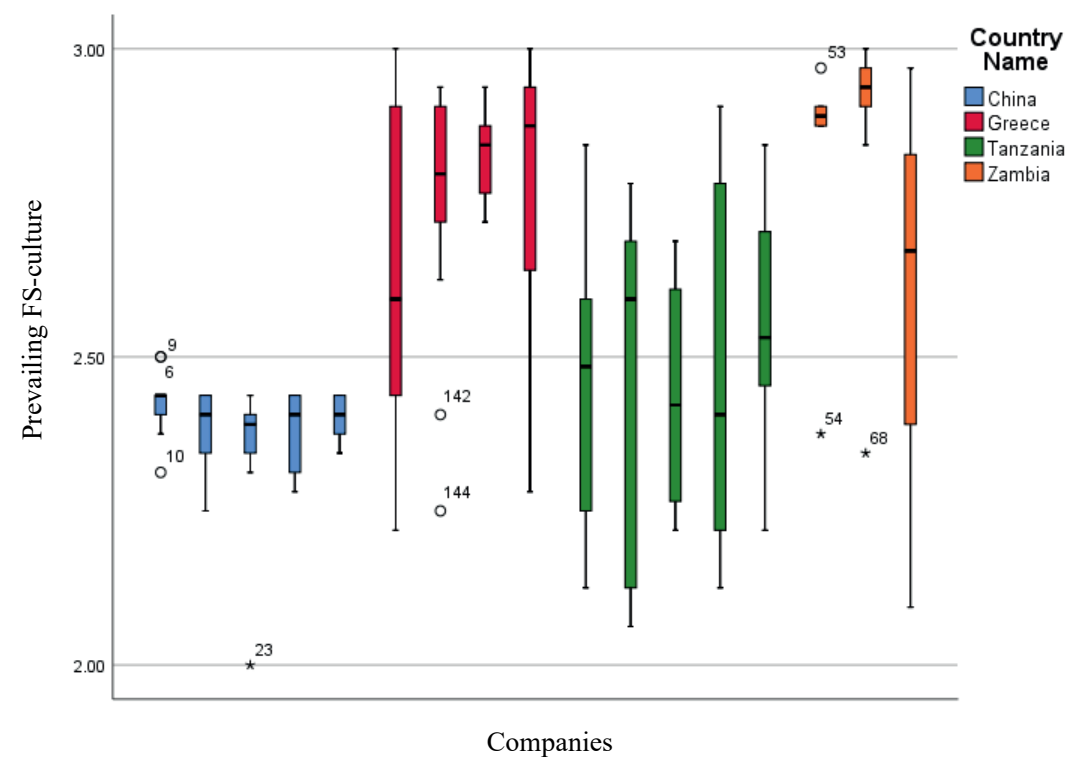

Figure 5.2: Boxplots showing differences within and between companies, and countries in the prevailing FS-culture scores

-For each country, each plot represents a single company, with companies plotted in ascending order e.g. for China, the first plot corresponds with $\mathrm{C} 1$ and the fifth with $\mathrm{C} 5$

- Plots are based on mean scores of FS-culture variables

-Prevailing FS-culture based on mean scores of employee characteristics and enabling conditions

- Scores below 1.6 reflect a reactive, $\geq 1.6<2.6$, active and $\geq 2.6-3$ proactive FS-culture 


\subsubsection{Food safety performance}

Table 5.3 depicts the scores used to assess the food safety performance of the companies. Overall, the results show that the food safety performance of Chinese and Tanzanian companies was lower than that of Greek and Zambian companies. Overall Chinese companies scored 2 for both the internal and external indicators, reflecting a moderate food safety performance. An exception was C3, which overall scored (1_2), reflecting a poor to moderate food safety performance owing to score 1 for both FSMS evaluation and seriousness of remarks. This was attributed to the poor FSMS evaluation, and minor remarks on multiple aspects of the FSMS. For Greece, the companies mostly scored 3 on both internal and external indicators, reflecting overall a good food safety performance. However, G2 scored 2 on the external FSMS evaluation as the audits were only done by a third party, and on hygiene and pathogen non-conformities as the company had a restricted number of non-conformities. This resulted in a score of 2_3 for G2, reflecting a moderate to good performance. In G4, the QA manager chose not to complete that part of the questionnaire.

In Tanzania, the scores were quite different among the companies. T5 was the only company that at least scored 2_3 (moderate to good performance), although it scored 1 on customer complaints as there was no complaint registration system in place. T1 and T3 overall scored 2, owing to the restricted issues from both the internal and external assessment of the food safety performance of the companies, implying a moderate food safety performance. T2 and T4 scored 1_2 (poor to moderate performance) as minimal criteria were used for food safety performance evaluation and the companies had various food safety problems from different aspects of the FSMS (details in Appendix). In Zambia, Z1 and Z2 scored 3 on most of the internal and external indicators, reflecting a good food safety performance. However, both companies scored 1 for microbial food safety complaints and 2 for hygiene and pathogenrelated non-conformities as both companies did not have microbial complaint systems in place and had a restricted number of non-conformities. In comparison, Z3 overall scored 2, indicating a moderate food safety performance. This could have been attributed to several criteria used for performance evaluation and food safety problems restricted to one problem in the FSMS characteristic of moderate food safety performance as described by Jacxsens et al. (2010). 


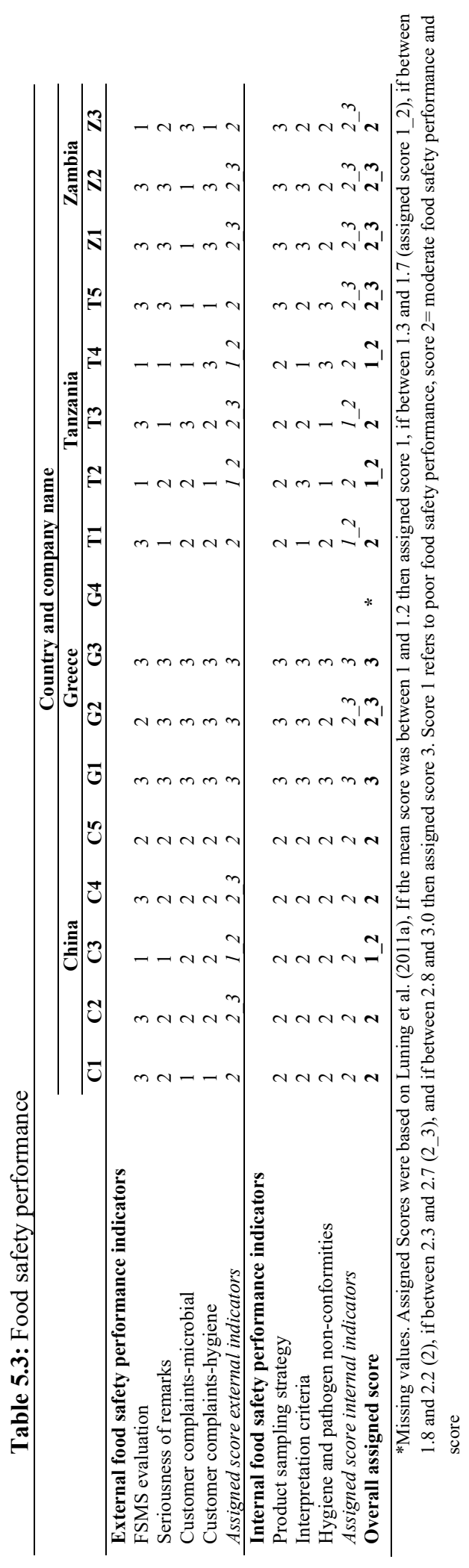




\subsubsection{Hierarchical cluster analysis}

A hierarchical cluster analysis was performed to further assess how the companies grouped according to their prevailing FS-culture, and their internal and external environment. Table 5.4 and Figure 5.3 present results of the cluster analysis, based on the individual scores of all FS-culture variables, intended behaviour, and the internal and external environment characteristics. Three clusters (A, B and C) were obtained and consisted of all Chinese (C1C5), all African (T1-Z3), and all Greek companies (G1-G4), respectively.

\section{Organisational and technological enabling conditions}

Table 5.4 shows differences between the clusters regarding technological and organisational enabling conditions. Closer analysis reveals that for organisational conditions, only cluster B, consisting of the African countries, shows some significant difference $(p<0.05)$ when compared to both cluster A (Chinese companies) and cluster C (Greek companies). Cluster B significantly differed with cluster $A(p<0.05)$ in the food safety communication system and in the availability of time to execute food safety and hygiene activities as cluster B had mean scores of 2.8 and 2.6, respectively, when compared to the 3 and 2.9 of cluster A. Moreover, food safety and hygiene procedures and training significantly differed in cluster $\mathrm{B}(M=2.6$; $2.5)$ when compared with both clusters A $(M=2.9)$ and C $(M=2.9 ; 3)$.

For technological conditions, cluster B significantly differed with both clusters $\mathrm{A}$ and $\mathrm{C}$ on five (zoning, hygiene design, equipment maintenance, sanitation program and protective clothing) out of the six variables. Results show that mean scores of these variables were lower in cluster B, e.g. for zoning $M=2.6$ and maintenance $M=2.5$ (Table 5.4), indicating that although companies in African companies prioritised food safety, some food handlers still perceived them to be less supportive in food safety and hygiene when compared to Chinese and Greek companies. For example, some food handlers gave responses such as breakdownrelated equipment maintenance and inadequate cleaning tools. Findings implied that although companies in both African countries highly prioritised food safety, the Chinese and Greek companies were more supportive to food safety than the African companies in our study.

\section{Employee characteristics}

\section{i. $\quad$ Attitude}

Table 5.4 shows that most differences were between the Chinese (cluster A) and the African companies (cluster B). Cluster B differed with clusters A and C (Greek companies) on 
protective clothing, handwashing procedures, correct execution of cleaning procedures, and cleaning up in the event of spillages as food handlers in the African companies sometimes scored 1 and 2, indicating negative and ambivalent attitudes, respectively. This is because some food handlers either had a negative or uncertain predisposition to comply with food safety hygiene requirements. Cluster A only differed with both clusters B and C on checking product and process temperatures, where cluster A scored 1 (negative attitude). Cluster $\mathrm{C}$ only significantly differed from clusters $\mathrm{A}$ and $\mathrm{B}$ on cleaning behaviour of colleagues $(M=2.5)$, as some food handlers scored 1 and 2, reflecting negative and ambivalent attitudes.

\section{ii. Risk perceptions}

Risk perceptions significantly differed for cluster A as compared to clusters B and C (Table 5.4), because most food handlers in the Chinese companies (cluster A) scored 1, reflecting incorrect risk perceptions as they were not aware of most food safety and hygiene risks.

\section{iii. Intended behaviour}

Table 5.4 shows that handwashing behaviour and control of process temperature of food handlers in cluster $\mathrm{C}$ significantly differed with that in clusters $\mathrm{A}$ and $\mathrm{B}$. Closer analysis of results indicates that the Greek companies (cluster C) scored 2 (moderate inclination to engage in risky behaviour) on handwashing practices and on corrective actions taken when product processing temperature deviated from specifications.

\section{Internal company environment}

Figure 5.3 shows differences amongst the clusters regarding the internal company environment. The African companies (cluster B) revealed weaker FS-programs as compared to the non-African companies since these either scored 1 (T2, T3) or 2 (T4, T5, Z1, Z2, Z3) as they were still in the process of being implemented or implemented but not yet certified, respectively. An exception was T1, which did not have a food safety program in place. On the contrary, Chinese and Greek companies scored 3 as their programs were all certified. Additionally, some African companies scored 1_2 (Z3) or 2_3 (T1, T3) for the food safety vision since it only slightly motivated food handlers in doing their work tasks. Companies in Greece (cluster $\mathrm{C})$ significantly differed $(\mathrm{p}<0.05)$ in the vulnerability of the production system $(M=2.3)$ when compared to companies in clusters A and $\mathrm{B}$, thereby indicating less susceptibility of the product and production system to contamination, especially regarding product properties and intervention steps. 


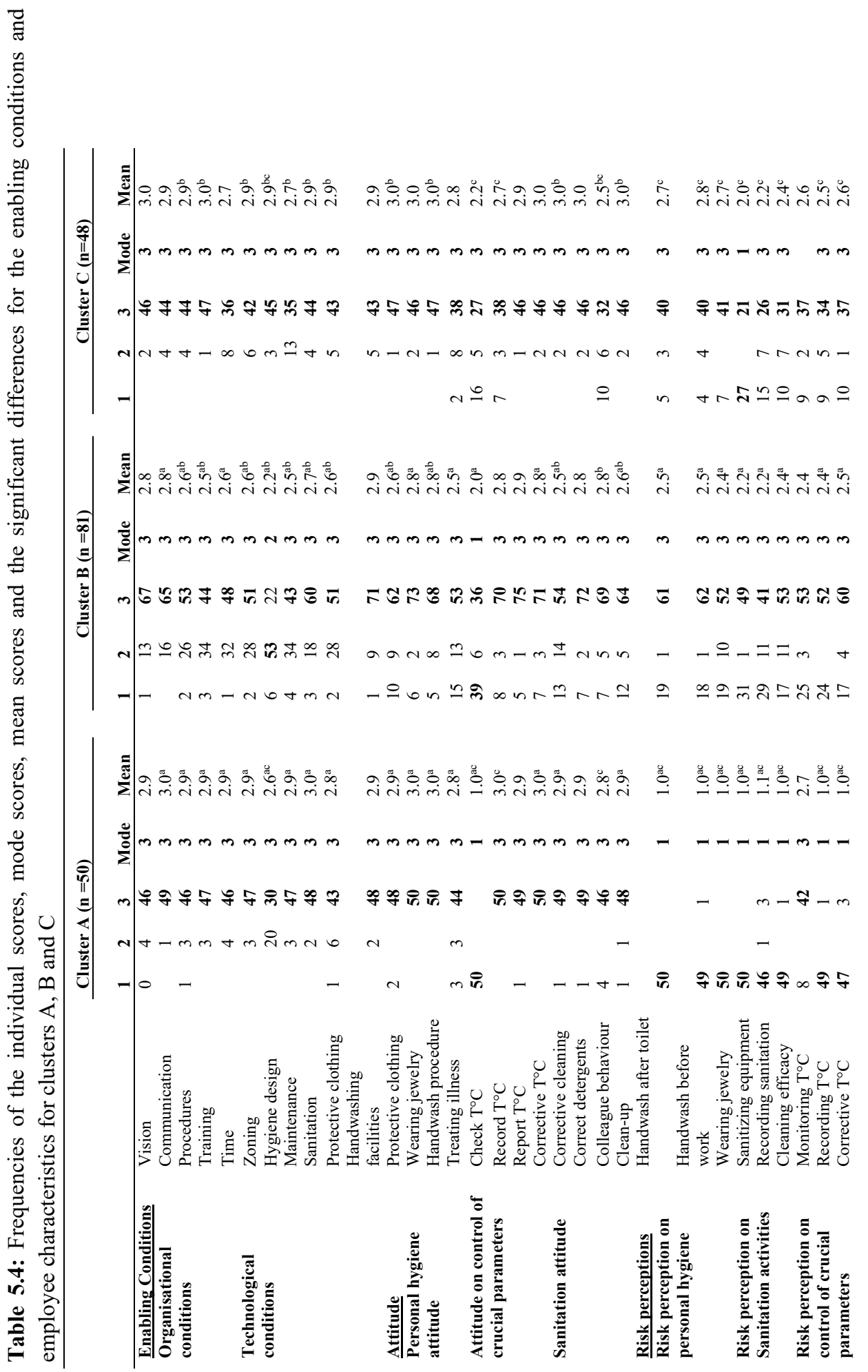




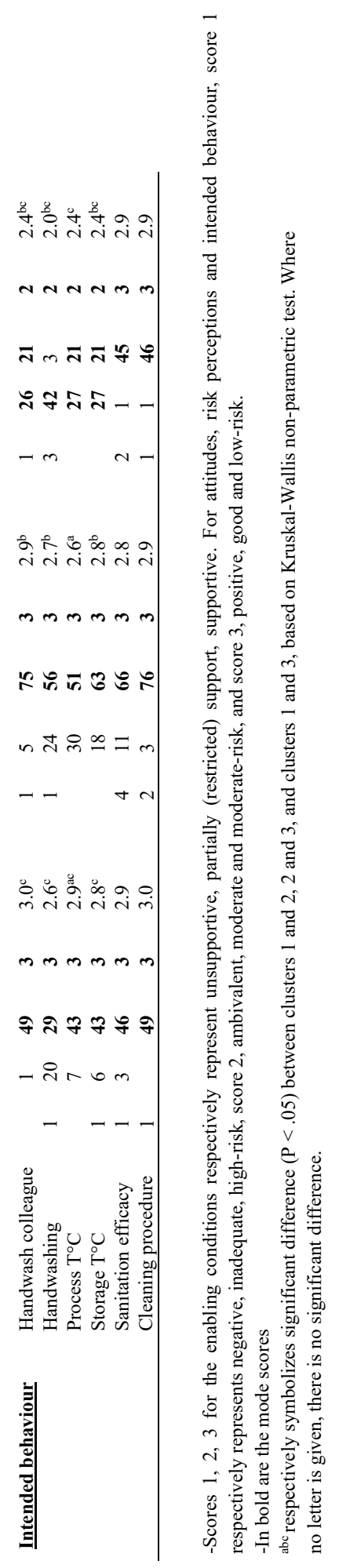


Internal company environment

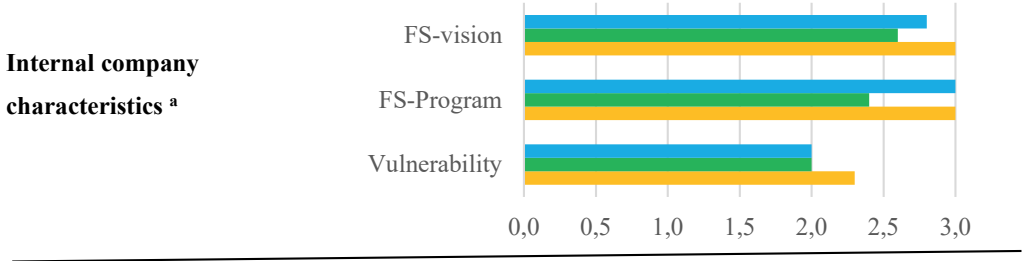

External company environment

Food safety

governance $^{b}$

National

values $^{b}$

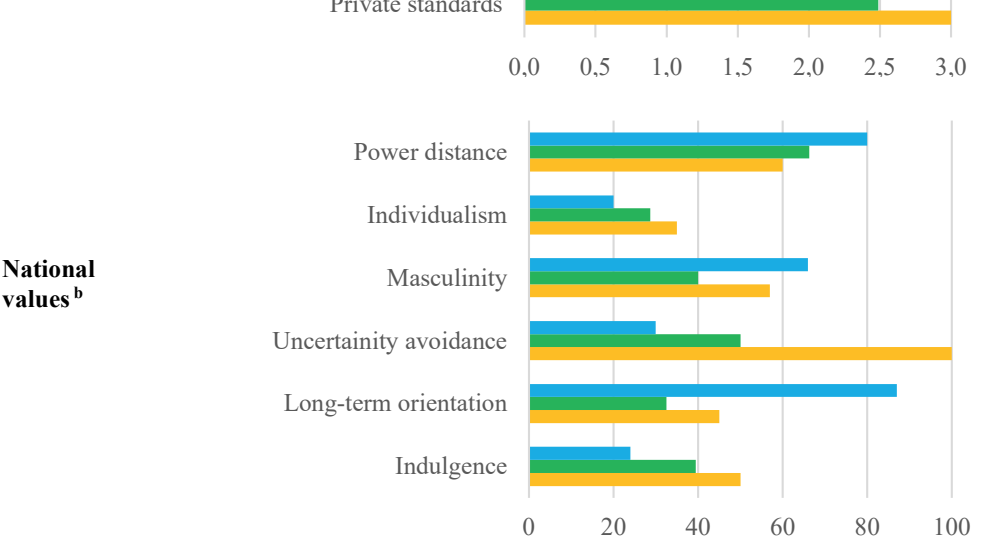

Figure 5.3: Mean scores of the company environmental characteristics for clusters $A, B$ and C

m Cluster A $\equiv$ Cluster B $₫$ Cluster C

${ }^{a} p<.05$ symbolises significant difference between clusters 2 and 3 for vision, clusters 1 and 2 , and 2 and 3 for food safety program, and 1 and 3 and 2 and 3 for vulnerability based on Kruskal-Wallis non-parametric test.

${ }^{\mathrm{b}}$ symbolizes significant difference $(\mathrm{P}<.05)$ between clusters 1,2 and 3 for both food safety governance and national values.

For the internal company characteristics and food safety governance, score 1 was assigned for mean scores between 1 and 1.2, score 1_2 between 1.3 and 1.7, score 2 (1.8 and 2.2), score 2_3 (2.3 and 2.7) and score 3 (2.8 and 3.0) (based on Luning et al., 2011a). Scores 1, 2, 3 for the vision, food safety program and food safety governance respectively represent unsupportive, restricted support, supportive. For vulnerability of the food production system, scores 1, 2 and 3 respectively refer to high, potential and unlikely susceptibility to contamination. For national values, low scores represent low power distance, collectivism, femininity, low uncertainty avoidance, short-term orientation and restraint. High scores represent high power distance, individualism, masculinity, high uncertainty avoidance, long-term orientation and indulgence.

\section{External company environment}

Figure 5.3 also shows statistically significant differences $(\mathrm{p}<0.05)$ in the food safety governance and national values amongst the three clusters. The QA managers in the Chinese companies (cluster A) scored 3 for legislation and enforcement as they considered both to be supportive, i.e. more facilitative to companies when compared to the private standards, which on average scored 2 (restricted support) as most companies $(\mathrm{C} 1, \mathrm{C} 2, \mathrm{C} 3)$ did not adopt private 
standards. In comparison, the public authorities in Greece (cluster C) mainly scored 2 owing to the restricted support, especially regarding communication of legislation and the enforcement thereof. However, private standards scored 3 as all companies adopted private standards and these were adequately enforced. In cluster B (African countries), public authorities and private standard bodies scored 2_3 as they provided restricted support, especially regarding clarity, usefulness and communication of legislation, and enforcement. Moreover, private standards were sometimes not adopted. For example, most QA managers (6/9) assigned score 2 for communication of legislation and for enforcement strategy as they regarded them as mostly available upon requisition by the companies and as more punitive, respectively.

Analysis of national values (Figure 5.3) shows that in our study, China (Cluster A) has the highest power distance (80), masculinity (66), and long-term orientation (87) scores, respectively, depicting a culture were inequality exists, people are assertive and are futureoriented. However, the lowest scores on individualism (20), uncertainty avoidance (30), and indulgence (24), show that the Chinese culture is typified by collectivism, risk-taking and indulgence, respectively. The African countries (Cluster B) had an intermediate to high power distance $(60,70)$, and intermediate uncertainty avoidance (50) as no preference could be depicted. However, although slightly higher than for cluster A, low scores were also seen on individualism $(25,35)$, and indulgence $(38,42)$. Differences with cluster A were only seen for masculinity (40) and long-term orientation $(30,34)$ as the culture in the African countries in our study is more feminine and with a short-term focus. Greece (Cluster C) depicts a culture with an intermediate power distance (60), masculinity (57), long-term orientation (45), and indulgence (50) showing no clear preference. However, they score highest on uncertainty avoidance (100) which means they are risk-averse, and relatively low on individualism (35).

Further statistical analysis revealed correlations between national values and the FS-culture variables. All six cultural dimensions were statistically significantly correlated $(p<0.01)$ with risk perceptions (details in supplementary material S2). Masculinity and long-term orientation were strongly correlated with enabling conditions ( $p<0.01$ in both cases). Masculinity also significantly correlated with attitudes, and uncertainty avoidance and indulgence with intended behaviour $(\mathrm{p}<0.05)$. 


\subsection{Discussion}

This study gained insight into characteristics of the internal and external company environment that could potentially influence the prevailing FS-culture of food companies operating in different countries differing in national values and their food safety governance approach. Overall, our study revealed differences among the four countries with African companies exhibiting more similarities when compared to China and Greece (Table 5.4, Figure 5.3). As such, results are discussed from an intercontinental perspective in view of the external company environment.

\subsubsection{Prevailing FS-culture and food safety performance in view of food safety governance}

Findings for China show that food safety legislation and public enforcement are perceived to be supportive to the dairy companies in our study, which probably explains the high scores for the technological and organisational conditions in all the companies (Table 5.2). This could be typical for the dairy industry, owing to the 2008 melamine incident, where milk and infant formula were adulterated. Since then there has been considerable effort by food safety authorities to reform and enforce the food safety law (Jia \& Jukes, 2013; Yang et al., 2009). Particularly in the dairy industry, new regulations and standards set out HACCP requirements (Pei et al., 2011). The Food Safety Law established as a basis for food safety governance, was updated in 2015, focusing now more on risk prevention, assessment and communication (Jiang et al., 2018; Lepeintre \& Sun, 2018). Food safety governance evolved from following the traditional direct command and control approach by the government to social coregulation, which incorporates multiple stakeholders (Lepeintre \& Sun, 2018; Kirezieva \& Luning, 2017). Regarding enforcement, an accountability system was put in place, which incentivises companies with positive records and punishes the offenders (e.g. fines, imprisonment) (Jia \& Jukes, 2013; Lepeintre \& Sun, 2018). However, private standards were not really adopted when compared to the other countries in our study, as companies mainly based their food safety system on national legislation, confirming our supposition of food safety governance reforms in the Chinese dairy industry as principally a public authority intervention.

Evaluation of the food safety performance data revealed a moderate performance in most Chinese companies. This was maybe a result of the incorrect perceptions regarding food safety and hygiene risks (Table 5.2), which could have resulted in non-conformance of 
hygiene behaviour. Our results suggest that even if there have been substantial investments and improvements in the food safety programs, technological and organisational support, the human dimension is equally important, as also a shift in perceptions is required.

The overall proactive FS-culture in the Greek companies (Table 5.2) was consistent with their good food safety performance (Table 5.3). This could have been due to the supportive private standards as all companies adopted multiple internationally accepted private standards. Moreover, HACCP-based procedures are mandatory for all food business operators (Chaidoutis \& Koutou, 2018). Private standards were effectively enforced (score 3), as the private certification bodies immediately acted in cases of non-compliance and supported the organisations by, e.g., providing training and guidance. When compared to China, national legislation was perceived as not openly exchanged with organisations as companies had to request for them. In cases of non-compliance, public authorities resorted to punitive measures rather than assistance by training, incentives etc. This could be due to the national law, Law 4235/2014, which specifies administrative penalties in the food sector (Hellenic Republic, 2014). However, since Greece is within the EU, it has adopted regulations such as (EC) No 178/2002 and (EC) No. 853/2004 on setting general principles and requirements of food law and specific hygiene rules for food of animal origin (EC., 2002; EC, 2004), which are comprehensive. Due to the use of both private and public standards (both EU and national), the enforcement strategy in Greece is based on principles of co-regulation (Chaidoutis \& Koutou, 2018; Kirezieva et al., 2015a). Co-regulation involves public-private initiatives and integrates the use of primary regulation and market self-regulation (Eijlander, 2005; Kirezieva et al., 2015a).

Cluster B comprised companies in both African countries (Tanzania and Zambia). Although some companies in both countries showed similarities such as inadequate training and availability of time (e.g. T1, T5 and Z3), and restricted support for equipment maintenance (T1, T3, T4, Z3) and protective clothing (T1, T5 and Z3), Zambian companies had a more proactive FS-culture and a good food safety performance compared to the active FS-culture and moderate performance in Tanzanian companies (Tables 5.2 and 5.3). Several reasons could possibly explain the findings for these two African countries. Firstly, regarding internal company characteristics, all Zambian companies were large organisations when compared to the five companies in Tanzania (Table 5.1), which were mostly small to medium. Fatimah et al. (2014b) found an association between company size and employee perceptions. Of the five 
Tanzanian companies, none had certified FSMS as was the case with the three Zambian companies. This could be because most African companies have certified food safety programs only in place as an export requirement (Kussaga et al., 2014b; Macheka et al., 2013). The Tanzanian companies in our study also had a highly susceptible production process environment as processes were partially automated with a lot of product handling, which could have partially contributed to the moderate food safety performance. Secondly, regarding the external company environment, a majority (3/5) of the Tanzanian companies, perceived the national legislation to range from generic to only setting general requirements, which was concerning as the companies relied on national legislation only (score 1).

However, the companies in both countries seemed to agree that the legislation was only useful to a certain extent, and not properly communicated and enforced, possibly because legislation in most sub-Saharan African countries is still underdeveloped (Steier \& Patel, 2017). For Tanzania, Kashoma et al. (2018) indicated that enforcement of legislation is still weak with limited laboratory capacity. In Zambia, the laboratories at least provide basic lab support service although they still need accreditation (Steier \& Patel, 2017). Furthermore, the Tanzania Bureau of Standards (TBS) and Food and Drug Authority (TFDA), the main entities responsible for food safety, are beset by several challenges such as lack of sufficient resources and infrastructure. The food safety control system in Tanzania, as is typical of most subSaharan African countries, is fragmented and could potentially contribute to the inadequate food safety performance (Kussaga et al., 2014a; Grace, 2015). Compared to China and Greece, African countries mainly follow the traditional direct command and control approach, where companies mainly use national public standards (Global Food Safety Partnership, 2018). Still, a small sign of co-regulation exists with the existence of TBS and the Zambian Bureau of Standards (ZBS).

\subsubsection{Prevailing FS-culture in view of national values}

The three clusters obtained mainly differed in masculinity, uncertainty avoidance and longterm orientation, with both African countries exhibiting similarities in national values when compared to China and Greece (Figure 5.3). This shows that level of assertiveness, risk tolerance and time orientation depicted by the three dimensions could be crucial dimensions to consider as the three were also significantly correlated with two or more variables for FSculture (i.e. enabling conditions, attitude, risk perceptions) and intended behaviour. In addition, of all the FS-culture variables, risk perceptions were seen to be strongly correlated 
with all the cultural dimensions. Seymen and Bolat (2010) also found risk perceptions to be related to masculinity, uncertainty avoidance, and individualism. This could be because food safety and hygiene risks are differently perceived in different cultures (Wallace, 2009).

In our study, companies in China and Greece with more masculine cultures had more supportive enabling conditions and positive attitudes (Table 5.2). This could be because masculine cultures are assertive, hence the positive attitudes, and are success-oriented as they focus on getting the job done. They also tend to work hard to produce results (Hofstede et al., 2010; Seymen \& Bolat, 2010), which could have prompted them to ensure that they had the right (supportive) conditions to do the job right. On the contrary, the African countries, especially Tanzania, were typified to have a feminine culture (Figure 5.3) and thus could be perceived as less assertive, and reliant on consensual decision-making as a good working relationship between superior(s) and subordinates is valued. This could explain the restricted support given by the Tanzanian companies to food handlers and the reciprocal negative and ambivalent attitudes by the food handlers (Table 5.2). Interestingly, Zambian companies had a proactive FS-culture and a good food safety performance when compared to Tanzania (Tables 5.2 and 5.3). This could have been partially attributed to the management in Z1 and Z2, who were Indians (Table 5.1) and the fact that Z2 is an Indian-owned company. Indians typically are considered to be a masculine culture (score of 57) (Hofstede et al., 2010), which could have contributed to the assertiveness, emphasis on getting things done and consequentially the proactive FS-culture. However, Wallace (2009) postulated that femininity or masculinity could both be beneficial for food safety performance as the ability to work in teams, which is characteristic of feminine cultures and the focus on getting the job done, typical of masculine cultures, are both essential aspects to achieving food safety.

We also found a positive correlation between uncertainty avoidance and the prevailing FSculture regarding risk perceptions. Various safety culture studies also found a relationship between uncertainty avoidance and safety culture (e.g. Burke et al., 2008; Havold, 2007). Greek companies with a very high uncertainty avoidance (100), had good risk perceptions (Table 5.4) and overall revealed a pro-active FS-culture (Table 5.2). Seymen and Bolat (2010) suggested that the higher the uncertainty avoidance, the less-risk taking tendencies were preferred by employees. As Greeks are characteristically risk-averse, they dislike ambiguous situations, and are thus reliant on a structured organisation and on rules and regulations, as these provide some sense of control and predictability (Burke et al., 2008). This could explain 
the adoption of multiple private standards when compared to the other countries (Table 5.1) and the perceived technological and organisational supportiveness (score 3) to the food handlers in performing their food safety and hygiene tasks. However, uncertainty avoidance was negatively correlated with intended behaviour as in Greece the handwashing behaviour was moderately risky (score 2). This could be due to the statements presented to the food handlers, which could have implied different situations to the norm. In high uncertainty avoidance cultures, employees often depend on standard procedures and have limited adaptability when exposed to different situations other than the norm (Burke et al., 2008). When compared to Greece, Chinese companies showed poor risk perceptions (Table 5.4), possibly because the Chinese are more tolerant of ambiguous situations (Hofstede et al., 2010) and are more accepting of new ideas as depicted by their low uncertainty avoidance (Figure $5.3)$.

Long-term orientation was positively correlated with the enabling conditions and negatively with risk perceptions. The Chinese being long-term-oriented (Figure 5.3), tend to plan for the future and focus on future rewards (Hofstede et al., 2010). As such, they could have invested in the organisational and technological conditions to ensure a good performance of their operations. However, the African countries (Tanzania and Zambia) being short-term oriented they focus on short-term planning and on prevailing issues (Figure 5.3). This probably explained the restricted support by the public authorities in food safety legislation and enforcement thereof.

Furthermore, we found power distance to be negatively and individualism to be positively correlated with level of risk perception, in other words, food safety and hygiene risk perceptions were better in conditions of lower power distance and higher individualism. Findings are corroborated by Seymen and Bolat (2010), who found individualism to be positively related with risk perceptions. Hofstede et al. (2010) found that many countries that score low on individualism score high on power distance as the two dimensions are negatively correlated. All countries studied in our research had a high power distance and low individualism, which suggests that other dynamics could have moderated the correlation with risk perceptions. For example, Seymen and Bolat (2010) proposed power distance to be negatively related to employee involvement, which is an aspect we did not study that could have been an influential factor. The level of employee involvement brings other elements such as clarity of communication and standardisation of procedures, which could be beneficial 
in ensuring correct perceptions (Seymen \& Bolat, 2010). Although all countries scored similar, we therefore postulate that our findings could have been related to the level of power distance as the Chinese scored highest on this dimension. This might explain why Chinese employees showed lack of awareness of the risks posed by most food safety and hygiene issues. A possible clarification could be the centralisation of decision-making, typical of high power distance cultures where employees are told what to do (Mearns \& Yule, 2009) and might not feel free to approach their superiors (Gyekye \& Salminen, 2005). Some studies suggest that low power distance cultures where employees are empowered, involved, and feel encouraged to participate in the decision-making process can be beneficial for a good safety culture (e.g. Okolie \& Okoye, 2012 ) and operation of HACCP (Wallace, 2009). However, we did not have a comparison with a low power distance culture.

Although countries sometimes had similar national values, e.g. Tanzania and Zambia, the prevailing FS-culture and the food safety performance differed per country (Tables 5.2 and 5.3). Other factors such as legislation, political environment, economic environment and food safety approaches at organisational level could have influenced the organisational and technological support, attitudes and risk perceptions of the employees. In African countries, for example, economic instability might have hindered companies to invest in the organisational and technological enabling conditions (Macheka et al., 2013). Moreover, organisations have their own traits independent of the national culture (Mearns et al., 2004; Mearns \& Yule, 2009; Seymen \& Bolat, 2010), which could explain why companies operating within the same cultural context slightly differed in food safety performance. A full understanding of national values of the country companies operate in and of the workforce composition (Mearns \& Yule, 2009) is essential for companies to assure best approaches to food safety.

\subsection{Conclusion, limitations and research recommendations}

An intercontinental analysis of the FS-culture of food companies in China, Greece, Tanzania and Zambia revealed that Chinese and Tanzanian companies exhibited an overall active FSculture, whilst Greek and Zambian companies exhibited a proactive FS-culture. No statistically significant differences were found between companies operating within the same country. Findings also showed that food safety performance was consistent with the prevailing FS-culture as companies with a proactive FS-culture reflected better food safety performance. 
Cluster analysis revealed that clustering of companies was attributed to the internal and external environment, with African companies clustering together when compared to Greek and Chinese companies. The African countries showed similarities in national values and food safety governance. As such, national values and food safety governance seemed to influence the prevailing FS-culture of the companies. All national cultural dimensions were significantly correlated with risk perceptions, with masculinity and long-term orientation also significantly correlated with the enabling conditions and attitude. For the internal company environment, the African companies showed similarities in the implementation of food safety programs, which were not yet certified, when compared to Greek and Chinese companies.

One limitation noted in this study was that as an enquiry into the external company environment, this study was comparatively small as it only covered four different nationalities. Another limitation was that although findings revealed statistically significant correlations between national values and the prevailing FS-culture, the relationship between these two could have been influenced by other confounding factors such as the economic environment, which could have hindered investments in e.g. technological and organisational conditions. Moreover, differences in e.g. actual production characteristics among the companies could also have influenced this relationship making it difficult to differentiate cause and effect from the associations observed. Further research should include more respondents as this could improve the robustness of the study as the small number of QA managers provided a limited representation of the countries food safety governance approach. Although questionnaires are more appropriate for online surveys, we still advocate for companies to use method triangulation to fully understand their FS-culture. Understanding how national values and food safety governance approaches differently influence food safety culture is expected to enable formulation of best approaches tailored for companies operating in countries with different company environments, to improve food safety performance.

\section{Acknowledgements}

The authors are grateful to The Netherlands Fellowship Programmes (NFP) (Grant award number H4. 9421/2014) as well as to all respondents for their collaboration. We thank Beatha Mkojera, Sofia Pandi, and Sydney Phiri for assistance with data collection, and James Ledo and Dr ir Lesley Macheka with data analysis. 



\section{Chapter 6}

General discussion 


\subsection{Introduction}

Food safety culture (FS-culture) is becoming of key interest in food safety performance. Also, the food industry is increasingly recognising its importance (Emond \& Taylor, 2018; GFSI, 2018) in a bid to improve food safety. Having a good, strong and positive FS-culture is being acknowledged as beneficial to the sustenance of an organisation. The recognition of FSculture is mostly because food safety performance is currently anchored on more technological and traditional approaches such as sampling, testing, inspections and auditing. Although these are crucial to the functioning of the organisation, they are mainly reactive approaches. FS-culture studies are therefore incorporating human dimensions such as attitudes, perceptions, and the psychological well-being of employees to optimise company culture and improve food safety performance. This is because food safety challenges are mostly attributed to errors by humans, be it auditors, management or food handlers (Greig et al., 2007; Powell et al., 2013; Powell et al., 2011). This thesis focuses on food handlers as they are in direct contact with food products. Their decisions are shaped by an organisation's FS-culture. If a company's FS-culture is inadequate, it could lead to inadequate food safety performance.

Although the FS-culture concept has been acknowledged and has been found to contribute to food safety performance (this thesis), there remains a challenge for companies to incorporate it in their daily operations and food safety management. The research was therefore performed to evaluate the prevailing FS-culture in food processing organisations and to identify bottlenecks that could lead to food safety problems. Knowing the main food safety issues could be beneficial in ensuring that specific and tailored interventions are applied if FSculture is to become supportive in improving food safety performance. This discussion chapter summarises the major findings, discusses their relevance and the extent to which the objectives were achieved using an integrated approach.

\subsection{Main findings}

This thesis aimed at understanding aspects relevant in assessing an organisation's FS-culture and investigated the influence of an organisation's prevailing FS-culture on food handler behaviour and ultimately food safety performance. To attain this goal, existing literature on national, organisational and safety culture was firstly reviewed (chapter 2). The study discussed the positioning of FS-culture within different disciplines, resulting in the establishment of determinants for conducting FS-culture research. These determinants were 
suggested as a basis upon which FS-culture research could be built (Figure 6.1). Thereafter, owing to the findings in chapter 2, identified key elements were used to assess the prevailing FS-culture of companies in an explorative study (chapter 3) based on a mixed-method approach. The study validated the identified elements and supported the suitability and validity of a mixed-methods approach to assess an organisation's prevailing FS-culture. Moreover, three levels (reactive, active and proactive) were identified as suitable to distinguish an organisation's FS-culture.

Next, a FS-culture research framework (chapter 4), which included indicators and assessment grids to enable differentiated assessment of an organisation's FS-culture, was further developed based on the empirical study (chapter 3). The framework also included characteristics of the internal and external company environment that could influence an organisation's FS-culture. The prevailing FS-culture of companies operating in an emerging economy and differing in product riskiness was assessed to investigate whether product riskiness influences FS-culture. The hypothesis was that high-risk companies possess a better FS-culture when compared to medium and low-risk companies. Concurrently, the internal and external company environment was assessed to see whether it influences an organisation's FS-culture. Findings indicated no direct relationship between product riskiness and FS-culture but that the external environment could have shaped the prevailing FS-culture. The influence of the external company environment with further emphasis on national values and food safety governance was therefore explored in chapter 5 . The aim was to investigate whether companies in countries differing in national values and food safety governance differed in FSculture. Indeed, the external environment influenced the prevailing FS-culture to a certain extent as we found differences between companies in African and non-African companies regarding both food safety governance and national values.

Our research objectives were formulated and discussed from a systems thinking perspective, which considers the company and the interaction with its environment. This holistic approach gives insights into possible FS-culture characteristics and elements crucial to understanding an organisation's FS-culture. A foundation to comprehensively evaluate an organisation's prevailing FS-culture within its company environment was provided, which offers an opportunity for informed guidelines that could facilitate tailored interventions to create a better organisational FS-culture. Figure 6.1 summarises the findings in this thesis and the proposed theories and approaches used to elaborate this research. FS-culture is discussed from 
an organisational perspective (section 6.3) as we studied an organisation's FS-culture in this thesis. Section 6.4 zooms in on the individual as these were assessed to gain insights into organisational FS-culture. As our research anchors on the systems approach, we then discuss the external company environment and its influence on an organisation's FS-culture (section 6.5). Suggestions to improve and sustain an organisation's FS-culture are given (section 6.6), together with research recommendations (section 6.7).

\subsection{Food safety culture at an organisational level}

In chapter 2, the literature review unveiled useful characteristics, elements, indicators, and methodologies that formed the basis of our FS-culture research. The determinants were used as a foundation upon which we anchored our explorative studies in chapters 3, 4 and 5 . The focus of this thesis was on the "organisation" as we aimed at assessing the prevailing FSculture of food processing companies.

\section{Perspectives in organisational culture assessment}

Three perspectives, i.e. integration, differentiation and fragmentation, have been discussed in organisational culture literature as suitable to understand an organisation's culture (Harris \& Ogbonna, 1998; Martin, 1992; Schein, 2004; Wilson, 2001). Our analysis on the prevailing FS-culture in chapter 3 was initially based on the integration perspective. The integration perspective is one in which consensus and consistency within the organisation portrays a strong and desirable culture (Wilson, 2001). As such, the research was built on the premise that a proactive FS-culture is characterised by supportive enabling conditions, which are aligned with strong attitudes, good risk perceptions, good food safety and hygiene perceptions, and a high inclination to engage in non-risky behaviour. From this perspective, consistency, shared perceptions and a dominant, strong prevailing culture portrayed proactiveness (Kotrba et al., 2012; Martin, 1992). Inconsistencies and lack of consensus were deemed to reflect a reactive, weak and negative FS-culture. Although the integration perspective focuses on consensus, perfect unanimity is impossible to achieve as organisations are not homogenous entities as we saw in this thesis, but are divided into e.g. different departments, groups and levels of employment. In chapter 3, food handlers' perceptions on the supportiveness of technological and organisational conditions were not always aligned with that of managers, which was consistent with De Boeck et al., 2015), who also observed that managers and food handlers were not always on the same wavelength. 


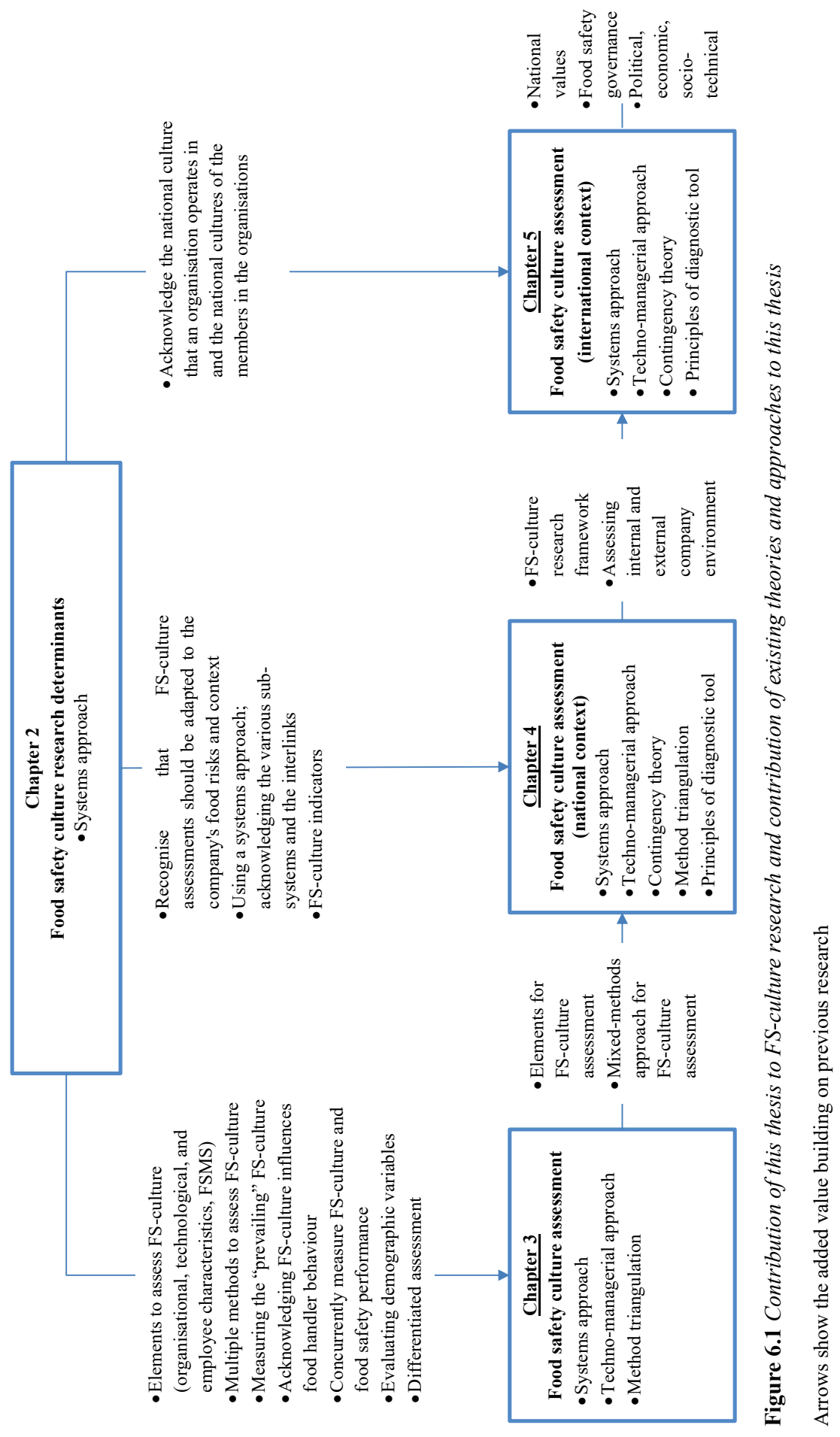


Differences were also observed between food handlers working in different shifts and in different departments (chapters 3 and 4). Organisations are complex adaptive systems and although they exhibit an aggregate behaviour (i.e. prevailing FS-culture), the individual parts (e.g. subgroups) can be conditioned differently and can be embedded in different and changing environments (Holland, 1992). This results in the aggregated behaviour of the systems being far from optimal (Holland, 1992), and provides a partial picture of an organisation's culture (Wilson, 2001).

It is important to note that different parts of an organisation could have different levels of culture at the same time (Clark, 2002; Fleming \& Lardner, 1999; Manning, 2017; Sadri \& Lees, 2001), which could pose hurdles if an overall organisational FS-culture is to be concluded. This led us to acknowledge the differentiation perspective, which disintegrates culture into parts and recognises that different subcultures (i.e. cultural groups emerging from different groups within the organisation e.g. professions, hierarchical levels, departments) may exist within an organisation (Davies et al., 2000; Martin, 2002). Moreover, Manning (2017) suggested that subcultures ought to be considered in FS-culture assessments as these can ultimately impact food safety performance. In this thesis, we evaluated the operational level, including food handlers, line managers/supervisors, and support functions (i.e. QA department and engineering of the organisation) and acknowledge that an organisation's FSculture is expressed differently within different hierarchical levels, organisational roles, shifts, employment status and different departments as observed in chapters 3, 4 and 5. One department may value production or profit over food safety and vice versa. In the former, food safety rules and procedures might be circumvented to ensure continuance of production and in the latter, risk assessments might always be conducted prior to starting every job (Cooper, 2000). Furthermore, senior management could have different priorities when compared to middle management and the operational level (Goffee \& Jones, 1996; Manning, 2017). For example, in the interviews reported in chapters 3, 4 and 5, respondents also indicated that sometimes the finance department would not be supportive to some choices made by the QA department citing costs, which might be indicative of other priorities. Sometimes leadership and management (chapter 3) were also observed and perceived not to follow food safety and hygiene protocols. Subcultures provide a diversity of perspectives and interpretation of emerging (food safety) problems (Pidgeon, 1998) but lack of congruence between the subcultures can be a cause for conflict and poor food safety performance (Manning, 2017). 
Another school of thought considers the fragmentation perspective, which entails research on specific food safety incidences within a company (Wilson, 2001), or in the event that a product consistently fails to meet product specifications. Examples are the Maple Leaf Foods and the John Tudor and Son cases (Jespersen \& Huffman, 2014; Pennington, 2009), where enquiries into the FS-culture of the company were made. In evaluating an organisation's FSculture, all three perspectives (integration, differentiation and fragmentation), together, could therefore give an in-depth insight into an organisation's FS-culture, thus enabling better understanding of the organisation's FS-culture. This is because there might be consensus on some aspects across the organisation, consensus only within subcultures and other ambiguous issues that need an in-depth analysis.

\section{Organisational effectiveness}

This thesis was hinged on the premise that an organisation's FS-culture must be taken into account to improve current food safety performance. Therefore, the explorative studies determined characteristics of an organisation's FS-culture (chapter 3) and of the organisations' internal and external environment (chapter 4 and 5) that could ultimately influence organisational effectiveness, i.e. food safety performance. Findings in chapters 3 and 5 revealed that food safety performance was reflected in the prevailing FS-culture as companies with a proactive FS-culture exhibited better food safety performance.

In organisational culture literature, four cultural traits, namely mission, involvement, consistency and adaptability, were identified that might influence an organisation's performance (Denison et al., 2006; Kotrba et al., 2012; Reason, 1998; Schein \& Schein, 2016; Sorensen, 2002). Although not specifically studied under those four dimensions, elements of these dimensions were captured in the explorative studies in this thesis. For example, concerning the first dimension "mission", the food safety vision of the organisation was assessed in chapters 3, 4 and 5 to get an insight into the clarity of the vision, supportiveness of the vision in setting food safety priorities, and the extent in which it motivated food handlers to execute their work tasks. Results showed that food handlers in some companies in developing countries indicated that the vision only slightly motivated them when executing their tasks, which was confirmed by QA managers, who mentioned that food handlers required supervision at times for them to carry out their tasks properly. Denison et al. (2006) posit that a successful organisation will have clear-cut goals and objectives, which give a clear sense of direction as is necessary for organisational effectiveness. Such organisations will 
have a mission that can shape behaviours to a desired state and where members can identify with and internalise the mission.

Secondly, regarding the dimension "involvement", we measured aspects of employee involvement such as whether employees can easily approach their bosses, whether their input was considered in aspects regarding their work, e.g. when considering changes in procedures or purchasing protective clothing, and whether they were given opportunities for feedback. Findings in this thesis showed that in most companies decision-making was centralised and employees were simply told what to do without their involvement (chapters 3 and 4). Moreover, food handlers were not always provided with opportunities to give feedback, or their feedback was just routine and rarely considered (chapter 4). If employees are empowered, they have a greater sense of ownership, accountability and commitment (Denison et al., 2006).

In assessing the prevailing FS-culture, we also measured aspects of the third dimension, "consistency". For example, we looked at consistency between organisational requirements and food handler perceptions, in food safety behaviour and in food safety performance. Moreover, consistency in organisational supportiveness, e.g. in food safety and hygiene training, record keeping, commitment (walking the talk, reward systems) and food safety priorities were also assessed. In chapters 3 and 4, food handlers' perceptions on food safety and hygiene were not always aligned with organisational requirements. Moreover, some managers in these studies openly violated food safety and hygiene requirements, and food safety and hygiene training was rarely done, leading to food handlers questioning management's commitment to food safety. The Global Food Safety Initiative considers consistency as " the proper alignment of food safety priorities with requirements on people, technology, resources and processes to ensure the consistent and effective application of a food safety program that reinforces a culture of food safety" (GFSI, 2018). As such, consistency should be reflected in the food safety decisions, intentions and in the execution of food safety and hygiene-related work tasks. Moreover, integration of different functions within the organisation should be visible with the common goal of focusing on food safety priorities.

Lastly, regarding the dimension "adaptability", the environmental characteristics in which the companies operated was assessed (chapters 4 and 5) with the intention to understand aspects 
of the internal and external environment that could influence an organisation's prevailing FSculture. However, only the first step was achieved, i.e. getting an insight into the company environment (chapters 4 and 5). How the company reacts to changes in the environment was not assessed, which could be crucial to the functioning of an organisation. In chapter 5, we found that characteristics such as national values and food safety governance were statistically significantly associated $(\mathrm{p}<0.05)$ with some FS-culture variables (i.e. enabling conditions, risk perceptions and attitudes). This led us to postulate that the environment in which a company operates could influence an organisation's prevailing FS-culture. Moreover, some food handlers in chapter 3 always referred to the economic environment as reasons for lack of motivation as they considered themselves to be insufficiently remunerated or rewarded, and some line managers cited the economic environment as reasons to e.g. lack of hygiene design, proper equipment maintenance and lack of adequate protective clothing. The capability of an organisation to adapt to its environment is crucial as it can both impact and be impacted by the FS-culture (GFSI, 2018). Issues such as anticipating, preparing, responding and adapting to change (Denison et al., 2006; GFSI, 2018; Holland, 1992; Reason, 1998; Schein \& Schein, 2016) could be crucial to measure. However, Denison et al. (2006) and Kotrba et al. (2012) suggested that even well integrated organisations might be the least adaptive. We therefore acknowledge that these four dimensions are integral to an organisation's effectiveness and FS-culture assessments and their evaluation is crucial to the functioning of an organisation. Jespersen et al. (2017a) suggested that these dimensions could unify FS-culture research and provide input towards continuous improvement.

\subsection{Food safety culture at the individual level}

Our research was centred on the FS-culture of an organisation as an organisation's FS-culture sets the environment in which food handlers are expected to work. Griffith et al. (2010a) suggested that food handlers can only be as hygienic as the organisation and its leadership requires, permits, and encourages them to be. Therefore, we assessed the individuals within these companies to get their opinions and perceptions on the FS-culture of their organisations. In chapter 2, individual characteristics crucial to FS-culture were identified (i.e. attitudes, perceptions, knowledge, risk awareness). These were assessed in chapters 3 and 4, where food handlers were interviewed, elicited to share stories of food safety incidences, given questionnaires to obtain their perceptions, and observed as they executed their hygiene tasks. Furthermore, in chapter 5 , questionnaires were disseminated to get an insight into perceptions of food handlers on the supportiveness of the enabling conditions. Our findings show that in 
some instances, e.g. in chapter 3, there was a clearly divided opinion (varied responses) on the extent of the supportiveness of the enabling conditions. For example, some food handlers perceived the food safety and hygiene training as structured and others mentioned that it was unstructured. Moreover, some perceived the communication style to be open and advanced, and others mentioned lack of communication tools and limited opportunities for feedback. The varied responses were found to be attributed to the business conditions at the time of assessment (e.g. HACCP implementation, external FSMS audits), positive and negative bias, over- or underestimation, and optimistic bias. A study by Fatimah et al. (2014a) also showed a divided opinion on communication with some respondents appreciating the communication style and others pointing at its inconsistencies.

Moreover, in chapters 4 and 5 findings showed that food handlers could have given socially desirable answers as individuals differently perceived similar issues. Furthermore, findings on employee characteristics did not always translate to good behaviour indicating the need to understand what drives employees to adopt food safety and hygiene behaviour. At the individual level, employees could have brought their experiences and attitudes towards food safety and the organisation, and dispositions such as conscientiousness as also described by De Boeck et al. (2017). These could influence motivation, knowledge, and behaviour at work and the way individuals perceive the value of safety in their organisation (Neal \& Griffin, 2004). Individuals could also have different assumptions regarding the perceived value of food safety, the magnitude of food safety risks, and the importance of the food safety priorities and programs. This could have resulted in different reactions to the same situation, which was consistent with findings in chapter 3 where food handlers expressed different perceptions on the training program, communication style, protective clothing and handwashing facilities. Moreover, the interaction between individual characteristics (e.g. attitudes, personality) and characteristics of the work environment could have affected both their well-being and job satisfaction as indicated by De Boeck et al. (2017) and HSE (2009).

Several authors suggested potential underlying elements that could influence food handler perceptions, attitudes, and behaviour (e.g. De Boeck et al., 2017; Jespersen et al., 2017b; Krumpal, 2013). Many have been linked to the psychological well-being of an individual as safety climate reflects a psychological environment that provides a motivational antecedent for safety behaviours (Neal \& Griffin, 2004). Given the dynamic food processing environments in which people work, there are various work stressors such as workload, time 
pressure, lack of job autonomy, which could all adversely affect employees well-being and ultimately an organisation's performance (De Boeck et al., 2017; HSE, 2009). For example, De Boeck et al. (2017) found a correlation between job stress and burnout with food safety climate and food safety behaviour. Job stress attributed to work conditions and a perceived imbalance on effort and rewards, and burnout (i.e. employees affective and emotional wellbeing) have both been identified as mediators to an organisation's safety climate (Dollard \& Bakker, 2010; Idris \& Dollard, 2014). In our study, food handlers worked in shifts, which were mostly two. The night shift would start at between 4-6 p.m. and end the following day between 6 and 8 a.m. This meant 12-14 hours of work. Such work conditions could have adverse effects on health and decision-making, resulting in carelessness and poor performance due to fatigue.

In addition to the work environment, self-efficacy, the perception or belief regarding one's ability to perform a certain behaviour, and outcome expectancy, the belief that a certain behaviour will lead to a specific outcome could have influenced food handlers' (Gilling et al., 2001) daily decision-making. This was reflected in the intended behaviour of food handlers as the food handlers were strongly inclined not to engage in risky behaviour. Analysing psychological well-being of employees could therefore be beneficial in minimising psychosocial risks (Pienaar \& Willemse, 2008) as the level of fit between the employee and the job could influence their sense of well-being (HSE, 2009).

In addition to psychological well-being, individuals could have made different assumptions related to the perceived value of food safety, and magnitude of food safety risks based on personal characteristics such as whether they were seasonal, contract or permanent workers, age and work experience. A study on safety culture, which assessed safety attitudes found major differences in attitudes and perceptions with respect to age, experience, and employment status (Mearns et al., 2001). Focusing on personal characteristics could help in development programs to ensure employees are food safety conscious and motivated to execute their work tasks properly.

\subsection{Understanding the influence of the external environment to an organisation's FS- culture}

The system approach formed the basis of this study. From that perspective, we evaluated the environment that the organisations operate in, in addition to the FS-culture of an organisation 
based on the contingency theory (Figure 6.1). The contingency theory posits that an organisation's performance is influenced by the context wherein it operates (Chenhall, 2006). Schein and Schein (2016) suggested that a company's environment is part of an organisation's culture, thus reflecting a socio-technical system. In that regard, our assessment of the role of a company's environment in an organisation's FS-culture in chapter 4 indicated that national values and the approach of food safety governance were reflected in the way food safety was prioritised, food safety programs were designed, and the observed food safety behaviour. Chapter 5, an intercontinental study, also made similar assumptions and differences were also found between countries, leading to the supposition that the way food safety is prioritised by food companies could be influenced by the food safety governance approach and national values. The intercontinental study revealed that Chinese and Tanzanian companies exhibited overall an active FS-culture, whilst Greek and Zambian companies exhibited a proactive FSculture. The latter could be seen back in the food safety legislation, its enforcement and in the national values. For example, companies in Greece adopted multiple internationally accepted private standards, which were also effectively enforced. Moreover, Greece being a masculine culture and management in Zambia being from India, also considered to be a masculine culture, could have contributed to the assertiveness, emphasis on getting things done and consequentially the proactive FS-culture.

Findings in this thesis are a step towards conceptualisation of the broad context, in which companies operate, as there is a diverse number of environmental characteristics that could influence an organisation's FS-culture. Most of these influencing factors may individually or in combination influence an organisation's FS-culture, thus the particular emphasis on the "prevailing" FS-culture of an organisation in this thesis as the status of an organisation's FSculture could also change with changes in the external environment. Sousa and Voss (2008) suggested that an organisation reacts to changes in its external environment to establish fit with the external environment. In our studies in an emerging economy, we established that at the time of assessment, especially in chapter 4, our case study, Zimbabwe was heading towards elections and therefore the political climate was unstable. Moreover, there was a major shift in the economy with devaluation of the currency and rise in job shortages, which inevitably reduced the value of the Zimbabwean dollar and labour market rates, respectively. This precarious situation created many uncertainties (Gukurume, 2018) as people were making do and getting by as the country was inundated with economic and social chaos. Moreover, this precarious situation could have played a role in our findings as most 
respondents were disgruntled about the current state of affairs and the uncertainty of the future with most discussions on food safety priorities centred on the status of the economy. Nayak and Waterson (2019) suggested that food safety is a complex adaptive system and that "disruptions at one point in the system can lead to reverberations in the form of economic, social and political impacts throughout the entire system". This led us to the postulation that the political, economic, social and technological (PEST) environment could also have been influential in our FS-culture assessments in chapters 2, 3, 4 and 5. Gupta (2013) suggested that the PEST stability of a country could influence the sustainability of organisations. Moreover, the adaptability of a company to its external environment is crucial for organisational effectiveness (Denison et al., 2006; Kotrba et al., 2012). Understanding the PEST environment could direct appropriate and more effective interventions.

\subsection{Towards improvements in an organisation's FS-culture}

This thesis established that an organisation's FS-culture cannot be attributed to a single factor but to multiple aspects related to the organisational conditions, technological infrastructure, human factors, and the environment in which a company operates. Chapters 3, 4 and 5 illustrate that whether technological and organisational conditions enabled or hindered food handlers in executing their work tasks is key to food safety performance. Employee characteristics such as food safety and hygiene attitudes and risk perceptions were also found to influence food handler behaviour, affect food safety performance (chapter 3 ) and induce complacency (chapter 4). Furthermore, features of the internal company environment such as the vulnerability of the food production system (chapter 4) and food safety programs (chapter 5), possibly shaped an organisation's FS-culture. Both chapters 4 and 5 also considered the possibility of the external company environment, i.e. national values and food safety governance to model an organisation's FS-culture as these were reflected in the prevailing FSculture.

Having established the influencers of an organisation's FS-culture, findings in this thesis directed the identification of possible FS-culture specific interventions and a roadmap, which could help companies to create, improve and sustain their FS-culture.

The first step is identification of the FS-culture level as shown in Figure 6.2, which illustrates FS-culture as a function of direction i.e. ranging from strongly negative to positive, and strength i.e. the extent to which food safety values are shared and held, and food safety is 
prioritised, practiced and rooted within the organisation (Griffith, 2013). These two dimensions form the basis upon which FS-culture was measured in this thesis and on which FS-culture could be improved. In this thesis we focused on FS-culture ranging from reactive to proactive and acknowledge that there could be other companies in the extremes (i.e. pathological, typifying non-existent food safety consciousness, and enlightened, typifying food safety conscientiousness). However, it does not necessarily mean that the more enlightened FS-culture will not face food safety issues as FS-culture paranoia could make operations rigid, and workers could lose motivation, resulting in performance losses (Pidgeon, 1998).

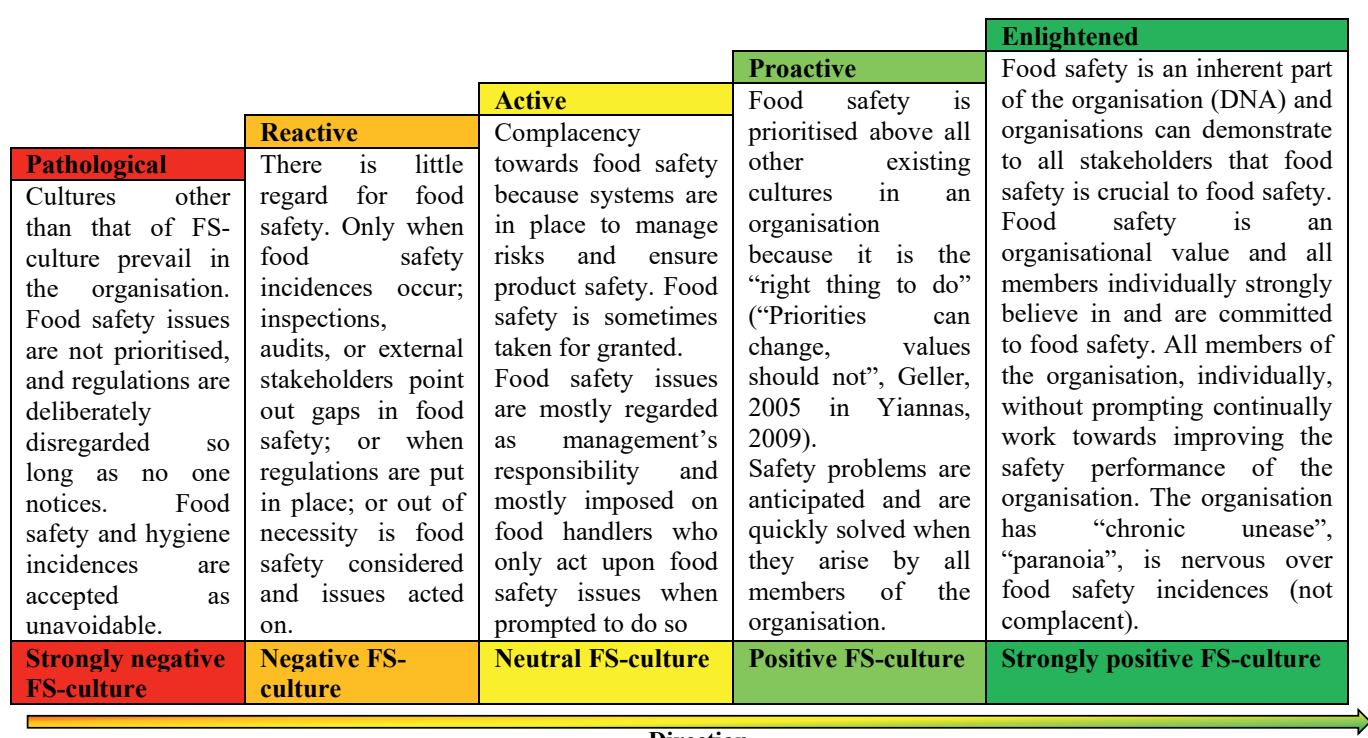

Direction

Figure 6.2: Different levels/types of FS-culture

Secondly, when organisations know their type or level of prevailing FS-culture, they can take steps to better the FS-culture (Wright \& Leach, 2013) by providing specific interventions, rather than generic "best practices". However, when a strong, well-established, unacceptable FS-culture exists, that makes it complex and a daunting task to change. This requires hard work and commitment to ensure an acceptable FS-culture is inculcated in the organisation (Yiannas, 2009).

Thirdly, organisations need to understand that to improve and sustain their FS-culture, they need to develop an informed, reporting, just, flexible and learning culture (Hudson, 2001b; Khatri et al., 2009; Reason, 1998; Weick \& Sutcliffe, 2001), as explained below: 
- In an informed culture, personnel in an organisation know the risks inherent to their food production system and understand the technological, organisational, human and company environment factors crucial to realising food safety.

- A reporting culture creates a transparent, confidential, and fair environment in which personnel can freely report food safety issues and concerns. This is achieved through a food safety information system that collects, analyses and disseminates information obtained from reported and observed issues and incidences, and even lessons drawn from other companies. Employees should want to report issues with the confidence that they will be heard, action will be taken, and management are committed to food safety and hygiene issues.

- In a just culture, fairness and consistency establish trust in the company. Companies move away from a blame culture. As such, acceptable and unacceptable behaviour are consistently praised or punished, respectively, in a systematic and appropriate manner.

- In a flexible culture, everyone can adapt and if necessary converge together, shifting from a rigid hierarchical mode to a flatter structure, which involves everyone in prioritising food safety.

- In a learning culture, continuous improvement is key. The company should be willing to draw lessons from the information system and implement reforms.

Table 6.1 illustrates a roadmap, which shows a broad framework that can guide companies on the type of interventions that they can take, depending on the type/level of FS-culture that they have (Figure 6.2). A stepwise approach is proposed below (i.e. immediate, intermediate and ultimate), which suggests what an organisation can immediately do to what it can do in the long-term to improve food safety performance based on Cooper (2001). The immediate level is concerned with basics that an organisation can easily achieve such as development of strategic plans, so the organisation can fully incorporate food safety in the whole system. In the intermediate level, systems are recommended, which facilitate organisational learning. Ultimately, a sustainable FS-culture, which advocates for food safety and incorporates views of all personnel, empowering them to be actively involved with food safety on a daily basis is proposed. When management, employees, and leadership feel personally committed to food safety, they will continuously strive to do the right thing even when no one is watching. Moreover, food safety becomes top priority, encouraging personnel to make the right 
decisions on food safety. Management should therefore start with the basic requirements (Table 6.1) when trying to improve their FS-culture because by-passing these steps and starting with advanced requirements could result in failures due to unrealistic expectations (Cooper, 2001).

It is imperative to note that while an organisation's FS-culture can be changed, it is easier to manipulate an organisation's policies, structures, practices and priorities, and can take longer to change the attitudes, perceptions and values of personnel within the organisation. Change can be achieved through cultural conditioning. This is where an increase in the desired actions and responses can be achieved through reinforcements and rewards following the desired response (Savani et al., 2011). As such, an organisation that consistently reinforces and fosters food safety priorities, empowers through involvement and can adapt to different internal and external situations, is more likely to succeed in food safety performance. It is crucial to note that an organisation's food safety performance not only depends on consistency in its internal processes, but also hinges on the organisation's ability to adapt to changes in the environment (Schein \& Schein, 2016; Sorensen, 2002), thus the need for companies to have an in-depth understanding of their operating environments. 


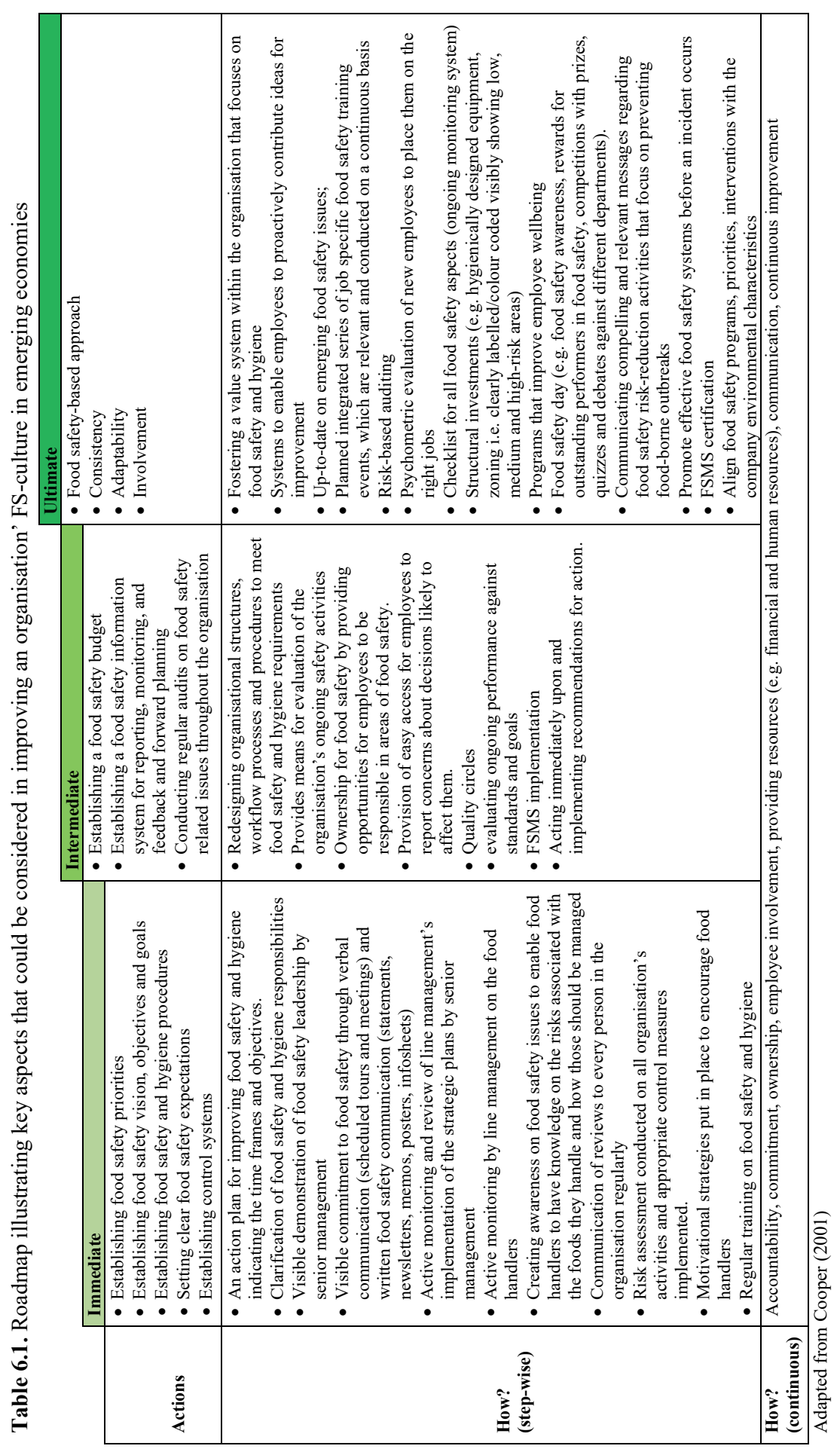




\subsection{Research implications and recommendations}

\subsubsection{Practical implications}

This thesis provides insights and tools that could help support the food industry, regulators, policy makers and researchers to make informed decisions regarding FS-culture assessments. The determinants for conducting FS-culture research could be used as a foundation upon which FS-culture research could be built and could guide regulators, i.e. inspectors and auditors, on aspects that could be useful in evaluating an organisation's FS-culture. The FSculture research framework developed in this thesis could also support organisations in assessing their prevailing FS-culture through differentiated assessment. Moreover, companies could also have an understanding of their operating environment, which could be beneficial in adapting to their environment, thus improving food safety performance. The mixed-methods approach could also be useful for companies to understand their prevailing FS-culture as different sources of information are used. Insights obtained from both FS-culture assessment and the mixed-methods approach could help companies identify areas of concern (bottlenecks) and help them identify improvement opportunities. The proposed roadmap could also guide recommendations that companies can adopt and the proposed step-wise approach could allow companies to ease into the interventions without being overwhelmed.

Considering the context of emerging economies studied in this research, and challenges that they could potentially face, companies could start with those interventions that require little or no capital investment and gradually transition to those where capital is required. However, policy makers should also be supportive as some issues regarding food safety governance can only be successfully implemented with their support. Moreover, trade associations could also support food companies by lobbying for policy makers to create policies that could help in solving problems that hinder companies in their mission for food safety.

\subsubsection{Research recommendations}

\section{Recommendations for food companies investigated in this study}

Companies need to demonstrate visible commitment to food safety. This can be achieved by setting clear food safety expectations, which include an action plan indicating time frames and objectives that should be achieved. It is imperative that the expectations must be achievable, clear, and understandable. Senior management should also set an example by demonstrating preferred behaviours (i.e. walking the talk) and cultural values through their responses to organisational emergencies. By leading by example, they demonstrate that they are enforcing 
the values of the company. Food safety should be a shared responsibility of everyone within the organisation and should incorporate all departments, including e.g. human resources and finance departments. For example, finance needs to understand the need to have appropriate suppliers and to purchase resources required to assure appropriate processing of food products. Moreover, employees should also be involved in decision-making, e.g. users of procedures can be involved in the design and updating of procedures to ensure that existing procedures reflect current work practices. Management also needs to ensure that food safety procedures that standardise the ways of doing things, codify work practices and include the organisation's best way to get things done, whilst minimising risks associated with human error and equipment failure are in place. Companies should also implement a culture of information sharing that fosters an open communication environment.

Members of the organisations should receive appropriate food safety training specific to their jobs. Training should consider individual needs, such as location of work and the products they handle by taking cognisance of repeated hygiene and safety control problems. Management should also put effort in creating a sustainable reward system in the form of open recognition. This does not necessarily have to be monetary, but can be simple as consistently praising or giving negative consequence to incorrect behaviour. This could be a beneficial motivator for better hygiene practices. Internal audits should be conducted and focus on the more important aspects of food safety. Risk-based auditing could also be considered as a useful tool in FS-culture assessments as it focuses on areas of risk (Albersmeier et al., 2009). The audits should span a wide spectrum from daily checks by peers, QA department, line management, system internal audits, and audits by third parties.

\section{Recommendations for further research}

Various factors have been introduced and are discussed in this thesis. Although essential to FS-culture, there is need to consider the practicability of having to assess all these factors, as assessing FS-culture should not be a daunting task and prove to be tedious. Further research should therefore establish the most appropriate factors that might be useful in understanding FS-culture. The complexity of FS-culture is acknowledged, which makes it a challenging task to capture pertinent aspects with a manageable assessment tool (Fatimah et al., 2014a). Further research could also add weight factors to the different FS-culture elements when these are found to differently contribute to food safety performance. Nayak and Waterson (2016) suggested that some FS-culture elements could be more detrimental than others and their 
effect on food safety performance could prove to be more damaging. Moreover, effective methods of assessment should also be considered based on the mixed-methods (i.e. method triangulation) approach. Method triangulation could allow counterbalancing of the weaknesses in each method, allowing for a more solid evaluation of FS-culture.

Further research needs to explore FS-culture at the different hierarchical levels of an organisation (i.e. strategic and tactical), in addition to the operational level evaluated in this study, and of different departments to get an insight into the overall prevailing FS-culture of a company. Moreover, our assessment of FS-culture was done in emerging economies and to generalise the FS-culture research framework developed in this thesis (chapter 4), there is need for studies in developed countries, which also have a different external environment (e.g. food safety governance and national values). Moreover, characteristics of the political (e.g. domestic political climate, changes in government, and legislation), economic (e.g. exchange rates, currency devaluation/appreciation, commodity prices, changes in the labour markets), social (e.g. demographic patterns) and technological (i.e. technological changes and their effects on the products and processes) (PEST) environment should be considered. This is to establish factors that could be influential in the prevailing FS-culture to enable companies to evolve with these changes and have strategies in place to address issues should they arise.

Although our thesis revealed statistical associations between FS-culture and the external environment (chapter 5), there is a need to assess whether there were no confounding factors that could have influenced the relationship. Havold (2007) suggested that underlying factors could influence this cause-effect relationship.

Finally, a roadmap was proposed. Further research is recommended to firstly validate the proposed interventions through longitudinal intervention studies. This could allow for more relevant interventions to be established. Secondly, interventions ought to be adapted to different business contexts to provide more suitable and context-specific roadmaps.

\subsection{Concluding remarks}

The research described in this thesis demonstrates that in addition to an organisation's FSMS, a company's organisational and technological supportiveness to food safety, and employee characteristics (i.e. knowledge, attitudes, perceptions, intentions and actual behaviour) give an indication of the prevailing FS-culture. Moreover, the internal company environment 
characterised by the vulnerability of the food production system and the supportiveness of the food safety programs could influence the prevailing FS-culture. At the broad context, i.e. the company's external environment, including food safety governance and national values seemed to influence an organisation's FS-culture as well. The findings therefore showed the importance of a systems approach in understanding FS-culture. Moreover, the overall goal of this thesis was to gain insight into an organisation's FS-culture and its influence on food safety performance, of which we found that indeed there was an association between the two. Our findings in this thesis broadened the understanding of elements that could be useful in assessing an organisation's FS-culture within the internal and external environment. Moreover, findings provided valuable insights that could be useful in designing FS-culture specific interventions, which could contribute to improvements in food safety performance. For example, national values could be beneficial in determining the type of interventions that could work in companies, e.g. long-term oriented cultures, which prefer future planning compared to short-term oriented cultures, which prefer to address prevailing issues. Moreover, some emerging economies would prefer more tailored interventions depending on e.g. economic stability. The capacity of a company to adapt to changing environments could prove to be important to successful food safety performance. 


\section{References}

Ababio, P. F., \& Lovatt, P. (2015). A review on food safety and food hygiene studies in Ghana. Food Control, 47, 92-97.

Adamson, G., Pine, J., Van Steenhoven, T., \& Kroupa, J. (2006). How storytelling can drive strategic change. Strategy \& Leadership, 34(1), 36-41.

Ajzen, I. (1991). The Theory of Planned Behaviour. Organizational behaviour and human decision processes, $50,179-211$.

Albersmeier, F., Schulze, H., Jahn, G., \& Spiller, A. (2009). The reliability of third-party certification in the food chain: From checklists to risk-oriented auditing. Food Control, 20(10), 927-935.

Alexopoulos, E. C. (2010). Introduction to multivariate regression analysis. Hippokratia, 14(Suppl 1), 23-28.

Alvesson, M. (2012). Understanding organizational culture (2nd ed.). London: Sage.

Amjadi, K., \& Hussain, K. (2005). Integrating food hygiene into quantity food production systems. Nutrition \& Food Science, 35(3), 169-183.

Arellano, C. (2008). Default risk and income fluctuations in emerging economies. American Economic Review, 98(3), 690-712.

Arendt, S. W., Ellis, J. D., Strohbehn, C., \& Paez, P. (2011). Development and use of an instrument to measure retail foodservice employees' motivation for following food safety practices. Journal of Foodservice Business Research, 14(1), 68-85.

Arnold, D. J., \& Quelch, J. A. (1998). New strategies in emerging markets. MIT Sloan Management Review, $40(1), 7$.

Arnold, R. D., \& Wade, J. P. (2015). A Definition of Systems Thinking: A Systems Approach. Procedia Computer Science, 44, 669-678.

Asdullah, M. A., Zohaib-ur-Rehman, \& Ahmad, R. N. (2015). Impact of External Factors on Fast Food Business. Journal of Resources Development and Management, 9, 30-34.

Ashkanasy, N. M., Wilderom, C. P. M., \& Peterson, M. F. (2000). Handbook of Organizational Culture and Climate: SAGE Publications.

Ball, B., Wilcock, A., \& Colwell, S. R. (2010). Tool for Measuring Food Safety Climate. Journal of Food Protection Supplement, 73(Supplement A), 84-85.

Balmer, J. M., \& Wilson, A. M. (2001). Understanding organisational culture and the implications for corporate marketing. European Journal of Marketing, 35(3/4), 353-367.

Banks, J. (2012). Storytelling to access social context and advance health equity research. Preventive medicine, 55(5), 394-397.

Banson, K. E., Nguyen, N. C., Bosch, O. J., \& Nguyen, T. V. (2015). A systems thinking approach to address the complexity of agribusiness for sustainable development in Africa: a case study in Ghana. Systems Research and Behavioral Science, 32(6), 672-688.

Bas, M., Yuksel, M., \& Cavusoglu, T. (2007). Difficulties and barriers for the implementing of HACCP and food safety systems in food businesses in Turkey. Food Control, 18(2), 124-130.

Bauwens, A. (2010). The use of method triangulation in probation research. European Journal of probation, 2(2), 39-52.

Bloor, G. (1999). Organisational culture, organisational learning and total quality management: a literature review and synthesis. Australian Health Review, 22(3), 162-179.

Boatemaa, S., Barney, M., Drimie, S., Harper, J., Korsten, L., \& Pereira, L. (2019). Awakening from the listeriosis crisis: Food safety challenges, practices and governance in the food retail sector in South Africa. Food Control, 104, 333-342.

Boyce, M. E. (1996). Organizational story and storytelling: a critical review. Journal of organizational change management, 9(5), 5-26.

Burke, M. J., Chan-Serafin, S., Salvador, R., Smith, A., \& Sarpy, S. A. (2008). The role of national culture and organizational climate in safety training effectiveness. European Journal of Work and Organizational Psychology, 17(1), 133-152.

Caduff, L., \& Bernauer, T. (2006). Managing risk and regulation in European food safety governance. Review of Policy Research, 23(1), 153-168.

Carugi, C. (2016). Experiences with systematic triangulation at the Global Environment Facility. Evaluation and program planning, 55, 55-66.

Casey, T. W., Riseborough, K. M., \& Krauss, A. D. (2015). Do you see what I see? Effects of national culture on employees' safety-related perceptions and behavior. Accident Analysis \& Prevention, 78, 173-184.

Centers for Disease Control and Prevention (CDC). (2018). Surveillance for Foodborne Disease Outbreaks, United States, 2016, Annual Report. Atlanta, Georgia: U.S. Department of Health and Human Services, CDC.

CFIA. (2012). Safe food for Canadians act (S.C. 2012, c. 24).

CFIA. (2014). Food safety enhancement program manual Retrieved from http://www.inspection.gc.ca/DAM/DAM-food-aliments/STAGING/texttexte/food fsep man 1343667674768 eng.pdf website: http://www.inspection.gc.ca/DAM/DAM-foodaliments/STAGING/text-texte/food_fsep_man_1343667674768_eng.pdf

Chaidoutis, E., \& Koutou, A. (2018). The Framework of Hygiene Inspections in the Food Sector in GreeceImplementation of HACCP Principles and Penalties in Case of Non-Compliance. Health Science Journal, 12(3). 
Chapman, B., Eversley, T., Fillion, K., MacLaurin, T., \& Powell, D. (2010). Assessment of food safety practices of food service food handlers (risk assessment data): testing a communication intervention (evaluation of tools). Journal of Food Protection \&, 73(6), 1101-1107.

Chen, E., Flint, S., Perry, P., Perry, M., \& Lau, R. (2015). Implementation of non-regulatory food safety management schemes in New Zealand: A survey of the food and beverage industry. Food Control, 47, 569-576.

Chenhall, R. H. (2006). Theorizing contingencies in management control systems research. Handbooks of management accounting research, 1, 163-205.

Chimboza, D., \& Mutandwa, E. (2007). Measuring the determinants of brand preference in a dairy product market. African Journal of Business Management, 1(9), 230-237.

Chimuti, S., Midzi, N., Njage, P. K., \& Mugadza, D. T. (2016). Microbial species of safety concern in milk from informal processors in Harare, Zimbabwe. African Journal of Microbiology Research, 10(32), 12571262.

Clark, G. (2002). Organisational culture and safety: an interdependent relationship. Australian Health Review, 25(6), 181-189.

Clarke, S. (2003). The contemporary workforce: Implications for organisational safety culture. Personnel Review, 32(1), 40-57.

Clayton, D. A., \& Griffith, C. J. (2008). Efficacy of an extended theory of planned behaviour model for predicting caterers' hand hygiene practices. International Journal of Environmental Health Research, 18(2), 8398.

Clayton, D. A., Griffith, C. J., Price, P., \& Peters, A. C. (2002). Food handlers' beliefs and self-reported practices. International Journal of Environmental Health Research, 12(1), 25-39.

Codex Alimentarius. (2003). Recommended International Code of Practice General Principles of Food Hygiene. CAC/RCP 1-1969, Rev. 4.

Codex Alimentarius. (2004). General Guidelines on Sampling. CAC/GL 50-2004.

Cogliser, C. C., Schriesheim, C. A., Scandura, T. A., \& Gardner, W. L. (2009). Balance in leader and follower perceptions of leader-member exchange: Relationships with performance and work attitudes. The Leadership Quarterly, 20(3), 452-465.

Consumer Goods Forum (CGF). ( 2011). Creating a Global Food Safety Culture. Paper presented at the Global food safety Conference, United Kingdom. http://www.mygfsi.com/images/mygfsi/gfsifiles/information-kit/Conference_Report_2011.pdf

Cooper, D. (2001). Improving Safety Culture: A Practical Guide (2 ed.). Chichester: John Wiley \& Sons

Cooper, D. (2002). Safety culture. Professional Safety, 47(6), 30-36.

Cooper, M. D. (2000). Towards a model of safety culture. Safety Science, 36(2), 111-136.

Creswell, J. W., Klassen, A. C., Plano Clark, V. L., \& Smith, K. C. (2011). Best practices for mixed methods research in the health sciences. Bethesda (Maryland): National Institutes of Health, 2094-2103.

Crim, S. M., Griffin, P. M., Tauxe, R., Marder, E. P., Gilliss, D., Cronquist, A. B., . . . Smith, K. (2015). Preliminary Incidence and Trends of Infection with Pathogens Transmitted Commonly Through FoodFoodborne Diseases Active Surveillance Network, 10 US Sites, 2006-2014. MMWR. Morbidity and mortality weekly report, 64(18), 495-499.

da Cunha, D. T., Stedefeldt, E., \& de Rosso, V. V. (2014). The role of theoretical food safety training on Brazilian food handlers' knowledge, attitude and practice. Food Control, 43, 167-174.

Davies, H. T., Nutley, S. M., \& Mannion, R. (2000). Organisational culture and quality of health care. Quality in Health Care, 9(2), 111-119.

De Boeck, E., Jacxsens, L., Bollaerts, M., Uyttendaele, M., \& Vlerick, P. (2016). Interplay between food safety climate, food safety management system and microbiological hygiene and safety. Food Control, 65, 78-91.

De Boeck, E., Jacxsens, L., Bollaerts, M., \& Vlerick, P. (2015). Food safety climate in food processing organizations: development and validation of a self-assessment tool. Trends in Food Science \& Technology, 46(2), 242-251.

De Boeck, E., Jacxsens, L., Mortier, A., \& Vlerick, P. (2018). Quantitative study of food safety climate in Belgian food processing companies in view of their organizational characteristics. Food Control, 88, 15-27.

De Boeck, E., Jacxsens, L., Vanoverberghe, P., \& Vlerick, P. (2019). Method triangulation to assess different aspects of food safety culture in food service operations. Food Research International, 116, 11031112.

De Boeck, E., Mortier, A. V., Jacxsens, L., Dequidt, L., \& Vlerick, P. (2017). Towards an extended food safety culture model: Studying the moderating role of burnout and jobstress, the mediating role of food safety knowledge and motivation in the relation between food safety climate and food safety behavior. Trends in Food Science \& Technology, 62, 202-214.

De Witte, K., \& van Muijen, J. J. (1999). Organizational Culture. European Journal of Work and Organizational Psychology, 8(4), 497-502.

Demirbas, N., Cukur, F., Yildiz, Ö., \& Gölge, E. (2009). Level of knowledge, practices and attitudes of dairy farmers regarding food safety in Turkey. Mediterranean J. Econ. Agric. Environ, 8(4), 43-46.

Denison, D. R., Janovics, J., Young, J., \& Cho, H. J. (2006). Diagnosing organizational cultures: Validating a model and method. Documento de trabajo. Denison Consulting Group.

Dollard, M. F., \& Bakker, A. B. (2010). Psychosocial safety climate as a precursor to conducive work environments, psychological health problems, and employee engagement. Journal of occupational and organizational psychology, 83(3), 579-599.

Donaldson, L. (2001). The contingency theory of organizations: Sage.

Dora, M., Kumar, M., Van Goubergen, D., Molnar, A., \& Gellynck, X. (2013). Food quality management system: Reviewing assessment strategies and a feasibility study for European food small and medium-sized enterprises. Food Control, 31(2), 607-616. 
EC. (2004). Regulation (EC) No. 853/2004 of the European Parliament and of the Council of 29 April 2004 laying down specific hygiene rules for food of animal origin. Official Journal of the Europian Union, 139, 22-82.

EC. (2002). No 178/2002 of the European Parliament and of the Council of 28 January 2002 laying down the general principles and requirements of food law, establishing the European Food Safety Authority and laying down procedures in matters of food safety. Official Journal of the European Communities, 31, 124.

Eijlander, P. (2005). Possibilities and constraints in the use of self-regulation and co-regulation in legislative policy: Experiences in the Netherlands-Lessons to be learned for the EU? European Journal of Comparative Law, 9(1).

Emond, B., \& Taylor, J. Z. (2018). The importance of measuring food safety and quality culture: results from a global training survey. Worldwide Hospitality and Tourism Themes, 10(3), 369-375.

European Food Safety Authority and European Centre for Disease Prevention Control. (2018). The European Union summary report on trends and sources of zoonoses, zoonotic agents and food-borne outbreaks in 2017. EFSA Journal, 16(12), e05500.

European Food Safety Authority European Centre for Disease Prevention Control. (2017). The European Union summary report on trends and sources of zoonoses, zoonotic agents and food-borne outbreaks in 2016. EFSA Journal, 15(12), e05077.

European Union Commission. (2003). Commission recommendation of 6 May 2003 concerning the definition of micro, small and medium-sized enterprises. Official Journal of the European Union, 46(L124), 36-41.

FAO. (2007). Bridging the gap between food safety policies and implementation, C2007/INF/19. Thirty fourth Session. Rome.

Fatimah, U. Z. A. U., Arendt, S. W., \& Strohbehn, C. H. (2014a). Food safety culture in onsite foodservices: development and validation of a measurement scale. Journal of Foodservice Management and Education, 8(1), 1-10.

Fatimah, U. Z. A. U., Strohbehn, C. H., \& Arendt, S. W. (2014b). An empirical investigation of food safety culture in onsite foodservice operations. Food Control, 46, 255-263.

FDA. (1998). Bacteriological Analytical Manual (BAM) FDA Retrieved from http://www.fda.gov/ Food/FoodScienceResearch/LaboratoryMethods/ucm2006949.htm\#intro: Accessed 03-01-2017

FDA. (2011). Food safety modernization act (FSMA). Public Law, 111-353.

Fernández-Muñiz, B., Montes-Peón, J. M., \& Vázquez-Ordás, C. J. (2007). Safety culture: Analysis of the causal relationships between its key dimensions. Journal of safety research, 38(6), 627-641.

Fleming, M. (2000). Safety culture maturity model. OFFSHORE TECHNOLOGY REPORT-HEALTH AND SAFETY EXECUTIVE OTH.

Fleming, M., \& Lardner, R. (1999). Safety Culture- the way forward. the chemical engineer. http://158.132.155.107/posh97/private/culture/way forward.pdf

Flin, R. (2007). Measuring safety culture in healthcare: A case for accurate diagnosis. Safety science, 45(6), 653-667.

Flin, R., \& Yule, S. (2004). Leadership for safety: industrial experience. Quality \& Safety In Health Care, 13, 4551.

Foster, P., \& Hoult, S. (2013). The safety journey: Using a safety maturity model for safety planning and assurance in the UK coal mining industry. Minerals, 3(1), 59-72.

Fulponi, L. (2006). Private voluntary standards in the food system: The perspective of major food retailers in OECD countries. Food Policy, 31(1), 1-13.

GFSI. (2018). A culture of food safety: A position paper from the global food safety initiative (GFSI), V1.0. https://www.mygfsi.com/images/A Culture of Food Safety/GFSI-Food-Safety-Culture-FULLVERSION.pdf.

Ghemawat, P., \& Reiche, S. (2011). National cultural differences and multinational business. Globalization Note Series, $1-18$

Gilling, S. J., Taylor, E. A., Kane, K., \& Taylor, J. Z. (2001). Successful hazard analysis critical control point implementation in the United Kingdom: understanding the barriers through the use of a behavioral adherence model. Journal of food protection, 64(5), 710-715.

Glendon, A. I., \& Stanton, N. A. (2000). Perspectives on safety culture. Safety Science, 34(1-3), $193-214$.

Global Food Safety Initiative (GFSI). (2016). Global Food Safety Initiative. from http://www.mygfsi.com/aboutus/about-gfsi/what-is-gfsi.html

Global Food Safety Partnership. (2018). Food Safety in Africa. Past endeavours and future directions. https://www.gfsp.org/sites/gfsp/files/public/GFSP\%20Report Food\%20Safety\%20in\%20Africaweb.pdf/ Accessed 28 June 2019.

Goffee, R., \& Jones, G. (1996). What holds the modern company together? Harvard Business Review, 74, 133148.

Grace, D. (2015). Food safety in low and middle income countries. International Journal of Environmental Research and Public Health, 12(9), 10490-10507.

Greig, J. D., Todd, E. C. D., Bartleson, C. A., \& Michaels, B. S. (2007). Outbreaks Where Food Workers Have Been Implicated in the Spread of Foodborne Disease. Part 1. Description of the Problem, Methods, and Agents Involved. Journal of food protection, 70(7), 1752-1761.

Griffith, C. (2013). Advances in understanding the impact of personal hygiene and human behaviour on food safety. In J. Sofos (Ed.), Advances in microbial food safety (Vol. 1, pp. 401-416). Cambridge, UK: Woohhead Publishing Limited.

Griffith, C. J. (2006). Food safety: where from and where to? British Food Journal, 108(1), 6-15.

Griffith, C. J., Jackson, L. M., \& Lues, R. (2017). The food safety culture in a large South African food service complex: Perspectives on a case study. British Food Journal, 119(4), 729-743. 
Griffith, C. J., Livesey, K. M., \& Clayton, D. (2010a). The assessment of food safety culture. British Food Journal, 112(4), 439-456.

Griffith, C. J., Livesey, K. M., \& Clayton, D. A. (2010b). Food safety culture: the evolution of an emerging risk factor? British Food Journal, 112(4), 426-438.

Gukurume, S. (2018). Navigating precarious livelihoods: Youth in the SME sector in Zimbabwe.

Guldenmund, F. W. (2007). The use of questionnaires in safety culture research - an evaluation. Safety Science, 45(6), 723-743.

Guldenmund, F. W. (2010). (Mis) understanding safety culture and its relationship to safety management. Risk Analysis, 30(10), 1466-1480.

Gupta, A. (2013). Environment \& PEST analysis: an approach to the external business environment. International Journal of Modern Social Sciences, 2(1), 34-43.

Gyekye, S. A., \& Salminen, S. (2005). Responsibility assignment at the workplace: A Finnish and Ghanaian perspective. Scandinavian Journal of Psychology, 46(1), 43-48.

Halligan, M., \& Zecevic, A. (2011). Safety culture in healthcare: a review of concepts, dimensions, measures and progress. British Medical Journal quality \& safety, 20(4), 338-343.

Harris, L., \& Ogbonna, E. (1998). A three-perspective approach to understanding culture in retail organizations. Personnel Review, 27(2), 104-123.

Harvey, J., Carter, S., \& Mudimu, G. (2000). A comparison of work values and motives among Zimbabwean and British managers. Personnel Review, 29(6), 723-742.

Havelaar, A. H., Kirk, M. D., Torgerson, P. R., Gibb, H. J., Hald, T., Lake, R. J., . . Gargouri, N. (2015). World Health Organization global estimates and regional comparisons of the burden of foodborne disease in 2010. PLoS medicine, 12(12), e1001923.

Havold, J. I. (2007). National cultures and safety orientation: A study of seafarers working for Norwegian shipping companies. Work and Stress, 21(2), 173-195.

Hayburn, G. (2014). Challenges for auditing and food safety management systems: a point of view. Perspectives in Public Health, 134(4), 196-197.

Hellenic Republic. (2014). Administrative Measures, Procedures and Sanctions for the Implementation Of EU and National Legislation in the Food, Feed and Animal Health and Animal Welfare Field and Other Provisions of the Ministry of Rural Development and Food.

Herath, D., Hassan, Z., \& Henson, S. (2007). Adoption of food safety and quality controls: do firm characteristics matter? Evidence from the Canadian food processing sector. Canadian Journal of Agricultural Economics/Revue canadienne d'agroeconomie, 55(3), 299-314.

Hofstede, G. (1998). Attitudes, Values and Organizational Culture: Disentangling the Concepts. Organization Studies, 19(3), 477-493.

Hofstede, G., Hofstede, G. J., \& Minkov, M. (2010). Cultures and Organizations: Software of the Mind (3rd ed.). New York, USA: McGraw-Hill Education.

Hofstede, G., Hofstede, G. J., Minkov, M., \& Vinken, H. (2013). Values survey module 2013. . URL: http://www. geerthofstede.nl/vsm2013.

Hofstede, G., \& Minkov, M. (2013). Values survey module 2013 manual. . Holanda, Geert Hofstede Bv.

Hofstede, G. H. (2001). Culture's consequences: comparing values, behaviors, institutions, and organizations across nations (2nd ed.). London: Sage Publications.

Holland, J. H. (1992). Complex adaptive systems. Daedalus, 121(1), 17-30.

Hoskisson, R. E., Eden, L., Lau, C. M., \& Wright, M. (2000). Strategy in emerging economies. Academy of management journal, 43(3), 249-267.

Hoskisson, R. E., Wright, M., Filatotchev, I., \& Peng, M. W. (2013). Emerging multinationals from mid-range economies: The influence of institutions and factor markets. Journal of Management Studies, 50(7), $1295-1321$.

HSE. (1999). Reducing Error and Influencing Behaviour (2 ed.). Sheffield: HSE Books.

HSE. (2005). Introduction to human factors INSPECTORS TOOLKIT: Human factors in the management of major accident hazards Health Safety Executive-HSE.

HSE. (2009). Reducing error and influencing behaviour. United Kingdom: Health and Safety executive.

Hudson, P. (2001a). Safety Culture-Theory and practice: Defense Technical Information Center.

Hudson, P. (2001b). Safety management and safety culture: the long, hard and winding road. Occupational health and safety management systems, 3-32.

Hudson, P. (2007). Implementing a safety culture in a major multi-national. Safety science, 45(6), 697-722.

Husted, B. W. (2000). A contingency theory of corporate social performance. Business \& Society, 39(1), 24-48.

Idris, M. A., \& Dollard, M. F. (2014). Psychosocial safety climate, emotional demands, burnout, and depression: A longitudinal multilevel study in the Malaysian private sector. Journal of occupational health psychology, 19(3), 291.

Ijabadeniyi, O. A. (2013). Food Safety Culture Paramount Than Traditional Food Safety System and Food Safety Culture in South African Food Industries. International Journal of Social, Management, Economics and Business Engineering, 7(4), 446-450.

INSAG. (1991). Safety Culture: A Report by the International Nuclear Safety Advisory Group (INSAG-4) Safety Series (Vol. 75-INSAG-4). Vienna, Austria: International Nuclear Safety Advisory Group (INSAG).

Jacxsens, L., Kirezieva, K., Luning, P., Ingelrham, J., Diricks, H., \& Uyttendaele, M. (2015). Measuring microbial food safety output and comparing self-checking systems of food business operators in Belgium. Food Control, 49, 59-69.

Jacxsens, L., Kussaga, J., Luning, P. A., Van der Spiegel, M., Devlieghere, F., \& Uyttendaele, M. (2009). A Microbial Assessment Scheme to measure microbial performance of Food Safety Management Systems. International Journal of Food Microbiology, 134(1-2), 113-125. 
Jacxsens, L., Luning, P., Marcelis, W., van Boekel, T., Rovira, J., Oses, S., . . . Uyttendaele, M. (2011). Tools for the performance assessment and improvement of food safety management systems. Trends in Food Science \& Technology, 22, S80-S89.

Jacxsens, L., Uyttendaele, M., Devlieghere, F., Rovira, J., Gomez, S. O., \& Luning, P. A. (2010). Food safety performance indicators to benchmark food safety output of food safety management systems. International Journal of Food Microbiology, 141, Supplement, S180-S187.

Jespersen, L., Griffiths, M., Maclaurin, T., Chapman, B., \& Wallace, C. A. (2016). Measurement of food safety culture using survey and maturity profiling tools. Food Control, 66, 174-182.

Jespersen, L., Griffiths, M., \& Wallace, C. A. (2017a). Comparative analysis of existing food safety culture evaluation systems. Food Control, 79, 371-379.

Jespersen, L., \& Huffman, R. (2014). Building food safety into the company culture: a look at Maple Leaf Foods. Perspectives in Public Health, 134(4), 200-205.

Jespersen, L., MacLaurin, T., \& Vlerick, P. (2017b). Development and validation of a scale to capture social desirability in food safety culture. Food Control, 82, 42-47.

Jespersen, L., \& Wallace, C. A. (2017). Triangulation and the importance of establishing valid methods for food safety culture evaluation. Food Research International, 100, 244-253.

Jia, C., \& Jukes, D. (2013). The national food safety control system of China-a systematic review. Food Control, 32(1), 236-245.

Jiang, Y., Stigter, H., \& Monnikhof, M. O. (2018). China Food Safety Law-Practical procedures, trends and opportunities for Dutch companies. Report by the Embassy of the Kingdom of the Netherlands in Beijing, 9.

Jianu, C., \& Chiş, C. (2012). Study on the hygiene knowledge of food handlers working in small and mediumsized companies in western Romania. Food Control, 26(1), 151-156.

Kamau Njage, P., Sawe, C., Onyango, C., Habib, I., Njeru Njagi, E., Aerts, M., \& Molenberghs, G. (2017). Microbiological Performance of Food Safety Control and Assurance Activities in a Fresh Produce Processing Sector Measured Using a Microbiological Scheme and Statistical Modeling. Journal of Food Protection.

Kaplan, H. C., Brady, P. W., Dritz, M. C., Hooper, D. K., Linam, W. M., Froehle, C. M., \& Margolis, P. (2010). The influence of context on quality improvement success in health care: a systematic review of the literature. The Milbank Quarterly, 88(4), 500-559.

Karaman, A. D., Cobanoglu, F., Tunalioglu, R., \& Ova, G. (2012). Barriers and benefits of the implementation of food safety management systems among the Turkish dairy industry: A case study. Food Control, 25(2), 732-739.

Kashoma, I. P., Komba, E. V., Abiad, M. G., \& Kassem, I. I. (2018). Food Safety Regulations and Enforcement in Tanzania.

Kawulich, B. B. (2005). Participant observation as a data collection method. Paper presented at the Forum Qualitative Sozialforschung/Forum: Qualitative Social Research.

Khatri, N., Brown, G. D., \& Hicks, L. L. (2009). From a blame culture to a just culture in health care. Health care management review, 34(4), 312-322.

Kirezieva, K., Jacxsens, L., Hagelaar, G. J., van Boekel, M. A., Uyttendaele, M., \& Luning, P. A. (2015a). Exploring the influence of context on food safety management: Case studies of leafy greens production in Europe. Food Policy, 51, 158-170.

Kirezieva, K., Jacxsens, L., Uyttendaele, M., Van Boekel, M. A. J. S., \& Luning, P. A. (2013a). Assessment of Food Safety Management Systems in the global fresh produce chain. Food Research International, 52(1), 230-242.

Kirezieva, K., \& Luning, P. A. (2017). The influence of context on food safety governance: Bridging the gap between policy and quality management.In: hybridization of food safety governance. Trends, Types and results. In P. Verbruggen \& T. Havinga (Eds.), Hybridization of food governance: Trends, types and results. United Kingdom: Edward Elgar Publishing.

Kirezieva, K., Luning, P. A., Jacxsens, L., Allende, A., Johannessen, G. S., Tondo, E. C., . . . van Boekel, M. A. J. S. (2015b). Factors affecting the status of food safety management systems in the global fresh produce chain. Food Control, 52, 85-97.

Kirezieva, K., Nanyunja, J., Jacxsens, L., van der Vorst, J. G. A. J., Uyttendaele, M., \& Luning, P. A. (2013b). Context factors affecting design and operation of food safety management systems in the fresh produce chain. Trends in Food Science \& Technology, 32(2), 108-127.

Kleboth, J., Luning, P., \& Fogliano, V. (2016). Risk-based integrity audits in the food chain-A framework for complex systems. Trends in Food Science \& Technology, 56, 167-174.

Ko, W.-H. (2013). The relationship among food safety knowledge, attitudes and self-reported HACCP practices in restaurant employees. Food Control, 29(1), 192-197.

Kopinak, J. K. (1999). The use of triangulation in a study of refugee well-being. Quality and Quantity, 33(2), 169-183.

Kotrba, L. M., Gillespie, M. A., Schmidt, A. M., Smerek, R. E., Ritchie, S. A., \& Denison, D. R. (2012). Do consistent corporate cultures have better business performance? Exploring the interaction effects. Human relations, 65(2), 241-262.

Krumpal, I. (2013). Determinants of social desirability bias in sensitive surveys: a literature review. Quality \& Quantity, 47(4), 2025-2047.

Kumar, R. (2011). Research Methodology: A Step-by-Step Guide for Beginners (3rd ed.). London: SAGE Publications.

Kussaga, J., Luning, P., Jacxsens, L., \& Tiisekwa, B. (2013). Diagnosis of food safety management systems performance in food processing sectors for export and domestic markets. Afr. J. Food Sci. Technol, 4, 240-250. 
Kussaga, J. B., Jacxsens, L., Tiisekwa, B. P., \& Luning, P. A. (2014a). Food safety management systems performance in African food processing companies: a review of deficiencies and possible improvement strategies. Journal of the Science of Food and Agriculture, 94(11), 2154-2169.

Kussaga, J. B., Luning, P. A., Tiisekwa, B. P., \& Jacxsens, L. (2014b). Challenges in performance of food safety management systems: a case of fish processing companies in Tanzania. Journal of Food Protection, 77(4), 621-630.

Kussaga, J. B., Luning, P. A., Tiisekwa, B. P., \& Jacxsens, L. (2015). Current performance of food safety management systems of dairy processing companies in Tanzania. International journal of dairy technology, 68(2), 227-252.

Lee, J.-E., Almanza, B. A., Jang, S. S., Nelson, D. C., \& Ghiselli, R. F. (2013). Does transformational leadership style influence employees' attitudes toward food safety practices? International Journal of Hospitality Management, 33, 282-293.

Lelieveld, H. L. M., Holah, J., \& Napper, D. (2014). Hygiene in Food Processing: Principles and Practice (Vol. 2). Amsterdam: Elsevier

Lepeintre, J., \& Sun, J. (2018). Building food safety governance in China. Luxembourg: Publications Office of the European Union.

Line, M. B. (1999). Types of organisational culture. Library management, 20(2), 73-75.

Lineback, D. R., Pirlet, A., Van Der Kamp, J. W., \& Wood, R. (2009). Globalization, food safety issues \& role of international standards. Quality Assurance and Safety of Crops \& Foods, 1(1), 23-27.

Lok, P., \& Crawford, J. (2004). The effect of organisational culture and leadership style on job satisfaction and organisational commitment: A cross-national comparison. Journal of Management Development, 23(4), 321-338.

Lu, C. S., Lai, K. H., Lun, Y. H. V., \& Cheng, T. C. E. (2012). Effects of national culture on human failures in container shipping: The moderating role of Confucian dynamism. Accident Analysis and Prevention, 49, 457-469.

Luning, P., Marcelis, W., Rovira, J., Van der Spiegel, M., Uyttendaele, M., \& Jacxsens, L. (2009a). Systematic assessment of core assurance activities in a company specific food safety management system. Trends in Food Science \& Technology, 20(6-7), 300-312.

Luning, P. A., Bango, L., Kussaga, J., Rovira, J., \& Marcelis, W. J. (2008). Comprehensive analysis and differentiated assessment of food safety control systems: a diagnostic instrument. Trends in Food Science \& Technology, 19(10), 522-534.

Luning, P. A., Jacxsens, L., Rovira, J., Osés, S. M., Uyttendaele, M., \& Marcelis, W. J. (2011a). A concurrent diagnosis of microbiological food safety output and food safety management system performance: Cases from meat processing industries. Food Control, 22(3), 555-565.

Luning, P. A., Kirezieva, K., Hagelaar, G., Rovira, J., Uyttendaele, M., \& Jacxsens, L. (2015). Performance assessment of food safety management systems in animal-based food companies in view of their context characteristics: A European study. Food Control, 49, 11-22.

Luning, P. A., \& Marcelis, W. J. (2006). A techno-managerial approach in food quality management research. Trends in Food Science \& Technology, 17(7), 378-385.

Luning, P. A., \& Marcelis, W. J. (2007). A conceptual model of food quality management functions based on a techno-managerial approach. Trends in Food Science \& Technology, 18(3), 159-166.

Luning, P. A., \& Marcelis, W. J. (2009a). A food quality management research methodology integrating technological and managerial theories. Trends in Food Science \& Technology, 20(1), 35-44.

Luning, P. A., \& Marcelis, W. J. (2009b). Food quality management: technological and managerial principles and practices: Wageningen Academic Publishers.

Luning, P. A., Marcelis, W. J., Rovira, J., van Boekel, M. A. J. S., Uyttendaele, M., \& Jacxsens, L. (2011b). A tool to diagnose context riskiness in view of food safety activities and microbiological safety output. Trends in Food Science \& Technology, 22, Supplement 1(0), S67-S79.

Luning, P. A., Marcelis, W. J., Rovira, J., Van der Spiegel, M., Uyttendaele, M., \& Jacxsens, L. (2009b). Systematic assessment of core assurance activities in a company specific food safety management system. Trends in Food Science \& Technology, 20(6-7), 300-312.

Macheka, L., Manditsera, F. A., Ngadze, R. T., Mubaiwa, J., \& Nyanga, L. K. (2013). Barriers, benefits and motivation factors for the implementation of food safety management system in the food sector in Harare Province, Zimbabwe. Food Control, 34(1), 126-131.

Manning, L. (2017). The influence of organizational subcultures on food safety management. Journal of Marketing Channels, 24(3-4), 180-189.

Manning, L. (2018a). Triangulation: effective verification of food safety and quality management systems and associated organisational culture. Worldwide Hospitality and Tourism Themes, 10(3), 297-312.

Manning, L. (2018b). The value of food safety culture to the hospitality industry. Worldwide Hospitality and Tourism Themes(just-accepted), 00-00.

Marder, E. P., Griffin, P. M., Cieslak, P. R., Dunn, J., Hurd, S., Jervis, R., . . . Smith, K. (2018). Preliminary incidence and trends of infections with pathogens transmitted commonly through food-Foodborne Diseases Active Surveillance Network, 10 US sites, 2006-2017. Morbidity and Mortality Weekly Report, 67(11), 324.

Marquis, C., \& Raynard, M. (2015). Institutional strategies in emerging markets. The Academy of Management Annals, 9(1), 291-335.

Martin, J. (1992). Cultures in organizations: Three perspectives: Oxford University Press.

Martin, J. (2002). Organizational culture: Mapping the terrain. Thousand Oaks, CA: Sage.

Martinez, M. G., Fearne, A., Caswell, J. A., \& Henson, S. (2007). Co-regulation as a possible model for food safety governance: Opportunities for public-private partnerships. Food Policy, 32(3), 299-314

Martins, E. C., \& Terblanche, F. (2003). Building organisational culture that stimulates creativity and innovation. European Journal of Innovation Management, 6(1), 64-74. 
Maull, R., Brown, P., \& Cliffe, R. (2001). Organisational culture and quality improvement. International Journal of Operations \& Production Management, 21(3), 302-326.

Mearns, K., Flin, R., Gordon, R., \& Fleming, M. (2001). Human and organizational factors in offshore safety. Work \& Stress, 15(2), 144-160.

Mearns, K., Rundmo, T., Flin, R., Gordon, R., \& Fleming, M. (2004). Evaluation of psychosocial and organizational factors in offshore safety: a comparative study. Journal of Risk Research, 7(5), 545561.

Mearns, K., \& Yule, S. (2009). The role of national culture in determining safety performance: Challenges for the global oil and gas industry. Safety science, 47(6), 777-785.

Mearns, K. J., \& Flin, R. (1999). Assessing the state of organizational safety-culture or climate? Current Psychology, 18(1), 5-17.

Mensah, P., Mwamakamba, L., Mohamed, C., \& Nsue-Milang, D. (2012). Public health and food safety in the WHO African region. African Journal of Food, Agriculture, Nutrition and Development, 12(4), 63176335.

Meshkati, N. (1995). Cultural context of the safety culture: a conceptual model and experimental study. Paper presented at the Conference Proceedings of the International Topical Meeting on Safety culture in Nuclear Installations, Vienna, Austria.

Morrow, S. L., Koves, G. K., \& Barnes, V. E. (2014). Exploring the relationship between safety culture and safety performance in US nuclear power operations. Safety Science, 69, 37-47.

Morse, T., Masuku, H., Rippon, S., \& Kubwalo, H. (2018). Achieving an Integrated Approach to Food Safety and Hygiene-Meeting the Sustainable Development Goals in Sub-Saharan Africa. Sustainability, 10(7), 2394.

Nakata, C., \& Sivakumar, K. (1996). National Culture and New Product Development: An Integrative Review. Journal of Marketing, 60(1), 61-72.

Nanyunja, J., Jacxsens, L., Kirezieva, K., Kaaya, A. N., Uyttendaele, M., \& Luning, P. A. (2015). Assessing the status of food safety management systems for fresh produce production in East Africa: evidence from certified green bean farms in Kenya and noncertified hot pepper farms in Uganda. Journal of food protection, 78(6), 1081-1089.

Nayak, R., \& Taylor, J. Z. (2018). Food safety culture-the food inspectors' perspective. Worldwide Hospitality and Tourism Themes(just-accepted), 00-00.

Nayak, R., \& Waterson, P. (2016). 'When Food Kills': A socio-technical systems analysis of the UK Pennington 1996 and 2005 E. coli O157 Outbreak reports. Safety science, 86, 36-47.

Nayak, R., \& Waterson, P. (2019). Global food safety as a complex adaptive system: Key concepts and future prospects. Trends in Food Science \& Technology, 91, 409-425.

Neal, A., \& Griffin, M. A. (2004). Safety climate and safety at work. In J. Barling \& M. R. Frone (Eds.), The Psychology of Workplace Safety (pp. 15-34). Washington D.C: American Psychological Association.

Newman, K. L., \& Nollen, S. D. (1996). Culture and congruence: The fit between management practices and national culture. Journal of international business studies, 27(4), 753-779.

Nguz, K. (2007). Assessing food safety system in sub-Saharan countries: An overview of key issues. Food Control, 18(2), 131-134.

Nickell, G. S., \& Hinsz, V. B. (2011). Having a conscientious personality helps an organizational climate of food safety predict food safety behavior. Food supplies and food safety: Production, conservation and population impact, 189-198.

Noort, M. C., Reader, T. W., Shorrock, S., \& Kirwan, B. (2016). The relationship between national culture and safety culture: Implications for international safety culture assessments. Journal of occupational and organizational psychology, 89(3), 515-538.

Nyarugwe, S. P. (2013). Identification of food safety culture factors that influence actual hygienic behaviour of food handlers and safety of dairy products in Zimbabwe. (MSc), Wageningen University, Wageningen, Netherlands.

Nyarugwe, S. P., Linnemann, A., Hofstede, G. J., Fogliano, V., \& Luning, P. A. (2016). Determinants for conducting food safety culture research. Trends in Food Science \& Technology, 56, 77-87.

Nyarugwe, S. P., Linnemann, A., Nyanga, L. K., Fogliano, V., \& Luning, P. A. (2018). Food safety culture assessment using a comprehensive mixed-methods approach: A comparative study in dairy processing organisations in an emerging economy. Food Control, 84, 186-196.

Nyarugwe, S. P., Linnemann, A. R., \& Luning, P. A. (2020). Prevailing food safety culture in companies operating in a transition economy-Does product riskiness matter? Food Control, 107, 106803.

Ogbonna, E. (1992). PART TWO: DIMENSIONS OF HRM 5 ORGANIZATION CULTURE AND HUMAN RESOURCE MANAGEMENT: DILEMMAS AND CONTRADICTIONS. Reassessing human resource management, 74.

Okolie, K., \& Okoye, P. (2012). Assessment of national culture dimensions and construction health and safety climate in Nigeria. Science Journal of Environmental Engineering Research, 2012.

Onjong, H. A., Wangoh, J., \& Njage, P. M. K. (2014). Current Food Safety Management Systems in FishExporting Companies Require Further Improvements to Adequately Cope with Contextual Pressure: Case Study. Journal of Food Science, 79(10), M2031-M2039.

Ortega, D. L., \& Tschirley, D. L. (2017). Demand for food safety in emerging and developing countries: A research agenda for Asia and Sub-Saharan Africa. Journal of Agribusiness in Developing and Emerging Economies, 7(1), 21-34.

Pacholewicz, E., Barus, S. A. S., Swart, A., Havelaar, A. H., Lipman, L. J., \& Luning, P. A. (2016). Influence of food handlers' compliance with procedures of poultry carcasses contamination: A case study concerning evisceration in broiler slaughterhouses. Food Control, 68, 367-378.

Papademas, P., \& Bintsis, T. (2010). Food safety management systems (FSMS) in the dairy industry: A review. International journal of dairy technology, 63(4), 489-503. 
Parker, D., Lawrie, M., \& Hudson, P. (2006). A framework for understanding the development of organisational safety culture. Safety Science, 44(6), 551-562.

Parker, R., \& Bradley, L. (2000). Organisational culture in the public sector: evidence from six organisations. International Journal of Public Sector Management, 13(2), 125-141.

Pederson, R., \& Hernández, G. (2014). Food Safety: State-of-Play, Current and Future Challenges. (IP/A/ENVI/2014-11). Brussels: European Union Retrieved from http://www.europarl.europa.eu/RegData/etudes/IDAN/2014/536287/IPOL IDA(2014)536287 EN.pdf.

Pei, X., Tandon, A., Alldrick, A., Giorgi, L., Huang, W., \& Yang, R. (2011). The China melamine milk scandal and its implications for food safety regulation. Food Policy, 36(3), 412-420.

Pennington, H. (2009). The public inquiry into the September 2005 outbreak of E. coli 0157 in South Wales. Cardiff: Welsh Government.

Pidgeon, N. (1998). Safety culture: key theoretical issues. Work \& Stress, 12(3), 202-216.

Pienaar, J., \& Willemse, S. A. (2008). Burnout, engagement, coping and general health of service employees in the hospitality industry. Tourism Management, 29(6), 1053-1063.

Powell, D. A., Erdozain, S., Dodd, C., Costa, R., Morley, K., \& Chapman, B. J. (2013). Audits and inspections are never enough: A critique to enhance food safety. Food Control, 30(2), 686-691.

Powell, D. A., Jacob, C. J., \& Chapman, B. J. (2011). Enhancing food safety culture to reduce rates of foodborne illness. Food Control, 22(6), 817-822.

Pswarayi, F., Mutukumira, A. N., Chipurura, B., Gabi, B., \& Jukes, D. J. (2014). Food control in Zimbabwe: A situational analysis. Food Control, 46, 143-151.

Qian, G., Guo, X., Guo, J., \& Wu, J. (2011). China's dairy crisis: impacts, causes and policy implications for a sustainable dairy industry. International Journal of Sustainable Development \& World Ecology, 18(5), 434-441.

Rapid Alert System for Food \& Feed. (2014). RASFF annual report 2014. Luxembourg: Publications Office of the European Union.

Reason, J. (1998). Achieving a safe culture: theory and practice. Work \& Stress, 12(3), 293-306.

Robbins, S., \& Coulter, M. (2007). Management. New Jersey, USA: Pearson Prentice Hall.

Rouvière, E., \& Caswell, J. A. (2012). From punishment to prevention: A French case study of the introduction of co-regulation in enforcing food safety. Food Policy, 37(3), 246-254.

Rubenstein-Montano, B., Liebowitz, J., Buchwalter, J., McCaw, D., Newman, B., Rebeck, K., \& Team, T. K. M. M. (2001). A systems thinking framework for knowledge management. Decision support systems, 31(1), 5-16.

Sadri, G., \& Lees, B. (2001). Developing corporate culture as a competitive advantage. Journal of Management Development, 20(10), 853-859.

Sampers, I., Jacxsens, L., Luning, P. A., Marcelis, W. J., Dumoulin, A., \& Uyttendaele, M. (2010). Performance of food safety management systems in poultry meat preparation processing plants in relation to Campylobacter spp. contamination. Journal of Food Protection $®$, 73(8), 1447-1457.

Sampers, I., Toyofuku, H., Luning, P. A., Uyttendaele, M., \& Jacxsens, L. (2012). Semi-quantitative study to evaluate the performance of a HACCP-based food safety management system in Japanese milk processing plants. Food Control, 23(1), 227-233.

Sanny, M., Luning, P. A., Marcelis, W. J., Jinap, S., \& Van Boekel, M. A. (2010). Impact of control behaviour on unacceptable variation in acrylamide in French fries. Trends in Food Science \& Technology, 21(5), 256267.

Savani, K., Morris, M. W., Naidu, N., Kumar, S., \& Berlia, N. V. (2011). Cultural conditioning: Understanding interpersonal accommodation in India and the United States in terms of the modal characteristics of interpersonal influence situations. Journal of Personality and Social Psychology, 100(1), 84

Sawe, C. T., Onyango, C. M., \& Njage, P. M. K. (2014). Current food safety management systems in fresh produce exporting industry are associated with lower performance due to context riskiness: Case study. Food Control, 40, 335-343.

Schein, E. H. (2004). Organizational culture and leadership (3rd ed.). San Francisco, CA: Jossey-Bass.

Schein, E. H., \& Schein, P. (2016). Organizational Culture and Leadership (5 ed.). New Jersey: Wiley \& Sons.

Seel, R. (2000). Culture and complexity: new insights on organisational change. Organisations \& People, 7(2), 2-9.

Seymen, O. A., \& Bolat, O. (2010). The role of national culture in establishing an efficient safety culture in organizations: An evaluation in respect of Hofstede's cultural dimensions. Balikesir University, Turkey.

Singla, A. K., Kitch, B. T., Weissman, J. S., \& Campbell, E. G. (2006). Assessing patient safety culture: a review and synthesis of the measurement tools. Journal of Patient Safety, 2(3), 105-115.

Skyttner, L. (2005). General systems theory: problems, perspectives, practice (2nd ed.). Singapore: World Scientific Publishing.

Sorensen, J. B. (2002). The strength of corporate culture and the reliability of firm performance. Administrative science quarterly, 47(1), 70-91.

Sousa, R., \& Voss, C. A. (2008). Contingency research in operations management practices. Journal of Operations Management, 26(6), 697-713.

Starren, A., Hornikx, J., \& Luijters, K. (2013). Occupational safety in multicultural teams and organizations: A research agenda. Safety Science, 52, 43-49.

Steier, G., \& Patel, K. K. (2017). International Food Law and Policy: Springer International Publishing.

Taylor, J. (2011). An exploration of food safety culture in a multi-cultural environment: next steps? Worldwide Hospitality and Tourism Themes, 3(5), 455-466.

Taylor, J., Garat, J. P., Simreen, S., \& Sarieddine, G. (2015). An industry perspective. Worldwide Hospitality and Tourism Themes, $7(1), 78-89$.

Thompson, N., Stradling, S., Murphy, M., \& O'neill, P. (1996). Stress and organizational culture. The British Journal of Social Work, 26(5), 647-665. 
Ungku Fatimah, U. Z. A., Arendt, S. W., \& Strohbehn, C. H. (2014a). Food safety culture in onsite foodservices: development and validation of a measurement scale. Journal of Foodservice Management \& Education, $8(1), 1-10$

Ungku Fatimah, U. Z. A., Strohbehn, C. H., \& Arendt, S. W. (2014b). An empirical investigation of food safety culture in onsite foodservice operations. Food Control, 46, 255-263.

Unnevehr, L. J. (2003). Food safety in food security and food trade: International Food Policy Research Institute (IFPRI).

Van den Berg, P. T., \& Wilderom, C. P. (2004). Defining, measuring, and comparing organisational cultures. Applied Psychology, 53(4), 570-582.

Van der Spiegel, M., Luning, P., Ziggers, G., \& Jongen, W. (2003). Towards a conceptual model to measure effectiveness of food quality systems. Trends in Food Science \& Technology, 14(10), 424-431.

Van Oudenhoven, J. P. (2001). Do organizations reflect national cultures? A 10-nation study. International Journal of Intercultural Relations, 25(1), 89-107.

Wadamori, Y., Gooneratne, R., \& Hussain, M. A. (2017). Outbreaks and factors influencing microbiological contamination of fresh produce. Journal of the Science of Food and Agriculture, 97(5), 1396-1403.

Walker, E., Pritchard, C., \& Forsythe, S. (2003). Hazard analysis critical control point and prerequisite programme implementation in small and medium size food businesses. Food Control, 14(3), 169-174.

Wallace, C. A. (2009). The impact of personnel, training, culture and organisational factors on application of the HACCP system for food safety management in a multinational organisation. University of Central Lancashire.

Wallace, C. A. (2014). HACCP-based food safety management systems: Great in theory but can we really make them work in practice? Perspectives in Public Health, 134(4), 188-190.

Watson, D., Husband, J., Yap, S., Hetherington, K., \& Pandi, S. (2018). A Dog's Brexit for UK Food Manufactures, in terms of Food Safety Culture. Journal of Applied Microbiological Research, 1(1), 2734.

Weick, K. E., \& Sutcliffe, K. M. (2001). Managing the unexpected (Vol. 9). San Francisco: Jossey-Bass.

Westrum, R. (1993). Cultures with requisite imagination Verification and validation of complex systems: Human factors issues (pp. 401-416). New York, USA: Springer.

WHO. (2015). WHO estimates of the global burden of foodborne diseases: foodborne disease burden epidemiology reference group 2007-2015. Geneva, Switzerland.

WHO. (2016). ROLE OF WOMEN IN FOOD OPERATIONS IN AFRICA, . FOOD SAFETY NEWSLETTER, 3(3), 5. Retrieved from http://who.insomnation.com/sites/default/files/pdf/food-safety-newletter-volume-3who-afro.pdf website:

Wiegmann, D. A., Zhang, H., Von Thaden, T. L., Sharma, G., \& Gibbons, A. M. (2004). Safety culture: An integrative review. The International Journal of Aviation Psychology, 14(2), 117-134.

Wilson, A. M. (2001). Understanding organisational culture and the implications for corporate marketing. European Journal of Marketing, 35(3/4), 353-367.

World Health Organization. (2015). WHO estimates of the global burden of foodborne diseases: foodborne disease burden epidemiology reference group 2007-2015.

World Health Organization. (2018). Listeriosis - South Africa. Retrieved 18 October, 2018

Wright, M., \& Leach, P. (2013). Diagnosing And Improving Food Safety Culture In Food Businesses. http://www.cieh-cymruwales.org/assets/0/72/118/262/c2b89b7d-d025-4dec-8302-8ccd44406e6d.pdf

Wright, M., Leach, P., \& Palmer, G. (2012). A Tool to Diagnose Culture in Food Business Operators Report from Greenstreet Berman Ltd for the Food Standards Agency (R1 V6 ed.). London, UK: Greenstreet Berman Ltd.

Yang, R., Huang, W., Zhang, L., Thomas, M., \& Pei, X. (2009). Milk adulteration with melamine in China: crisis and response. Quality Assurance and Safety of Crops \& Foods, 1(2), 111-116.

Yeasmin, S., \& Rahman, K. F. (2012). Triangulation research method as the tool of social science research. BUP journal, 1(1), 154-163.

Yiannas, F. (2009). Food safety culture: Creating a behavior-based food safety management system. New York, USA: Springer.

Yiannas, F. (2015). Food Safety= Behavior: 30 proven techniques to enhance employee compliance. New York: Springer.

Young, I., Thaivalappil, A., Greig, J., Meldrum, R., \& Waddell, L. (2018). Explaining the food safety behaviours of food handlers using theories of behaviour change: a systematic review. International Journal of Environmental Health Research, 28(3), 323-340.

Zimbabwe Economic Policy And Research Unit. (2014). Agro-Industries/Food and Beverages value chain diagnostic study ZEPARU Occassional Paper No. 03/14. 


\section{Supplementary Materials}

\section{Supplementary material 1 (S1): Ethical Approval}

\section{WAGENINGEN}

UNIVERSITY S RESERRCH

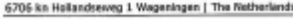

To whom it may concern

The following project proposal has been reviewed by the Social Sciences Ethics Committee (SEC):

Title: Influence of food safety governance on the prevailing food safety culture of an organisation

Project team: Shingai P Nyarugwe, Pieternel Luning, Anita Linneman

Funding: NFP

Period: $\quad$ November 2018 - February 2019

Location: Brazil, EU, Africa, China, Australia

The Committee has concluded that the proposal deals with ethical issues in a satisfactory way and that it complies with the Netherlands Code of Conduct for Research Integrity.

With kind regards,

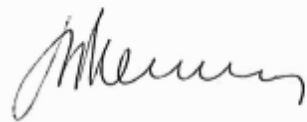

Professor Dr Marcel Verweij

Chair Social Sciences Ethics Committee 
Supplementary material 2 (S2):

Table S2: Correlation between national culture dimensions, and enabling conditions and employee characteristics

\begin{tabular}{|c|c|c|c|c|}
\hline 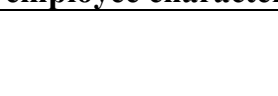 & $\begin{array}{l}\text { Enabling } \\
\text { Conditions }\end{array}$ & Attitude & Risk Perceptions & $\begin{array}{l}\text { Intended } \\
\text { Behaviour }\end{array}$ \\
\hline Power Distance & & & $-.925^{* *}$ & \\
\hline Individualism & & & $.858^{* *}$ & \\
\hline Masculinity & $.782^{* *}$ & $.485^{*}$ & $-.718^{* *}$ & \\
\hline Uncertainty avoidance & & & $.680^{* *}$ & $-.564^{*}$ \\
\hline Long-Term Orientation & $.629^{* *}$ & & $-.921^{* *}$ & \\
\hline Indulgence & & & $.912^{* *}$ & $-.493^{*}$ \\
\hline
\end{tabular}

$$
\begin{gathered}
* \mathrm{p}<.05 \\
* * \mathrm{p}<.01
\end{gathered}
$$




\section{Summary}

Food safety continues to be a challenge in many food companies especially in emerging economies, which are confronted with multiple issues in both the internal and external company environment. Previous efforts to improve food safety performance have been hinged on traditional and technical-oriented approaches such as sampling, testing, inspections, food safety management systems (FSMS) and auditing, which have proven to be not always adequate evidenced by inconsistencies in food safety performance. To enhance food safety performance in food companies, researchers proposed to look beyond these traditional and technical-oriented approaches towards a more integrated approach and suggested the adoption and strengthening of a positive and pro-active food safety culture (FS-culture). FS-culture encompasses a company's technological and organisational conditions, characteristics of the individuals within the company and the company's environment, in addition to the existing FSMS. However, FS-culture research is still developing when compared with other culture research domains such as organisational and safety culture. Moreover, there are still knowledge gaps on what FS-culture entails, its measurement, its relationship with food safety performance and how it could be improved.

This thesis, therefore, focused on understanding how an organisation's FS-culture influences food safety and hygiene-related behaviour and food safety performance of an organisation. To attain this goal, several studies were done, namely: (i) a structured analysis of literature on national, organisational and safety culture to identify determinants for conducting FS-culture research; (ii) evaluation and validation of FS-culture elements and a mixed-method research methodology for assessing an organisation's prevailing FS-culture, with a case study in dairy companies; (iii) development of a FS-culture research framework to enable assessment of an organisation's prevailing FS-culture in view of the company environment, and an investigation of the role of product riskiness on FS-culture; (iv) an explorative investigation of the possible influence of characteristics of food safety governance and national values on an organisation's prevailing FS-culture in food companies in different countries.

The literature review presented in chapter 2 identified determinants for conducting FSculture research. Findings revealed that numerous factors transcending different disciplines 
are interlinked and as such a systems approach is required to assess an organisation's FSculture. The review showed that several elements i.e. individual, group, organisational, technological and company environment characteristics are necessary to evaluate FS-culture, and its influence on food handler behaviour and food safety performance. Moreover, the research suggested that a company's food safety risks should be considered and to recognise the hierarchical levels (i.e. strategic, tactical and operational) as well. The research also suggested defining measurable indicators, development of classification systems, and the use of a triangulated methodology. The resultant determinants provided a basis upon which further FS-culture research could be built on.

As a result of these findings, elements suggested in the review were validated in chapter $\mathbf{3}$ as they enabled an understanding of the prevailing FS-culture of the companies investigated. Moreover, a mixed-methods approach was presented to assess the prevailing FS-culture, with dairy food companies in Zimbabwe as a case study. The methods included: microbial analysis to assess the microbial safety, observations to evaluate actual behaviour, card-aided interviews to assess organisational and technological enabling conditions, questionnaires and storytelling to collect data on employee characteristics, and document analysis to get insight into the microbial safety performance and actual behaviour. Results showed that a mixedmethods approach is suitable in FS-culture assessments due to the method triangulation, which could potentially increase the validity of the research findings. For example, storytelling elicited respondents to share stories, which reflected the food safety and hygiene control attitudes. Card-aided interviews gave insights into the perceived supportiveness of the enabling conditions, which was reflected in some of the observed food safety and hygiene attitudes. Both the FS-culture elements and the mixed-methods approach enabled the prevailing FS-culture to be distinguished into identified classification levels (reactive, active, proactive) further enhancing their validity.

Based on the empirical study, a FS-culture research framework was further developed in Chapter 4, to concurrently assess the prevailing FS-culture of companies differing in product riskiness, as well as the company's internal and external environment. The framework assessed the following factors: supportiveness of the organisational and technological enabling conditions, employee characteristics, intended and actual behaviour, food safety performance, and the internal (food safety vision, food safety programs, vulnerability of production systems) and external (national values and food safety governance) company 
environment. The framework was applied to Zimbabwean food companies differing in product riskiness i.e. low, medium and high-risk. Results indicated no direct relationship between product riskiness and FS-culture. However, the company environment seemed to be associated with the prevailing FS-culture. Regarding the internal environment, the vulnerability of the food production system (i.e. susceptibility to microbial contamination) seemed to influence the prevailing FS-culture. With respect to the external environment, food safety governance and national values seemed to influence the way food safety was prioritised, food safety programs were designed, and the way food handlers executed their tasks in actual practice.

Chapter 5 further explored the role of the internal and external company environment on an organisation's FS-culture, in companies operating in Greece, China, Tanzania and Zambia. Both the internal and external company environment seemed to influence the prevailing FSculture. Companies in African countries (i.e. Tanzania and Zambia) exhibited similarities in the implementation of food safety programs, and in the national values and food safety governance when compared to Greece and China. Food safety governance was reflected in the food safety programs and supportiveness of the organisation to food safety and hygiene. Hofstede cultural dimensions i.e. uncertainty avoidance, masculinity and long vs short-term orientation, reflecting national values, were significantly statistically correlated with aspects of FS-culture such as risk perceptions, attitude and the enabling conditions.

Chapter 6 discusses the overall findings in this thesis and presents a broader outlook on FSculture from an organisational, individual and company environment perspective. Furthermore, a stepwise approach to create, improve and sustain an organisation's FS-culture is presented. Practical implications of findings in this thesis and recommendations for further research and for the food companies studied are presented.

Overall, the research presented in this thesis contributes to the existing literature on FSculture by providing research determinants that could be useful as a basis upon which further FS-culture research can be built on. Moreover, it provides a FS-culture research framework and assessment grids that can be used for the concurrent analysis and differentiated assessment of an organisation's prevailing FS-culture, food safety performance, and the internal and external company environment. The mixed-methods approach could enable an indepth analysis of an organisation's FS-culture through method-triangulation. Insights 
provided in this thesis could enable the identification of the prevailing FS-culture, which could be useful in designing effective interventions to create, improve, strengthen and sustain a positive FS-culture. The stepwise approach developed in this thesis could help identify improvement opportunities towards a positive and sustainable FS-culture, thereby contributing to better food safety performance 


\section{Acknowledgements}

Behind every success there is a story and behind every successful story there is a support system. My story in incomplete without acknowledging the key people who make me look back and feel proud of this achievement.

Foremost, I am especially indebted to my promoter Prof. Dr Vincenzo Fogliano and my cosupervisors Dr ir Pieternel Luning and Dr ir Anita Linnemann who ensured the completion of this thesis through their guidance. Vincenzo, you always had a critical eye on the work done, which gave me so much to consider and to make sure that I produced quality work. Your invaluable input and insightful comments and suggestions probed me to critically reflect on my work. To Pieternel, thank you for welcoming me into the FS-culture research domain and into your home where we had long but fruitful discussions on my work and many dinners with your family. I am also deeply grateful for the input, discussions, guidance and your critical analysis, which moulded me into a better researcher. Anita, I thank you for your patience, motivation, encouragement, selflessness, thoughtfulness, tenacity and of course your supervision. Your support went even beyond the PhD studies to ensure my mental well-being was intact. Your counselling, gifts and the stories you shared will always be engraved as life lessons, especially the car metaphor. To Prof. Dr Gert Jan Hofstede and Dr ir Loveness Nyanga I would like to express my sincere gratitude for your supervision and your valuable support.

I am also very grateful to James Ledo and Lesley Macheka for the moral support, discussions, assistance with statistical analysis and responses to reviewers, and for lending an ear when I bounced off my ideas and frustrations on you. To Kimberly, Lysanne and Corine, you were the backbone to my $\mathrm{PhD}$ journey and I thank you for making sure that the administrative stuff was always running smoothly. To my colleagues Tavengwa, Persistence, Erica, Lais, Beatha, Sophia, Loveness, Onu, Yingxue, Kim, Bernard and Sydney you played a role in fulfilling my $\mathrm{PhD}$ dream. For that I am deeply indebted to you. I am also grateful to members of the Food Safety Culture Science group especially Liesbeth, Elien, Peter, Carol and John for the insightful discussions. To Ruud, I thank you for the talks, counselling and constant encouragement. I am also deeply indebted to all the companies and respondents for taking part in this study. Had it been not for you, this journey would never have been fulfilled. Aside from the stresses of work, I would like to thank my colleagues Ruth, Faith, Mutsva, Gilbert, 
Robert (Doc), and family Abigail, Enna, and Kuda for providing the lighter moments to distress. James Ledo and Onu Ekpa thank you for being my paranymphs, I am really grateful.

Nobody has been more important to me in the pursuit of this $\mathrm{PhD}$ than the members of my family. My awesome and lovely son Omari Joel, you came at the end of the PhD journey within the same time frame that my thesis was approved and I would like to thank you for the double blessing. Knowing that I would hold you in a few months gave me the strength to finalise on time so that I would be able to focus on you and share great moments with you. To Joanna-Anika, my beloved daughter, you came at the right time and I am grateful you did. Your bubbliness is contagious and at the end of a bad or hectic day, you always melted my heart. Even through Skype calls I could feel the warmth of your love, laughter and happiness. Though the ending was rocky, it was seeing though those deep innocent eyes that motivated me to finish to be able to provide for you and be there for you for the rest of our lives, which I intend to make a big deal out of especially for missing part of your first 18 months. For this $I$ dedicate this Thesis to you for this resonates with your Shona name "Matipaishe".

To my mother, you stood by me all through this journey. Since my MSc and time immemorial, you have always been there for me, rooted for me and always believed in me. Your constant encouragement and cheering on had me going even in the bleakest moments. You had faith for two people because your faith in me even when I did not have it and your belief in my abilities was what kept me going. Every day on the phone you would tell me to persevere and to be of good cheer as you would always pray for me. Your words of encouragement, your support even by taking care of my daughter when I was in the Netherlands defined what a mother's love is and can do. Words are not enough to express my gratitude of how you stood in the gap. To my siblings Karen and Munyaradzi, you were my cheerleaders, comforters and biggest support system. For that, I thank you. I will also salute my grandmother Rhoda, you prayed for me, stood by me and encouraged me. I am eternally grateful. Words fail to express my gratitude to my husband Brighton, you do not know the extent to which you pushed me into having this $\mathrm{PhD}$, for that I thank you.

Lastly, if you have not been acknowledged in this thesis, please rest assured that my gratitude is not less than those mentioned above! 


\section{About the author}

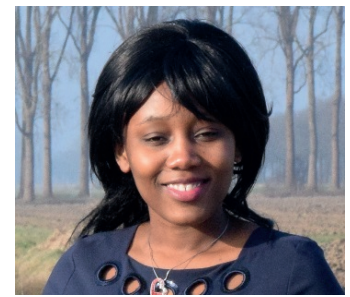

Shingai Patricia Nyarugwe was Born in Harare, Zimbabwe, on 13 June 1985. Shingai completed her Advanced level education at Queen Elizabeth Girls High School, in Harare. She then proceeded to Harare Institute of Technology for her Tertiary education where she graduated top of her class in 2008 with a B-Tech (Honours) degree in Food Processing Technology. Thereafter, she was employed as a Quality controller at Superbake Bakeries from 2009 to 2010. Shingai then joined Dairibord Private Limited as a graduate trainee in 2010, where she was then fully employed as a Production Controller. Due to her passion for academia and quality assurance, she left August 2011 to pursue an MSc in Food Quality Management at Wageningen University, the Netherlands after being awarded a NUFFIC scholarship. She completed her MSc in 2013 after graduating with a cum laude and joined ZimTrade as a Market Advisor from March 2014 to October 2016 and as a part-time lecturer at Masvingo Polytechnic B-Tech Food Science Department from February 2014 to December 2016. Shingai was granted another NUFFIC scholarship to pursue her studies in Food Safety Culture and in November 2014, she started a sandwich PhD with the department of Food Quality and Design. This thesis presents the results of her scientific research. 
Overview of completed training activities

\begin{tabular}{|c|c|c|}
\hline Discipline specific courses and activities & & \\
\hline Course & Graduate School/Institute & Year \\
\hline Management of Microbiological Hazards in & VLAG, Wageningen & 2014 \\
\hline Foods & & \\
\hline Fundamentals of process safety & Harare Institute of Technology, & 2015 \\
\hline & Harare, Zimbabwe & \\
\hline Human factors in health and safety & Harare Institute of Technology, & 2015 \\
\hline & Harare, Zimbabwe & \\
\hline Science of Food Safety Culture Workshop & Campden, BRI, Campden, & 2015 \\
\hline & United Kingdom & \\
\hline Science of Food Safety Culture Workshop & Campden, BRI, Campden, & 2016 \\
\hline & United Kingdom & \\
\hline Science of Food Safety Culture Workshop & Ghent University, Belgium & 2017 \\
\hline Healthy and sustainable diets: synergies and & VLAG, Wageningen & 2017 \\
\hline trade-offs & & \\
\hline 3rd International Conference on Global Food & Elsevier, South Africa & 2017 \\
\hline Security 2017 & & \\
\hline Towards healthy \& sustainable food systems & VLAG, Wageningen & 2018 \\
\hline
\end{tabular}

General courses and activities

Information Literacy for PhD including

WGS, Wageningen

2014

EndNote Introduction

The Essentials of Scientific Writing and

WGS, Wageningen

Presenting

Philosophy and Ethics of Food Science and WGS, Wageningen

Technology

VLAG PhD week

VLAG, Wageningen

2015

Project and time management

WGS, Wageningen

2016

Scientific Publishing

WGS, Wageningen

2016

Scientific Writing

WGS, Wageningen

2016

PhD Workshop Carousel

WGS, Wageningen

2016

Reviewing a scientific paper

WGS, Wageningen

2017

Brain Training

WGS, Wageningen 
Introduction to $\mathrm{R}$

VLAG, Wageningen

2017

Optional courses and activities

Preparation of research proposal

FQD, Wageningen

2015

Agent-Based Modelling of Complex Adaptive ITG, Wageningen

2015

Systems

Weekly group meetings

FQD, Wageningen

$2015-$

Weekly group meetings

2017

$\mathrm{PhD}$ study tour to Italy

FQD, Wageningen

2016

Organising trip for Supervisors

FQD, Wageningen and

2016

Zimbabwe 


\section{Funding}

The research described in this thesis was financially supported by the Netherlands Universities Foundation for International Cooperation (NUFFIC), Grant award number H4 $9421 / 2014$.

Financial support from Food Quality and Design, Wageningen University, the Netherlands for printing this thesis is gratefully acknowledged.

Cover design and layout by Shingai P. Nyarugwe and Lesley Macheka

Printed by Digiforce/Proefschriftmaken.nl 

